\title{
The interface between invasive species science and legal regulation, using Hymenopteran species and their pathogens as a model system
}

by

Evan Crofford Brenton-Rule

A thesis submitted to Victoria University of Wellington in fulfilment of the requirements for a degree of Doctor of Philosophy in Ecology and Biodiversity

Victoria University of Wellington Te Whare Wānanga o te Ūpoko o te Ika a Māui 2018 
This thesis was conducted under the supervision of Professor Philip J. Lester (primary supervisor)

Victoria University of Wellington, Wellington, New Zealand

and

Professor Susy Frankel (secondary supervisor)

Victoria University of Wellington, Wellington, New Zealand 


\section{Abstract}

Biological invasions are one of the major causes of biodiversity decline on the planet. The key driver of the global movement of invasive species is international trade. As a response to trade driven invasive species risk, international and domestic regulations have been promulgated with the goal of managing the spread and impact of non-native species. My aims in this thesis were twofold. First, my goal was to review a subset of international and domestic regulations with a view to commenting on their fitness for purpose and suggesting potential improvements. Second, I used the example of non-native and invasive Hymenoptera, as well as their pathogens, to illustrate the risks posed by invasive species and gaps in their management.

In order to assess international and domestic regulations, I reviewed the World Trade Organization's (WTO) Agreement on Sanitary and Phytosanitary Measures, as well as associated disputes. I argue that the WTO's regulatory system does, for the most part, allow domestic regulators to manage invasive species risk as they see fit. Subsequently, the focus of the thesis narrows to investigate New Zealand's pre- and post-border regime managing invasive species. I argue that New Zealand's pre-border approach represents international best practice, but the post-border management of species is fragmented. The power to manage invasive species has been delegated to sub-national and regional bodies, which typically approach invasive species management in different ways. This variation has led to regulatory inconsistencies in pests managed and funding allocated. There appears to be a substantial lack of planning in some spaces, such as the risk of aquatic invasions. I make recommendations to ameliorate these inconsistencies.

My second aim involved the study of non-native and invasive Hymenoptera in New Zealand, as well as the pathogens they carry, in order to illustrate the risks posed by invasive species and gaps in their management. I show that the globally widespread invasive Argentine ant (Linepithema humile) may play a role in the pathogen dynamics and mortality of honey bee hives where the species occur sympatrically. Hives in the presence of Argentine ants suffered significantly higher mortality rates relative to hives without ants and always had higher levels of a honey bee pathogen Deformed wing virus. I demonstrate that honey bee pathogens are found in a range of invasive Hymenoptera in New Zealand. I amplify entire genomes of the honey bee virus Kashmir bee virus (KBV) from three species of non-native or invasive 
Hymenoptera (Argentine ants, common wasps and honey bees). I show that there is KBV strain variability within and between regions, but more between regions. Further, I demonstrate the result that as sampled KBV sequence length increases, so too does sampled diversity. These results highlight how 'an' invasive species is typically not alone: they carry a range of diseases that are almost always not considered in international and regional management plans.

Patterns of non-native Hymenoptera carrying honey bee diseases were not restricted to New Zealand. I used mitochondrial DNA to find the likely origin of invasive populations of the globally distributed invasive German wasp. I demonstrate that German wasps show reduced genetic diversity in the invaded range compared to the native range. Populations in the introduced range are likely to have arrived from different source populations. In some regions there were likely multiple introductions. Other regions are genetically homogenous and represent potential areas for use of gene drive technologies. All four different honey bee pathogens assayed for were found in German wasp populations worldwide. These results highlight how the introduction of one exotic species likely brings a range of pathogens. This example of pathogens in Hymenoptera is likely to be true for nearly all non-native introductions.

Many of the impacts of biological invasions, such as predation and competition, are relatively obvious and are frequently studied. However some, such as the impact of pathogens, are unseen and poorly understood. Legal regulation is often a post-hoc response implemented once a problem has already arisen. At a global level regulatory regimes operate relatively effectively. As the focus becomes more granular, such as the case of pathogens of Hymenoptera, fewer controls exists. This thesis helps to reduce uncertainty in this area as well as makes recommendations as to how these risks may be managed. 


\section{Acknowledgements}

First, my sincere thanks go to my supervisors, Professors Phil Lester and Susy Frankel. It was some of the best luck in my life that led me to meet Phil. I am beyond grateful for the years I have spent benefiting from his mentorship.

I also extend my gratitude to members of the Lester Lab group with whom I have worked with during my time at Victoria University. These include Allan Burne, Julien Grangier, Hendrik Munks, Valentin Reulet, Alexandra Sebastien, Rafael Barbieri, Meghan Cooling, Oliver Quinn, Fabian Westermann, Davide Santoro, Jessica Russell, Jana Dobelmann, James Baty and Mariana Bulgarella.

Dr Monica Gruber deserves special mention for the role she has played in my time at Victoria. From my undergraduate days she has provided unfailing guidance, time, and advice. Monica and Phil represent the thinkers I aspire to be.

Special thanks go to my friends at VUW who have been there throughout: Zak Murray, Antoine Felden, Orin Robb and Shalen Kumar. Each of these men contributed in different ways to make my experience a wonderful one. Also, James Mulholland and Henry Stephens.

To my parents, Susan and Tony, who have always encouraged me in whatever endeavour I pursued, you will always have my gratitude. Also, Judy and Walt Hennig.

Thank you to Paul Marsden, Mary Murray, Mark Stephen and Sandra Taylor. Each of these individuals reduced the friction of day-to-day life in VUW greatly, as well as being wonderful people with whom to work.

Laura Kelly has shared this journey since our Honours year. Thank you Laura.

For financial support I thank the Royal Society London, Victoria University of Wellington, the VUW Postgraduate Student Association and the Royal Society of New Zealand Wellington Branch. 
Finally, thank you to my wife Jane Zervos. At the time of writing Jane and I have been together for a decade. Nine of those years have been spent with me studying. Her patience and support have never failed. I am very lucky to have had her along for the ride. 


\section{Contents}

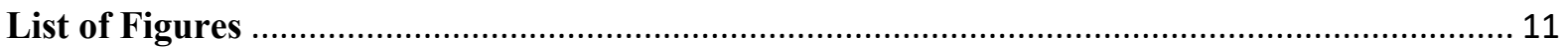

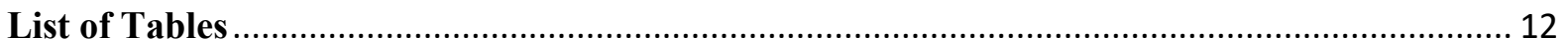

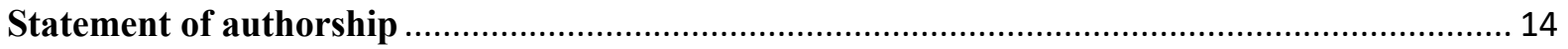

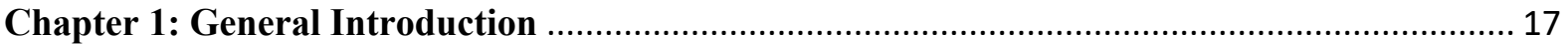

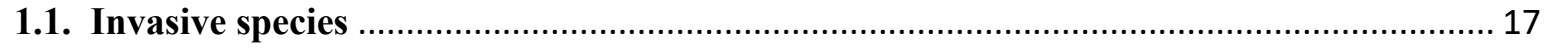

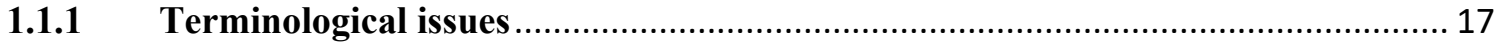

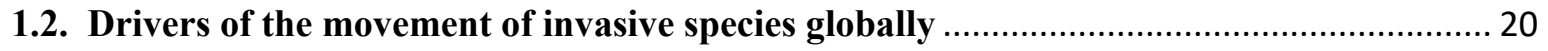

1.3. Legislative attempts to control invasive species............................................................... 21

1.4. Globally dispersed invasive and non-native Hymenoptera .......................................... 23

1.5. Pathogens of non-native species including Hymenoptera …............................................. 24

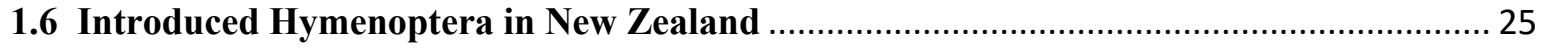

1.7 Thesis outline

Chapter 2: Regulating invasive species: Reconciling ecological and legal views of acceptable risk

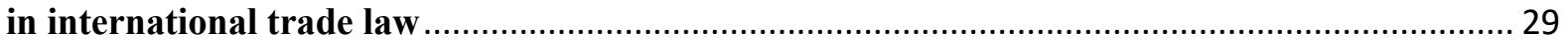

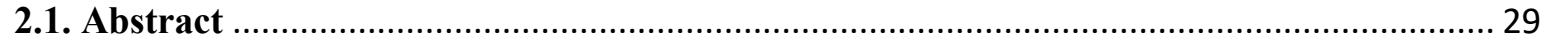

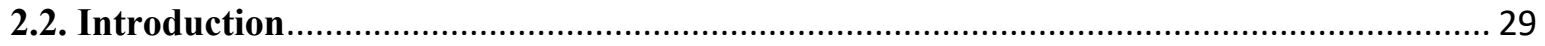

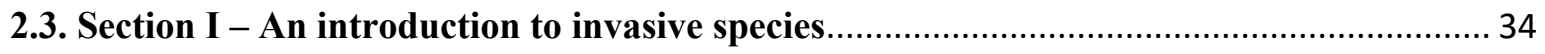

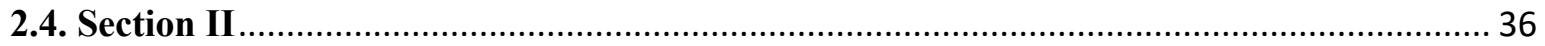

2.4.1. A Member's Acceptable Level of Protection ............................................................... 36

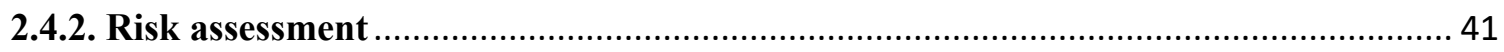

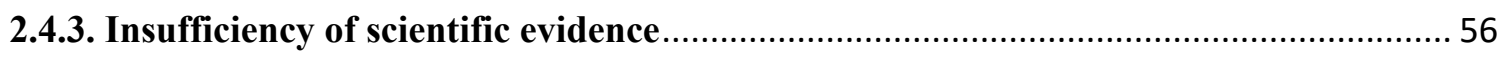

2.5. Section III - Other SPS disciplines that have been the subject of dispute ........................ 61

2.5.1. The objective of achieving non-discrimination and consistency ................................. 61

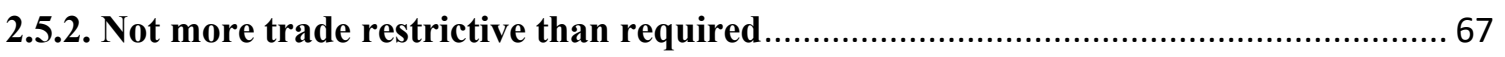

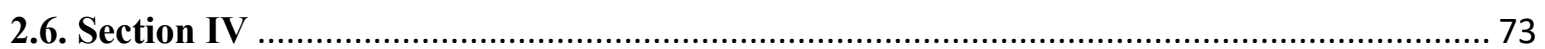

Chapter 3: Improving management of invasive species: New Zealand's approach to pre-and

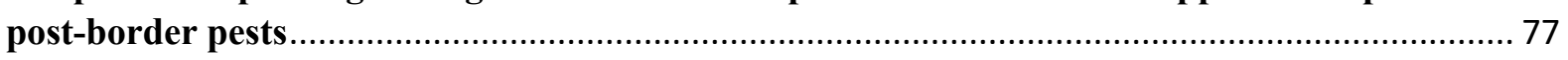

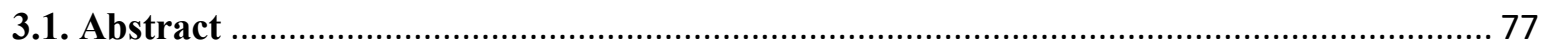

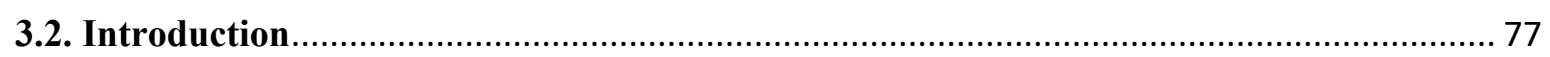

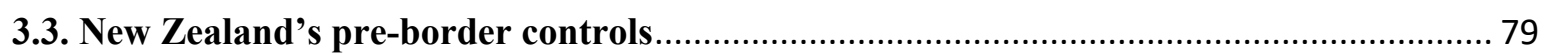

3.3.1. New Zealand's pre-border framework: Legal intentional species introductions ....... 79

3.3.2. A risk assessment approach to intentional introductions ............................................ 81

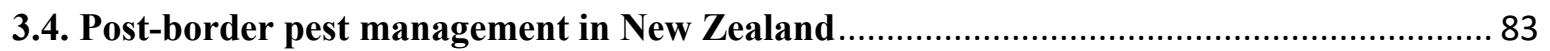

3.4.1. New Zealand's post-border management framework ............................................... 83 


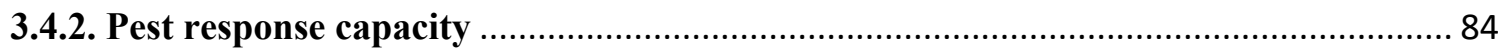

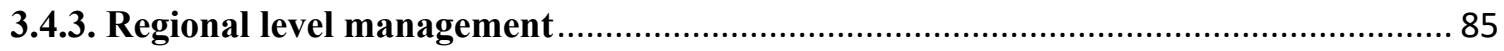

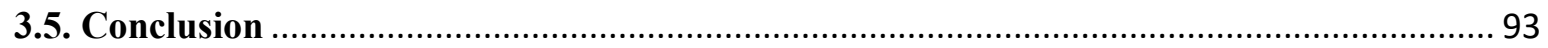

Chapter 4: Honey bee hive collapse associated with an invasive ant and viral pathogens .......... 95

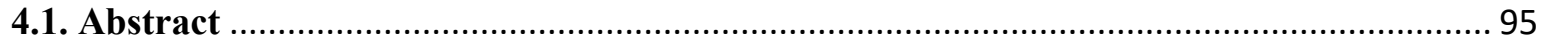

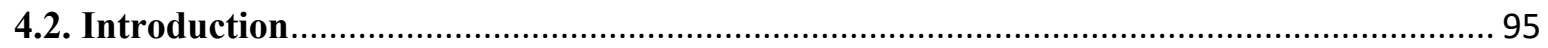

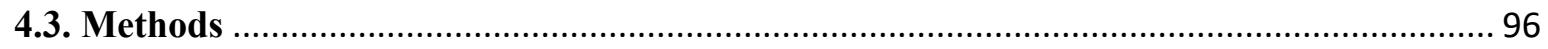

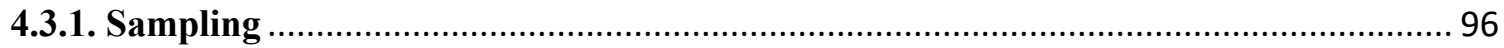

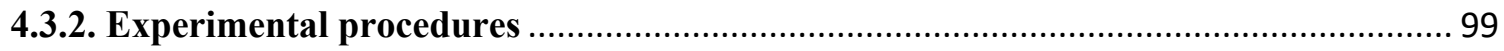

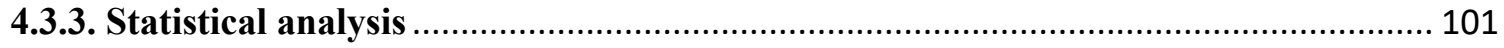

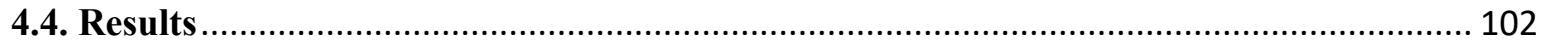

4.4.1. Direct hive robbing, predation and bee colony mortality ....................................... 102

4.4.2. High infection levels associated with ant presence ................................................... 105

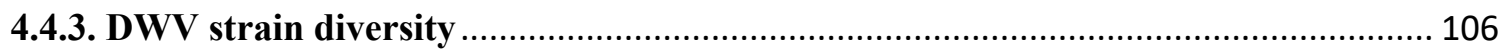

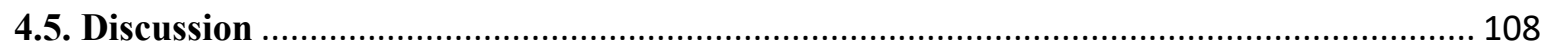

Chapter 5: The origins of global invasions of the German wasp (Vespula germanica) and its

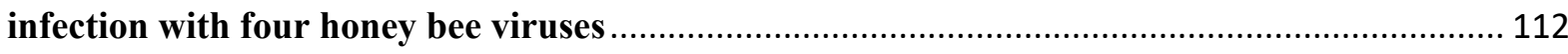

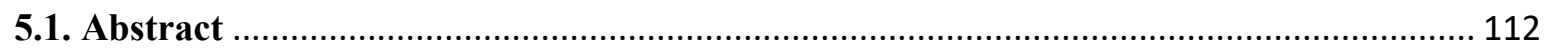

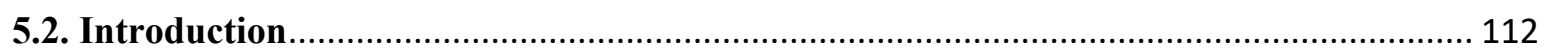

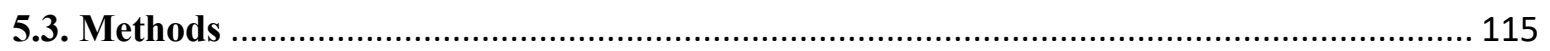

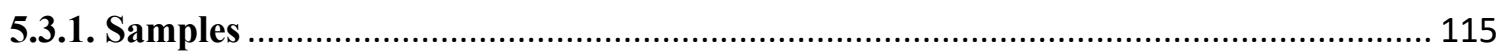

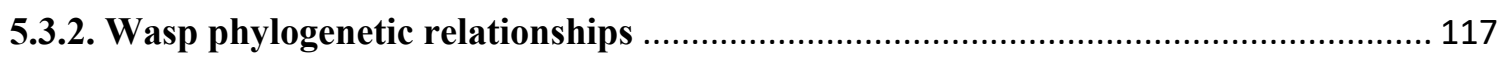

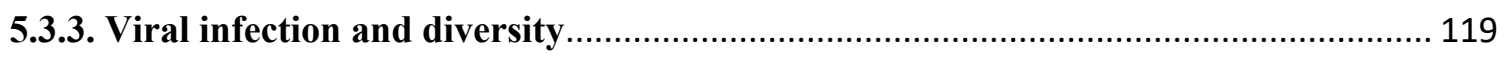

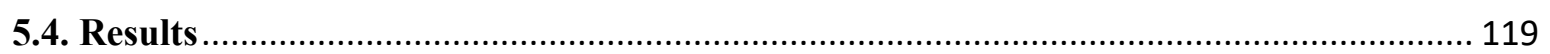

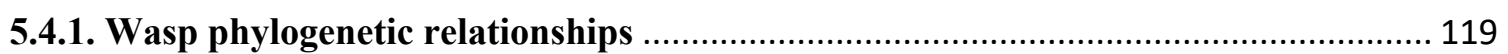

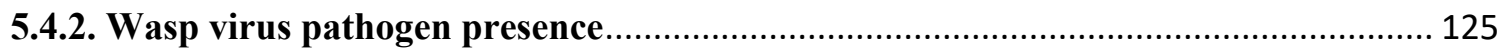

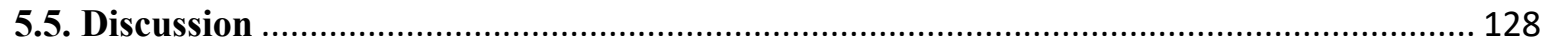

Chapter 6: Full genome genetic diversity and regional grouping of Kashmir bee virus in three

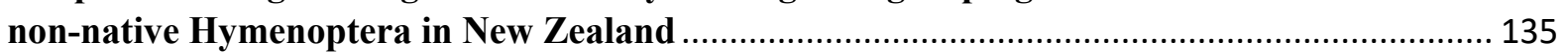

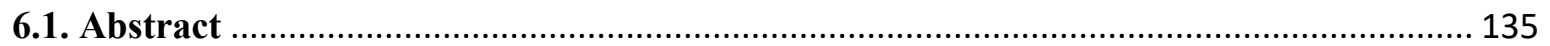

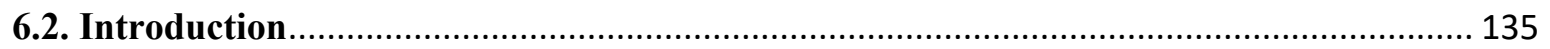

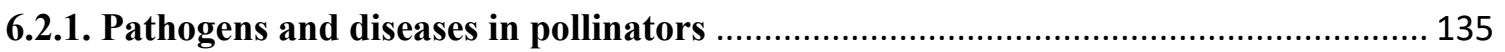

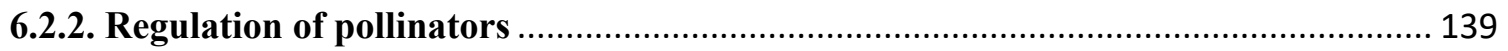

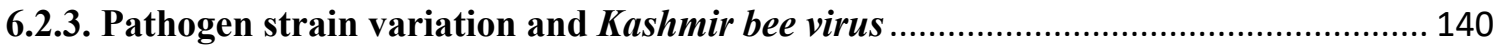

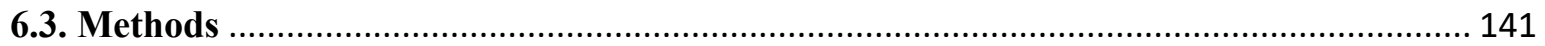

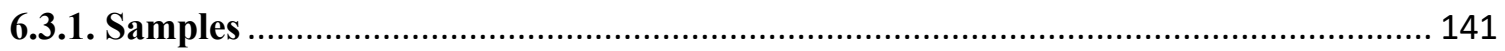




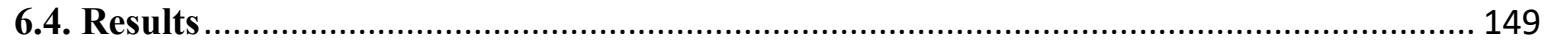

6.4.1. Kashmir bee virus phylogenetic relationships ........................................................... 149

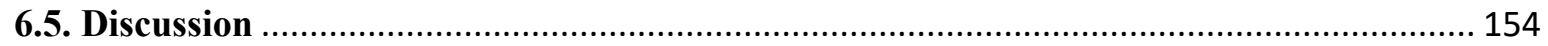

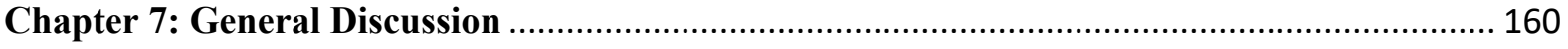

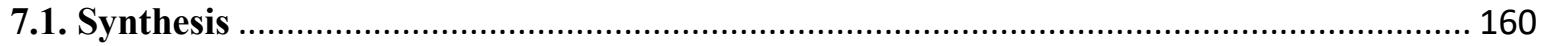

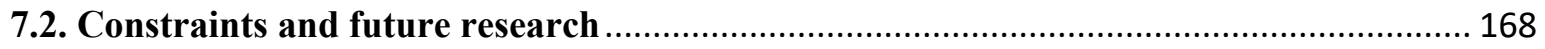

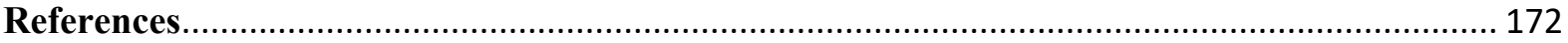

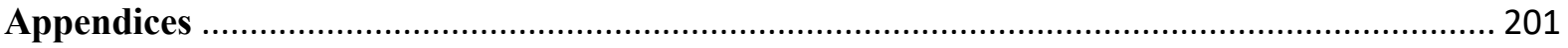




\section{List of Figures}

Fig. 1.1. Increases in global seaborne trade and the use of the phrase 'invasive species' in the English language ..................................................................

Fig 1.2. How high and low ALOPs affect risk management............................. 38

Fig. 3.1. Map of New Zealand showing regional councils and their boundaries.............86

Fig. 3.2. Venn diagram showing inconsistency of management of pest species within RPMPs........................................................................ 90

Fig. 4.1. Sample locations of Argentine ants and honey bees..........................97

Fig. 4.2. Argentine ant infestations of bee hives.................................. 103

Fig. 4.3. Kaplan-Meier curves for honey bee hives in areas with or without Argentine ants.

Fig 4.4. Viral loads of (a) Argentine ants, with either Deformed wing virus (DWV) or Linepithema humile virus 1 over time, and (b) DWV in honey bees when Argentine ants are present or absent. (c) shows all data for honey bee DWV loads from all sampling times...106

Fig. 4.5. A maximum-likelihood phylogenetic analysis of DWV $\ldots \ldots \ldots \ldots \ldots \ldots \ldots \ldots \ldots \ldots$

Fig. 5.1. Origin of the Vespula germanica samples used in this study....................116

Fig. 5.2. Spatially structured haplotype network of Vespula germanica constructed in TempNet.

Fig. 5.3. Maximum composite likelihood tree for Vespula germanica sampled throughout the native and introduced range.

Fig. 5.4. Haplotype discovery curves from the six population areas sampled.

Fig. 5.5. Maximum composite likelihood tree for Dicistroviridae sequences sampled, as well as samples from utilised from GenBank..........................................126

Fig. 5.6. Maximum composite likelihood tree for DWV sequences sampled, as well as samples from utilised from GenBank.

Fig. 6.1. Map showing the locations of the specimens used in this study....

Figure 6.2 (a)-(c). Maximum composite likelihood trees for $98.5 \%$ and $82.5 \%$ complete KBV genome sequences sampled, as well as samples from utilised from GenBank.

Fig. 6.3. Between and within group genetic distance of the $98.5 \%$ and $82.5 \%$ complete genomes sampled....

Fig. 6.4. Haplotype discovery curve of the three datasets

Fig. Appendix 1 Radar Graph of Estimates of Evolutionary Divergence over Sequence Pairs between Group. 


\section{List of Tables}

Table 3.1. Data obtained from Regional Pest Management Plans

Table 4.1. Sampling origins and collection data for Apis millifera and Linepithema humile.

Table 4.2. Primers used in RT-qPCR.

Table 4.3. The maximum likelihood fits for the four best fitting nucleotide substitution models calculated in MEGA 6.06 from the DWV sequences.

Table 4.4. The Cox regression analysis showing differences in hive survival between sites

Table 5.1. Summary of number of $V$. germanica specimens sampled and the unique haplotypes found in each range.

Table 5.2. Viral presence in German wasps in the native and invaded range

Table 5.3. Summary of previous literature and findings of this study on the origin of invasions of $V$. germanica populations around the world.

Table 6.1. Top 15 global honey producers by weight (2016)

Table 6.2. Top 15 global live bee exporters by US\$ value (2016)

Table 6.3. Sampling locations and collection dates for the KBV positive samples collected during this study

Table 6.4. Primer pairs used to amplify entire genomes....

Table 6.5. The maximum likelihood fits for the five best-fitting models of the 24 different nucleotide substitution models calculated in MEGA7 for the three datasets of KBV sequences 148

Table 6.6. Summary statistics on nucleotide variation within datasets

Table Appendix 1. Sampling locations and collection date for the $V$. germanica and $V$. vulgaris utilised in this study.

Table Appendix 2. The maximum likelihood fits for the five best-fitting models of the 24 different nucleotide substitution models calculated in MEGA7 for the separate CO1, CO2 and $c y t b$ datasets and concatenated dataset (1957 bases)................................208

Table Appendix 3. The maximum likelihood fits for the five best-fitting models of the 24 different nucleotide substitution models calculated in MEGA7 for the ABPV, KBV and IAPV polyprotein gene sequenced (330 bases).

Table Appendix 4. The maximum likelihood fits for the five best-fitting models of the 24 different nucleotide substitution models calculated in MEGA7 for the DWV polyprotein gene

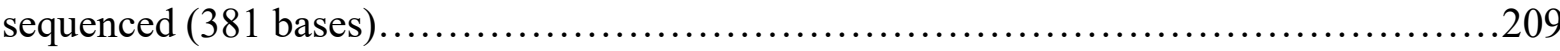


Table Appendix 5. Estimates of evolutionary divergence over sequence pairs between

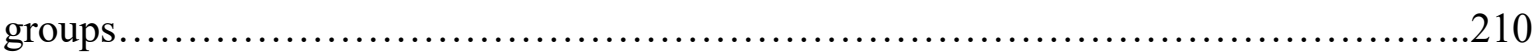




\section{Statement of authorship}

I hereby declare that this thesis is my own work and that all sources quoted, paraphrased or otherwise referred to, have been properly acknowledged in the references.

Chapters 2, 3, 4, 5 and 6 have been written as independent manuscripts, so there is inevitable repetition between the introductions and discussions of these chapters. As most chapters contain contributions from collaborators, they are written in first person plural tense. In all cases I wrote the manuscripts. Professors Phil Lester and Susy Frankel provided advice and support throughout. The contributions of co-authors for each chapter are outlined below.

Chapter 2 was written with the intention to publish in a legal journal. Therefore the structure of the article differs from others within this thesis. Author contributions: EBR formulated the research questions, undertook the research and wrote the manuscript. PJL and SF provided comments on draft versions.

Chapter 3 was published in Policy Quarterly during February 2016. It is a legal/policy journal and therefore the structure of the paper differs from traditional scientific papers. Author contributions: EBR designed the research. EBR conducted the analyses. EBR, PJL and SF contributed towards the writing of the manuscript.

Chapter 4 author contributions: PJL and EBR designed the study. EBR, JFEJR and MS collected samples. EBR and JWB performed the laboratory work. EBR, JWB and PJL analysed and interpreted the results. EBR led the writing with input from all authors.

Chapter 5 was submitted to Biological Invasions during February 2018. Author contributions: EBR and PJL conceived the project; EBR, CM, CVZ, CRS, JD, JG, JS, LD, MM, RLB, and RV collected the samples. EBR conducted the laboratory work. EBR analysed and interpreted the data; EBR led the writing with input from all authors.

Chapter 6 author contributions: EBR and PJL formulated the research. EBR conducted the sample collection. EBR performed the laboratory work. EBR analysed the results. EBR led the writing with input from PJL. 
${ }^{1}$ Author initials and names: EBR Evan Brenton-Rule, CM Chris McGrannachan, CRS Chris Shortall, CVZ Carolien van Zyl, JD Jana Dobelmann, JFEJR Jessica Russell, JG Julien Grangier, JS Julia Schmack, JWB James Baty, LD Libor Dvorak, MM Maité Masciocchi, MS Marion Saunders, PJL Phil Lester, RLB Robert Brown, RV Ruan Veldtman, SF Susy Frankel. 


\section{Chapter 1: General Introduction}

\subsection{Invasive species}

Biological invasions have been labelled as one of the major causes of biodiversity loss on the planet (Vitousek \& D'Antonio, 1997). The impacts of some invasive species are catastrophic and threaten native species and ecosystem function globally (Lockwood et al., 2009). Impacts may be the displacement of other species through competition and predation (O'Dowd et al., 2003; Grangier \& Lester, 2011) or via consequences such as alteration of nutrient cycling causing ecosystem change (Vitousek et al., 1987). In some regions the introduction of multiple invasive species has resulted in synergistic interactions between the invaders, driving ecosystem change (Simberloff \& Holle, 1999; O’Dowd et al., 2003). Beyond environmental effects, the economic costs of invasive species are often high. Invasive insects globally are particularly damaging (Bradshaw et al., 2016). Costs of insects to specific industries within countries, such as forestry, can amount to billions of dollars annually (Aukema et al., 2011). Invasive species may also be vectors of both human and animal disease (Juliano \& Lounibos, 2005; Karesh et al., 2005; Yap et al., 2015) and can have extreme impacts on the amenity values of areas important to humans (MacIntyre \& Hellstrom, 2015).

\subsubsection{Terminological issues}

The sub-discipline of ecology known as invasion biology is the study of the causes and consequences of the introduction of organisms to areas outside their native range. From an ecological perspective the field has contributed insights into questions such as the role of disturbance in community structuring (Vilà et al., 2011), ecological naïveté (Cox \& Lima, 2006; Banks \& Dickman, 2007) and rapid evolution (Stockwell et al., 2003; Phillips \& Shine, 2006). Increasingly, the field is interdisciplinary in scope, drawing on techniques and knowledge from epidemiology, economics, human geography, human history, and law.

However, an ongoing robust discourse exists debating, amongst other things, the normative foundations of the discipline and the terminological problems with the definition of an invasive species. This debate is lively, and at times acrimonious (Richardson \& Ricciardi, 2013; Briggs, 2017; Courchamp et al., 2017; Crowley et al., 2017; Russell \& Blackburn, 2017a, 2017b; Tassin et al., 2017). The fine details of this discourse are beyond the scope of this thesis. Indeed it could be the topic of an interesting $\mathrm{PhD}$ in itself. However, a broad delineation of the issues 
will help to place in context how the term 'invasive' is used in this thesis, as well as acknowledge concerns both internal and external to the field.

Various definitions of the term 'invasive species' have been proposed (Blackburn et al., 2011; Richardson, 2011). One relatively orthodox definition of an invasive species, including that used in this thesis, generally cites three requirements: First, the organism must arrive in a new area, usually via human conveyance. Second, the organism must increase in density and distribution. Finally, the species must have negative social, economic or environmental impacts. The major perceived problem with such a definition is its requirement for a negative impact or harm (Rejmánek et al., 2002; Tassin et al., 2017). The kernel of this issue is that the concept of harm has embedded within it normative concepts of 'good' and 'bad'. In the scientific context in which invasive species science operates, these normative concepts exist within the matrix of the ethics preeminent in western democracies. However, normative imperatives and values are not homogenous across or within human societies globally. Even within individual countries, valid alternative social views will compete to determine whether a species is classified as invasive and by definition, harmful. For instance, the introduction of new species may increase the total species diversity in a region, but reduce abundance per species. These changes in diversity and abundance may be described in an objective scientific manner. However, the judgement as to whether the previous or current state is preferable, is purely subjective. The European honey bee, Apis millifera, is illustrative of this issue. It was introduced globally centuries ago, largely by European colonists. Currently it is infrequently presented as invasive and its negative impact on local pollinators is largely overlooked.

No literature the author has encountered has satisfactorily refuted this criticism of the normative judgements inherent in the definition of invasive species. However, from a pragmatic perspective, the ecological and socioeconomic damage non-native species can cause is often the reason for studying them (Blackburn et al., 2014). The incentive to adopt an objective norm-free definition of invasive species is misaligned with the imperative of researchers to advocate for funding and communicate their message to the public. Researchers studying biological invasions in New Zealand have perhaps been most successful in gaining traction in public discourse. The country has high levels of public engagement in biosecurity and conservation issues surrounding invasive species. However, the public conservation is 
laden with warlike language and xenophobic metaphors that gloss over the nuance with which most ecologists do, or should, approach the study of biological invasions. Some of the critiques of invasion biology may be precipitated by failures in scientific communication (Groffman et al., 2010) and compounded by lack of involvement of social scientists (Nisbet \& Scheufele, 2009). Language is meaningful and scientists should be particularly careful how these use it.

The definitional issue may or not be soluble. It may be that the issue could be ameliorated somewhat by more inclusive approaches to science communication and the management of invasive species. These approaches should involve social scientists skilled at communicating scientific ideas. The debate should involve conversations that recognise, respect and incorporate differences in knowledge, values, perspectives and goals (Nisbet \& Scheufele, 2009; Verbrugge et al., 2013; Ellender et al., 2014; Novoa et al., 2016).

The vast majority of invasion biologists accept that the probability of any given species becoming invasive is very low (Williamson \& Fitter, 1996). Most species are not entrained in a transport pathway and those that are entrained rarely survive the journey. The small proportion of species that arrive in a new region rarely establish, and those that do establish rarely cause negative impacts. However, in some instances non-native species do become invasive and do cause harm (Bradshaw et al., 2016; Early et al., 2016).

For the purposes of this thesis, the phrase 'invasive species; is used specifically to refer to species that fit within the following definition: An invasive species is a species that has -

(1) Arrived in a geographic location outside its native range by human-mediated conveyance;

(2) Become widespread and abundant in the new range; and

(3) Caused significant economic, societal or environmental harm.

When the term 'invasive species' is used in this thesis, the author is cognisant of the fact that the requirement of harm is informed by subjective values that may not be shared by all readers. 


\subsection{Drivers of the movement of invasive species globally}

Humans have been vectoring species around the world for millennia (Druett, 1983; Crosby, 1986; Yan et al., 2001; Savolainen et al., 2004). However, the modern quantum of people and goods moving, and the speed with which they travel, are unparalleled through history (Hulme, 2009). Since around 1850 there has been no saturation in the accumulation of non-native species worldwide (Seebens et al., 2017) and arrival of invasive species is predicted to continue (Tittensor et al., 2014). The key driver of the movement of invasive species globally is international trade (Levine \& D’Antonio, 2003; Kobelt \& Nentwig, 2008; Westphal et al., 2008; Hulme, 2009; Brenton-Rule et al., 2016; Bertelsmeier et al., 2017; Seebens et al., 2018). Human-mediated dispersal is different to natural dispersal as the mixing of biota is often global, not regional; the mixing is human-facilitated; there are multiple introductions from multiple sources to multiple locations; and the rates of species introductions are higher than before (Wilson et al., 2009). Part of the reason for these differences is that trade and travel provide vectors and pathways for plants, animals, diseases and biological material to cross what would have historically been impassable barriers to dispersal. The distance between similar climatic zones, once spatially isolated, has been effectively reduced by functionally instantaneous worldwide airline transportation (Tatem \& Hay, 2007). Introductions of non-native species may be intentional or unintentional and both can, in some instances, result in harm.

Intentional introductions are instances in which a species is moved intentionally to a new location, usually in the hope of establishing a new industry, for recreational reasons, as a biological control agent, or historically because of normative judgments as to the impoverishment of local biota (Druett, 1983). The scale of the intentional movement of species around the world is vast. Between the years 2000 and 2006 over 1.48 billion live animals were imported into the United States (Smith et al., 2009). Almost $80 \%$ of these shipments contained animals from wild populations, the majority of which have no mandatory testing for pathogens before or after shipment (Smith et al., 2009). Notorious intentional introductions of species that have become invasive include the Golden apple snail (Pomacea canaliculata) (Carlsson et al., 2004), the Common carp (Cyprnus carpio) (Matsuzaki et al., 2009), and the invasive plant Kuzdu (Pueraria montana) (Forseth \& Innis, 2004). Intentional introductions raise a normative problem in that, even if the importing country accepts the risk of import, geographically contiguous national borders have little relevance to the dispersal of many species. Therefore, unilateral decisions concerning species introduction may set the stage for transnational species 
invasions; as has been the case with non-native bumblebees in South America (Schmid-Hempel et al., 2014; Aizen et al., 2018).

Most non-native species arriving in new areas are not transported intentionally (Hulme et al., 2008). Instead non-native species may arrive as stowaways such as pests on commodities that include horticultural or ornamental plants (Simberloff, 2005; Brenton-Rule et al., 2016). Alternatively, they may arrive independent of a particular commodity as a hitchhiker associated with mediums such as ballast water, packing materials or air freight (Roman \& Darling, 2007; Hulme et al., 2008). Propagule pressure as a result of unintentional introductions is difficult to empirically ascertain, however it appears to be a significant global pattern (Work et al., 2005; McCullough et al., 2006; McNeill et al., 2011; Brenton-Rule et al., 2016). It seems that exposure of economies to trade increases the volume of invasive species they receive; with increased trade resulting in higher numbers of invasive species establishing, probably as a result of heightened propagule pressure (Hulme, 2009).

\subsection{Legislative attempts to control invasive species}

Invasive species have an anthropogenic origin, driven by increasing trade interconnectivity. As a response, legal regulations have been developed attempting to stop the spread of invasive species and ameliorate the harm they cause. Legal management of invasive species may be conceptualised as occurring at three levels: internationally, regionally and domestically. There are many international instruments for the purpose of managing the risks of invasive species. Given the importance of trade in the growth of invasive species as a problem, arguably the most important is the WTO (World Trade Organization) Agreement on the Application of Sanitary and Phytosanitary Measures 1995 (SPS Agreement). Among other things, the SPS Agreement sets the rules for how WTO Members may manage the risk of invasive species posed by trade. Disputes under the SPS Agreement over the past 20 years have provided guidance to domestic authorities on how the provisions of the SPS Agreement will be interpreted; thereby influencing the risk assessment and management processes of domestic regulators. Under the WTO, international standards relevant to invasive species risk assessment are set by two bodies. The World Organisation for Animal Health which has a mandate over 
animal health and the Secretariat of the International Plant Protection Convention which manages risks to plant health ${ }^{1}$.

Another important agreement is the Convention on Biological Diversity 1992 (CBD). The CBD obliges parties to take action on invasive species issues. Article $8(\mathrm{~h})$ of the CBD requires that each party shall prevent the introduction of, control or eradicate those alien species which threaten ecosystems, habitats or species. At the tenth meeting of the Conference of the Parties to the CBD an updated Strategic Plan for Biodiversity was unveiled. This plan includes the Aichi 2020 Biodiversity Targets. Target nine of this plan is that by 2020 invasive alien species and pathways are identified and prioritised, priority species are controlled or eradicated and measures are in place to manage pathways to prevent their introduction and establishment. Internationally, beyond the SPS Agreement and the CBD, a wide range of other agreements seek to manage risks from invasive species, including: the United Nations Convention on the Law of the Sea, the International Maritime Organisation Ballast Water Convention, and the Convention on the Conservation of Antarctic Marine Living Resources.

Management of invasive species also occurs at a national level through the implementation of domestic regulation. This occurs at three broad levels: pre-border, border intervention and postborder management. In New Zealand these risks are managed under the Biosecurity Act 1993, and the Hazardous Substances and New Organisms Act 1996 (HSNO Act). The first level, preborder biosecurity, utilises risk assessments and focuses strongly on early detection, intervention and prevention. Risk assessment typically focuses on identifying high-risk species, commodities and pathways of introduction, as well as managing intentional introductions. The second level, border intervention, involves implementing management regulations by inspecting people and goods entering a country, as well as assessing applications for the intentional importation of new organisms. Finally, post-border management focuses on surveillance, rapid response to incursions and incipient populations, and long-term management of more established populations. An emphasis on the first level, pre-border risk assessment and management, is generally agreed upon as the most effective and economical method of preventing the introduction of invasive species (Leung et al., 2002; Springborn et

\footnotetext{
${ }^{1}$ Annex A, Paragraph 3, SPS Agreement.
} 
al., 2011; Kumschick \& Richardson, 2013). Therefore international regulations, such as the SPS Agreement, dealing with trade at the pre-border stage, are particularly important to restrict the movement and impacts of invasive species.

\subsection{Globally dispersed invasive and non-native Hymenoptera}

As is the case with most invasive species, patterns of global Hymenopteran spread are likely also governed to a large extent by global trade. In the case of invasive ant species it has been found that the effects of globalisation, world wars and global recessions have had a particular influence on dispersal (Bertelsmeier et al., 2017). Introduced Hymenoptera, such as ants and wasps, are often particularly successful invaders (Holway et al., 2002). On the IUCN list of "100 of the world's worst invasive alien species", six of the species are Hymenopterans (Lowe et al., 2000). Invasive wasps such as the Vespula wasp species included in the IUCN list share a number of traits that contribute to their success as invasive species. First, a single fertilised queen is sufficient to found a population. Queens are relatively small and will overwinter in a range of human structures that are easily transported from place to place. For instance in the folds of curtains, within bookshelves and stacks of wood (personal observations). Further, Vespula wasps have high reproductive rates, generalist diets, excellent competitive abilities, and even without human conveyance effectively disperse across landscapes (Crosland, 1991; Masciocchi \& Corley, 2013). In the case of invasive ants, species are often polygynous which leads to relatively fast rates of reproduction and colony size (Tsutsui \& Suarez, 2003). Colony reproduction may also occur via budding, where a new queen together with a coterie of workers, will walk away from the nest of her birth to establish a new colony nearby. Finally, invasive ants are often unicolonial which means there is no intraspecific aggression between workers. This results in energy that would otherwise be expended on nest defence and interspecific aggression being redirected to foraging and reproduction (Thomas et al., 2006).

While invasive wasps and ants are often intercepted at the border, sufficient individuals or even colonies elude detection to enable ongoing establishment of non-native species (Lester, 2005; Ward et al., 2006; Foucaud et al., 2010). For instance, four of the species on the IUCN list, Argentine ants (Linepithema humile), the little fire ant (Wasmannia auropunctata), the big headed ant (Pheidole megacephala) and the yellow crazy ant (Anoplolepis gracilipes) have global distributions and in some areas form polydomous supercolonies exhibiting no or little 
interspecific aggression (Holway et al., 2002; Tsutsui \& Suarez, 2003; Errard et al., 2005). Genetic studies of wasps also indicate that there have likely been multiple introduction events of non-native wasp species, such as the seed feeding wasp (Megastigmus transvaalensis) and the common wasp (Vespula vulgaris) (Scheffer \& Grissell, 2003; Lester et al., 2014b).

As with the native-non-native controversy, not all non-native Hymenoptera are invasive and many are intentionally introduced. Honey bees are the world's most important pollinator species (Klein et al., 2007; Aizen \& Harder, 2009). They are globally widespread and provide substantial economic benefits to agriculture through pollinator services (Aizen \& Harder, 2009; Gallai et al., 2009). Bumble bees too are an important and beneficial non-native Hymenopteran with a global distribution. Besides benefits through pollination, non-native Hymenoptera including parasitoid wasps have been introduced as biological control agents in attempts to control invasive species (Beggs et al., 2008; Avila et al., 2013). As is the case with many nonnative species, many unintentionally introduced Hymenoptera do not become invasive. For example, New Zealand has a diverse non-native ant fauna, but many of these species would likely not fulfil the definition of an invasive species put forward in this thesis (Don, 2007).

\subsection{Pathogens of non-native species including Hymenoptera}

The intentional and unintentional movement of species provides a disease transmission pathway that affects human health, livestock, native species and the overall health of ecosystems (Juliano \& Lounibos, 2005; Karesh et al., 2005; Pejchar \& Mooney, 2009; Yap et al., 2015). One hypothesis for the success of invasive species globally is release from natural enemies, including pathogens (Torchin et al., 2003; Colautti et al., 2004). Data on this hypothesis is equivocal with studies both supporting and not supporting the hypothesis (Colautti et al., 2004). A similar pattern of ambiguity emerges in the case of release of invasive invertebrates from pathogens (Roy et al., 2011; Lester et al., 2014b, 2015). Intentional international movement of Hymenoptera has been occurring for at least the past 130 years (Gurr, 1972). More recently, international trade in pollinators and material associated with their rearing has been demonstrated as a pathway for honey bee pathogens (Graystock et al., 2013; Murray et al., 2013). The export of queen bees is a substantial industry in some countries. Larvae and eggs of the small hive beetle (Aethina tumida) have been identified in cages of queens imported to Portugal from the United States (Murilhas, 2004). Honey bee queens mate 
with up to 28 drones (Kraus et al., 2005) and their risk of being infected by a virus within semen is not negligible. Mated queens are therefore a possible source of viral introduction (Chen et al., 2005; Yue et al., 2006). Bee products too pose a risk. Honey has been shown to carry American foulbrood (Paenibacillus larvae ssp. larvae), European foulbrood (Melissococcus plutonius), Kashmir bee virus, Sacbrood virus, Deformed wing virus and Black queen cell virus (Mutinelli, 2011).

Declines in pollinator abundance and colony collapse disorder in honey bee colonies has led to increased research on honey bee health. This research has shed light on the pathogens affecting honey bees. Research on pathogens of other arthropods has not advanced in a commensurate manner. As the majority of research on invertebrate epidemiology has been in the context of honey bee studies, the pathogens discovered have been labelled as pathogens of honey bees. However, when the presence of honey bee diseases are assayed for in other insect species, they are often found (Levitt et al., 2013; Lester et al., 2014b; Sébastien et al., 2015; Dobelmann et al., 2017; Gruber et al., 2017; Santamaria et al., 2017). In fact, honey bee pathogens have been found in at least eight insect orders (Levitt et al., 2013). These data raise the possibility that some of what have been labelled honey bee pathogens are in fact generalist pathogens capable of infecting a range of arthropods. Data on virulence of these diseases in hosts other than honey bees are largely absent. However, many of these species, and especially Hymenopterans, are constantly moved both domestically and internationally. The constant introductions of nonnative species and resulting admixture of pathogens may mean that invasive and non-native Hymenopterans do not fully benefit from enemy release and are subject to much the same pathogen biosphere as in their native range (Lester et al., 2014b, 2015). Accidentally introduced Hymenoptera, such as invasive ants, have been found to carry and form reservoirs of honey bee diseases (Sébastien et al., 2015).

\subsection{Introduced Hymenoptera in New Zealand}

New Zealand has a diverse non-native Hymenopteran fauna, including invasive wasps, bees and ants (Lester et al., 2003; Don, 2007; Soper \& Beggs, 2013; Tsuchida et al., 2014; Lester, 2018). One of the most notorious species, the common wasp (Vespula vulgaris), is a globally widespread invasive species native to Eurasia (Lester \& Beggs 2018). It has been present in New Zealand since approximately 1921 (Donovan, 1983). In New Zealand's honeydew beech forest this species reaches the world's highest recorded densities of up to 370 wasps $\mathrm{m}^{-2}$ of tree trunk (Moller et al., 1991) and 34 nests ha-1 (Beggs et al., 1998). In addition to the common 
wasp, the German wasp (Vespula germanica) is also present in New Zealand having established during the 1940s (Thomas, 1960). It has many of the same ecosystem impacts as the common wasp (Beggs, 2001; Beggs et al., 2011; Lester et al., 2013).

The impacts of invasive Hymenoptera in New Zealand are significant. Invasive Vespula wasps are estimated to cost around $\$ 75$ million per year (MacIntyre \& Hellstrom, 2015). Their impacts on biodiversity are commensurately prodigious. In honeydew beech forests their biomass is as great or greater than that of all birds and introduced mammals (Thomas et al., 1990). This high density combined with their generalist feeding habits has reduced the probability of some invertebrate species surviving the wasp season to near0\% (Toft \& Rees, 1998). Invasive ants in New Zealand have similarly been shown to have impacts on horticulture, biodiversity and amenity areas (Lester et al., 2003; Ward et al., 2010). For instance, the invasive Argentine ant has been empirically shown to negatively affect native ant abundance and species richness in some circumstances (Cooling et al., 2015). Climatically, much of New Zealand's land area is considered suitable for this species (Hartley \& Lester, 2003).

Like other areas of the world a wide range of honey bee pathogens have been found to be present in New Zealand across a range of Hymenoptera (Lester et al., 2014b, 2015; Sébastien et al., 2015; Murray et al., 2016; Dobelmann et al., 2017; Gruber et al., 2017), although some pathogens are still notably absent (McFadden et al., 2014). It has been proposed that Hymenopteran pathogens in New Zealand may not be host-specific and instead are shared across native and non-native Hymenopteran communities (Lester et al., 2015). Trade in honey bees and honey bee products have been shown to provide pathways for the introduction of pathogens of honey bees (Murilhas, 2004; Mutinelli, 2011). International regulations, such as the World Organisation for Animal Health Terrestrial Code and import health standards, exist to stem the flow of these diseases internationally (Mutinelli, 2011). However, at a domestic level in countries such as New Zealand, there are very few controls on the movement of honey bees for pollination purposes. Further management of well-established invasive Hymenoptera, such as Argentine ants and Vespula wasps, is typically restricted to specific areas. Such an approach means there is virtually no management or oversight of the intentional and unintentional movement of non-native Hymenoptera across the New Zealand landscape. This 
system of pathogen dynamics in Hymenoptera communities is not well-explored. It is therefore unsurprising that the potential risks associated with these pathogens are not well-managed. The apicultural industry is of increasing importance to New Zealand. For instance, from 2005-2015 New Zealand honey exports have increased from USD25million to USD200million per annum with an increase in price $\mathrm{kg}^{-1}$ of $\$ 6.25 \mathrm{~kg}^{-1}$ to $\$ 18.71 \mathrm{~kg}^{-1}$ (UN Comtrade Data). Hive numbers have increased from 344,123 in 2008 to 422,728 in 2012; total beekeepers from 2,594 to 3,806 (MAF 2008; 2012). Given this importance efforts should be made to fill some of the knowledge gaps that exist, which in turn will inform the need for regulation.

\subsection{Thesis outline}

In this thesis I investigate the relationship between the scientific study of invasive species and legal regulations intended to limit their spread. My overall goals were:

(1) To review a subset of international and domestic level regulations targeting invasive species with a view of commenting on their fitness for purpose and suggesting potential improvements to regulatory regimes; and

(2) To use the example of non-native and invasive Hymenoptera, as well as their pathogens, to illustrate both the risks posed by invasive species and gaps in their management.

In Chapter 2, I respond to critiques by other researchers that the sanitary and phytosanitary regulatory regime embodied by the SPS Agreement that exists under the aegis of the World Trade Organisation is ill-suited to the management of invasive species. I conclude that the regime, for the most part, provides adequate space for domestic regulators to manage the risks posed by invasive species.

Chapter 3 narrows the focus, from global to regional, and addresses New Zealand's approach to the management of potential invaders both pre- and post-border. Gaps are highlighted in the management regime and improvements suggested.

In Chapter 4, a specific industry, apiculture, is focussed upon. The potential risks posed by the Argentine ant to honey bees via competition and pathogen sharing are explored. 
Chapter 5 focuses yet further. Here I use mitochondrial DNA to trace the origins of global invasions of the globally distributed invasive species the German wasp (Vespula germanica). The presence of honey bee pathogens are assayed for. Both Chapters 4 and 5 highlight that the invasive species investigated are, in fact, a multitude of non-native organisms in that they carry an exotic pathogenic biome.

In Chapter 6 entire genomes of the honey bee virus Kashmir bee virus are sequenced to determine viral diversity both within and between regions. This chapter examines in detail one pathogen, and the patterns of genetic variation it displays.

Finally, Chapter 7 summarises and synthesises the key finding of my thesis, as well as outlining constraints. Avenues for future research are also explained.

One appendices is attached. It includes data from this thesis. 


\section{Chapter 2: Regulating invasive species: Reconciling ecological and legal views of acceptable risk in international trade law}

\subsection{Abstract}

Striking a balance between furtherance of global trade and national regulatory autonomy of domestic regulators is a vexed problem in the international trading system. Managing health and environmental risks are increasingly the focus of domestic regulatory authorities. Invasive species are a widespread problem. The movement of invasive species globally is exacerbated by the movement of people and goods. World Trade Organization rules and dispute resolution outcomes have been criticised by scientists and environmental groups as weakening the management of invasive species by imposing arduous requirements on domestically imposed sanitary and phytosanitary measures. This chapter argues that some of these critiques go too far as they do not take into account the nuance with which WTO panels approach individual cases. Further, critiques can be at least partially ameliorated through the mechanism of an appropriate level of protection - the level of protection deemed appropriate by the WTO Member establishing a sanitary or phytosanitary measure to protect human, animal or plant life or health within its territory. Part of the mandate of the WTO is to operate a global system of trade rules. The goal of these rules is to ensure that trade flows as smoothly, predictably and freely as possible. Given this goal, the WTO is unlikely to act as an environmental reformer. Meaningful change in the international management of invasive species must therefore be instituted by domestic authorities. This change could be the setting of high appropriate levels of protection, which in turn facilitate the imposition of stricter sanitary and phytosanitary requirements for incoming commodities.

\subsection{Introduction}

The World Trade Organisation (WTO) was formed in 1995. A basic challenge facing the WTO system is how best to balance the furtherance of liberalised trade whilst allowing WTO Members freedom to promulgate domestic regulations, intended to protect values such as the environment. The public and dramatic protests surrounding issues relating to liberalised trade, such as the 1999 Seattle protests (Trebilcock, 2005) and more recently the Trans-Pacific Partnership ${ }^{2}$ and Transatlantic Trade and Investment Partnership ${ }^{3}$, demonstrate that trade

\footnotetext{
${ }^{2}$ The Comprehensive and Progressive Agreement for Trans-Pacific Partnership (opened for signature 4 February 2016, not yet entered into force).

${ }^{3}$ The Transatlantic Trade and Investment Partnership (not yet opened for signature, not yet entered into force).
} 
negotiations are no longer arcane and hidden areas of diplomacy. Instead they have become well-publicised and socially divisive issues. The formation of the WTO signalled a shift in the locus of attention in trade negotiations; from a historic focus on tariff reduction, to differing approaches to precaution concerning issues such as pollution and human health. This shift in focus has continued to progress. Commentators disagree on the question of whether WTO rules and dispute resolution outcomes erode domestic regulatory authority (Wagner, 1998; Bohanes, 1999, 2002; Foster, 2008), or give sufficient autonomy to WTO Members (Davey, 2001; Trebilcock, 2005; Du, 2010a). It seems unlikely these groups will ever reach consensus given the polarisation of the dialogue. Critics of the WTO and trade liberalisation level accusations of increasing inequality, harm to the environment and human rights, as well as enervation of health and safety legislation (Trebilcock, 2005). Alternatively, advocates argue that the WTO has been deferential to the wishes of domestic legislatures, and trade liberalisation is at least partially responsible for the movement of a significant proportion of humanity out of poverty and maintenance of global peace (Trebilcock et al., 2012). A basic principle of the field of welfare economics is that countries trade so that they are better off (Trebilcock et al., 2012).

An illustrative example of the modern health-focused tension between domestic regulatory autonomy and trade liberalisation are the regulations created to inhibit the movement of potentially invasive species. Invasive species are non-native species that are transported to a new area, establish and increase in density and distribution to the detriment of the recipient environment (Lockwood et al., 2009). Certain non-native species, such as agricultural pests and vectors of human disease, are of increasing concern globally and attempts at management of their risks and impacts have been implemented in regulations at an international, regional and domestic level (McGeoch et al., 2010) ${ }^{4}$. A large and growing body of research has convincingly demonstrated that international trade is the key driver of the movement of nonnative species globally; via accidental imports associated with the movement of people and goods (Levine \& D’Antonio, 2003; Kobelt \& Nentwig, 2008; Westphal et al., 2008; Hulme, 2009; Brenton-Rule et al., 2016; Bertelsmeier et al., 2017; Seebens et al., 2018). Intentional introductions also play a role in invasive species distributions (Druett, 1983; Levine \& D’Antonio, 2003; Westphal et al., 2008; Hulme, 2009, 2011).

\footnotetext{
${ }^{4}$ For example: Article 8(h), Convention on Biology Diversity 1992; Article 196, The United Nations Convention on the Law of the Sea 1982; The International Maritime Organisation Ballast Water Management Convention 2004; The New Zealand Biosecurity Act 1993.
} 
Measures necessary for the protection of the life or health of humans, animals or plants from risks related to diseases and pests, including invasive species, are known as sanitary and phytosanitary measures (SPS measures). They are informed by an appropriate level of protection (ALOP) set by the importing state under the WTO's Agreement on the Application of Sanitary and Phytosanitary Measures (SPS Agreement). The SPS Agreement is a WTO agreement that entered into force with the establishment of the WTO on 1 January 1995. The Agreement defines an 'appropriate level of protection' as: "The level of protection deemed appropriate by the Member establishing a sanitary or phytosanitary measure to protect human, animal or plant life or health within its territory". Panels and the Appellate Body of the WTO have stated on several occasions that it is the undisputed fundamental right of WTO members to determine the protection they consider appropriate with respect to risk ${ }^{5}$.

Given that the global movement of invasive species is largely driven by international trade, the SPS Agreement with its focus on preventing disease and pest risks, is one of the most important instruments stemming the spread of invasive species (Burgiel, 2015). SPS measures promulgated for the protection of human health or the environment are often highly detailed and complex. As a result of this complexity there is a risk such measures may be used, or perceived, as illegitimate technical barriers to trade and become the subject of dispute. As of February 2018, there have been 47 WTO disputes citing the SPS Agreement ${ }^{6}$. Subjects of disputes have been wide ranging, from disease risks associated with the import of salmon ${ }^{7}$, to moths associated with apple market access ${ }^{8}$.

The imposition of SPS measures by national regulatory authorities is not an unfettered right and measures must be carefully crafted in order to comply with the rules of the SPS Agreement. First, measures must be based upon risk assessment informed by sufficient scientific evidence ${ }^{9}$. The requirement of the words 'sufficient scientific evidence' have been the subject of much

\footnotetext{
${ }^{5}$ Appellate Body Report, European Communities - Measures Affecting Asbestos and Asbestos-Containing Products (2001) at [168]; Appellate Body Report, Korea - Measures Affecting Imports of Fresh, Chilled and Frozen Beef (2000) at [176], Appellate Body Report, Brazil-Measures Affecting Imports of Retreaded Tyres (2008) at [210]; Appellate Body Report European Communities - Measures Concerning Meat and Meat Products (1998) (EC-Hormones) at [172]; Appellate Body Report, Australia-Measures Affecting the Importation of Salmonids (1998) (Australia - Salmon) at [199].

${ }^{6} \mathrm{https}$ ://www.wto.org/english/tratop_e/dispu_e/dispu_agreements_index_e.htm?id=A19 - Last accessed 28 March 2018.

${ }^{7}$ Appellate Body Report, Australia - Salmon.

${ }^{8}$ Appellate Body Report, Japan - Measures Affecting the Important of Apples (2003) (Japan-Apples).

${ }^{9}$ Articles 2.2 and 5.1, Agreement on Sanitary and Phytosanitary Measures 1995 (SPS Agreement).
} 
debate in SPS disputes. For example, in Japan - Apples where Japan attempted to argue sufficient scientific evidence was available supporting SPS measures restricting the import of apples to prevent the spread of fire blight (Erwinia amylovora). As a second requirement, SPS measures must be applied in a non-discriminatory manner such that they do not represent a disguised restriction on international trade ${ }^{10}$. That is, similar risks must be treated the same way across risks and trade partners. Additionally, any measure imposed must not be more trade restrictive than required to meet a Member's appropriate level of protection ${ }^{11}$. It is around these requirements that the majority of disputes involving invasive species have precipitated. These requirements are also where the formal scientific study of invasive species most closely interacts with the SPS Agreement. Given the wide purposes of SPS measures and issues arising in disputes, SPS issues have been of significant concern to the scientific community generally, and invasive species researchers specifically.

This chapter does not address whether WTO jurisprudence and regulations enervate domestic regulation in general. Instead, it focuses on the narrower concerns relating to the management of invasive species. The intention of this chapter is to review SPS jurisprudence to demonstrate to scientists and a lay-audience that WTO dispute resolution panels do not simply undertake a linear, mechanistic investigation; in which the only outcome is that which best serves the interests of liberalised trade. Instead the pattern has been that WTO decisions on these issues are earnest well-intentioned attempts to grapple with highly complex, specialised issues in order to reach a fair outcome within the strictures imposed by the WTO Agreements.

Section I introduces the concept of invasive species. Section II discusses the concept of an ALOP and replies to criticisms that the requirement of risk assessment under the SPS Agreement means that domestic authorities cannot effectively regulate the idiosyncratic risks posed by invasive species. I argue that while risk assessment under the WTO system may be imperfect from the perspective of invasive species management, it is not fatally so. Section III demonstrates that the requirements that SPS measures be consistent and not more trade restrictive than required, do not prevent WTO Members from managing risk. Overall I argue that critiques of the WTO from the perspective of managing invasive species risks: (1) Overstate the role of WTO Panels and discount the nuance and sensitivity with which Panels

\footnotetext{
${ }^{10}$ Articles 2.3 and 5.5, SPS Agreement.

${ }^{11}$ Articles 5.4 and 5.6, SPS Agreement.
} 
approach the right to impose measures that achieve Members' ALOPs with respect to invasive species; (2) Do not address sufficiently the failure of domestic authorities to maintain coherent and consistent quarantine regimes; and (3) Ignore the reality that imperfect quarantine regimes may simply reflect a lack of political will on the part of WTO Members to impose a high ALOP to address invasive species risk.

Section IV concludes and highlights that the WTO is a treaty. Member states, in the pursuit of their own respective national interests made a bargain. In exchange for the benefits they expected to derive as WTO Members, member states have agreed to exercise their sovereignty circumscribed by the commitments they have made in the WTO Agreement ${ }^{12}$. The WTO has a mandate as an international trade body, not an environmental regulator. Large-scale changes to the WTO called for by some commentators would likely precipitate drawn out international negotiations with highly uncertain outcomes given the different cultural and societal imperatives with which different parties approach environmental issues. Further, most critiques do not address the trade and economic consequences of a restrictively precautionary approach towards invasive species. I offer a pragmatic view: that the management of invasive species is possible through the device of an ALOP. However, the calibration of this ALOP is a domestic political decision. Critiques and lobbying to alter management should therefore be directed at domestic authorities.

${ }^{12}$ Appellate Body Report, Japan - Taxes on Alcoholic Beverages (1996) at 15. 


\subsection{Section I - An introduction to invasive species}

The study of invasive species is a sub-discipline of ecology that has grown exponentially in the past three decades (Richardson \& Pyšek, 2008) (Fig. 1.1.).

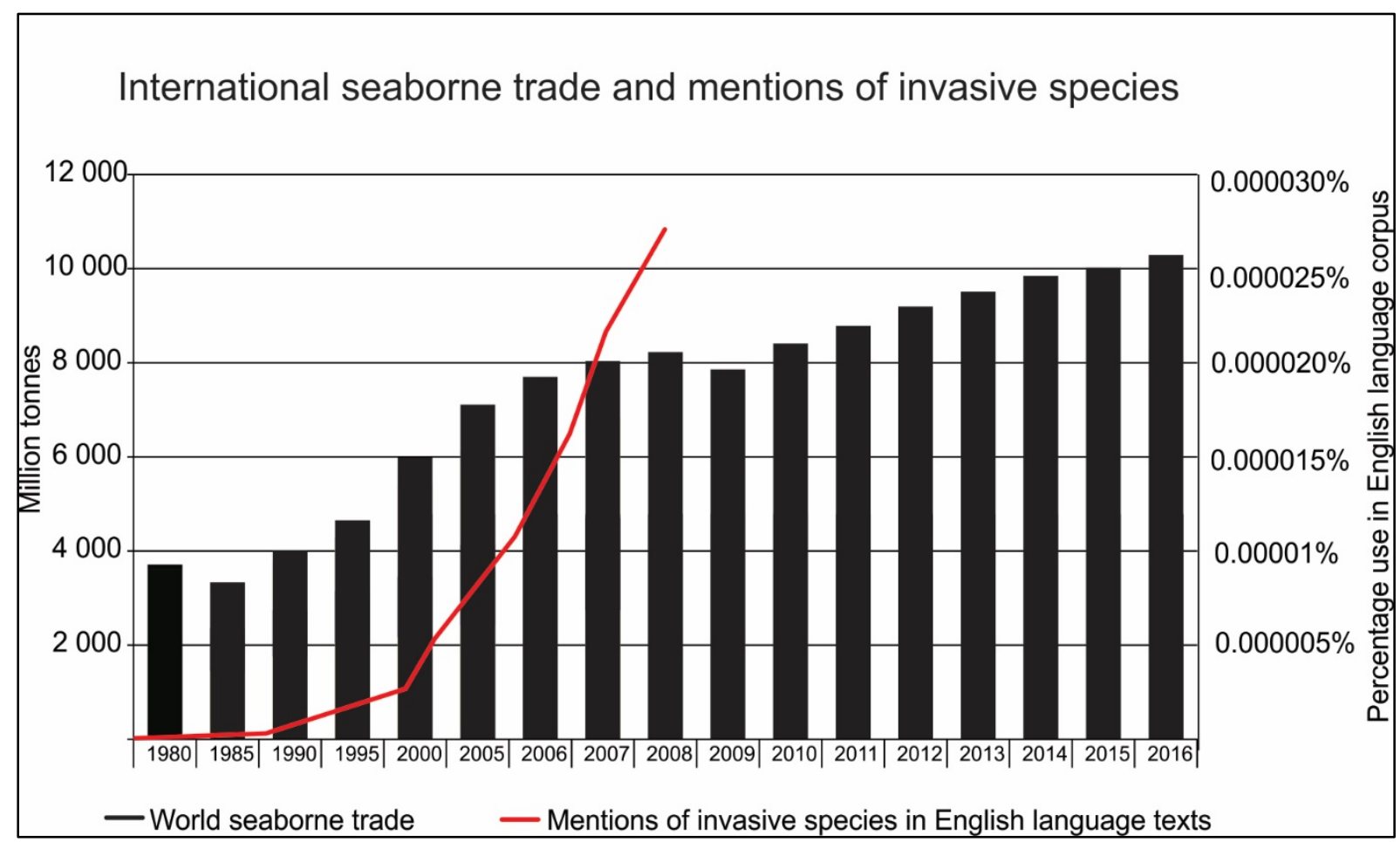

Fig. 1.1. Increases in global seaborne trade and the use of the phrase 'invasive species' in the English language. Data sourced from UNCTAD 2017 report and Google NGram (Michel J-B. et al. 2010). Ngram data availability ends in 2008.

This growth has been spurred by the sometimes-enormous impacts invasive species have upon recipient environments. From an environmental perspective, invasive species have been implicated in large-scale changes in ecosystem composition and function, nutrient cycles and agricultural productivity, and are cited as a major component driving global change (Vitousek \& D’Antonio, 1997; DiTomaso, 2000; Ehrenfeld, 2003). Economic impacts can also be significant (Scalera, 2010; Aukema et al., 2011; Bradshaw et al., 2016). For instance, annual costs of invasive species to the United States have been estimated at $\$ 120$ billion (Pimentel et al., 2005). These costs are primarily through direct loss and damage, as well as costs of control. One group, invasive insects, are estimated to inflict costs to general goods and services of around US\$70 billion globally per year, while associated health costs exceed US\$6.9 billion annually (Bradshaw et al., 2016). Social impacts can also be substantial through the erosion of areas' amenity values and interference with traditional ways of life (Gruber, 2018). 
International trade is increasing (Fig. 1) and is the key driver of the introduction of invasive species globally (Levine \& D’Antonio, 2003; Hulme et al., 2008; Kobelt \& Nentwig, 2008; Hulme, 2009; Bertelsmeier et al., 2017; Seebens et al., 2017). Non-native species are often accidentally introduced associated with commodities such as fresh produce and timber (Work et al., 2005; McCullough et al., 2006; Brenton-Rule et al., 2016), as well as ballast water, hull fouling and international airline passengers (Early et al., 2016). Invasive species include plants, animals and diseases. Globally widespread and well-known invasive species include: the Red imported fire ant (Solenopsis invicta), the Black rat (Rattus rattus), Chytrid fungus (Batrachochytrium dendrobatidis) and Avian malaria (Plasmodium relictum). In response to the increasing movement and impacts of such invasive species, international and domestic regulations intended to prevent or control their spread have proliferated since the 1970s (MacLeod et al., 2010; McGeoch et al., 2010) ${ }^{13}$.

These regulatory instruments operate at three broad levels: pre-border, border intervention and post border management. Implementation of such regulations are conducted by domestic biosecurity agencies, such as New Zealand's Ministry for Primary Industries, or Australia's Department of Agriculture and Water Resources. The first level, pre-border biosecurity, utilises risk assessments and focuses strongly on early detection, intervention and prevention ${ }^{14}$. Risk assessment focuses on identifying high-risk species, commodities and pathways of introduction, as well as managing intentional introductions. The second level, border intervention, involves implementing management regulations by inspecting people and goods entering a country, as well as assessing applications for the intentional import of new organisms. Finally, post-border management focuses on surveillance, rapid response to incursions and incipient populations, and long-term management of more established populations. Scientists generally agree that an emphasis on the first level, pre-border risk assessment and management, is the most effective and economical method of preventing the introduction of invasive species (Leung et al., 2012; Kumschick \& Richardson, 2013; Keller \& Springborn, 2014). Therefore, international regulations, such as the SPS Agreement, dealing with trade at the pre-border stage are particularly important to restrict the international movement and impacts of invasive species.

\footnotetext{
${ }^{13}$ Regulations intended to manage pest species have existed since at least the 1660s (MacLeod et al. 2010).

${ }^{14}$ The author appreciates that the term 'biosecurity' is inclusive of epidemiological and bioterror concerns in some jurisdictions. In this article I refer only to pest-focussed biosecurity.
} 
Scholars from a range of fields have critiqued the SPS Agreement from the perspective of managing invasive species (Campbell, 2001; Miller, 2003; Riley, 2005; Simberloff, 2005; Roy et al., 2014). Criticisms have largely focused on risk assessments, inconsistent treatment of similar risks and Member's rights to choose specific SPS measures to meet their ALOP. These critiques are often founded on normative judgements of how precautionary a Member's ALOP with respect to invasive species should be. The preamble of the SPS Agreement outlines several objectives intended to be accomplished by the Agreement. One of these is the establishment of a framework of rules that regulate the development, adoption and enforcement of SPS measures in order to minimise their negative trade effects ${ }^{15}$. However, the preamble also circumscribes this goal by emphasising that SPS disciplines are not intended to prevent WTO Members from adopting or enforcing measures necessary to protect human, animal, or plant life or health ${ }^{16}$. In Sections II and III of this paper I address specific articles and requirements of the SPS Agreement and their relevance to the management of invasive species. Where applicable I respond to critiques from the perspective of managing invasive species.

\subsection{Section II}

\subsubsection{A Member's Acceptable Level of Protection}

An acceptable or appropriate level of protection (ALOP) defines how much risk is acceptable for a society. This risk management tool is used in a range of fields, including environmental management, food safety and biomedical research (Davidson et al., 2015). It defines the highest level of risk that a society is prepared to tolerate with respect to a particular threat and has become an established part of SPS nomenclature. The term is defined in Annex A of the SPS Agreement as: "The level of protection deemed appropriate by the Member establishing a sanitary or phytosanitary measure to protect human, animal or plant life or health within its territory". An ALOP is an expression of government policy and reflects community expectations to risk regulated generally and, more specifically in the context of the SPS Agreement, the regulation of risk to protect the environment and agricultural security (Wilson, 2000). When applied to invasive species an ALOP is an aggregate societal value judgement to which biosecurity and conservation departments, as well as other relevant agencies contribute by providing technical advice (Wilson, 2000). A low ALOP will help to maximise the benefits

\footnotetext{
${ }^{15}$ Recital no 4, Preamble to the SPS Agreement.

${ }^{16}$ Recital no 1, Preamble to the SPS Agreement.
} 
of trade, but increase the risk of pest and disease incursions and their associated costs on biodiversity and agricultural industries. A high ALOP should lower the risk of incursion, but may impose costs in terms of market access, as well as maintaining an extensive biosecurity apparatus (Fig. 1.2.). 


\section{Hypothetical different ALOPs with respect to specific pests}
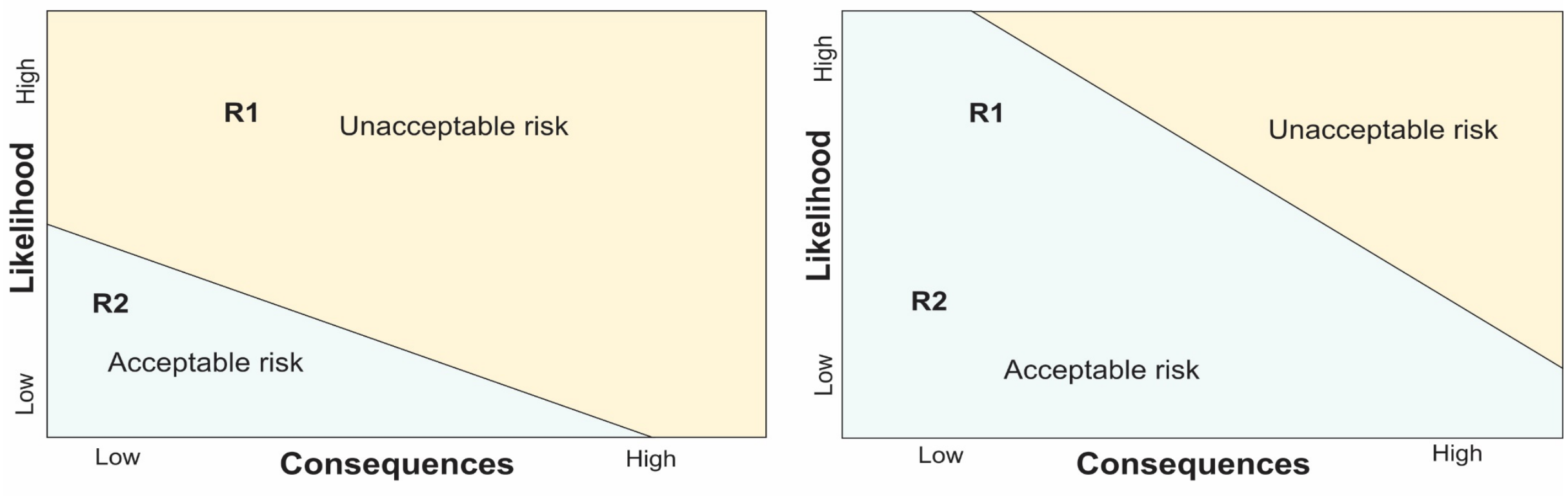

\section{Country A}

Strong agricultural industry

Conservation focus

\section{Country B \\ No or small agricultural industry \\ No conservation estate \\ Trade focus}

Fig 1.2. How high and low ALOPs affect risk management. The line dividing the blue and orange sections represents a country's ALOP - the maximum amount of risk a country will tolerate. Country A has a high ALOP therefore the orange unacceptable 'risk space' is large. Country B reflects the opposite scenario. Risk is a function of (a) the likelihood of a particular harm occurring (y axis); and (b) the consequences or level of damage that could occur (x axis). If a risk assessment finds that the SPS risk associated with a particular import is at point R1, Country A should choose SPS measures to ensure the risk of R1 moves down to the ALOP. Country B would choose more relaxed SPS measures as R1 is below country B's ALOP. R2 represents an acceptable risk in both countries. This diagram represents a simplification for illustrative purposes. No country promulgates such a precise and defined ALOP. 
How a WTO Member calibrates their ALOP with respect to invasive species reflects the economic, normative and political considerations unique to each Member. For instance, New Zealand has strict SPS requirements imposed on imported commodities. The setting of risk thresholds is driven by several factors, including the country's reliance on agricultural productivity and its valued conservation estate. Such strictness is also much easier to impose given New Zealand is an isolated island. On the other hand, a country such as Singapore lacks these imperatives to impose a high ALOP. Singapore lacks significant agricultural production or conservation estate; instead its role as a shipping hub for goods flowing through the Straits of Melaka and Southeast Asia impose a fundamentally different set of considerations to involve in the calculus of setting an ALOP.

The Appellate Body has stated on several occasions, with regard to disputes under the SPS Agreement, that it is the undisputed fundamental right of WTO members to determine the level of protection they consider appropriate with respect to risk when adopting an SPS measure ${ }^{17}$. Although the SPS Agreement does not explicitly oblige members to determine an ALOP, the Appellate Body has found that such an obligation is implicit in the Agreement ${ }^{18}$. This requirement is because setting of an ALOP logically precedes the establishment of an SPS measure $^{19}$. An ALOP may be expressed in qualitative or quantitative terms. This flexibility in choice of qualitative or quantitative formulation is important from the perspective of domestic autonomy as a qualitative expression of risk tolerance - e.g. very high, moderate, or low affords greater latitude for domestic regulators to impose SPS measures without having to peg those measures to a rigid quantitative standard. Further, flexible measures may be less costly and quicker to comply with. However, an ALOP cannot be determined with such vagueness or equivocation that the application of the relevant provisions of the SPS Agreement becomes impossible $e^{20}$.

As an example, the cases of US - Animals and US - Poultry ${ }^{21}$ were invasive species cases in which qualitative ALOPs were accepted by the Panel. The case of US - Animals was about the

\footnotetext{
${ }^{17}$ Appellate Body Report, EC - Hormones at [172]; Appellate Body Report, Australia - Salmon at [199].

18 Appellate Body Report, Australia - Salmon at [205].

${ }^{19}$ Appellate Body Report, Australia - Salmon at [203]; Although, note comments of Gruszczynski on the complex process of developing an ALOP (Gruszczynski, 2010).

${ }^{20}$ Appellate Body Report, Australia - Salmon at [203].

${ }^{21}$ Panel Report, US - Measures Affecting the Importation of Animals, Meat and Other Animals Products from Argentina (US - Animals) (2015); Panel Report, US - Certain Measures Affecting Imports of Poultry from China (2010).
} 
risk posed by foot-and-mouth incursions into the United States carried by Argentinian beef. The relevant domestic legislation in that case gave the US Secretary of Agriculture the discretion to take measures necessary to prevent the introduction into or dissemination within the United States of any pest or disease of livestock ${ }^{22}$. The Panel accepted this standard, holding that it was higher than that achieved by the relevant World Organisation for Animal Health international standard and somewhere between low and zero risk ${ }^{23}$. The Panel accepted a similarly qualitatively formulated ALOP in US - Poultry. In that case the United States' ALOP for poultry products was accepted to be "healthful, wholesome, fit for human food, not adulterated, and contain no dye, chemical, preservative or ingredient which renders them unhealthful, unwholesome, adulterated, or unfit for human food" ${ }^{24}$. Both of these ALOPs are examples of the fairly general ALOP formulation that appears to be tolerated with respect to SPS matters.

The establishment of an ALOP is not an unfettered right. When determining their ALOPs, Members must take into account WTO disciplines such as the most favoured nation (treating all countries equally) and national treatment (prohibiting discrimination between imported and domestically produced goods) principles ${ }^{25}$, as well as the requirement of risk assessment ${ }^{26}$. Additionally, Members should take into account the objective of minimising negative trade effects $^{27}$ and avoid arbitrary or unjustifiable distinctions in the levels of protection deemed appropriate in different situations, if these distinctions lead to discrimination or disguised restrictions on trade ${ }^{28}$. Further, Members should ensure that measures are not more trade restrictive than necessary to meet its $\mathrm{ALOP}^{29}$ and on occasion must assess the SPS measures of other Members as equivalent to its own, on the basis that the former achieve the importing Member's ALOP ${ }^{30}$. Finally, Members must ensure that there is a scientific justification for SPS measures which result in a higher level of SPS protection than would be achieved by measures based on the relevant international standard ${ }^{31}$.

\footnotetext{
227 United States Code 8303(a); Panel Report, US - Measures Affecting the Importation of Animals, Meat and Other Animals Products from Argentina (US - Animals) (2015) at [7.378] for commentary.

${ }^{23}$ Panel Report, US - Animals at [7.387].

${ }^{24}$ Panel Report, US - Certain Measures Affecting Imports of Poultry from China (2010) at [7.242] citing Poultry Products Inspection Act 21 USC 466.

${ }^{25}$ Article 5.5, SPS Agreement.

${ }^{26}$ Article 5, SPS Agreement.

${ }^{27}$ Article 5.4, SPS Agreement.

${ }^{28}$ Article 5.5, SPS Agreement.

${ }^{29}$ Article 5.6, SPS Agreement.

${ }^{30}$ Article 4.1, SPS Agreement.

${ }^{31}$ Article 3.3, SPS Agreement.
} 
Commentators have argued that the tension between full authority to set an ALOP on the one hand, and respect of other WTO disciplines on the other, erode the ability of domestic regulators to effectively manage risk. Arguments have been advanced that WTO requirements are undemocratic, overly focussed on science, and allow insufficient regulatory autonomy for domestic regulators to manage risk according to their countries' specific social perceptions of risk and how it should be managed (Scott, 2000, 2005; Skogstad, 2001). As a subset of this controversy the manner in which WTO rules restrict domestic management of invasive species risk have also been questioned (Campbell, 2001; Miller, 2003; Riley, 2005; Simberloff, 2005; Dahlstrom et al., 2011; Roy et al., 2014). The first area in which this issue is particularly acute is that of risk assessment.

\subsubsection{Risk assessment}

Commentators have criticised the WTO and national governments for an over reliance on the process of scientific risk assessment and the lack of a sufficiently precautionary approach with respect to environment risks, such as invasive species (Bohanes, 2002; Simberloff, 2005; Peel, 2007, 2012; Haseeb Ansari \& Wartini, 2014). Risk assessments have been labelled limited, and their predictions "illusory" as scientists have insufficient knowledge to predict which species may establish and become harmful (Simberloff, 2005). Critics of risk assessments in trade from the perspective of invasive species management have argued that current risk assessment methods have not been effective in guiding policy on, and management of, introduced species (Simberloff, 2005). Various published papers have presented evidence that these approaches and increasing international regulation has not stemmed the arrival of non-native species globally (Simberloff, 2005; McGeoch et al., 2010; Tittensor et al., 2014).

Risk assessment, for the purposes of the SPS Agreement with respect to pests and diseases, is defined by Annex A, paragraph 4 of the SPS Agreement as:

The evaluation of the likelihood of entry, establishment or spread of a pest or disease within the territory of an importing Member according to the sanitary or phytosanitary measures which might be applied, and of the associated potential biological and economic consequences. 
International standards are relevant to risk assessment, as SPS measures which conform to international standards are deemed consistent with the SPS Agreement ${ }^{32}$. International standards are set by three organisations: the Codex Alimentarius Commission (Codex) deals with food safety, the World Organisation for Animal Health (OIE) has a mandate over animal health and the Secretariat of the International Plant Protection Convention (IPPC) manages risks to plant health ${ }^{33}$.

Article 5 of the SPS Agreement addresses risk assessment as it pertains to the SPS Agreement. Article 5.1 requires that if a Member's measure does not 'conform to' international standards, that measure must be based on an assessment of the risks to human, animal or plant life or health. For instance, in the case of $U S$ - Animals the United States ALOP with respect to the risks posed by foot-and-mouth disease from imports of Argentinian beef was set at between low and zero risk ${ }^{34}$. The SPS measure that the United States had taken was a total ban on Argentinian beef imports. As this level was higher than the relevant OIE standard, the United States was bound to comply with the requirements of Article 5.1 requiring a risk assessment.

Article 5.2 requires that when assessing risk, Members must take into account: available scientific evidence; relevant processes and production methods; relevant inspection, sampling and testing methods; prevalence of specific diseases or pests; existence of pest- or disease-free areas; relevant ecological and environmental conditions; and quarantine or other treatments. With respect to scientific evidence, Article 2.2 of the SPS Agreement provides that SPS measures must be based on scientific principles and not be maintained without sufficient scientific evidence, except as provided for in paragraph 7 of article 5. In the Appellate Body decision in $E C$-Hormones it was made clear that this list was not exhaustive ${ }^{35}$. The preferred means of complying with the basic obligations under Article 2 is through the particular routes or specification obligations set out in Article $5^{36}$.

Article 5.3 requires that when assessing the risk to animal or plant life or health and determining the measure to be applied for achieving the ALOP, Members shall take into account various

\footnotetext{
${ }^{32}$ Article 3.2, SPS Agreement.

${ }^{33}$ Annex A, Paragraph 3, SPS Agreement.

${ }^{34}$ Panel Report, US - Animals at [7.387].

${ }^{35}$ Appellate Body Report, EC - Hormones at [187] and [206].

${ }^{36}$ Appellate Body Report India - Measures Concerning the Importation of Certain Agricultural Products (2015) (India - Agricultural Products) at [5.12]; Appellate Body Report, Australia - Apples at [339]; Appellate Body Report, EC-Hormones at [212]; Panel Report, Australia - Salmon at [8.52].
} 
economic factors, such as: potential loss of production, establishment or spread of a pest or disease and costs of control and eradication.

Three main areas of concern have been articulated with respect to SPS risk assessments of invasive species. These are specificity of risk assessment and the standard of review. To exemplify my analysis, I will discuss each of these areas and discuss using examples from WTO disputes the nuanced approached of the WTO panels and the Appellate Body.

\subsubsection{Specificity requirement of risk assessment}

The requirement of specificity in risk assessment dictates that a general discussion of risk is insufficient and may not include theoretical risk $^{37}$. Instead, the risk assessor must evaluate the specific potential of harm resulting from a specific SPS risk. This specificity requirement could be problematic from the perspective of managing invasive species as SPS measures applied on the basis of non-specific risks are unlikely to prove durable to WTO scrutiny. Here I outline this issue in more detail and use evidence from the scientific literature to argue that the requirement of specificity is not ruinous to the management of invasive species.

Two SPS cases provide relevant examples of the potentially problematic nature of the specificity requirement of risk assessment. In the Japan - Apples dispute an evaluation of the risks associated with all possible hosts of fire blight was held to be not sufficiently specific to qualify as a risk assessment under the SPS Agreement for the evaluation of the likelihood of entry, establishment or spread of fire blight in Japan specifically through US apples ${ }^{38}$. In ECHormones - regarding hormone additives in meat products - the Appellate Body found the risk assessment to be insufficiently specific as the scientific papers cited in that case evaluated the carcinogenic potential of hormones in general. Instead, according to the Appellate Body, the correct approach was to review the carcinogenic potential of residues of those hormones found in meat derived from cattle to which the hormones had been administered for growth promotion purposes $^{39}$. In that case, the Appellate Body's finding that no empirical studies were presented where any data indicated human health risks from the ingestion of hormone treated beef is correct. However, the burden of displaying specific positive evidence of this risk, either

\footnotetext{
${ }^{37}$ Theoretical uncertainty for the purposes of the SPS Agreement is the kind of uncertainty that is inherent in the scientific method and stems from the intrinsic limits of experiments, methodologies, statistics, or instruments deployed by scientists to explain a given phenomenon.

${ }^{38}$ Appellate Body Report, Japan - Apples at [202]-[203].

${ }^{39}$ Appellate Body Report, EC-Hormones at [199]-[200].
} 
quantitatively or qualitatively, in the hormone scenario is extremely difficult. Given the low risks involved, positive evidence would require longitudinal studies performed with large sample sizes, controlling for factors such as hormone ingestion from other sources, natural hormone production and genetic predisposition to cancer. Whilst such a study may be possible in theory, in practice it is a standard that is very difficult and costly to implement.

This strict specificity requirement has been critiqued by authors who claim that an accommodation between scientific evidence requirements and regulatory sovereignty is exceedingly difficult in compliance with WTO law (Bohanes, 1999; Sykes, 2002). Their view is that meaningful scientific evidence requirements conflict with regulatory sovereignty in all cases of serious scientific uncertainty when applying strict specificity requirements to risk assessments. WTO decision-makers must therefore choose between interpretations that enfeeble scientific evidence requirements and defer to national judgements on science, or an interpretation that gives the requirements traction at the expense of national regulators ability to choose their ALOP (Sykes, 2002).

Specificity requirements mapped onto the risks posed by invasive species face similar pitfalls. Risk assessments must address a risk with a high degree of specificity, including the form harm will take, the mechanism by which harm might be caused, and the degree of the likelihood of harm $^{40}$. An argument against this approach is that science has a superficial understanding of the world's biodiversity and a shallow appreciation of the dynamic processes and interacting networks governing species' population dynamics and the ecosystems in which they exist. Therefore, researchers' ability to model risks in such systems is constrained (Simberloff, 2005; Cooney \& Lang, 2007). By way of example, some species are not problematic in their native environment but have become invasive elsewhere unpredicted by domestic authorities. An example of this phenomenon is given by Roy et al. (2014) citing that the Sirex wood wasp (Sirex noctilio) and the fungal disease Red band needle blight (Dothistroma septosporum) are not recognised as pests in their native range, but are hugely destructive forestry pests across much of the southern hemisphere (Eldridge \& Simpson, 1987; Burgess \& Wingfield, 2001). Further, risk assessments of invasive species may require taking into account a large range of both known and unknown impacts. For instance, a regulator may be required to assess the

\footnotetext{
40 Appellate Body Report, EC - Hormones at [186] and [189]; Appellate Body Report - Japan - Apples at [200]-[206]; This requirement is also built into the definition of risk assessment, see Annex A, Para 4 SPS Agreement.
} 
possible impacts of pest insects and pathogens associated with a new source of lumber imports; however, many insects, bacteria and fungi are as yet undescribed and therefore their potential ecological impacts are not able to be incorporated into risk assessment. Given these issues, it is not unimaginable that a hypothetical domestic regulator may wish to impose import restrictions on a new source of forestry products on the basis of unknown pest and pathogen risks.

As a response to these comments, generally, newly introduced species which become invasive are for the most part well-known. Scientific knowledge of invasiveness elsewhere is an excellent predictor of whether a new species will become problematic (Pheloung et al., 1999). Further, regulators are able to call upon an increasingly sophisticated knowledge of serious invaders that cause substantial problems globally (Lowe et al., 2000; Gruber, 2018). These are species for which risk assessments may define risk with a high degree of specificity, including the form harm will take, the mechanism by which harm might be caused and the degree of the likelihood of harm. Serious invasive species that cause significant economic, conservation and social harm, such as the Red imported fire ant, have been the subject of intensive research. Countries imposing a high ALOP and stringent SPS measures with respect to risks posed by such invaders would be able to provide highly specific information and would be unlikely to find their SPS measure seriously challenged on the basis of lack of specificity. The pattern of decision-making in this space has not been a binary decision between interpretations of specificity that enfeeble scientific evidence requirements and defer to national judgements on science, or an interpretation that gives the requirements traction at the expense of national regulators ability to choose their ALOP. Instead, the approach in SPS cases has been to attempt to incorporate both of these approaches depending on the circumstances and the specificity of the information available.

\subsubsection{Standard of review}

The second issue is that of the standard of review applied to risk assessments under Article 5.1. During WTO dispute resolution, when a risk assessment informing an SPS measure is challenged, the risk assessment is subject to review by the Panel or Appellate Body. The question becomes, should Panels step back and give the benefit of the doubt to the regulating country? Or ought they to look more closely into the domestic decision-making process (Epps, 2012)? This concept of standard of review has been defined as the level of intensity of the scrutiny that a reviewing body will impose on the regulation or decision being reviewed 
(Button, 2004). The SPS Agreement itself is silent on the matter of what constitutes an appropriate standard of review ${ }^{41}$. Here I trace the standard of review applied in SPS disputes involving invasive species issues. I argue that a more intrusive objective approach applied in earlier cases has given way to a more nuanced approach that takes better account of the expectations of domestic regulatory authorities.

The Appellate Body in EC - Hormones and Australia - Apples has held that the standard of review in proceedings under the SPS Agreement "must reflect the balance established in that Agreement between the jurisdictional competences conceded by the Members to the WTO and the jurisdictional competences retained by the Members for themselves"42. According to the Appellate Body, the appropriate standard of review under Article 5.1 of the SPS Agreement is not a de novo review, nor total deference to the risk assessment. This statement has been dismissed by several commentators who posit that the standard applied has been, in fact, a de novo assessment (Bohanes \& Lockhart, 2009; Du, 2010b; Gruszczynski, 2010). The reasoning for this view is based upon the approach of the early Appellate Body decision in $E C-$ Hormones where the standard of review of a risk assessment under Article 5.1 was held to be an objective assessment of the facts of the case, as well as the applicability of and conformity with relevant agreements. Such an objective standard is arguably an intrusive standard of review not significantly deferential to the findings of national authorities (Covelli \& Hohots, 2003; Du, 2010b, 2011). The view that this is an intrusive standard is because an 'objective assessment' has been used to allow Panels to determine the existence, quality and sufficiency of scientific evidence without reference to the approach of domestic regulators; thereby attenuating the ability of domestic regulators to manage risks, such as invasive species, within the paradigm of their subjective cultural expectations.

An objective assessment approach applied in this manner is problematic from the perspective of invasive species management. Subsequent to the original EC-Hormones dispute, the 'objective assessment' approach was applied by the Appellate Body in two invasive species cases, Japan - Agricultural Products and Japan - Apples. In both cases, the Appellate Body afforded little deference to the national authority. In Japan - Apples the Appellate Body entirely rejected Japan's contention that the Panel should have made its assessment in light of

\footnotetext{
${ }^{41}$ Appellate Body, EC-Hormones at [114].

${ }^{42}$ Appellate Body Report, EC - Hormones at [115]; Appellate Body Report, Australia - Apples at [211].
} 
Japan's approach to risk and scientific evidence. Instead the Appellate Body relied on the 'objective assessment of the facts' approach of the Appellate Body in EC - Hormones with regard to the appropriate standard of review. It was on this basis that the Appellate Body found that Japan's argument that the Panel was obliged to favour Japan's approach to risk and scientific evidence over the views of the experts ran afoul of the Appellate Body's articulation of the standard of "objective assessment of the facts". This is despite statements from the Appellate Body in EC - Hormones, Japan - Apples, and Japan - Varietals that national regulators have the right to choose their own ALOP.

In Japan - Apples, Japan argued that the Panel should have evaluated scientific evidence with regard to Japan's approach to managing the bacterial disease fire blight (Erwinia amylovora), which reflected "the historical facts of trans-oceanic expansion of the bacteria"; "the rapid growth of international trade" and "the fact that the pathways of transmission of the bacteria are still unknown in spite of several efforts to trace them"43. This argument was rejected by the Appellate Body as "Japan's submission that the Panel was obliged to favour Japan's approach to risk and scientific evidence over the views of the experts conflicts with the Appellate Body's articulation of the standard of objective assessment of the facts" ${ }^{\prime 4}$. This rejection is problematic as it arguably attenuates the ability of a Member to establish and enforce its ALOP. Although, as noted by Epps (2012), while this could be interpreted as a rejection by the Appellate Body of a deferential approach, it can also be seen as specific to the facts of the case where Japan was, in effect, asking the panel to show total deference to its risk assessment and effectively not to review it at all.

Appropriate levels of protection allow members to implement their regulatory philosophies and concerns, which are motivated by idiosyncratic cultural, economic and social factors. It is an important part of the balance struck between the jurisdictional competences conceded by Members to the WTO and the jurisdictional competences retained by the Members for themselves. If an 'objective approach' towards risk assessment impinges too greatly on the establishment of an ALOP then the statements in EC-Hormones - that the standard of review must reflect the balance established in that Agreement between the jurisdictional competences conceded by the Members to the WTO and the jurisdictional competences retained by the

\footnotetext{
${ }^{43}$ Appellate Body Report, Japan - Apples at [161].

${ }^{44}$ Appellate Body Report, Japan-Apples at [165].
} 
Members for themselves - becomes functionally meaningless. Such an outcome would give credence to the argument that the ability of domestic regulators to manage invasive species is overly circumscribed by WTO decision-makers focussed on trade liberalisation.

However, the Appellate Body's approach to the standard of review in the more recent cases of US/Canada - Hormones Continued Suspension and adopted in an invasive species decision, Australia - Apples, has arguably reshaped the standard of review that a Panel applies when reviewing the conformity of a measure with Article 5.1 of the SPS Agreement ${ }^{45}$. This approach may alleviate some of the concerns of commentators regarding overly intrusive standards of review. Importantly, the Appellate Body in US/Canada - Hormones Continued Suspension stated that the role of a Panel is not to determine whether or not a risk assessment is correct, but instead whether the risk assessment is objectively justifiable in that it is supported by coherent reasoning and respectable scientific evidence ${ }^{46}$. A Panel's task is to review a WTO Member's risk assessment and not substitute its own scientific judgment for that of a risk assessor ${ }^{47}$. A Panel should verify whether the scientific basis underlying an SPS measure "comes from a respected and qualified source" and has "the necessary scientific and methodological rigour to be considered reputable science" ${ }^{\text {"48 }}$. Where a Panel goes beyond this mandate and acts as a risk assessor, it would be substituting its own judgement and making a de novo review, thereby exceeding its mandate ${ }^{49}$.

In the same decision, the Appellate Body lays out the appropriate standard of review. First, Panels should determine whether the scientific basis relied upon in the risk assessment came from a respected and qualified source, which can include minority opinion. Second, the Panel should determine whether the reasoning articulated on the basis of scientific evidence is objective and coherent, so that the conclusions reached in the risk assessment sufficiently warrant the SPS measure ${ }^{50}$. The Appellate Body was at pains to note that the role of technical experts is not to undertake their own risk assessment, but to inform the Panel and the Appellate

\footnotetext{
${ }^{45}$ Appellate Body Report, US - Hormones Continued Suspension of Obligations in the EC (US - Hormones Continued Suspension) (2008) at [590-592]; and Australia - Apples at [211]-[215].

${ }^{46}$ Appellate Body Report US - Hormones Continued Suspension at [590]; Appellate Body Report AustraliaApples at [213].

${ }^{47}$ Appellate Body Report, US - Hormones Continued Suspension at [590]; Appellate Body Report, AustraliaApples at [213].

${ }^{48}$ Appellate Body Report US - Hormones Continued Suspension at [591]; Australia - Apples at [214].

${ }^{49}$ Appellate Body Report, US - Hormones Continued Suspension at [590].

${ }^{50}$ Appellate Body Report, US - Hormones Continued Suspension at [598].
} 
Body in the answering of the two requirements of the standard of review. This standard requires that disputed SPS Measures must be evaluated and verified in light of the WTO Member's own risk assessment and chosen level of protection ( $\mathrm{Du}, 2010 \mathrm{~b})$. This approach to the standard of review was first described in EC-Hormones Suspension ${ }^{51}$ and subsequently followed in the invasive species case of Australia - Apples ${ }^{52}$.

In Australia - Apples the Panel had found that several of the steps in Australia's risk assessment, the Import Risk Analysis (IRA), had attached scientifically unsupported probabilities to potential events occurring in a causative chain resulting in introduction of apple diseases. This causative chain in Australia's IRA included eight 'importation steps', each with an associated probability. For instance importation step 1, represented the likelihood that the pest is present in the source orchards. The Australian IRA estimated that the likelihood that fire blight was present in source orchards at $100 \%{ }^{53}$. New Zealand argued that the IRA's estimate that fire blight would be in $100 \%$ of source orchards in New Zealand was incorrect and constituted a "significant overestimation" 54 . Importation step 2 assessed the likelihood that picked fruit is contaminated with fire blight ${ }^{55}$. Importation step 3 represented the likelihood that clean fruit from infected or infested orchards is contaminated during picking and transport to the packing house $\mathrm{e}^{56}$. These steps continue until importation step 8 . Importation step 8 represents the likelihood that infected or infested fruit remains infected or infested after minimum border procedures on fruit arrival to Australia ${ }^{57}$.

Australia claimed that the Panel: (1) misinterpreted and misapplied the standard of review applicable to its review of the IRA under Article 5.1; (2) erred in its assessment of the use of IRA expert judgment; and (3) failed to assess the materiality of the faults it found with the reasoning in the IRA. As to the first point, Australia claimed that in finding the conclusions of the IRA were not supported by sufficient scientific evidence and were thus not objective and

\footnotetext{
${ }^{51}$ Appellate Body Report, US - Hormones Continued Suspension at [590].

${ }^{52}$ Although in that case the Appellate Body drew a clear distinction between: (1) the standard of review to be applied to scientific evidence relied upon by the risk assessor; and (2) the reasoning employed and conclusions reached by the risk assessor on the basis of that scientific evidence. Appellate Body, Australia - Apples, at [224].

${ }_{53}$ Australia's IRA, Part B, at 53-55.

${ }^{54}$ New Zealand's first written submission at [4.212]. See also New Zealand's second written submission at [2.402].

${ }_{55}^{5}$ Australia's IRA, Part B, at 19-21.

${ }^{56}$ Australia's IRA, Part B, at 19-21.

${ }^{57}$ Australia's IRA, Part B, at 19-21.
} 
coherent, the Panel misapplied the standard of review from US/Canada - Continued Suspension. Australia argued that the probability attached to each event did not need to do more than fall within a range that could be considered legitimate by the standards of the scientific community ${ }^{58}$. Australia further contended that the standard of 'objectivity and coherence' does not relate to the quality of the reasoning per se, but to the quality of the "particular conclusion ultimately reached"59. The Appellate Body disagreed with this approach stating that the Appellate Body in US/Canada - Continued Suspension was not setting a mechanical standard that must be followed, but instead suggesting a manner to verify the consistency of risk assessment with Article 5.1 that is centred on the notion that a risk assessment should be evaluated in light of the scientific evidence upon which it relies ${ }^{60}$. The Panel should verify the existence of a "rational or objective relationship" between the SPS measures and risk assessment on one hand, and the scientific evidence on the other ${ }^{61}$. The Panel found that in several instances the IRA's conclusions were neither objective nor coherent because their probabilistic estimation of certain risks and consequences did not find support in the scientific evidence relied upon ${ }^{62}$. Such an approach is appropriate. If the Panel could not assess the objectivity and coherence of the intermediate conclusions and the reasoning of a risk assessment then there would have been no manner in which to assess the consistency of the IRA with Article 5.1. Further, it is necessary that an objective and coherent conclusion is predicated on objective and coherent reasoning.

The second point of Australia's appeal was the Panel's evaluation of the use of IRA expert judgment to reach conclusions regarding intermediate steps in the IRA. The Australian IRA team engaged experts to assess the probability of intermediate events where there was scientific uncertainty ${ }^{63}$. The issue with this approach was that little information was provided in the IRA on how the experts discussed, reviewed and attached quantitative likelihoods to factors associated with the entry, establishment and spread of disease ${ }^{64}$. The issue was not with the use of expert judgment in the absence of scientific evidence ${ }^{65}$. Instead, the problem was the IRA's

\footnotetext{
${ }^{58}$ Australia-Apples, Australia's appellant's submission at [77].

59 Australia - Apples, Australia's appellant's submission at [76]-[77]; [103].

${ }^{60}$ Appellate Body Report, Australia-Apples at [219].

${ }^{61}$ Appellate Body Report, Australia - Apples at [219].

62 Appellate Body Report, Australia-Apples at [222].

${ }^{63}$ Appellate Body Report, Australia-Apples at footnote 360.

${ }^{64}$ Panel Report, Australia - Apples at [7.432].

${ }^{65}$ Appellate Body Report, Australia-Apples at [240].
} 
consistent use of expert judgment in situations where scientific evidence was available ${ }^{66}$, the IRA's non-reliance on that evidence, and the absence of reasoning as to why such an approach was followed ${ }^{67}$. Australia even acknowledged that "it is true that certain steps in the pathways assessed were better supported by evidence than others" and that "in those latter cases, expert judgment was employed"68. Australia attempted to argue, based on international IPPC standards, that only identification of where expert judgment has been used and an explanation of what scientific uncertainty has given rise to the need for that expert judgment to be made, is all that is required. There is, however, no suggestion for any need to explain how a particular expert judgment was reached ${ }^{69}$; no need for a requirement of transparency. From this author's perspective such an approach would be untenable from the perspective of ascertaining consistency with Article 5.1 of the SPS Agreement. It would effectively shelter any decision made by experts from regulatory scrutiny. The Appellate Body took a similarly dim view of this proposition and stated that documentation and transparency is required in the use of expert judgment and is necessary to determine whether a risk assessment relies on available scientific evidence and is consistent with the SPS Agreement ${ }^{70}$.

Australia's third claim was that the Panel erred in failing to assess the materiality of the faults it found in the intermediate conclusions of the IRA ${ }^{71}$. The Appellate Body reviewed the Panel's findings ${ }^{72}$ and found that a Panel is not required to establish whether each fault is material, but rather whether all the flaws in aggregate are serious enough to render the risk assessment inconsistent with Article 5.173; which was the approach followed by the Panel in this decision. This approach essentially follows the example set in the Australia - Salmon compliance proceedings that there is no general standard as to when individual flaws in a risk assessment will be fatal to the assessment as a whole. Instead, in that decision the Panel had found that the methodological flaws were not serious enough for a Panel to no longer have reasonable confidence in the risk assessment ${ }^{74}$.

\footnotetext{
${ }^{66}$ Panel Report, Australia-Apples at [7.803].

${ }^{67}$ Appellate Body Report, Australia-Apples at [240].

${ }^{68}$ Australia Apples, Australia's opening statement at the second Panel meeting at [12].

${ }^{69}$ Australia Apples, Australia's appellant's submission at [97].

${ }^{70}$ Appellate Body Report, Australia - Apples at [244]; [248].

${ }^{71}$ Appellate Body Report, Australia - Apples at [249].

72 Appellate Body Report, Australia - Apples at [249]-[257].

${ }^{73}$ Appellate Body Report, Australia - Apples at [258].

${ }^{74}$ Panel Report, Australia - Salmon (Article 21.5 Panel Report) at [7.57].
} 
What might the approach of the Appellate Body to the standard of review in Australia - Apples mean for the management of risks posed by invasive species associated with commodities? In Japan - Apples and Japan - Varietals the Appellate Body relied heavily on the opinions of scientific experts and then attempted to decide whether Japan's actions aligned with those experts' opinions (Du, 2010b). This approach discounted Japan's attitude to risk, thereby curtailing Japan's ability to decide on an ALOP and impose an SPS measure to give effect to that ALOP. As noted by Epps (2012) while this could be interpreted as a rejection by the Appellate Body of a deferential approach, it can also be seen as specific to the facts of the case where Japan was, in effect, asking the Panel to show total deference to its risk assessment and effectively not to review it at all.

The new approach laid out in US/Canada - Continued Suspension and Australia - Apples limits the mandate of scientific experts and panels. In theory, this limited mandate means that risk assessments undertaken by domestic authorities informing SPS measures will be subject to a less onerous standard of review. In this author's opinion, this is a preferable approach. Such a standard takes into account more fully a Member's ALOP and their chosen level of protection. Essentially, only two key requirements are thus required of a risk assessment in the review process. First, the scientific basis relied upon in the risk assessment must come from a respected and qualified source, which can include minority opinion. Second, the reasoning articulated on the basis of scientific evidence must be objective and coherent, so that the conclusions reached in the risk assessment sufficiently warrant the SPS measure. Under this approach, a Member's risk assessments no longer must fit into the Panel's experts' notions of the scientific status quo. As illustrated above, Australia's IRA failed, not because scientific experts disagreed with Australia's data and science. Instead, it failed because: (a) the probabilistic conclusions were not supported by scientific evidence; and (b) where expert opinion was used, the decisionmaking process of the experts was opaque and therefore impermeable to any standard of review. This approach from US/Canada - Continued Suspension and Australia -Apples represents a more lenient standard that grants greater discretion to domestic regulators when managing invasive species and should ameliorate some concerns regarding an intrusive standard of review under Article 5.1. Overall it also provides guidance to countries imposing SPS measures as to the methodological steps that should be followed when undertaking risk assessment. 


\subsubsection{Flexibility of risk assessment}

The above points addressed specific critiques of risk assessment levelled by some commentators. Here I posit a more general defence of risk assessment as it occurs in the WTO process. Risk assessment is not a calcified undertaking to be performed by rote; there exists a degree of flexibility in the process. In EC - Hormones the Appellate Body described risk assessment as a process characterised by systematic, disciplined and objective enquiry and analysis, that is, a mode of studying and sorting out facts and opinions ${ }^{75}$. The Appellate Body has specifically cautioned against taking too narrow an approach towards risk assessment ${ }^{76}$. In Australia-Apples the Appellate Body stated that Article 5.2 requires a risk assessment to take account of the available scientific evidence, together with other factors. It is not a closed list ${ }^{77}$.

Risk assessment assesses the likelihood and severity of potential exposure to hazardous agents or activities. Risk management is the process of identifying, evaluating, choosing and implementing measures to reduce risk ${ }^{78}$. Risk management under the SPS Agreement involves the choice of an ALOP in order to manage the risk identified and the selection of an SPS measure to achieve the chosen level of protection. Typically, risk assessment and risk management have been characterised as interacting, but functionally separate risk analysis activities (Andersen et al., 2004). This strict delineation between risk assessment and management was the approach taken by Panels in EC-Hormones ${ }^{79}$ and EC-Hormones Suspension $^{80}$. However, in both of the Hormones disputes the Appellate Body stated that risk assessment cannot be isolated from a Member's ALOP ${ }^{81}$, which is usually part of risk management. The reason for this statement is that a Member's ALOP in some instances may affect the scope and method of risk assessment ${ }^{82}$. The Appellate Body stated that this may be the case "where a WTO Member decides not to adopt an SPS measure based on an international standard because it seeks to achieve a higher level of protection"83.

\footnotetext{
75 Appellate Body Report, EC-Hormones at [187].

${ }^{76}$ Appellate Body Report, US - Hormones Continued Suspension at [527].

77 Appellate Body Report, Australia - Apples at [208].

78 The Presidential/Congressional Commission on Risk Assessment and Risk Management (1997). Risk Assessment and Risk Management in Regulatory Decision-Making. Washington DC.

${ }^{79}$ Panel Report, EC-Hormones at [8.97] - [8.100].

${ }^{80}$ Panel Report, US - Hormones Continued Suspension at [6.91]; [6.99].

${ }^{81}$ Appellate Body Report, EC - Hormones at [181]; Appellate Body Report, US - Hormones Continued Suspension at [534] - [542].

82 Appellate Body Report, EC - Hormones Continued Suspension at [537]-[543].

${ }^{83}$ Appellate Body Report, EC - Hormones Continued Suspension at [534].
} 
In the first hormones dispute the Appellate Body stated that a "Member's appropriate level of protection may be higher than that implied in the international standard. The right of a Member to determine its own appropriate level of sanitary protection is an important right" ${ }^{\prime 24}$. The Appellate Body explains that in such a situation the choice of a higher level of protection may require a Member to perform different research as part of its risk assessment than that carried out for the international standard ${ }^{85}$. These statements are important as they provide regulatory space for domestic authorities to undertake risk assessments based on their particular ALOP. This space is useful for domestic regulators as it allows WTO Members to articulate, if desired, an extremely high ALOP with respect to specific risks which may help to inform a risk averse risk assessment and the restriction of imports based on identified risks. Indeed, in theory a Member could implement a zero-risk policy across comparable risks ${ }^{86}$; even if there is an internationally agreed standard already in existence.

Further flexibility is provided by the fact that an evaluation of the likelihood of risk for the purposes of a risk assessment informing an SPS measure may be expressed quantitatively or qualitatively ${ }^{87}$. For instance, in Australia - Salmon, Australia's ALOP was described as "a high or very conservative level of protection aimed at reducing risk to very low levels, while not based on a zero-risk approach"; although a zero-risk approach would have been acceptable ${ }^{88}$. The decision in the Australia - Salmon dispute is regarded as one of the strictest SPS decisions taken by the Appellate Body (Motaal, 2005), but even there, Australia was not required to produce numerical probabilities. Instead the Appellate Body would have been satisfied with a qualitative assessment of a particular risk.

There is also flexibility in the factors to be considered in risk assessment. The Appellate Body in $E C$ - Hormones elaborate that scientific evidence in risk assessments is only the beginning and other factors such as relevant inspection, sampling and testing methods should also be considered. It also stresses the point that there is nothing to indicate the list of factors to be taken into account in a risk assessment as per Article 5.2 is a closed list, more factors may be considered $^{89}$. This approach to flexibility was affirmed and applied in the case of Australia-

\footnotetext{
${ }^{84}$ Appellate Body Report, EC-Hormones at [170]-[172].

${ }^{85}$ Appellate Body Report, EC-Hormones Continued Suspension at [685].

86 This right has been confirmed by the Appellate Body: Appellate Body Report, Australia - Salmon at [125].

87 Appellate Body Report, EC - Hormones at [184] and [186]; Appellate Body Report, Australia - Salmon at [123]-[124]; [204]; Guidelines to Further the Practical Implementation of Article 5.5 at [A1].

88 Appellate Body Report, Australia - Salmon at [125].

89 Appellate Body Report, EC-Hormones at [187].
} 
Apples where the Appellate Body elaborated that Article 5.2 does not exclude factors that are not susceptible to quantitative analysis by the empirical or experimental laboratory methods commonly associated with the physical sciences ${ }^{90}$.

A key message here is that although a high ALOP should not affect the rigor and objective nature of the assessment, it may enable a more precautionary risk assessment as it could allow for changes to the scope and methodology utilised. From the perspective of risk assessments for invasive species various factors may influence invasion success, such as habitat and climatic suitability, biotic interactions with local fauna, and temporal variability in reproduction. Risk assessments may include models incorporating these and other factors. Model parameters could be altered under a high ALOP regime to take a more precautionary approach, resulting in different modelled invasion risk outcomes (Hastings et al., 2005; Hartley et al., 2006). By way of example, Paini et al. (2010) found risk assessment methodologies, such as self-organising maps, can provide significant differences in estimates of pest species establishment risk than those given in expert consultation ${ }^{91}$. Further, they demonstrated that changes in model parameters and data inputs can alter the outcomes of risk models. Under a high ALOP scenario model, parameters could be calibrated in a highly precautionary manner, providing the scientific evidence required for valid imposition of SPS measures. Such an approach could extend to a Member's risk modelling generally.

The flexibility outlined above means that risk assessment is not a mechanistic, linear exercise. Variability is permitted within the requirements that the risk assessment is objectively justifiable in that it is supported by coherent reasoning and respectable scientific evidence ${ }^{92}$. Where a SPS measure is higher than the relevant international standard, the implementing country should pay particular attention to SPS decisions and craft their SPS measures accordingly. Although Appellate Body decisions are not binding, risk assessments that are made cognisant of the requirements articulated by Panels and the Appellate Body in SPS cases are more likely to be durable to formal challenge.

\footnotetext{
${ }^{90}$ Appellate Body Report, Australia - Apples at [207].

${ }^{91}$ A self-organising map is a neural network that can be used to generate values that indicate the strength of association of a species with a species assemblage, which can be used as a risk index. See Paini et al. (2010) for a more detailed explanation.

92 Appellate Body Report US - Hormones Continued Suspension at [590]; Appellate Body Report AustraliaApples at [213].
} 


\subsubsection{Insufficiency of scientific evidence}

Article 5.1 of the SPS Agreement requires that SPS measures are based on risk assessment. Article 2.2 provides that SPS measures must be based on scientific principles and not maintained without sufficient scientific evidence, except as provided for in Article 5.7. This requirement of sufficient scientific information could be seen as problematic from the perspective of managing invasive species because, as mentioned previously, scientists' understanding of biological systems is nascent. Given this, national authorities may wish to restrict imports of certain commodities in situations where the risk posed by invasive species is uncertain. This issue is a reasonable concern to level at the WTO system with regard to invasive species, given (a) the uncertain impacts that may be catalysed through the introduction of mutualists that facilitate the spatial spread and population increase of species (O'Dowd et al., 2003), (b) hybridisation with natives resulting in hybrid vigour and loss of native genetic diversity (Ellstrand \& Schierenbeck, 2006), or (c) the release from natural enemies such as predators or parasites (Torchin et al., 2003). In addition, some species may be benign in their home range, but damaging when introduced elsewhere (Roy et al., 2014).

Article 5.7 states that in cases where relevant scientific evidence is insufficient, a Member may provisionally adopt SPS measures on the basis of available pertinent information. The Appellate Body in Japan - Varietals expanded on what is needed for such a provisional measure under Article 5.7. A Member may provisionally adopt an SPS measure if this measure is ${ }^{93}$ :

(1) Imposed in respect of a situation where relevant scientific evidence is insufficient; and

(2) Adopted on the basis of available pertinent information; and

(3) The measure may not be maintained unless the Member seeks to obtain the additional information necessary for a more objective assessment of risk; and

(4) Reviews the measure accordingly within a reasonable period of time.

Article 5.7 is critical from the perspective of managing invasive species risks because it allows Members to take precautionary measures on a provisional basis, based on available pertinent information. This ability addresses some of the concerns of scientists critical of the outcomes

\footnotetext{
${ }^{93}$ Appellate Body Report, Japan - Measures Affecting Agricultural Products (1999) (Japan - Varietals) at [89]; Appellate Body Report, Japan - Apples at [176]; Panel Report, US - Hormones Continued Suspension at [7.593].
} 
of WTO trade disputes on the management of invasive species. Essentially, if scientific evidence is insufficient to perform an adequate risk assessment a WTO Member may implement a provisional measure that is supported by the lower standard of pertinent information, rather than sufficient scientific evidence. In Australia - Salmon the panel labelled Article 5.7 "an exception to the obligation to base sanitary measures on a risk assessment, namely in cases where relevant scientific evidence is insufficient" ${ }^{94}$.

It should be noted at this point that the Appellate Body does not recognise the precautionary principle as customary international law ${ }^{95}$. Customary international law, although there are various definitions, can be defined broadly as the general practice of states that has been accepted as law. It is binding upon state actors unless they have specifically repudiated it at the time it was formulated. Despite this lack of recognition of the precautionary principle, the Appellate Body does state that the precautionary principle finds reflection in Article 5.7 of the Agreement ${ }^{96}$. This article was held to "explicitly recognise the right of Members to establish their own ALOP, the level of which may be higher than that implied in existing international standards, guidelines and recommendations" ${ }^{\prime 97}$. However, the precautionary principle has not been written into the SPS Agreement as a method to justify measures that are otherwise inconsistent with the SPS Agreement itself $f^{98}$. Whilst the precautionary principle is triggered by the presence of uncertainty, Article 5.7 is applied in situations where there is insufficient scientific evidence, which is arguably a higher standard (Peel, 2006). The bounds imposed by the interpretation of Article 5.7 by Panels and the Appellate Body are therefore extremely important to the management of invasive species as they define how little information may support a temporary SPS measure. Here I argue that the case-by-case approach advocated by the Appellate Body is appropriate under Article 5.7 as it recognises that establishing sufficient scientific information for certain species will be far more difficult than for others.

\subsubsection{When is scientific evidence insufficient?}

The four requirements above from Japan - Varietals are cumulative in nature and are equally important to determine consistency with Article 5.7. According to the Appellate Body they

\footnotetext{
${ }^{94}$ Panel Report, Australia - Salmon at [8.57]; See also: Panel Report, EC-Measures Affecting the Approval and Marketing of Biotech Products (2006) at [7.2998].

95 Appellate Body Report, EC-Hormones at [124].

${ }^{96}$ Appellate Body Report, EC-Hormones at [124].

${ }^{97}$ Appellate Body Report, EC-Hormones at [124].

${ }^{98}$ Appellate Body Report, EC - Hormones at [124] Appellate Body Report, Japan - Varietals at [81] - [83].
} 
should be interpreted keeping in mind that the precautionary principle finds reflection in this provision $^{99}$. The Appellate Body has stated that the interrelationship between Articles 5.1 and 2.2 on the one hand, and of Article 5.7 on the other, will depend on the sufficiency of scientific evidence $^{100}$; with Articles 5.1 and 5.2 providing the relevant context for interpreting the phrase "maintained without scientific evidence" in Article 2.2 ${ }^{101}$. A WTO Member may take a provisional SPS measure on the basis provided by Article 5.7, but that Member must meet the obligations of that provision ${ }^{102}$.

Given this statement, the calibration of what is sufficient scientific evidence becomes extremely important. The standard from cases has been that insufficiency of scientific evidence is present if a body of available scientific evidence does not allow in qualitative or quantitative terms, the performance of an adequate assessment of risks as required under Article 5.1 and as defined in Annex A to the SPS Agreement ${ }^{103}$. In US/Canada - Continued Suspension the Appellate Body held that whether evidence is sufficient must be informed by a WTO Member's predetermined ALOP. Specifically, it stated that a WTO Member may require scientific evidence in their risk assessment that was not examined in the process leading to the adoption of an international standard ${ }^{104}$. Put another way, a WTO Member with a very high ALOP may require certain additional research over and above the parameters investigated underlying the international standard. Scientific sufficiency for the purposes of an international standard does not decide whether relevant scientific information qualifies as sufficient for the purposes of Article $5.7^{105}$. By way of example, the Secretariat of the International Plant Protection Convention (IPPC) has been designated under the SPS Agreement as the standard-setting body for plant health ${ }^{106}$. Standards are released as International Standards for Phytosanitary Measures (ISPMs). As of June 2018, 96 such standards have been promulgated ${ }^{107}$. For instance, ISPM 26 outlines in detail guidelines for the establishment of pest free areas for fruit flies of economic importance, and for the maintenance of their pest free status ${ }^{108}$. Fruit flies are

\footnotetext{
${ }^{99}$ Appellate Body Report, EC-Hormones at [680].

${ }^{100}$ Appellate Body Report, EC-Hormones at [674].

101 Appellate Body Report India - Agricultural Products at [5.15]; Appellate Body Report Japan - Varietals at [74]-[80].

102 Appellate Body Report, EC-Hormones at [674].

103 Appellate Body Report, Japan - Apples at [179]; Panel Report, US - Hormones Continued Suspension at [7.608].

${ }^{104}$ Appellate Body Report, EC-Hormones at [685].

105 Appellate Body Report, EC-Hormones at [697].

${ }^{106}$ Annex A (3)(c), SPS Agreement.

107 https://www.ippc.int/en/core-activities/standards-setting/ispms/\#publications - Last accessed 4 August 2018.

108 ISPM 26. 2006. Guidelines for inspection. Rome, IPPC, FAO.
} 
a major pest in Asia and the Pacific as their larvae feed on a range of fruit and vegetables (Waterhouse, 1993, 1997). ISPM 26 outlines specific requirements for this pest, such as trapping and surveillance procedures, controls on the movement of regulated articles and buffer zones $^{109}$. A Member with an extremely high predetermined ALOP could, if desired, go beyond the information required leading to the adoption of ISPM 26, and require measures higher than the Standard regarding controls on movement of fruit flies. Such an approach would likely have implications for trade, but a hypothetical national regulator with a strong conservation focussed agenda would be able to impose such requirements based on their ALOP provided that the political and trade costs were viewed as acceptable by the country concerned. For example, the Panel in US - Animals accepted the United States' argument that it's ALOP with respect to preventing the introduction of foot-and-mouth disease (FMD) into the United States was permitted to be higher than the relevant OIE standard ${ }^{110}$.

\subsubsection{Additional information}

The third element of the test in Article 5.7 is that the Member adopting the provisional measure must seek to obtain the additional information necessary for a more objective assessment of risk. The Appellate Body has noted that neither Article 5.7, nor any other provision of the SPS Agreement sets out explicit prerequisites regarding the additional information to be collected or a specific collection procedure ${ }^{111}$. Instead, the only requirement is that the information must be germane to conducting a risk assessment ${ }^{112}$.

\subsubsection{Reasonable time}

A key question under Article 5.7 with respect to invasive species risks is what is a reasonable period of time to undertake a risk assessment? In Japan - Varietals the Appellate Body indicated that the concept of reasonableness should be determined on a case-by-case basis ${ }^{113}$. It depends on the circumstances, including the difficulty of obtaining the additional information and the characteristics of the provisional measure ${ }^{114}$. In that decision, a six year period was found to be unreasonable ${ }^{115}$. This unreasonableness was because the Panel found that collecting

\footnotetext{
${ }^{109}$ ISPM 26. 2006. Guidelines for inspection. Rome, IPPC, FAO at 9-14.

110 The Terrestrial Code Article 8.5.23; See Panel Report, US - Animals at [7.502] for commentary.

${ }^{111}$ Appellate Body Report, Japan - Varietals at [92].

112 Appellate Body Report, Japan - Varietals at [92].

113 Appellate Body Report, Japan - Varietals at [93].

${ }^{114}$ Appellate Body Report, Japan - Varietals at [93].

115 Appellate Body Report, Japan - Varietals at [93].
} 
the necessary additional information would be relatively easy ${ }^{116}$. In US - Animals the Panel held that the United States' measures did not fall within the scope of Article 5.7 as the United States did not seek to obtain additional information or review the measures within a reasonable period of time. In that case import restrictions and consultations on Argentinian beef product access to the United States lasted for almost 13 years; delays reviewing measures applied to FMD free areas occurred variously from June 2005 until 28 January $2013^{117}$. Also in that decision the Panel observed that WTO jurisprudence on the meaning of 'a reasonable period of time' suggests that when WTO Members must take legislative or regulatory actions involving complex legal processes to bring their measures into conformity with their WTO obligations, reasonableness can be understood to mean as quickly as legally possible while accepting legitimate legal or scientific reasons for delay.

Evidence from the biological invasion literature has shown that some impacts of invasive species may take decades to appear (O’Dowd et al., 2003; Wangen \& Webster, 2006; Aikio et al., 2010). It has therefore been argued that risk assessment is ill-suited to the idiosyncratic risks posed by invasive species. However, the approach of the Appellate Body to the question of a reasonable time for the purposes of Article 5.7 attempt to give some space to domestic regulators. A case-by-case approach means that a domestic regulator that has set a very high ALOP may be afforded a greater period of time in which to review the measure. If it is a plant, animal or disease about which very little is known then there is likely to be greater difficulty in ascertaining relevant additional information about that species in order to perform a risk assessment. A case-by-case approach means that a provisional measure under Article 5.7 managing risks of a poorly known species will likely be afforded a greater period of time in which to produce relevant data. The reasoning above provides substantial latitude for the measures of domestic regulators to fall within the umbrella of Article 5.7. In fact, there is nothing in Article 5.7 requiring that sufficient scientific evidence ever be obtained. It is therefore possible that if despite ongoing scientific investigative efforts there remains insufficient scientific evidence a precautionary measure under Article 5.7 could result in the permanent retention of provisional measures. Such a result would run counter to the aims of the WTO system and is not necessarily desirable, but does not appear to be an impossibility. Nor is it a scientific absurdity. Producing the required relevant data could be extremely difficult

\footnotetext{
${ }^{116}$ Panel Report, Japan - Varietals at [8.56].

${ }^{117}$ Appellate Body Report, US - Animals at [7.162] - [7.172] and [7.303].
} 
to gather because, for example field data are difficult to gather and research techniques are not well-established. That said, it is possible that a country might 'lean on' such excuses to buy time. If a state wishes to be part of the global trading system operating under a global set of rules, there must be an arbitrator to make decisions on these sorts of issues.

\subsection{Section III - Other SPS disciplines that have been the subject of dispute}

In this section of this chapter I look beyond risk assessment and examine other articles from the SPS Agreement that have been the subject of disputes involving invasive species risks; as well as criticism from academics and environmentalists. The SPS Agreement has been criticised from the perspective of managing risks posed by invasive species (Campbell, 2001; Miller, 2003; Riley, 2005; Simberloff, 2005; Dahlstrom et al., 2011; Roy et al., 2014). Here, I continue my argument that the WTO regime does give space to sovereign governments to regulate invasive species risks through the device of an ALOP. As demonstrated in Section II, a Member's ALOP may partially modulate how risk assessment is conducted. Further, a high ALOP can also have a bearing on a Panel's evaluation of whether scientific evidence is insufficient such that a precautionary measure under Article 5.7 may be legitimately adopted. In this section I demonstrate that the actual SPS measures intended to meet an ALOP are largely under the control of national regulators. However, like risk assessment, this exercise of sovereignty is circumscribed by commitments countries made in the WTO Agreement. As I demonstrate through examination of case law, this circumscription is significantly limited by the ability of Members to formulate and impose their individual ALOP.

\subsubsection{The objective of achieving non-discrimination and consistency}

One of the key purposes of the WTO system is to create a liberalised trading system in which rules are consistent across all parties. This objective is incorporated in the SPS Agreement by Article 5.5 which provides that:

"with the objective of achieving consistency in the application of the concept of appropriate level of sanitary or phytosanitary protection... each Member shall avoid arbitrary or unjustifiable distinctions in the levels it considers to be appropriate in different situations, if such distinctions result in discrimination or a disguised restriction on international trade..." 
The use of this article to challenge SPS measures has been described as emphasising 'the weakest link' in a WTO Member's SPS regime (Atik, 2004) and thereby diminishing a Member's ability to use quarantine laws to protect its biodiversity against invasive species by setting the standard to that of the weakest link (Riley, 2005). However, it is arguable that is not the case. The series of SPS decisions in which discussion of Article 5.5 is particularly salient from the perspective of the risk of invasive species are the Australia-Salmon disputes. These disputes comprise three decisions running from 1997 until 2000. Article 5.5 was particularly relevant in these disputes and the treatment by Panels and the Appellate Body of its requirements demonstrate that these decision-makers are actively searching for plausible justifications for different ALOPs in comparable circumstances as discussed below.

In EC - Hormones the Appellate Body laid out three requirements that must be demonstrated if a violation of Article 5.5 is to be found ${ }^{118}$ :

(1) The Member imposing the measure has adopted its own appropriate levels of protection in several different situations;

(2) That those levels of protection exhibit arbitrary or unjustifiable differences in their treatment of different situations; and

(3) These differences result in discrimination or a disguised restriction of international trade.

These requirements are cumulative in nature and all of them must be demonstrated if a violation of Article 5.5 is to be found ${ }^{119}$. In terms of management of invasive species the decision in the Australia - Salmon disputes demonstrates the WTO's flexible approach to interpretation of violations of Article 5.5 when dealing with issues relating to invasive species.

Under this first prong of Article 5.5 - The Member imposing the measure has adopted its own appropriate levels of protection in several different situations - the Appellate Body is seeking to ensure that different quarantine protections in prima facie comparable situations are justifiable. In Australia - Salmon, the issue under Article 5.5 was that Australia imposed

\footnotetext{
118 Appellate Body Report, EC-Hormones, at [214].
}

119 Appellate Body Report, EC-Hormones at [215]. 
different import requirements on products that posed very similar risks. Essentially, salmon products originating in Canada had very strict 'consumer-ready' requirements imposed upon them, which narrowed market access of Canadian salmon to Australia. At the same time relative to Canadian salmon products, Australia granted lower import protection to the: (1) admission of imports of herring and certain cod products from any location; (2) herring used as bait; and (3) imports of live finfish. To defend this inconsistency, Australia attempted to argue that for situations to be comparable they must involve both: a risk of entry establishment or spread of the same or similar disease and a risk of the same or similar associated potential biological and economic consequences ${ }^{120}$. The Appellate Body disagreed and found that situations can be compared under Article 5.5 if the situations involve either a risk of entry establishment or spread of the same or similar disease, or a risk of the same or similar associated potential biological and economic consequences ${ }^{121}$. In Australia - Salmon both elements were present for all of the comparison situations.

Under the second prong of this test - that those levels of protection exhibit arbitrary or unjustifiable differences in their treatment of different situations - the Appellate Body in Australia - Salmon investigated whether the ALOP adopted in the different situations exhibited arbitrary or unjustifiable differences. Australia attempted to argue that the Panel had made a mistake in limiting its investigation to pathogens positively detected in ocean-caught Pacific salmon, thereby reducing the perceived potential risk. The Appellate Body rejected this argument on the basis that the Panel did take into account other disease agents and that taking into account all disease agents would be impractical. This argument was also largely moot as the risks associated with herring used as bait and finfish were considered to be at least as high a risk as salmon; therefore the differences in levels of protection were found to be arbitrary and unjustifiable ${ }^{122}$.

Before a violation of Article 5.5 can be found, the third prong of the test must be met: any arbitrary or unjustifiable distinction in ALOP needs to result in discrimination or a disguised restriction on international trade. The Appellate Body in Australia - Salmon identified three warning signals and two additional factors to help determine whether the differences in an

\footnotetext{
${ }^{120}$ Appellate Body Report, Australia - Salmon at [145].

${ }^{121}$ Appellate Body Report, Australia - Salmon at [146]; Guidelines to Further the Practical Implementation of Article 5.5 at [A2].

${ }^{122}$ Appellate Body Report, Australia - Salmon at [158].
} 
ALOP result in discrimination or a disguised restriction on international trade ${ }^{123}$. These are: (1) Arbitrary differences in levels of protection; (2) Substantial differences in the level of protection; and (3) Absence of risk assessment; as well as two warning factors; (i) Changes in policy potentially inspired by domestic events, and (ii) the absence of domestic controls for internal movement of products versus strict controls on the international import of the same products.

In Australia - Salmon the first warning signal was the arbitrary and unjustifiable differences in levels of protection between salmonids and herring and live finfish products ${ }^{124}$. The second warning signal was the substantial difference in the levels of protection between the classes of products. The third warning signal was the inconsistency of the measure with Articles 5.1 and 2.2. The first warning factor was particularly salient. Following consultations in 1994 Australia agreed to document an import risk analysis on the quarantine issues involved with the importation of uncooked salmon from North America. Two draft reports were issued in May 1995 and May 1996, and a Final Report in December 1996 ${ }^{125}$. Both draft reports recommended allowing the importation of ocean-caught Pacific salmon under certain conditions; however the 1996 Final Report recommended continuing the import prohibition. This change was unexplained and occurred in the context of pressure from the domestic salmon industry. Whilst this change did not constitute proof, it could be taken into account cumulatively with other factors $^{126}$. The next warning factor was the absence of controls on the internal movement of salmon products within Australia compared to the prohibition of the importation of oceancaught Pacific Salmon ${ }^{127}$. Neither the Panel nor the Appellate Body concluded on this point, but said it could be considered as a factor which can be taken into account in examination of the third element of Article 5.5 $5^{128}$.

Overall in the initial Australia - Salmon proceedings both the Panel and the Appellate Body held that Australia was in violation of Article 5.5. As mentioned previously, some commentators have highlighted this case as evidence of the vulnerability of national regulations to "weakest link" arguments with respect to their ALOP's (Atik, 2004; Riley, 2005). However,

\footnotetext{
${ }^{123}$ Appellate Body Report, Australia - Salmon, at [159], [161], [163] and [165].

${ }^{124}$ Appellate Body Report, Australia - Salmon at [162]; Panel Report, Australia - Salmon at [8.149].

125 Panel Report, Australia Salmon at [2.27].

${ }^{126}$ Appellate Body Report, Australia - Salmon at [173]; Panel Report, Australia - Salmon at [8.154].

${ }^{127}$ Panel Report, Australia - Salmon at [8.155].

${ }^{128}$ Appellate Body Report, Australia - Salmon at [176].
} 
subsequent to the Appellate Body decision, Australia undertook a new risk assessment (the 1999 IRA). Australia's purpose was to impose a less restrictive import regime on the salmonid imports at issue, but also tighten the import restrictions on non-salmonids, in particular herring and live ornamental finfish referred to in the original dispute. The 1999 IRA was intended to support the new measures imposed ${ }^{129}$. Canada directly challenged whether these regulatory changes by Australia adequately ameliorated the breaches of Article 5.5. In the resulting Australia - Salmon implementation dispute the Panel rejected Canada's argument and upheld Australia's approach, noting that: two of the three scientific experts advising the panel were of the view that Australia's treatment of imports of salmonids on the one hand, and live and ornamental finfish achieved similar levels of protection ${ }^{130}$. Additionally, they considered that the differential treatment accorded by Australia to these different categories of fish was scientifically justified ${ }^{131}$.

Further, the Panel found that no stricter controls had been imposed on the internal movement of dead Australian fish as a result of the previous decisions. The Panel accepted Australia's explanation that the risk related to the internal movement of Australian fish is different, and of a lesser magnitude, than that of imports of salmonids ${ }^{132}$. This reasoning was on the basis that the diseases associated with the movement of domestic caught fish in Australia, are already in Australia i.e. there is no risk of a new introduction. Additionally, internal waterways within Australia would make it difficult to contain these diseases. In contrast, the diseases of concern in respect of salmonid imports are not present in Australia and - according to Australia - were of more concern both in terms of the risk of introduction of the disease and its potential impact $^{133}$. Overall, the panel held in the implementation proceeding under the second element of the test that Canada had not met its burden of demonstrating the second element of Article 5.5 as: (1) Australia had increased its convergence in the treatment of different categories of fish referred to by Canada; and (2) the apparent justification for the differential treatment of domestic salmonids put forward by Australia ${ }^{134}$.

\footnotetext{
${ }^{129}$ AQPM 1999/77; AQPM 1999/79 which identifies herring as a "specified finfish species" that will not be permitted for importation unless in a consumer ready form.

${ }^{130}$ Panel Report, Australia - Salmon 21.5 at [7.92].

${ }^{131}$ See answers of Drs. Brückner and McVicar to Panel Questions 10, 11 and 15; Panel Body Report AustraliaSalmon Article 21.5 at Annex 1.

132 Panel Report, Australia - Salmon Article 21.5 at [7.93].

${ }^{133}$ On this point the Panel makes specific note of the advice of Panel expert Dr. McVicar, regarding internal versus border control against diseases; Panel Report, Australia - Salmon at footnote 207.

${ }^{134}$ Panel Report, Australia - Salmon Article 21.5 at [7.94] and [7.101].
} 
In respect of the third prong of Article 5.5 (differences result in discrimination or a disguised restriction of international trade) no evidence was found. Instead, the Panel noted that all but one of the three "warning signals" and both "additional factors" outlined by the Appellate Body in the original dispute were no longer present or of less importance due to the regulatory changes made by Australia ${ }^{135}$. The Panel were not convinced that Australia maintained arbitrary or unjustifiable distinctions in ALOP's - the first warning signal - nor that any such distinctions were substantial - the second warning signal ${ }^{136}$. Additionally, the first additional factor - the unexplained change in the 1996 report - was ameliorated by the 1999 IRA. Finally, the second "additional factor" - the absence of controls on the internal movement of domestic salmon products relative to imports of salmon - had lost its weight because: first, a new import regime had been introduced that allowed import under certain conditions; and second, Australia had provided scientific justification on the differential treatment between internal movement of salmon and imports that the Panel accepted as not arbitrary or unjustifiable ${ }^{137}$.

As has been noted by other commentators, the reasoning in the SPS disputes to date seems to indicate that the Appellate Body will actively search for plausible justifications for different ALOPs in comparable circumstances (Du, 2010a). The approach of the Panel in the Australia - Salmon disputes demonstrates that if a Member is able to provide reasonable explanations, the Appellate Body is willing to accept that differences in ALOP are not arbitrary or unjustifiable. Indeed, even if it was found there are arbitrary and unjustifiable regulatory differences between comparable situations it is not enough to violate the consistency requirement. Elements of discrimination between WTO Members or protection of domestic production need to be proven $(\mathrm{Du}, 2010 \mathrm{a})$; which substantially narrows the applicability of Article 5.5. Further, the Appellate Body has held that Article 5.5 does not establish a legal obligation of consistency of appropriate levels of protection ${ }^{138}$. In addition, the goal of the article is not absolute or perfect consistency as governments establish their ALOPs frequently and on an ad hoc basis. Instead, it is only arbitrary or unjustifiable inconsistencies that are to be avoided ${ }^{139}$. Part of the role of domestic regulatory authorities when assessing risk of invasive species is to maintain consistency with their approach towards risk. This requirement is part of

\footnotetext{
135 Panel Report, Australia - Salmon Article 21.5 at [7.103].

${ }^{136}$ Panel Report, Australia - Salmon Article 21.5 at [7.103].

${ }^{137}$ Panel Report, Australia - Salmon Article 21.5 at [7.104].

${ }^{138}$ Appellate Body Report, EC-Hormones at [213].

${ }^{139}$ Appellate Body Report, EC-Hormones at [213].
} 
the bargain of entering the WTO; the ceding of elements of national sovereignty in exchange for the benefits of membership ${ }^{140}$.

The Australia - Salmon proceedings were about risks posed by invasive species - the introduction of exotic diseases of fish. As illustrated by the decision-making in that process, Panels will give significant latitude to Members to argue their case. In the implementation proceedings Canada's arguments were rejected on the basis of Australia having brought its measures into compliance with Article 5.5. These decisions do not represent an antienvironmental stance on the part of the WTO, nor do they necessarily reduce a Member's quarantine policy to the weakest link as has been argued (Atik, 2004; Riley, 2005). Australia, could have responded by increasing protections across all products to meet those imposed on salmonids. That Australia did not was fundamentally a political decision, perhaps recognising that such an approach would likely be unacceptable to the public given the costs it would have on Australian consumers through restricted access to imported goods and potential retaliation by trade partners.

\subsubsection{Not more trade restrictive than required}

When a national regulatory body is establishing SPS measures intended to mitigate risks posed by invasive species the goal is to reduce risk to the level of an ALOP. Therefore, SPS measures that are implemented by a domestic regulator should not be more trade restrictive than required to achieve the importing country's ALOP. This requirement is written into the SPS Agreement in the form of Article 5.6, which provides:

When establishing or maintaining sanitary or phytosanitary measures to achieve the appropriate level of sanitary or phytosanitary protection, Members shall ensure that such measures are not more trade-restrictive than required to achieve their appropriate level of sanitary of phytosanitary protection, taking into account technical and economic feasibility.

The footnote to article 5.6 elaborates:

${ }^{140}$ Appellate Body Report, Japan - Taxes on Alcoholic Beverages at 15. 
...a measure is not more trade-restrictive than required unless there is another measure, reasonably available taking into account technical and economic feasibility, that achieves the appropriate level of sanitary or phytosanitary protection and is significantly less restrictive to trade

The SPS measure, or measures, chosen by a national regulator to achieve their ALOP are important as in the view of the national regulator they are the most appropriate risk management tools available. In Australia-Salmon the Appellate Body set out a three-pronged test to establish whether there has been a violation of Article 5.6. In order to be a breach of Article 5.6, there must be an SPS measure which:

(1) Is reasonably available taking into account technical and economic feasibility;

(2) Achieves the Member's appropriate level of sanitary or phytosanitary protection; and

(3) Is significantly less restrictive to trade than the SPS measure contested.

In order to breach Article 5.6 each of these elements must be met ${ }^{141}$. Determining whether an alternative less trade restrictive measure achieves the ALOP of a member is important as the measure chosen gives effect to a Member's ALOP. In this section I argue that the Appellate Body was sensitive to this issue in four SPS cases involving substantive discussion of this provision: Australia-Salmon, Japan-Varietals, Australia-Apples and US-Animals. These decisions cover almost 20 years of WTO decision-making on Article 5.6 issues with respect to invasive species and demonstrate consistent deferral by Panels and the Appellate Body to the right of Members to choose both their ALOP and the SPS measure intended to achieve that ALOP. Below I review each of these four SPS cases to illustrate this point.

\subsubsection{Australia - Salmon}

In Australia - Salmon Australia's SPS measures designed to reduce disease risk were referred to as "consumer-ready" requirements. Australia required that imported salmonid products from Canada must be ready for the householder to cook/consume. This phrase was defined as meaning $^{142}$ :

\footnotetext{
${ }^{141}$ Appellate Body Report, Australia - Salmon at [194]; Confirmed in Appellate Body Report, Japan - Varietals at [95].

142 Panel Report, Australia - Salmon at [7.126].
} 
- Cutlets - including the central bone and external skin, but excluding fins - of less than $450 \mathrm{~g}$ in weight;

- Skinless fillets - excluding the belly flap and all bones except the pin bones - of any weight;

- Skin on fillets - excluding the belly flap and all bone except pin bones - of less than $450 \mathrm{~g}$ in weight;

- Eviscerated, headless 'pan size' fish of less than 450g in weight; and

- Product that is processed further than the stage described above.

Any salmon that was not in a consumer ready form was required to be processed at an approved processing plant before release from quarantine. Canada recognised that this requirement was to prevent commercial processing of salmon in Australia, as discharge of waste from processing plants could lead to a risk of disease spreading in Australian salmonid populations. Canada asserted that an alternative measure was available that met Australia's ALOP. This measure was that Australia could ensure that imported salmon only underwent processing in commercial facilities that did not discharge untreated waste ${ }^{143}$. In the Australia Salmon implementation dispute the Panel specifically examined whether Canada's alternative measure could provide Australia's ALOP; specifically noting that none of the scientific experts consulted could find a justification for Australia's consumer-ready requirements. It even concluded that there were other measures available that would achieve Australia's ALOP and that Australia had acted inconsistently with Article 5.6 ${ }^{144}$. Despite this, it did not reach a conclusion on what method should be imposed. Instead the statement made was:

"We leave it up to Australia, preferably in close co-operation with Canada and other trading partners, to select and identify the details of such other measures"145

Despite the breach of Article 5.6, Australia was still given an opportunity to implement a measure that it and Canada found mutually acceptable. The Panel was entirely unwilling to circumscribe Australia's sovereignty in this regard and impose a measure without the consent of the importing party.

\footnotetext{
${ }^{143}$ Panel Report, Australia - Salmon Article 21.5 at [7.119]-[7.127].

144 Panel Report, Australia Salmon Article 21.5 at [7.140]; [7.153].

${ }^{145}$ Panel Report, Australia Salmon Article 21.5 at [7.144].
} 


\subsubsection{Japan - Varietals}

Japan - Varietals is another decision in which the Appellate Body gave precedence to the ALOP of the importing Member under Article 5.6. In Japan - Varietals the measure at issue was Japan's Plant Protection Law which imposed a varietal testing requirement on the import of certain types of plants because the plants were possible hosts of codling moth (Cydia pomonella $)^{146}$. Japan's ALOP in this case was a desired level of mortality of codling moth as a result of quarantine treatment on different varieties of the same product type, i.e. treatment on different varieties of peaches ${ }^{147}$. This mortality level was specified as complete mortality in large-scale tests on a minimum of 30,000 codling moths ${ }^{148}$. The alternative measure proposed by the United States involved testing product-by-product, instead of variety-by-variety i.e. testing for peaches as a product, as opposed to different varieties of peaches ${ }^{149}$. The scientific experts consulted also proposed other alternatives based on differences of sorption of fumigant by different variety types ${ }^{150}$. In the Panel decision the United States' product-by-product measures was rejected as lacking scientific basis in light of evidence presented and the advice of scientific experts ${ }^{151}$. The United States appealed this finding to the Appellate Body and again this point was rejected ${ }^{152}$. The Appellate Body agreed with the Panel that the United States' alternative measure of testing by product was reasonably available taking into account technical and economic feasibility ${ }^{153}$; and significantly less restrictive to trade ${ }^{154}$. However, Japan was found not to have acted inconsistently with Article 5.6 because the method did not achieve Japan's ALOP ${ }^{155}$.

\subsubsection{Australia - Apples}

Australia-Apples is a case in which the measures under Article 5.6 were found to be more trade restrictive than required. In the case, New Zealand disputed Australian measures restricting the import of New Zealand apples based on concerns about the risk of entry, establishment and spread of the Apple leaf curling midge (ALCM) (Dasineura mali), the

\footnotetext{
146 The specific plants were: apples, apricots, cherries, peaches, pears, plums, quince and walnuts.

${ }^{147}$ Panel Report, Japan - Varietals at [8.82].

148 Panel Report, Japan - Varietals at [2.23]; [8.11].

149 Panel Report, Japan - Varietals at [8.65].

${ }^{150}$ Panel Report, Japan - Varietals at [8.74]; this measure was rejected by the Appellate Body as the Panel breached procedural requirements regarding rules the allocation of burden of proof in a claim under Article 5.6

- see Appellate Body Report, Japan - Varietals at [130].

${ }^{151}$ Panel Report, Japan - Varietals at [8.84].

152 Appellate Body Report, Japan - Varietals at [100].

${ }^{153}$ Panel Report, Japan - Varietals at [8.78].

${ }^{154}$ Panel Report, Japan - Varietals at [8.79].

${ }^{155}$ Panel Report, Japan - Varietals at [8.84].
} 
fungus European canker (Neonectria galligena) and the fire blight bacterium (Erwinia amylovora $)^{156}$. The Panel's findings under Article 5.6 were appealed to the Appellate Body on a procedural point. There, the Appellate Body held that they were unable to complete legal analysis of New Zealand's claim under this Article with respect to ALCM and fire blight due to deficiencies in the Panel's approach to evaluating the scientific evidence ${ }^{157}$. However, the Panel's findings relevant to European canker were unchallenged and relevant to this discussion.

Australia's ALOP in the case was framed as providing a high level of protection aimed at reducing risk to a very low level, but not to zero ${ }^{158}$. Australia imposed 12 separate quarantine measures to meet this standard. As an alternative, New Zealand proposed that restricting imports to mature symptomless apples would achieve Australia's ALOP ${ }^{159}$. The Panel found this measure to be reasonably available taking into account technical and economic feasibility ${ }^{160}$. Further, New Zealand argued and the Panel agreed that the Article 5.6 test requires that the complainant identify an alternative measure that is significantly less restrictive to $\operatorname{trade}^{161}$. As, in that decision, the Australian measures were more numerous, stringent, and costly to comply with, New Zealand's measure was affirmed to be significantly less trade restrictive $^{162}$. In finding a breach of Article 5.6 with regard to European canker the Panel relied heavily on the advice of its scientific experts ${ }^{163}$. The difference from the preceding two cases discussed above (Australia - Salmon and Japan - Varietals) is that in Australia - Apples extensive expert testimony throughout the case affirmed that Australia's measures were more trade restrictive than required.

\subsubsection{US - Animals}

The most recent invasive species decision involving Article 5.6 is that of US - Animals. The SPS issue in this dispute was the risk posed by foot-and-mouth disease (FMD) in imports of Argentinian beef. The Panel found that the United States' ALOP with regard to this risk was to prevent the introduction or dissemination of FMD within the United States. The level of this

\footnotetext{
${ }^{156}$ Appellate Body Report, Australia-Apples at [2.1].

${ }^{157}$ Appellate Body Report, Australia - Apples at [402]. Note that this finding only related to two of the pests at issue: fire blight and apple leaf-curling midge. The Panel's finding that Australia's measures with respect to the third pest in that case, European canker, were inconsistent with Article 5.6 were unchallenged.

${ }^{158}$ Australia's IRA, Part A at 3.

159 Panel Report, Australia - Apples at [7.1252].

${ }^{160}$ Panel Report, Australia-Apples at [7.1258].

${ }^{161}$ Panel Report, Australia-Apples at [7.1264].

162 Panel Report, Australia - Apples at [7.1265].

${ }^{163}$ Panel Report, Australia - Apples at [7.1199]; [7.1213] - [7.1251].
} 
ALOP was described as higher than the international standard of the World Organisation for Animal Health (OIE) and somewhere between low and zero risk ${ }^{164}$. The SPS measure that the United States had taken was a total ban on Argentinian beef imports. In this case the Panel applied the three-pronged test from Australia - Salmon ${ }^{165}$. The parties agreed that the alternative measures proposed by Argentina were reasonably available and would be significantly less restrictive. Therefore, the issue between the parties for the purposes Article 5.6 was whether the alternative measures proposed by Argentina would meet the United States' ALOP for FMD ${ }^{166}$.

Argentina had proposed two alternative measures. The first was reliance upon the OIE's Terrestrial Code Article 8.5.23 ${ }^{167}$, which makes several recommendations regarding veterinary certification and abattoir procedures to reduce FMD risk. However, this argument was dismissed, as the Panel accepted the United States' right to impose a higher ALOP than that of the international standard. As its alternative measure, Argentina identified the application of the strict mitigating protocols that the US Animal and Plant Health Inspection Service (APHIS) applied to imports of fresh beef from Uruguay ${ }^{168}$. The measures provided several layers of mitigating measures covering virtually all stages of the production of beef, from birth and raising of cattle to the processing of the final product ${ }^{169}$. The Panel held that these measures would effectively minimise the risk of FMD introduction from beef into the United States and were already applied to a comparable FMD risk posed by beef exports from Uruguay ${ }^{170}$.

Argentina limited the area in which it argued it could meet the measures imposed by APHIS to Northern Argentina. Argentina argued that the same measures enforced on Uruguayan beef could be applied to beef originating in Northern Argentina as the area had adequate veterinary capacity and infrastructure to prevent and control FMD in its territory as well as prevent new incursions ${ }^{171}$. Upon much advice of scientific experts the Panel agreed with this assertion and

\footnotetext{
${ }^{164}$ Panel Report, US - Animals at [7.387].

165 Panel Report, US - Animals at [7.430].

166 Panel Report, US - Animals at [7.434].

${ }^{167}$ Panel Report, US - Animals at [7.500].

168 Panel Report, US - Animals Table 5: Protocols under 9 CFR 94.22 and their effectiveness in mitigating FMD risk at 170.

169 Panel Report, US - Animals at [7.508].

${ }^{170}$ Panel Report, US - Animals at [7.508].

${ }^{171}$ Panel Report, US - Animals at [7.4998].
} 
that with respect to imports of beef from Northern Argentina the United States was in breach of Article 5.6 $6^{172}$.

In all four of these cases, representing almost 20 years of decision-making, panels and the Appellate Body have been sensitive to the authority of Members to both choose their ALOP with respect to invasive species and the method appropriate to achieve that ALOP. A general pattern in SPS jurisprudence with respect to Article 5.6 can be derived from these decisions. In each of these cases there has been high reliance on the advice of scientific experts. If experts' assessment of the evidence is equivocal on whether a measure will reach a Member's ALOP the Appellate Body is unwilling to impose a measure. In Australia - Salmon the Appellate Body was silent on the issue and left it to Australia and Canada to find a solution that suited them both. In Japan - Varietals no breach of Article 5.6 was found as the United States' measure would not achieve Japan's ALOP. If scientific experts exhibit high confidence in the alternative measures meeting a defending party's ALOP, the Panel or Appellate Body are more likely to accept the alternative measure. Australia - Apples and US - Animals represent cases in which breaches of Article 5.6 were proven as in those cases New Zealand and Argentina respectively were able to point to alternative measures that could be implemented in order to achieve ALOPs of the importing parties, as well as being significantly less trade restrictive. Overall, this stream of decisions shows that an assessment under Article 5.6 is not a mechanistic investigation. The Appellate Body will, with assistance from experts, carefully work through the Australia - Salmon test elucidated for the purposes of Article 5.6. My purpose in analysing these cases in which Article 5.6 was a live issue is not to demonstrate a general rule. Rather, I have sought to show that Panels and the Appellate Body are sensitive to the desire of national regulators to implement their own ALOP with respect to risks posed by invasive species.

\subsection{Section IV}

Ever since the establishment of the WTO there have been concerns over the loss of domestic regulatory autonomy. Even before WTO establishment, issues of sovereignty were controversial politically (Jackson, 1997). However, an alternative scenario that unfettered decision-making authority should remain with individual states would make the WTO system untenable. The Appellate Body put this point eloquently, stating:

\footnotetext{
172 Note also: US - Animals also involved a dispute regarding the inclusion of Patagonia in the list of FMD-free countries or territories under 9 CFR 94.1(a). The Brazilian state of Santa Catarina was included and Patagonia was not. A finding was made that the United States was in breach of Article 5.6 as Patagonia had adequate veterinary capacity and infrastructure and the same disease status as Santa Catarina.
} 
"The WTO Agreement is a treaty - the international equivalent of a contract. It is self-evident that in an exercise of their sovereignty, and in pursuit of their own respective national interests, the Members of the WTO have made a bargain. In exchange for the benefits they expect to derive as Members of the WTO, they have agreed to exercise their sovereignty according to the commitments they have made in the WTO Agreement" ${ }^{\text {"173. }}$

How these competing rights are balanced will always be controversial. Commentators are likely to always disagree on the question of whether WTO rules and dispute resolution outcomes erode domestic regulatory authority, or give sufficient autonomy to Members. As a subset of this tension, environmental concerns surrounding WTO jurisprudence will always be a live issue. Enormous increases in trade volumes, as well as trade interconnectivity will continue to impact environments, ecosystems and biodiversity. However, the thrust of this Chapter has been that the tool of an ALOP does in fact give national regulators space to manage unacceptable risks as they relate to invasive species. Although the requirements for a risk assessment under Article 5 are rigorous, it is not a mechanistic process and flexibility exists in the decision-making. In the event a risk assessment cannot be performed due to insufficient scientific information WTO Members still have temporary recourse to the haven provided by Article 5.7. The fact that the shelter provided by Article 5.7 is circumscribed is in keeping with the basic contract of the WTO expressed above. Essentially, a Member should not be able to take permanent refuge under a precautionary provision without attempting to provide dispositive evidence on the invasive species risks at issue.

Critiques of the WTO system focusing on invasive species conflate trade regulation and protection of the environment. The WTO has a mandate as a regulator of international trade. It is not tasked with managing the environmental impacts that trade has upon its Members; although this may be relevant to decision-making. Instead, in the situation of invasive species issues, the task of risk management should be managed by individual Members through the tool of setting an ALOP and ensuring measures imposed to reach that ALOP do not breach the requirements of the SPS Agreement. In this regard, New Zealand provides a salient example of a country with a high ALOP and a rigorous biosecurity regime, but has not been the target of a dispute at the WTO. However, an ALOP is an expression of government policy and reflects

${ }^{173}$ Appellate Body Report, Japan - Taxes on Alcoholic Beverages at 15. 
public expectations with regard to risk regulated generally and in particularly with regard to protecting agricultural industries and the environment. It is a societal value judgement to which biosecurity services and other relevant agencies contribute by providing technical advice (Wilson, 2000). New Zealand's particular cultural, political and geographic context has been such that it has been able to develop and impose a highly precautionary biosecurity regime.

Elsewhere in the world regulations regarding invasive species have been extensively criticised (McCubbins et al., 2013; Riley, 2013; Smith et al., 2014). However, these regulatory regimes represent accretions of decision-making informed by government policy and ultimately public expectations. A country with little domestic agricultural production or conservation estate may calibrate its ALOP as low with respect to certain classes of pests, thereby benefiting as much as possible from trade (Fig. 1.2.). On the other hand, a country such as New Zealand with high reliance on primary production and biodiversity must engage in a different calculus. Ultimately it is a political decision between maximising the benefits of trade, and protection of domestic agricultural production and the environment. How this risk tolerance is calibrated is, and should be, informed by constructive, informed public opinion. Ultimately, the issue of international management of invasive species lies less with the structure of international regulations and more with a lack of political appetite to restrict trade flows for the benefit of the environment or agriculture. The calls of commentators for a more precautionary approach toward the management of invasive species risk seldom take into account the multifarious impacts extremely strict SPS measures would have; or the political acceptability of such decisionmaking.

Viewpoints advocating for a more precautionary regime managing invasive species in international trade are not inimical to the WTO Agreements. A Member's ALOP with respect to invasive species is not calcified and can be reviewed to ensure that it continues to express a government's policies, as well as reflect public and industry expectations on risk taking and the benefits of trade (Wilson, 2000). Given this fact, a more profitable avenue for academic critique or public lobbying could be domestic regulators and their regulations and policies. Interested parties - including scientists - who are keen to move invasive species policy towards a more precautionary approach should focus their attention upon the actions and policies of their domestic regulatory bodies. The WTO has demonstrated in cases such as Australia Salmon implementation proceedings that it will uphold properly crafted SPS measures. Admittedly, a significant change in ALOP from non-precautionary to precautionary would 
likely require a compete overview of biosecurity practices and policies to ensure that a WTO Member was not in breach of its obligations. However, such a change is possible under WTO rules.

Overall, the WTO has a mandate as an international trade regulator and operates within the confines of its founding agreements. These agreements, which WTO Members have ratified, do circumscribe national regulatory sovereignty. However, the ceding of some regulatory autonomy is part of the bargain of trading under a globally applied system. Despite WTO Membership, domestic regulatory authorities retain significant latitude to manage the risk of invasive species through the mechanism of an ALOP. When SPS measures are challenged the WTO has shown itself willing, at least in the case of invasive species, to give substantial space to domestic regulators to manage risk. Any change sought to manage invasive species in international trade is unlikely to occur by structural change of the WTO agreements. Instead, it could be pursued through the avenue of domestic biosecurity policy. 


\section{Chapter 3: Improving management of invasive species: New Zealand's approach to pre-and post-border pests}

This paper was published in the February 2016 issue of Policy Quarterly. A copy of the paper is included as an appendix to this thesis. It is written intended for a policy or legal audience and as such differs from a traditional scientific paper.

Since the publication of this chapter, New Zealand's biosecurity system has entered a state of significant flux. In November 2016, New Zealand's Ministry for Primary Industries instituted the Biosecurity 2025 project, the intention of which is to strengthen New Zealand's biosecurity system. This project is ongoing, but it is clear significant changes are underway. It is likely that the outcomes of this project will affect many of the findings of this paper.

\subsection{Abstract}

Invasive species are one of the key drivers of biodiversity loss globally. Regulation of invasive species risks occur at three broad levels: pre-border, at the border and post-border. Here we review New Zealand's pre- and post-border approach to invasive species. We find that New Zealand's pre-border approach represents global best practice. Post-border management is more fragmented with differences in plants and animals controlled between regions, as well as significant differences in regional spending. Further, aquatic invasion strategies are lacking in many regions. We provide several recommendations to provide more coherence to New Zealand's post-border management regime.

\subsection{Introduction}

Biological invasions are a ubiquitous global concern. Invasive species are non-native species that arrive in a new area, establish and increase in density and distribution to the detriment of the recipient environment (Lockwood et al., 2009). Non-native species that become invasive are a major threat to biodiversity (Vitousek \& D'Antonio, 1997). Non-native species that become invasive can reach high abundances across broad geographic distributions in some cases leading to enormous environmental and economic effects (Vilà et al., 2010; Bradshaw et al., 2016). Invasive species have been implicated in large-scale changes in ecosystem composition and function (Vitousek et al., 1987), nutrient cycles (Ehrenfeld, 2003) and agricultural productivity (DiTomaso, 2000). Economic costs are significant. One early study 
estimated the broad cost of invasive species to the United States as \$USD 120 billion annually (Pimentel et al., 2005). New Zealand is particularly vulnerable given its unique island ecosystem biota and economically important primary sector. Early introductions of rats, mustelids and rabbits have driven extinctions of native species and damaged ecosystems historically (Druett, 1983) and continue to do so. More recently, the accidental introduction of the bacterial kiwifruit disease Psa (Pseudomonas syringae pv. actinidiae) has had large economic impacts and even prompted court action against the Crown ${ }^{174}$. In 2003 the Reserve Bank estimated a foot-and-mouth outbreak could cost the economy \$10 billion (Reserve Bank 2003).

During the last 50 years global trade has been the primary cause of the introduction of nonnative species (Kobelt \& Nentwig, 2008; Westphal et al., 2008; Hulme, 2009; Bertelsmeier et al., 2017). Introductions may be intentional or unintentional. Intentional introductions are species deliberately introduced, legally and illegally, to a new region. Unintentional introductions are non-native species that are associated with commodities for import, for instance insects associated with fresh fruit and vegetables (Brenton-Rule et al., 2016). Other unintentional introductions include hitch-hiker species, such as those attached to the hull or in the ballast water of vessels (Roman \& Darling, 2007; Williams \& Smith, 2007).

The most effective and cheapest method of preventing trade associated introductions is preborder risk assessment and management (Keller et al., 2007; Springborn et al., 2011; Kumschick \& Richardson, 2013). Management of pests post-border is a much more expensive and difficult process. This increased expense is due to the fact costs are ongoing as eradication is unlikely; as well as the fact a well-established species may spread across a wide spatial scale. Risk assessment characterises the likelihood and severity of potential adverse effects of biological invasion. Risk management is the process of evaluating, selecting and instituting actions designed to reduce that risk (Andersen et al., 2004). The processes of assessing and managing invasion risk are related, but functionally separate risk analysis activities (Andersen et al., 2004).

International approaches and policies with regard to pre-border risk assessment and management of invasive species have been described as inconsistent and piecemeal (Secretariat

${ }^{174}$ Strathboss Kiwifruit Ltd v Attorney-General [2015] NZHC 1596. 
of CBD, 2001; Reichard et al., 2005; Lodge et al., 2006; Ward et al., 2010). Globally, trade is largely governed by the rules of the World Trade Organization (WTO). Members of the WTO can impose restrictions on imports based on trade-linked risk associated with invasive species. Such restrictions are permitted provided they are consistent across similar risks and based on scientific risk assessment. Upon arrival and establishment of non-native species, domestic agencies may or may not begin pest management. The type of pest management initiated depends on several factors, including the risk posed by the pest to the domestic environment and economy, as well as whether there is realistic chance of control or eradication.

New Zealand's current regulatory and legislative approach towards pre-border invasive species' risk associated with trade is precautionary when compared with other developed jurisdictions. Scholars cited New Zealand's management and assessment of pre-border invasive species' risk as the 'gold-standard' (Jenkins, 2005; Simberloff, 2013). However, gaps exist in the current management regime that could be productively addressed to ameliorate the challenge of invasive species in New Zealand. The aim of this article is to highlight these potential gaps. We do this in two ways: First, we illustrate the benefits of New Zealand's risk assessment based pre-border approach, but highlight its failings from a conservation perspective. Second, we compare the inconsistent post-border approach to the management of invasive species between regions within New Zealand and suggest potential improvements.

\subsection{New Zealand's pre-border controls}

\subsubsection{New Zealand's pre-border framework: Legal intentional species introductions}

In 2007 the WTO governed $96.4 \%$ of global trade ${ }^{175}$. Under the WTO, invasive species' risk associated with international trade is largely regulated by the Agreement on the Application of Sanitary and Phytosanitary Measures (SPS Agreement). The SPS Agreement imposes requirements on import regulations implemented at a domestic level that are concerned with animal, plant and food safety and health ${ }^{176}$. These requirements are in part aimed at preventing or limiting the establishment and spread of pests ${ }^{177}$. The SPS Agreement attempts to ensure that any protective regulations in trade are non-discriminatory, transparent and scientifically justified $^{178}$. WTO members are free to determine what the SPS Agreement labels an

\footnotetext{
${ }^{175} \mathrm{https}: / /$ www.wto.org/english/thewto e/acc e/cbt course e/c1s1p1 e.htm - Last accessed 2 April 2018.

176 Annex A definitions, SPS Agreement.

177 Annex A definitions 1(d), SPS Agreement.

${ }^{178}$ Articles 3.3 and 5.1, SPS Agreement.
} 
'appropriate level of protection' (ALOP). An ALOP may be defined as: "where the politically acceptable benefits produced by any increase in quarantine effort will be insufficient to offset the increased costs (Cook et al., 2008)". An ALOP is permitted to provide a higher level of protection than relevant international standards, provided there is scientific justification and a risk assessment is undertaken ${ }^{179}$.

A common international approach presupposes that only an organism or commodity that is a proven risk elsewhere poses risk to the country to which it is being imported (Simberloff, 2005; Lodge et al., 2006; Roy et al., 2014). This approach has been criticised by invasion ecologists as being insufficiently stringent (Simberloff, 2005; Lodge et al., 2006; Brasier, 2008; Roy et al., 2014). New Zealand's pre-border relatively risk-intolerant regime and management system attempts to take a 'guilty until proven innocent' approach and has been cited as particularly progressive (Simberloff, 2003, 2013; Jenkins, 2005). New Zealand's intended ALOP is strict when compared to most other developed countries. Globally, New Zealand's Biosecurity Act 1993 (Biosecurity Act) was the first national law that took a 'risky until proven otherwise' approach towards regulating the risk of non-native species associated with imports.

Intentional introductions of new species into New Zealand are governed by the Biosecurity Act and the Hazardous Substances and New Organisms Act 1996 (HSNO Act). The purpose of the Biosecurity Act is to prevent unintentional introductions of invasive species and their spread within New Zealand ${ }^{180}$. The purpose of the HSNO Act is to protect the environment, and the health and safety of peoples and communities, by preventing or managing the adverse effects of hazardous substances and new organisms. Any new organism proposed for import must be approved by both the Ministry for Primary Industries (MPI) under the Biosecurity Act and the Environmental Protection Authority (EPA) under the HSNO Act. The HSNO Act is governed by the Ministry for the Environment, administered by the EPA and policed by MPI. Both MPI and EPA undertake risk assessments. The EPA considers the risks and benefits of an organism's introduction before granting approval and must have 'particular regard' to the Department of Conservation's (DOC) view ${ }^{181}$. MPI govern accidental organism arrivals. This involves assessing the potential biosecurity risks from pests and diseases EPA approved imported organisms may carry. For instance, the EPA may approve a new plant introduction.

\footnotetext{
${ }^{179}$ Article 3.3, SPS Agreement; Appellate Body Report, EC Hormones at [173].

180 Sections 16, 42, 54, 143, Biosecurity Act 1993.

${ }^{181}$ Section 58(1)(c), Hazardous Substances and New Organisms Act 1996.
} 
MPI would identify any pathogens associated with that introduction and impose appropriate sanitary measures. Proposed introductions may be rejected by MPI or the EPA based on risk posed to New Zealand. Costs of the risk assessments may be borne partly, or wholly, by the importer.

In terms of ability to manage non-native species' introduction, nations have far more control over the intentional import of non-native species than over unintentional introductions associated with commodities or transport. It is here therefore that risk-intolerant policies are at their most efficacious in reducing non-native species' risk and impacts - although risk assessment is commonly applied to unintentional introductions too. Species can be evaluated before introduction and if found to be high-risk may be denied import; thereby directly preventing any impact and costs associated with post-border control.

\subsubsection{A risk assessment approach to intentional introductions}

No biosecurity regime provides a failsafe 'zero-risk' system. Instead, non-native species' risk management of intentional introductions exists on a continuum. At one end of the continuum no species are accepted for import; though no nation employs this approach. Towards the other end of the continuum most or all species are accepted for import. New Zealand sits towards the risk-aversion end of this continuum as MPI and EPA undertake risk assessments for all potential importations and only species assessed to be of low risk are accepted for import.

\subsubsection{The benefits of risk assessment}

Species specific risk assessment tools and methodologies have been developed that allow for robust and transparent predictions of risk posed by new species (Pheloung et al., 1999). Risk screening systems have been demonstrated to be accurate across many parts of the world (Gordon et al., 2008). Risk assessment protocols have also been shown to produce an economic benefit, even accounting for losses through the incorrect rejection of species with net benefits (Keller et al., 2007). These benefits are consistent across both the animal and plant trade (Springborn et al., 2011; Schmidt et al., 2012).

The SPS Agreement makes it clear that countries may choose their own ALOP, which may be highly precautionary. This rule holds true so long as there is scientific justification, risk assessment is undertaken and similar risks are treated in a non-discriminatory way so they are not a disguised restriction on trade. International disputes have arisen over inconsistent 
treatment of risk. Formal, transparent and consistent risk assessment policies therefore have the added benefit of reducing the risk of trade related disputes regarding non-native species' risk, as well as reducing the economic, environmental and social impacts of invasive species.

\subsubsection{Potential conservation issues}

From a New Zealand conservation perspective risk assessment is beneficial, but not a panacea for the problem of invasive species. Evidence suggests that islands are more easily invaded than mainland environments (Courchamp et al. 2003) and New Zealand has a particularly unique natural history of the evolution of flora and fauna in the absence of mammals. The WTO's Appellate Body has made clear that risk assessments must explicitly consider the "probability" as opposed to the "possibility" of potential consequences of the importation of new species or commodities ${ }^{182}$; although this formulation may be qualitative and not quantitative. This is problematic in a country such as New Zealand with high levels of endemism, as it difficult to probabilistically predict how endemic species will react to novel invaders. During the writing of this paper, Department of Conservation staff drew my attention to species with high ALOPs in place but with few if any protective measures imposed by MPI. This result appeared to occur where MPI possessed little information on the species and so they defaulted to a 'low risk' categorisation. This is understandable as protective measures imposed without evidence could be seen as potential barriers to free trade. However, it means that new organisms entering New Zealand may not be picked up as environmental pests until their impacts are felt. This is likely an intractable issue from a New Zealand conservation perspective. Risks of international trade disputes will not increase political appetite to reform the risk assessment process for species on which little information exists. It is therefore important that the post-border management regime is well-developed and effective at dealing with species that do pass pre-border controls.

Notwithstanding the conservation issues, prevention of unwanted non-native species' arrivals is the most cost-effective method of managing risks of invasive species and does have conservation benefits (Keller et al., 2007; Springborn et al., 2011; Schmidt et al., 2012). Empirically validated risk assessment protocols are currently available and are steadily improving (Pheloung et al., 1999; Lester, 2005; Gordon et al., 2008). New Zealand's pre-border approach to intentional new organism introductions provides a good blueprint of policies and

${ }^{182}$ Appellate Body Report, Australia - Measures Affecting Importation of Salmon at [123]-[124]. 
legislation that effectively utilise these tools to prevent the introduction of potentially invasive non-native species. Biological invasions are a major driver of extinction and biodiversity loss (Vitousek \& D’Antonio, 1997) as well has having major economic impacts (Pimentel et al., 2005). A consistent, risk-based approach is critical to mitigating the effects of invasive species. Formal risk assessments represent a readily available tool that should form part of governments' policies for managing risks arising from this global challenge. However, if a species does elude pre-border management, or is imported through lack of evidence of harm, then it is crucial the domestic regime can respond quickly and effectively.

\subsection{Post-border pest management in New Zealand}

\subsubsection{New Zealand's post-border management framework}

Management of pests at the border has two main goals: species exclusion or eradication. However, post-border New Zealand has a large number of well-established and establishing pest species. Management of these pests is undertaken by a range of agencies, operating under different strategies, at different geographic levels and under a range of legislation. Initiatives may be pest-led or site-led. Pest-led initiatives are intended to manage pests across large areas. Such programmes may be undertaken at national, regional or sub-regional scales and are usually for pests with limited distributions.

Site-led initiatives focus on spatially limited areas with high amenity or economic values. Limited area size means pest control or eradication is feasible. These programmes usually address widespread animal pests and weeds for which broader scale management is impractical. Site-led management includes most of DOC's management in reserves and national parks for biodiversity outcomes, community restoration projects and farmers' pest control activities. A wide range of legislation is involved including: The Wild Animal Control Act 1977, Conservation Act 1987, Resource Management Act 1991 and the Biosecurity Act. Many groups undertake work, including: MPI, DOC, regional councils, TBfree New Zealand, agricultural industry groups, public bodies and private landowners.

Besides regulation of pre-border risk, the Biosecurity Act also regulates management of invasive species' incursions and establishment in New Zealand. Pest management activities take part under Part 5 of the Act. The purpose of Part 5 is to provide for the eradication or 
effective management of harmful organisms that are present in New Zealand ${ }^{183}$. Part 5 does this by enabling the development of national or regional pest and pathway management plans, and small scale management programmes.

The Biosecurity Act states that MPI provides overall leadership for pest management in New Zealand $^{184}$. Leadership includes overseeing and developing management systems, as well as measuring performance. Further, it includes promoting public support of an aligned, collaborative approach involving a range of stakeholders. MPI has a memorandum of understanding on biosecurity with DOC and the Ministry of Health (MAF 2006). The memorandum provides a framework describing how these agencies work together on biosecurity matters. Responsibility for management of pests post-border is largely led by MPI, DOC and regional government bodies.

\subsubsection{Pest response capacity}

MPI is the lead manager of pest management if an organism: (a) has not been previously detected in New Zealand; or (b) the pest is already in New Zealand and an objective has been set to eradicate the pest or contain it nationally. Recent examples include the Queensland fruit fly (Bactrocera tryoni) incursion in Northland, the Mycoplasma bovis incursion and the Myrtle rust (Austropuccinia psidii) response. Response is a capacity-area within MPI that responds adaptively to incursions as they arise to attempt to eradicate species before they are fully established. Response activities are initiated rapidly upon detection of species of national concern and typically involve a flexible scaling of effort within MPI, including temporary or long-term secondment of staff into dedicated response teams. Country-wide preparation drills are run to simulate incursion events of key risk species such as foot-and-mouth disease (Aphthae epizooticae). Such practice events allow weaknesses in response systems to be highlighted and adjusted in preparation for a major event.

Some pest species that have established are managed by the MPI-led 'National Interest Pest Response'. Species are included in this programme due to their potential to significantly impact economic, social and cultural values, e.g. water hyacinth and the Rainbow lorikeet. DOC has an interest in any pests or diseases that are potentially harmful to native flora, fauna and natural

\footnotetext{
183 Section 54, Biosecurity Act 1993.

${ }^{184}$ Section 12A, Biosecurity Act 1993.
} 
ecosystems (MAF 2006) and will undertake eradication for conservation pests MPI has decided not to respond to, such as the Great white butterfly (Pieris brassicae).

\subsubsection{Regional level management}

At the regional level, New Zealand is divided into sixteen regions for devolved local government (Fig. 3.1). Bodies governing these regions are classified as regional councils or unitary authorities and have responsibility for pest management within their regions. The distinction between regional councils and unitary authorities is not relevant to pest management and the term 'regional council' will be used in this paper.

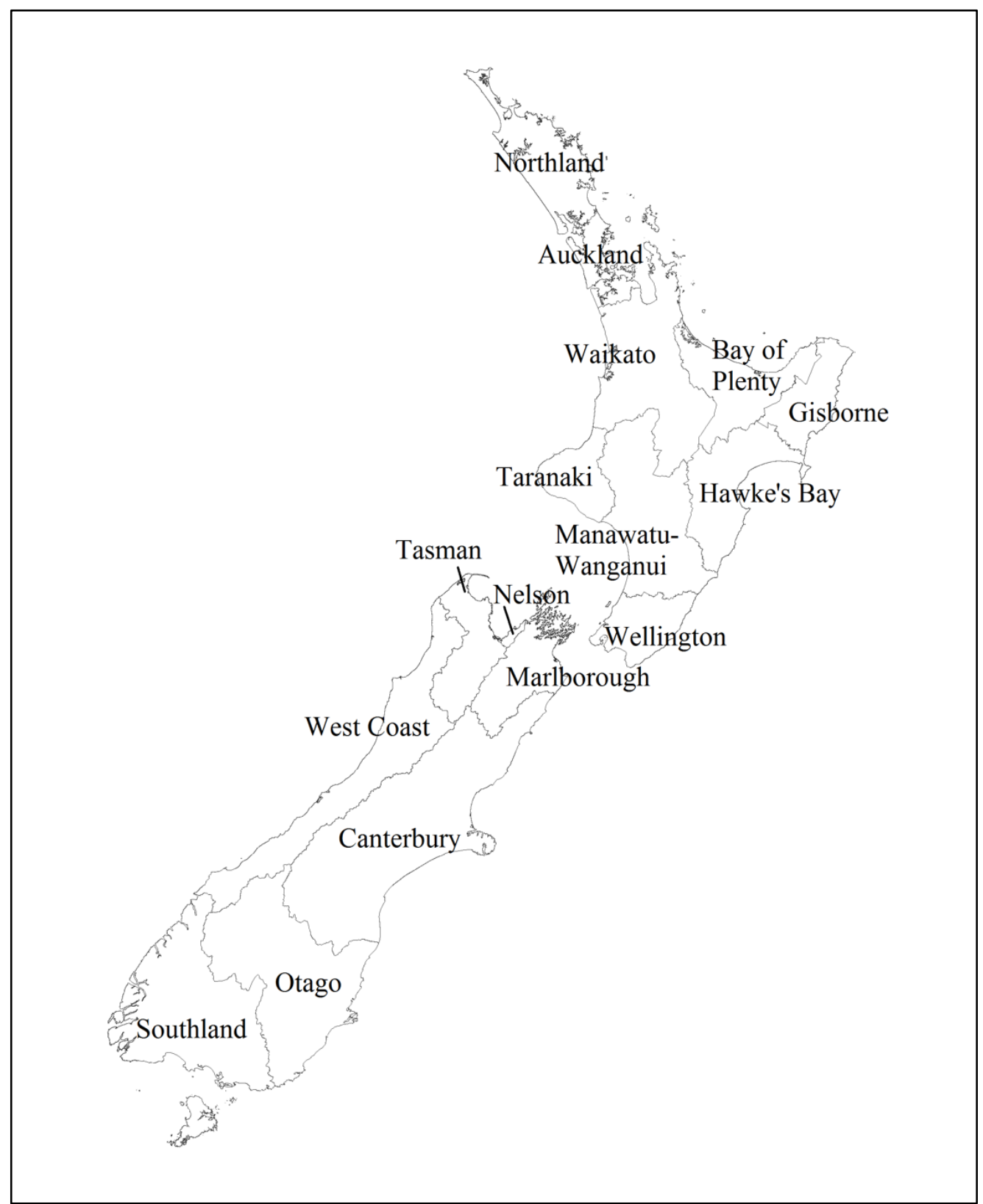

Fig. 3.1. Map of New Zealand showing regional councils and their boundaries. 
Regional councils lead control efforts for pests that are already in New Zealand where no decision has been made to eradicate or contain the pest nationally - most pest species. The Biosecurity Act states that regional councils provide leadership regionally ${ }^{185}$. Regional council leadership under the Act envisages a nuanced and collaborative approach to pest management involving: aligning interested groups, facilitating management activities and promoting public support $^{186}$. Regional council management is done through Regional Pest Management Plans (RPMPs). An RPMP is drafted under Part 5 of the Biosecurity Act for the purpose of the eradication or effective management of particular pests in a region ${ }^{187}$.

\subsubsection{National Policy Direction}

The Biosecurity Act requires that the responsible Minister enact a National Policy Direction $(\mathrm{NPD})^{188}$. The purpose of a NPD is to ensure that activities under Part 5 of the Act provide the best use of available resources for New Zealand's interests and align with one another. In August of 2015 the Ministry for Primary Industries released the 'National Policy Direction for Pest Management 2015'. According to the NPD, it will achieve its purpose by (MPI 2015):

(a) Clarifying requirements for Part 5 regulatory instruments; and

(b) Ensuring consistent application of these requirements nationally and between regions as appropriate.

The NPD provides directions on:

(a) The setting of plan objectives: The adverse effects being addressed, planned outcomes and the geographic area to which the outcomes apply;

(b) Programme descriptions: Limiting programmes to one of five broad categories of pest management: Exclusion, Eradication, Progressive Containment, Sustained Control and Site-Led;

(c) Analysing benefits and costs: Providing criteria to be considered in a benefit cost analysis;

(d) Allocation of costs: Directions on considerations when allocating costs of the plan. For instance, who benefits? Who exacerbates the problem?; and

\footnotetext{
185 Section 12, Biosecurity Act 1993.

${ }^{186}$ Section 12(B)(2) Biosecurity Act 1993.

187 Section 2, Biosecurity Act 1993.

188 Section 56(1), Biosecurity Act 1993.
} 
(e) Good neighbour rules: Directions on criteria to be met when setting rules that impose requirements on land-owners to manage spread of pests between properties so that the impacts on neighbours are not unreasonable.

The changes required by the NPD to RPMPs will very likely improve New Zealand's domestic pest management system. It sensibly aims to provide more consistent management by providing guidance on:

(a) The language used to describe programmes;

(b) Outcomes required of programmes;

(c) What is required for a robust analysis of benefit-cost analyses; and

(d) What constitutes the new "good neighbour" rules.

Whilst the NPD very usefully adds consistency to the pest management system there are some notable regulatory inconsistencies and gaps that should be addressed. Below we provide evidence for this standpoint.

\subsubsection{Inconsistency in pest species regulated}

The number of pest species directly regulated between RPMPs is inconsistent, ranging from 254 in Auckland, to 24 in Otago (Table 3.1). It might be argued that the lower South Island regions, such as Otago, are environmentally less hospitable to invasive species and therefore it is reasonable fewer pest species are regulated. However, the inconsistency is a national phenomenon. For example, Auckland, Waikato and Bay of Plenty are similar climatically and share borders with one another (Fig. 3.1). The number of pests species regulated varies significantly between these regional councils: Auckland - 254, Waikato 190 and Bay of Plenty 141. 


\begin{tabular}{|c|c|c|c|c|}
\hline Authority & $\begin{array}{l}\text { Pest } \\
\text { plants } \\
\text { regulated }\end{array}$ & $\begin{array}{l}\text { Pest } \\
\text { animals } \\
\text { regulated }\end{array}$ & $\begin{array}{l}\text { Publicly } \\
\text { available } \\
\text { marine pest } \\
\text { management } \\
\text { strategy } \\
\text { available? }\end{array}$ & $\begin{array}{l}\text { Annual } \\
\text { regional } \\
\text { council spend } \\
\$ / \mathbf{k m}^{2}\end{array}$ \\
\hline Northland & 118 & 63 & Yes & $\$ 91 *$ \\
\hline Auckland & 208 & 46 & No & $\begin{array}{l}\text { Incomplete } \\
\text { data }^{1}\end{array}$ \\
\hline Waikato & 146 & 44 & Developing & $\$ 259^{*}$ \\
\hline Bay of Plenty & 113 & 28 & Yes & $\$ 210^{*}$ \\
\hline Gisborne & 45 & 25 & No & $\$ 131^{*}$ \\
\hline Hawke's Bay & 24 & 14 & No & $\$ 239^{*}$ \\
\hline Manawatu-Wanganui & 62 & 35 & No & $\$ 260^{*}$ \\
\hline Taranaki & 28 & 23 & No & $\$ 271^{*}$ \\
\hline Wellington & 71 & 25 & No & $\$ 658^{*}$ \\
\hline Marlborough & 34 & 4 & $\begin{array}{l}\text { Top of South } \\
\text { Marine } \\
\text { Biosecurity } \\
\text { Partnership }\end{array}$ & $\$ 110^{*}$ \\
\hline Nelson/Tasman & 45 & 17 & $\begin{array}{l}\text { Top of South } \\
\text { Marine } \\
\text { Biosecurity } \\
\text { Partnership }\end{array}$ & $\$ 51^{*}$ \\
\hline Tasman/Nelson & 45 & 17 & $\begin{array}{l}\text { Top of South } \\
\text { Marine } \\
\text { Biosecurity } \\
\text { Partnership }\end{array}$ & $\$ 51^{*}$ \\
\hline Canterbury & 84 & 19 & No & $\$ 74^{*}$ \\
\hline West Coast & 35 & $\begin{array}{l}\text { No publicly } \\
\text { available } \\
\text { animal pest } \\
\text { managemen } \\
\text { t plan }\end{array}$ & No & $\$ N o$ data $^{1}$ \\
\hline Otago & 20 & 4 & No & $\$ 67 *$ \\
\hline Southland & 63 & 42 & $\begin{array}{l}\text { Included in } \\
\text { RPMP }\end{array}$ & $\$ 72 *$ \\
\hline \multicolumn{4}{|c|}{${ }^{1}$ Incomplete or no data available from RPMP. } & Average: $\$ 182$ \\
\hline
\end{tabular}


* These figures were sourced as council spending RPMP reports.

There may be additional pest management spending not included in report figures.

Further, the species actually regulated are different (Fig. 3.2). Auckland has 117 unique species in its RPMP not covered in the Bay of Plenty or Waikato RPMPs. Of all species regulated only 57 are regulated by all three councils. Additionally, some significant invasive species are being regulated inconsistently across these councils. The International Union for Conservation of Nature (IUCN) list of 100 of the world's worst invasive alien species (Lowe et al., 2000) includes 36 species that are, or have been, present in New Zealand. Eight of these species are unregulated by the three councils (Figure 3.2). Of the other 27 only 10 are regulated by all three councils. 


\section{Bay of Plenty}

Waikato

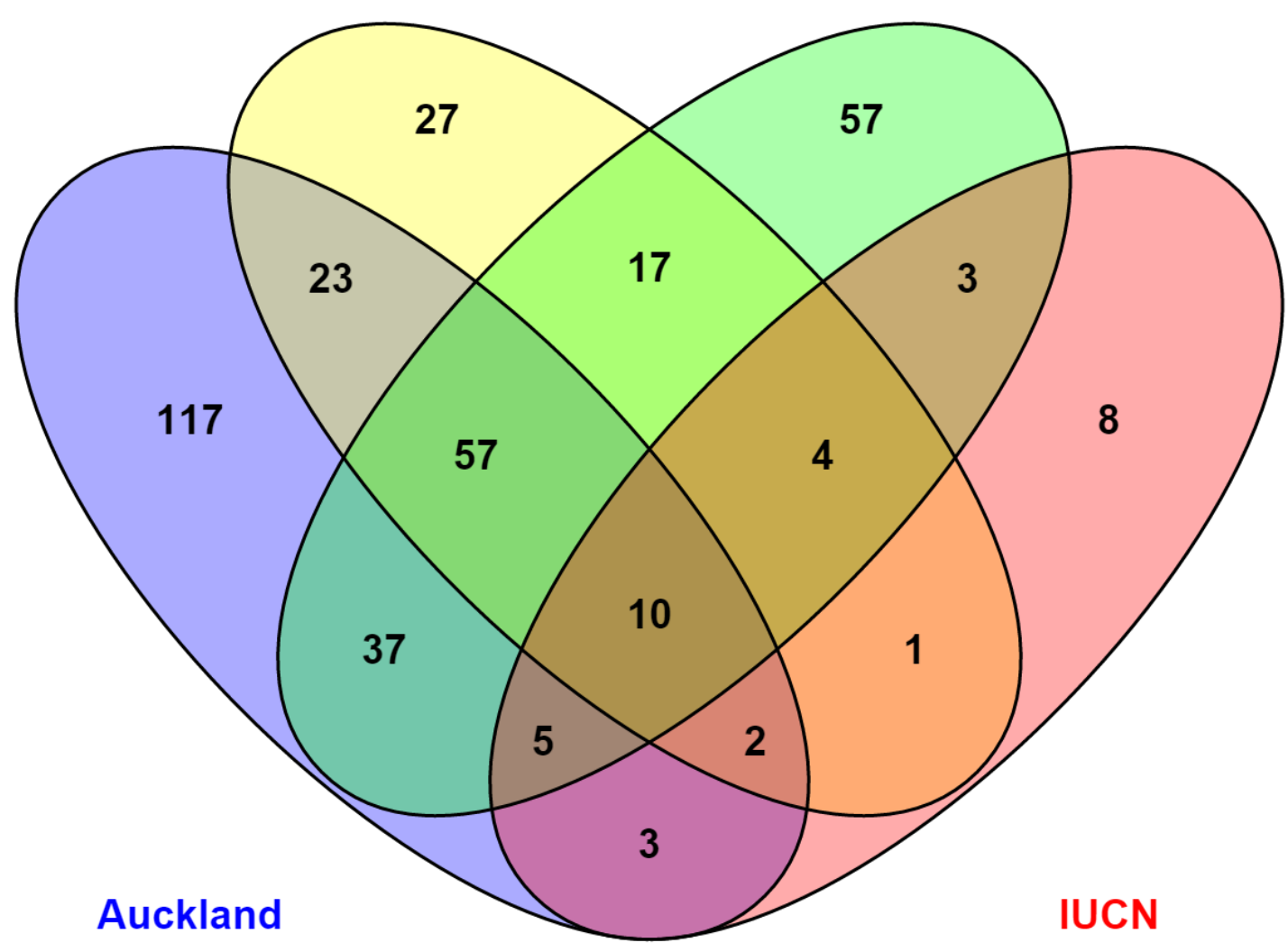

Fig. 3.2. Venn diagram showing inconsistency of management of pest species within RPMPs. The diagram includes numbers of pest species regulated by the RPMPs of three regionally proximate, environmentally similar councils. Additionally, the number of animal species from the International Union for Conservation of Nature (IUCN) list of 100 of the world's worst invasive species (Lowe et al. 2000) that are, or have been, present in New Zealand are included.

This inconsistency of pest regulation is potentially problematic. These regions are broadly geographically contiguous (Fig. 3.1), with well-developed transport connections and frequent inter-region movement. Transport corridors such as roads and railways have been shown to facilitate the spread of non-native species across landscapes (Müllerová et al., 2005; Wangen \& Webster, 2006; von der Lippe \& Kowarik, 2007). There is a risk that species not regulated 
in one region could provide a source population to invade or reinvade a contiguous region, or attenuate efforts at population control or containment. Additionally, trade is a major driver of invasive species' risk. The top three ports by dollar value for commodities imported to New Zealand are: Auckland Seaport, Auckland Airport and Tauranga Seaport (Bay of Plenty). In 2015 these three ports imported by dollar value $43.7 \%, 19.9 \%$ and $10.6 \%$ of New Zealand's total commodity imports respectively ${ }^{189}$. Given the likely import-associated pest pressure, these regions should have consistent approaches to pest management. Consistency would help to ameliorate the potential issue of source populations and ensure a consistent approach to the same pests across a broad geographical area with high import associated pest pressure.

We are not suggesting a standardised 'black list' approach for all RPMPs nationally. Such approaches assume all potentially invasive species have similar impacts wherever they are found. In reality, invasive species' impacts can vary depending on a range of factors, including species' distributions, densities and the climatic suitability of a particular region. Instead, we suggest in areas where species may pose similar risks - such as Waikato, Auckland and Bay of Plenty - there should be significant coordination, and possible standardisation, of control programmes.

\subsubsection{Inconsistency in funding}

Domestic pest management spending involves financial contributions from a variety of stakeholders including: private landowners, Maori, regional councils, MPI, DOC and other public bodies. Direct regional council spend is only a part of the total management spend. However, as the Biosecurity Act tasks regional councils with leadership in pest management at a regional level it is instructive to assess their relative pest management effort using the proxy of spending. Pest management under RPMPs is partially funded from rates ${ }^{190}$. Rates levied on land occupiers can vary depending on the interests of the occupiers; that is, the extent to which they benefit from pest management and the extent to which they exacerbate the pest ${ }^{191}$. However, this funding system is problematic for pest management as regions' populations differ substantially in terms of size, demographics and income; therefore rate-dependent funding for pest management will also differ. These differences may be reflected in the 2013-

\footnotetext{
${ }^{189} \mathrm{http}: / /$ nzdotstat.stats.govt.nz/wbos/Index.aspx?DataSetCode=TABLECODE7302 - Last accessed 19 October 2015.

${ }^{190}$ Section 100T, Biosecurity Act 1993.

${ }^{191}$ Section 100T(2)(a)-(d), Biosecurity Act 1993.
} 
2014 pest management spend per $\mathrm{km}^{2}$ across regional councils (Table 3.1). By far the most spent by any one council was Wellington at $\$ 658 / \mathrm{km}^{2}$, whereas Tasman $/$ Nelson spent $\$ 51 / \mathrm{km}^{2}$; the national average was $\$ 182 / \mathrm{km}^{2}$. Per $\mathrm{km}^{2}$ spend on pest management may be reflective of variable council pest management effort across regions. This inconsistency may be counterproductive in that while one region may be controlling pests effectively, neighbouring regions may expend less effort, undermining broader scale management effectiveness. It should be noted, other potential explanations exist for inconsistency in management spend. For instance, population variation may lead to variable rate intake across regions. Alternatively, expenditure may be influenced by how many pests there are in a region and the vulnerability of habitat to invasion. For example two councils with relatively low spends per $\mathrm{km}^{2}$ - Otago and Southland - are cold environments ill-suited to pest establishment. Finally, councils generally do not undertake management on protected Crown land; so regions with higher proportions of Crown land may have lower council activity.

\subsubsection{Marine Biosecurity}

Maritime transport is a major source of non-native species' introductions (Molnar et al., 2008; Rahel \& Olden, 2008). For example, ballast water harbours many non-native species (Roman \& Darling, 2007). Although ballast water exchange protocols have been implemented, their efficacy has been questioned (Tsolaki \& Diamadopoulos, 2010). Ships themselves also act as vectors. Hull fouling - the hitchhiking of non-native species on ship hulls - is a major issue (Molnar et al., 2008). Marine invasive species are an increasing threat to marine biodiversity worldwide (Molnar et al., 2008). In New Zealand, recent invaders include Mediterranean fanworm which has been found in Northland and Bay of Plenty and the highly invasive seaweed Undaria pinnatifida which is present in almost all of New Zealand's international ports $^{192}$.

Despite the high risk of ballast and hull-fouling, only six of New Zealand's 16 regional councils have specific marine pest management plans in place (Table 3.1). Auckland region's major seaport handles $43.7 \%$ of all of New Zealand's goods by dollar value, but does not have a publicly available marine pest management plan. Council's recognise their lack of management plans to be a problem as evidenced by the fact the Waikato Regional Council has specifically requested direction on this issue in its RPMP ${ }^{193}$. Encouragingly, the country's second biggest

192 http://www.biosecurity.govt.nz/pests/undaria - Last accessed 12 January 2015

${ }_{193}$ Waikato Regional Council RPMP at 254. 
port by dollar value - Port of Tauranga - does have a marine pest management plan. This management plan could be developed or enhanced for use by other ports.

Another encouraging development is the 'Top of South Marine Biosecurity Partnership'. This regionally focussed group was formed with the intention to improve marine biosecurity management in the northern half of the South Island. It involves representatives from Tasman, Nelson and Marlborough councils, MPI, DOC, the aquaculture industry, Maori, port companies and other groups. It undertakes a range of roles including project management, media and public awareness, development of manuals and plans, scientific support/technical solutions and incident readiness and response. We suggest that such a regionally focused management approach should be applied to other marine areas with similar risk profiles around New Zealand.

\subsection{Conclusion}

New Zealand's pre-border approach to invasive species management has been heralded as particularly effective (Jenkins, 2005; Simberloff, 2013).. Evidence suggests that pre-border risk assessments can result in long-term economic net benefits (Keller et al., 2007; Springborn et al., 2011; Schmidt et al., 2012). However, from a conservation perspective the current paradigm of risk assessment in international trade is imperfect, given the need for probabilistic scientific evidence of harm. New organisms that are environmental pests are often not picked up until their impacts are felt. It seems unlikely this problem will be addressed given the differing political priorities attached to trade and conservation.

Therefore it is particularly important that New Zealand's post-border management of invasive species is well-developed and effective. Funding and species regulated in RPMPs is inconsistent across regions, even in environmentally similar areas. Further, key regions lack marine pest management strategies. This is not to say that New Zealand's post-border approach is poor relative to the rest of the world. Similar issues exist in other jurisdictions such as Australia, Canada and the United States (Riley, 2012, 2013; McCubbins et al., 2013; Quinn et al., 2013). However, New Zealand is world-leading in its pre-border pest risk management. So too in certain areas of domestic pest management, such as predator removal on off-shore and mainland islands (Bellingham et al., 2010). Trade-related invasive species pressure is highly likely to increase. Therefore regulatory change should come sooner, rather than later. A truly 
integrated, consistent and effective pest management framework would go some way towards ameliorating the challenge of invasive species to New Zealand. 


\section{Chapter 4: Honey bee hive collapse associated with an invasive ant and viral pathogens}

\subsection{Abstract}

Invasive species and emerging infectious diseases are threats to biodiversity, human health and agriculture. Here, I highlight the potential role of the globally widespread and invasive Argentine ant (Linepithema humile) in the mortality and disease dynamics of honey bees. Over a six-month period, hive survival in apiaries with Argentine ants was 52.8\% compared to 89.5\% in apiaries without ants. Bees within these hives were afflicted with Deformed wing virus, which is a globally widespread cause of honey bee colony losses. Average Deformed wing virus infection levels were always higher in bees when Argentine ants were present. Bees in apiaries with ants acquired viral infections up to 220 -fold higher than the maximum infection in apiaries without ants. Argentine ants may be contributing to honey bee hive collapse through the combined effects of predation, hive robbing, and disease. Because these invasive ants and many other insects nest in hive boxes, the movement of honey bees for pollination may help spread this invasive ant and promote disease. Current management of the international and domestic movement of honey bees requires reform. Invasive species can have substantial effects as predators, but may also have a significant 'hidden' role in disease dynamics.

\subsection{Introduction}

Honey bees are the most economically valuable pollinator species worldwide, as well as being managed for honey production (Klein et al., 2007; Gallai et al., 2009). Severe regional declines in managed honey bee hives have occurred, as well as extinction of wild honey bee colonies (Potts et al., 2010). A variety of causes of declines have been proposed (Potts et al., 2010). Of potential mechanisms in the literature, the Deformed wing virus (DWV), appears to be a key driver of honey bee colony losses (Dainat et al., 2012; Schroeder \& Martin, 2012; McMahon et al., 2016; Natsopoulou et al., 2017). Recent studies investigating pollinator and honey bee decline as a result of disease generally focus on interactions between pollinators within communities (e.g. Fürst et al. 2014), but honey bees interact with a wide variety of species around their hive and while foraging (Stirling, 1921; Levitt et al., 2013; Levan \& Holway, 2015; Sidhu \& Wilson Rankin, 2016). A range of ant species have been found within beehives (Stirling, 1921; Burrill, 1926). 
Globalisation has led to vastly increased volumes of trade worldwide. Two by-products of this increase, invasive species and emerging infectious diseases, are major threats to biodiversity, food security and human health globally (Daszak et al., 2000; Jones et al., 2008; Hulme, 2009; Bertelsmeier et al., 2017). Newly introduced species can harbour a diverse community of microorganisms, some of which may be pathogenic and facilitate invasion through pathogen spillover (Strauss et al., 2012). The Argentine ant, Linepithema humile, has been described as one of the six most abundant, widely distributed and damaging invasive ant species (Holway et al., 2002). This ant can severely damage native communities and ecosystems where it has invaded (Holway et al., 2002). Argentine ants are also host to a diverse microbial community, which includes the honey bee virus DWV and a related Dicistrovirus, Linepithema humile virus 1 (LHUV-1) (Sébastien et al., 2015). Here we asked two questions: First, does the presence of the Argentine ant increase honey bee hive mortality and collapse? Second, does the presence of Argentine ants lead to increased viral loads in honey bees? To my knowledge, this is the first study showing a globally widespread invasive ant associated with honey bee hive mortality and disease. We believe this work has important implications for the domestic and international management and movement of honey bees, especially as the association between honey bee hive movement and invasive species spread has been observed elsewhere around the world (Dowell et al., 1997; Mutinelli, 2011).

\subsection{Methods}

\subsubsection{Sampling}

Our study examined six sites in the north of New Zealand's North Island over a period of five months (Fig. 4.1, Table 4.1); three sites with, and three sites without Argentine ant presence. Sampling took place at each of the six sites at approximately monthly intervals. Bees were collected from within individual beehives. Ants were collected either within or upon beehives. Five collection events were undertaken (Table 4.1.). Collections at each site were completed in a single day. Sampling of all sites took a maximum of three days on each sampling event. Samples collected were put in sampling tubes, freeze-killed at $-20^{\circ} \mathrm{C}$ and transferred into liquid nitrogen $\left(-196^{\circ} \mathrm{C}\right)$ on the evening of collection to ensure RNA preservation. Beekeepers were questioned about their experience with Argentine ants under the VUW Human Ethics permit \#022813 'Survey of Colony Losses due to Argentine Ants'. 


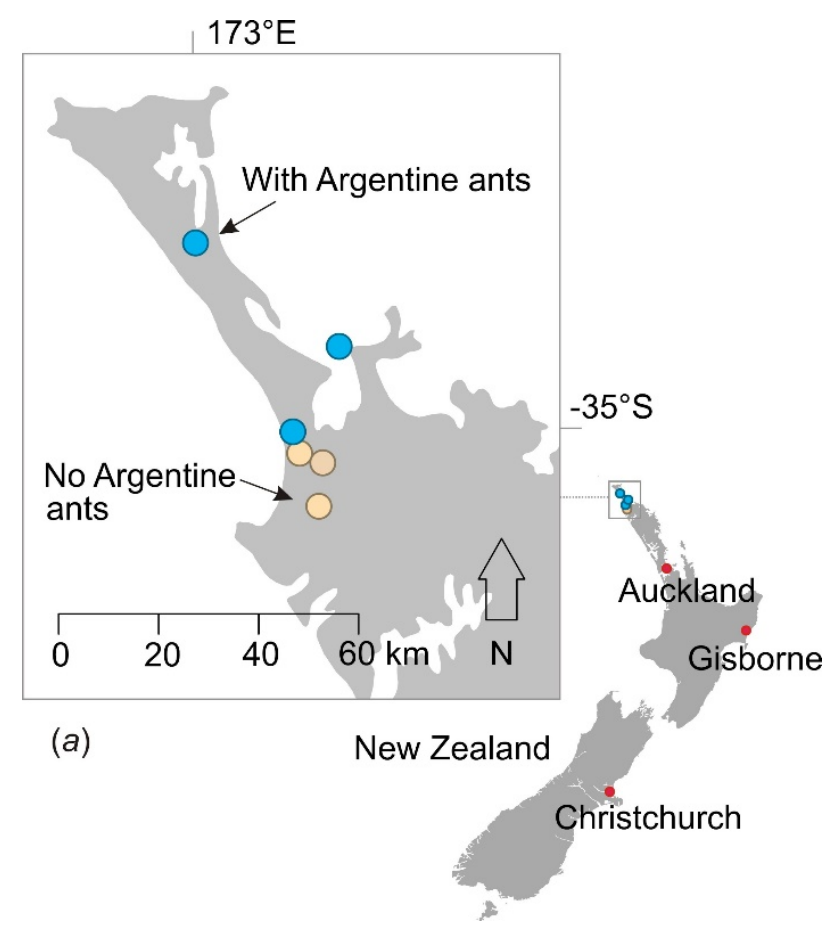

Fig. 4.1. Sample locations of Argentine ants and honey bees. Argentine ants in New Zealand occur as far south as Christchurch. Beekeepers have reported hive mortality due to Argentine ants in areas from Gisborne northwards including Auckland.

Table 4.1. Sampling origins and collection data for Apis millifera and Linepithema humile. Bees were collected directly from bee hives. Ants were collected either within or upon beehives

\begin{tabular}{|l|l|l|l|}
\hline Sampling site & Latitude & Longitude & Collection date \\
\hline Rangiputa (ants present) & -34.867 & 173.318 & Time 1: 2 February 2016 \\
& & & Time 2: 2 March 2016 \\
& & & Time 3: 13 April 2016 \\
& & & Time 4: 2 June 2016 \\
\hline Salt Road (ants present) & -34.681 & 173.001 & Time 5: 6 July 2016 \\
\hline
\end{tabular}




\begin{tabular}{|c|c|c|c|}
\hline & & & $\begin{array}{l}\text { Time 2: } 2 \text { March } 2016 \\
\text { Time 3: } 13 \text { April } 2016 \\
\text { Time 4: } 2 \text { June } 2016 \\
\text { Time 5: } 6 \text { July } 2016\end{array}$ \\
\hline Waipapa (ants present) & -35.021 & 173.216 & $\begin{array}{l}\text { Time 1: } 2 \text { February } 2016 \\
\text { Time 2: } 2 \text { March } 2016 \\
\text { Time 3: } 13 \text { April } 2016 \\
\text { Time 4: } 2 \text { June } 2016 \\
\text { Time 5:6 July } 2016\end{array}$ \\
\hline Airport (no ants) & -35.077 & 173.282 & $\begin{array}{l}\text { Time 1: } 3 \text { February } 2016 \\
\text { Time 2: } 3 \text { March } 2016 \\
\text { Time 3: } 14 \text { April } 2016 \\
\text { Time 4: } 3 \text { June } 2016 \\
\text { Time 5: } 7 \text { July } 2016\end{array}$ \\
\hline Bellinghams (no ants) & -35.1560 & 173.273 & $\begin{array}{l}\text { Time 1: } 3 \text { February } 2016 \\
\text { Time 2: } 3 \text { March } 2016 \\
\text { Time 3: } 14 \text { April } 2016 \\
\text { Time 4: } 3 \text { June } 2016 \\
\text { Time 5: } 7 \text { July } 2016\end{array}$ \\
\hline Gills Road (no ants) & -35.060 & 173.231 & $\begin{array}{l}\text { Time 1: } 3 \text { February } 2016 \\
\text { Time 2:3 March } 2016 \\
\text { Time 3: } 14 \text { April } 2016 \\
\text { Time 4: } 3 \text { June } 2016 \\
\text { Time 5: } 7 \text { July } 2016\end{array}$ \\
\hline
\end{tabular}




\subsubsection{Experimental procedures}

Viral loads were quantified in bees and ants using RT-qPCR. RNA was extracted by beadbeating (BeadBeater 16, Biospec Products, USA) samples in GENEzol reagent (Geneaid, Taiwan) and 5\% $\beta$-mercaptoethanol followed by chloroform and isopropanol purification. RNA concentrations were quantified with a NanoDrop spectrophotometer (NanoDrop/ThermoFisher Scientific, USA) and $1 \mu \mathrm{g} / \mathrm{sample}$ was used for cDNA synthesis using qScript XLT SuperMix (Quantabio, USA). Each sample was analysed in duplicate by qPCR with PerfeCTa SYBR Green reagent (Quantabio, USA) using $1 \mu 1 \mathrm{cDNA} /$ reaction. Viral and internal reference gene primers were utilised and negative controls were included for each primer assay (Table 4.2.).

\begin{tabular}{|l|l|l|}
\hline \multicolumn{2}{|l|}{ Table 4.2. Primers used in RT-qPCR } & Reference \\
\hline Primer name & Primer sequence & This study \\
\hline LHUV-1_66F & 5'-AAGGTCGTCCTCAATGCGAA-3' & \\
\hline L. humile Ndufa8-F & 5'-TGACACCTGCCCTAGAGCTA-3' & This study \\
L. humile Ndufa8-R & 5'-CCAGGTAACGTCCAACTCCC-3' & \\
\hline DWV-F8668 & 5'-TTCATTAAAGCCACCTGGAACATC-3' & (Yañez et al., \\
DWV-B8757 & 5'-TTTCCTCATTAACTGTGTCGTTGA-3' & 2012) \\
\hline A. mellifera Pros54-F & 5'-TCGAACCAAGATGGTACTGGAA-3' & (Cameron et al., \\
A. mellifera Pros54-R & 5'-TTGTTGTGCTTGCAGTCGTG-3' & 2013) \\
\hline
\end{tabular}

A QuantStudio 7 (Applied Biosystems/Thermo Fisher Scientific, USA) was used for qPCR with fast cycling conditions and fluorescence detection during the elongation step (Stage 1: $95^{\circ} \mathrm{C}, 30 \mathrm{~s}$; Stage $2: 40$ cycles of $\left.95^{\circ} \mathrm{C}, 5 \mathrm{~s} ; 60^{\circ} \mathrm{C}, 15 \mathrm{~s} ; 72^{\circ} \mathrm{C}, 20 \mathrm{~s}\right)$. Quantification cycle $(\mathrm{Cq})$ values were analysed to calculate viral loads using external standard curves generated for the 
viruses and internal reference genes. The external standards were 150-156 bp DNA fragments (GeneArt Strings DNA Fragments, Invitrogen/Thermo Fisher Scientific, USA) that matched the region recognised by the primers. Internal species specific reference genes L. humile Ndufa 8 and A. mellifera Pros54 were used to normalise the calculated viral loads. L. humile Ndufa8 (NADH dehydrogenase [ubiquinone] 1 alpha subcomplex subunit 8) was used based on the study of Cameron et al. (2013) which identified Ndufa8 as a useful internal reference in developing honey bees. All PCR assays were run using positive and negative controls.

We compared strains of DWV from Argentine ants and honey bees. Nine sequences of DWV from four ants and five bees were aligned using MEGA 6.06 (Kumar et al., 2015). Ends were trimmed manually. We manually checked sequences for quality. Alignments of bases for phylogenetic analyses were performed using 387 bases. A phylogenetic tree was built to demonstrate relationships between New Zealand DWV and DWV globally (Fig. 4.3). The nine sequences of DWV were supplemented with 17 sequences of DWV obtained from GenBank. To determine the most appropriate model of sequence evolution for my dataset we used Bayesian information criterion scores derived in MEGA, which also estimated base frequencies, substitution rates, the uniformity of substitution rates among sites $(G)$, and the proportion of invariable sites (I) (Table 4.3.). The best-fitting model of sequence evolution was the Tamura model with a gamma distribution parameter (T92 + G Model) (Tamura, 1992). We then used this model to build a maximum composite likelihood tree and the level of support was assessed with 1000 bootstrap replications in MEGA.

DWV replication was analysed by detection of the virus negative strand using reverse transcription (SuperScript IV, Invitrogen/Thermo Fisher Scientific, USA) with tagged primer tag-F15 followed by PCR using the primers B23 and Tag (Yue \& Genersch, 2005). To investigate DWV sequence variation sample cDNA was amplified using DWV VP2 region primers $1848 \mathrm{f}$ and $2364 \mathrm{r}$ (Berényi et al., 2007). PCR products were sequenced by Sanger sequencing using the forward primer (1848f). 


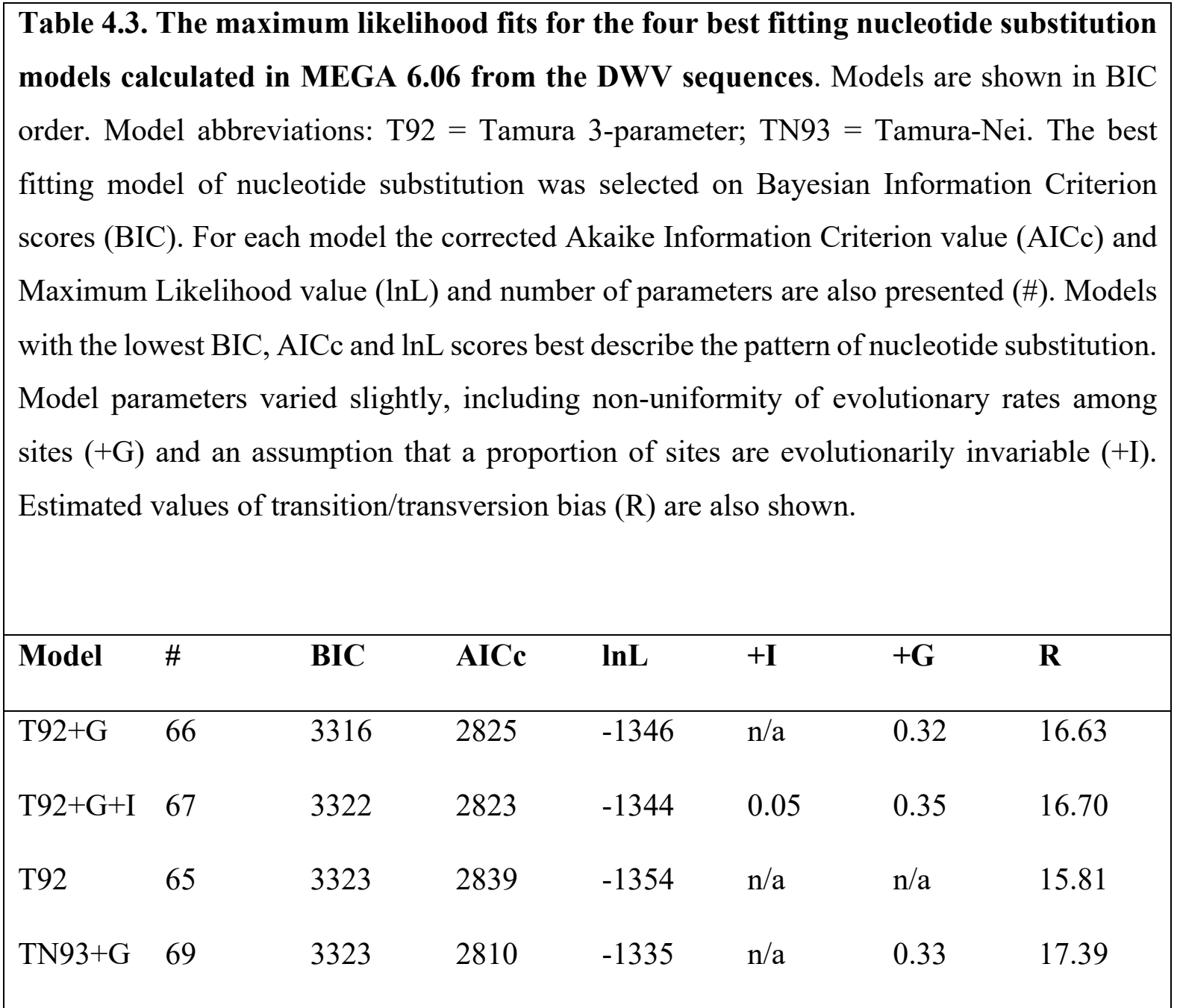

\subsubsection{Statistical analysis}

All analyses and figures were implemented in R version 3.2 (R Team, 2016). The hive survival analysis was conducted using Cox proportional hazard regression models in the package survival (Therneau, 2015). Although our initial design involved a repeated measures approach, which is statistically appropriate, this design was not able to be implemented, as sampled hives were destroyed by Argentine ants and alternative hives had to be substituted within apiaries. Consequently to test our hypothesis that viral load varies between sites with Argentine ants we used a permutational ANOVA, or PERMANOVA, with 999 permutations. We used the adonis function in the vegan package in $\mathrm{R}$ (Oksanen et al., 2007). 


\subsection{Results}

\subsubsection{Direct hive robbing, predation and bee colony mortality}

Beekeepers from throughout New Zealand were surveyed regarding the prevalence of Argentine ants attacking and destroying beehives (Fig. 4.2.). Numerous reports of hive mortality and resulting apiary site abandonment were made from the warmer regions of New Zealand where Argentine ants are often in high abundance. We observed ants uncapping juvenile cells with pupae being attacked and killed. Adult honey bees were observed hovering near individual ant workers, attempting to pick up ants in their mandibles and remove them from hive sites in a similar fashion to that observed in wasp-ant interactions (Grangier \& Lester, 2011). However, unlike those interactions between wasps and ants, all observed attempts by honey bees to remove ants were unsuccessful. The bees appeared to be agitated by the presence and attacks from ants. Entire nests of Argentine ant queens, workers, males and brood were observed within hives. Densities of ants were extremely high, with up to 12 queens observed in one hive frame. Other ant nests were often found immediately beneath or adjacent to hives with foraging trails leading directly into hives (Fig. 4.2). 


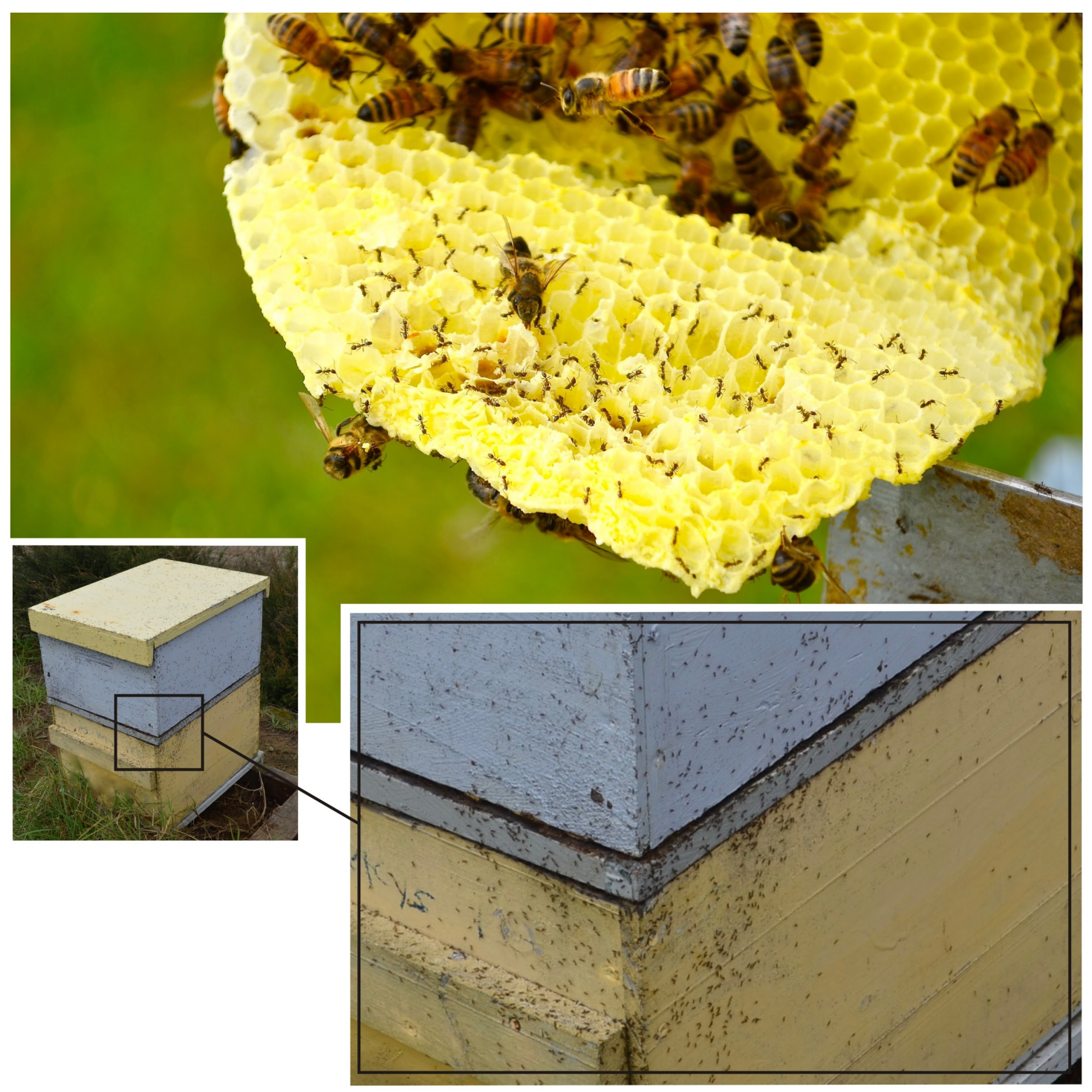

Fig. 4.2. Argentine ant infestations of bee hives. Ants were frequently seen attacking pupae or bee larvae in hives. Beekeepers reported them commonly attacking brood, and less frequently robbing honey. Many thousands of ants could be seen on the outside of this hive; many thousands more were inside.

The survival of honey bee hives was substantially reduced in sites with Argentine ants over the five month observation period (Fig. 4.3; Table 4.4). Where ants were present just $52.8 \%$ of hives survived (Kaplan-Meier; 95\% C.I. $=41.0$ - 68.1\%) over the 150 days of the study, compared to $89.5 \%(95 \%$ C.I. $=83.3-96.2 \%)$ in sites without ants (Fig. 4.3). Argentine ant presence was negatively associated with hive survival (Cox regression; $\beta=1.74 \pm 0.39$ S.E., 
$\exp (\beta)=5.68, p<0.001)$. Some variation in hive survival was observed between sites (Table 4.4).

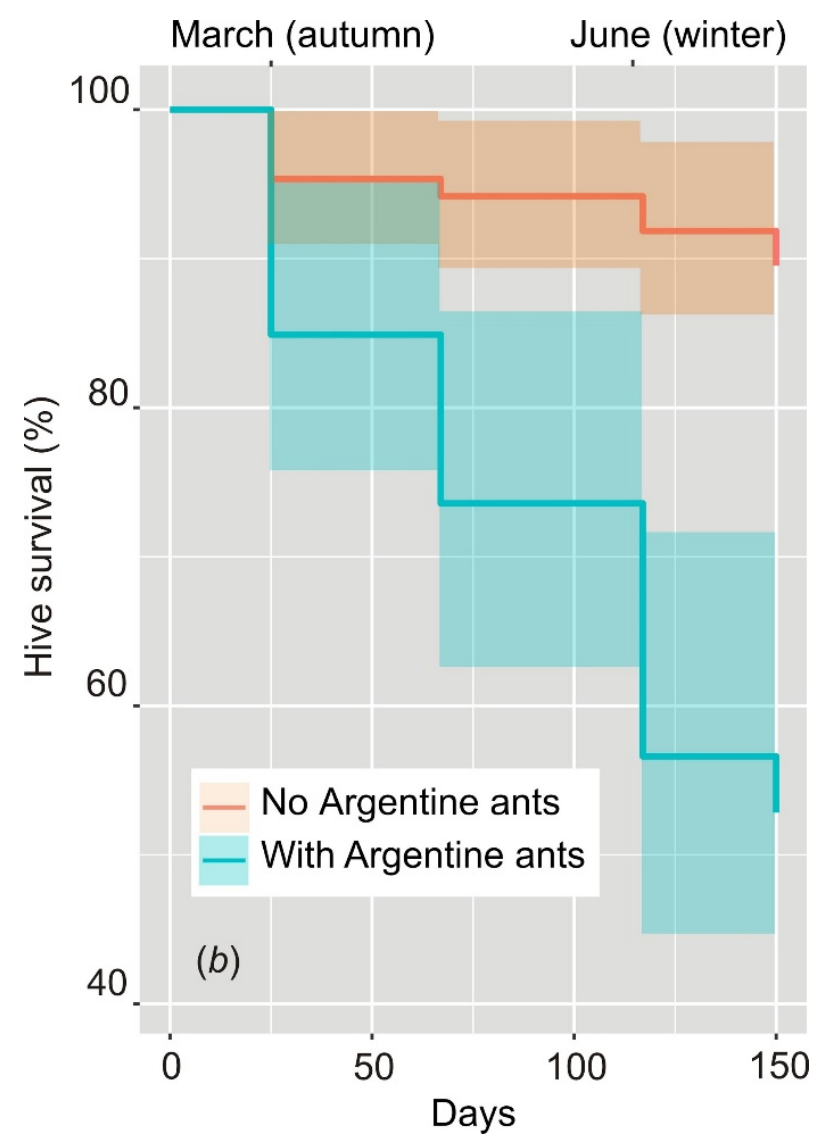

Fig. 4.3. Kaplan-Meier curves for honey bee hives in areas with or without Argentine ants. The coloured area around each line represents a 95\% confidence interval. 


Table 4.4. The Cox regression analysis showing differences in hive survival between
sites. The reference site for this analysis was a site with no Argentine ants. Differences
between sites are likely to have come about due to a range of factors including pesticide
application by beekeepers and different alternative resource availability at the sites for ants
(see also Fig. 4.3).

Likelihood ratio test $=48.9$ on 5 d.f., $P<0.001, \mathrm{n}=139$

\subsubsection{High infection levels associated with ant presence}

Disease is a factor frequently implicated as a cause of honey bee decline (Potts et al., 2010), with DWV cited as a key driver of hive losses (Dainat et al., 2012; Schroeder \& Martin, 2012; McMahon et al., 2016). Recent work has shown Argentine ants form a reservoir for DWV and the related virus LHUV-1 (Sébastien et al., 2015). Of the two viruses in the ants, significantly more DWV was observed than LHUV-1 $(\mathrm{F}=18.82$; d.f. $=1,52 ; p=0.001)$. Virus abundance in ants varied over time $(\mathrm{F}=6.83$; d.f. $=4,52 ; p=0.002)$ with a species $\times$ time interaction trend in the expected direction $(\mathrm{F}=2.54$; d.f. $=1,52 ; p=0.059)($ Fig $4.4 \mathrm{a})$. This interaction term may indicate competition between viruses within cells of their ant hosts (Carrillo-Tripp et al., 2016).

DWV in honey bees showed considerable variation encompassing several orders of magnitude (Fig 4.4c). The mean DWV infection was always higher in honey bees where Argentine ants were present. However, DWV loads were not significantly different from sites with no Argentine ants (PERMANOVA; $\mathrm{F}=3.85$; d.f. $=1,44 ; p=0.201$ ), but with no effects of time $(\mathrm{F}=0.31 ;$ d.f. $=1,44 ; p=0.877)$ and a species $\times$ time interaction in the expected direction $(\mathrm{F}=$ 2.37; d.f. $=3,44 ; p=0.054)$. If a trend does exist, our lack of a significant result may be attributable to inadequate replication. Despite no significant effects of the Argentine ants on DWV in honey bees, the highest observed infection levels in bees by two orders of magnitude 
were seen at sites with Argentine ants (Fig 4.4c). No LHUV-1 was ever observed in honey bee samples.
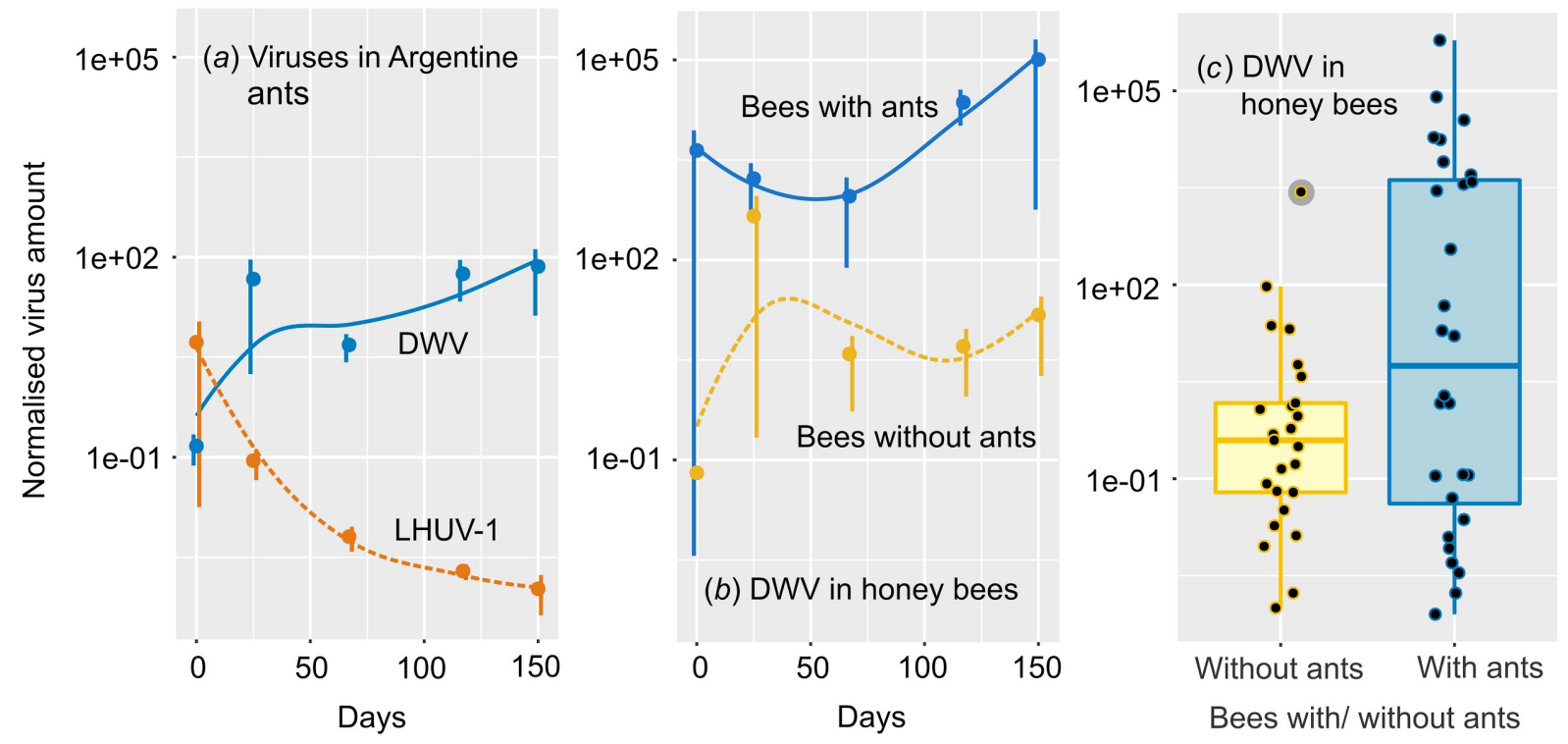

Fig 4.4. Viral loads of (a) Argentine ants, with either Deformed wing virus (DWV) or Linepithema humile virus 1 over time, and (b) DWV in honey bees when Argentine ants are present or absent. Error bars are \pm one standard error. Note the log axes. (c) shows all data for honey bee DWV loads from all sampling times. The boxes show the upper and lower quartiles. Outliers are identified with a grey circle.

\subsubsection{DWV strain diversity}

We detected three different DWV strains from our Sanger sequencing of a 387bp amplicon of a DWV polyprotein gene (Fig. 4.5). The clustering of our New Zealand samples relative to samples from the rest of the world had a high level of bootstrap support. There was some variability in the DWV strains sequenced, however the same strain was found in both Argentine ants and honey bees suggesting that pathogen exchange is possible. 


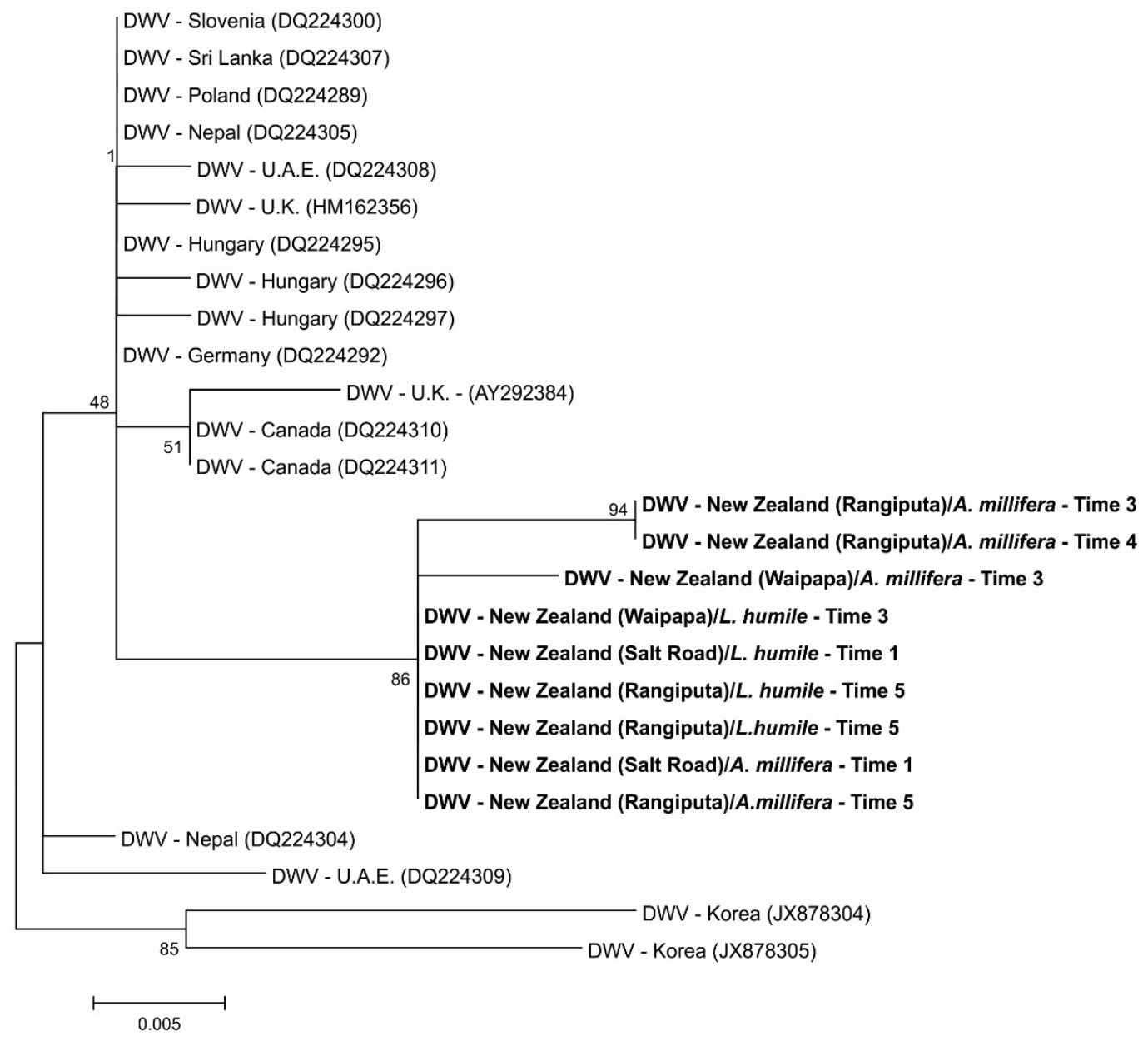

Fig. 4.5. A maximum-likelihood phylogenetic analysis of DWV. This analysis based on a 387 bp sequence of a polyprotein gene with the level of support assessed with 1000 bootstrap replications. DWV accession numbers shown in brackets. 


\subsection{Discussion}

Invasive species and emerging infectious diseases are major threats to global biodiversity, human health and agriculture (Daszak et al., 2000; Jones et al., 2008). Effects of invasive species on ecological communities have previously been considered to be mainly driven by predation and competition. Here we show that Argentine ants may be associated with substantial bee hive mortality and collapse; potentially through direct predation, hive robbing and the introduction of disease (Figs. 4.3-4.4). We observed uncapping of juvenile cells and ant removal of bee pupae, with extremely high densities of ants within hives. The highest observed DWV infection levels by two orders of magnitude were seen at sites with Argentine ants (Fig. 4.4c). However, few sites were investigated in this study and replication was limited. Given this fact, our data are insufficient to support causal claims. However, they suggest interesting patterns that could be better explored with further sampling.

Hives and bees that display lower infection levels may be unlikely to experience virally induced mortality. Most healthy beehives will likely have low to medium viral loads, with extremely high viral titres only occurring briefly prior to colony collapse (Francis et al., 2013). The considerable variation we observed at Argentine ant invaded sites and associated hive mortality soon thereafter, are consistent with this hypothesis. One question to explore is whether the presence of ants weaken the hive making it more vulnerable to infection, or whether disease weakens the hive making it more vulnerable to invasion by ants. It is possible the answer may be both and could be conceptualised as a hive-level 'invasional meltdown'. Argentine ants prey on bee brood and rob honey, thereby weakening the hive and increasing susceptibility to disease. The disease then weakens the hives, which in turn is less able to respond to ant incursions.. Our data demonstrate that DWV is observed in bees at orders of magnitude higher when Argentine ants are present in hives, compared to our study sites with no ants.

Viral replication was confirmed in both honey bee and Argentine ant samples, providing evidence of DWV actively parasitising both species, rather than a passive acquisition. Our maximum likelihood phylogenetic tree demonstrates that the DWV strains analysed in our study form a distinct grouping relative to DWV from around the world (Fig. 4.5).This finding concords with a previous study (Sébastien et al., 2015). Further, Sanger sequencing from PCR assays confirmed an identical DWV strain is parasitising both honey bees and Argentine ants 
(Fig. 4.5). This result provides some evidence suggesting potential pathogen exchange and sharing between ants and honey bees, just as has been observed with pathogen sharing between honey and bumble bees (Fürst et al., 2014). A range of insects can host 'honey bee viruses' (Evison et al., 2012; Levitt et al., 2013; Sébastien et al., 2015; Dobelmann et al., 2017; Gruber et al., 2017; Santamaria et al., 2017). The dynamic we describe may exacerbate the already existing, recognised high risk of disease spillover to managed and native pollinators (Graystock et al., 2013; Murray et al., 2013; Fürst et al., 2014; Manley et al., 2015). When hives are moved, not only do the bees and their pathogens travel, their associated arthropod community and their pathogens travel as well.

If Argentine ants are causing high rates of hive collapse, this could have large potential economic costs. The hive mortality that we observed of up to $50 \%$ represents a significant cost to both beekeepers and horticulturalists. Beekeepers may experience lost income from honey production and pollination contracts, from destroyed or infested hives, and from the need for Argentine ant control via pesticides. Horticulturalists utilising ant-infested hives for pollination could also incur costs in terms of less efficacious pollination services provided by stressed hives. Given the nesting behaviour of the ants within hives, horticulturalists may also be importing a major pest in the form of Argentine ant infestation into their crops creating potential for conflict with beekeepers.

Pollinator contracts require large-scale domestic movement of beehives significant distances to fulfil contractual conditions. Hives are moved for pollination purposes in nearly all countries, including New Zealand. It is clear from previous experience that invasive ants can and do nest in honey bee hives, where they are then moved wherever the bees travel. For instance, in February of 1997, a truck and its cargo of 512 Texan honey bee colonies were inspected at the Californian border. These colonies were found to be infested with the Red Imported Fire Ant (RIFA), Solenopsis invicta, which was not known to be previously established in California. Despite the observation of ants, the hives were allowed to proceed to their destination. Subsequent surveys in the recipient orchard revealed the presence of 18 RIFA colonies, some of which were large and had produced winged reproductive forms for dispersal (Dowell et al., 1997). Similarly, internationally over one million commercially produced bumblebee colonies are traded annually (Velthuis \& van Doorn, 2006). Though some disease monitoring 
requirements do exist for commercial pollinators, these measures may be ineffective (Mutinelli, 2011; Graystock et al., 2013; Murray et al., 2013). One study found that 77\% of internationally transported commercially produced certified "parasite free" bumblebee colonies carry parasites (Graystock et al., 2013).

International trade plays a key role in the global movement of invasive species and emerging infectious diseases (Kobelt \& Nentwig, 2008; Westphal et al., 2008; Hulme, 2009; Yap et al., 2015; Bertelsmeier et al., 2017). Poorly understood pollinator pathogen epidemiology means that regulators are at an information deficit, retarding effective management of disease spread. Unknown consequences and potential for irreversible damage from invasive species and the potential transfer of disease arguably supports the application of a precautionary approach towards management. As part of such an approach we recommend four management strategies. First, ongoing monitoring requirements and movement controls are crucial. Much as other domesticated animals are monitored for disease, honey bees and other commercial pollinators may need to be screened for pathogen presence via sensitive molecular methods. Within viral species such as DWV there are a range of genotypes, some with more harmful effects than others (McMahon et al., 2016). Genetic sequencing is essential to identify highly pathogenic viral biotypes. Secondly, we recommend the internalisation of costs of disease and invasive species spread. Funding could be achieved by levying apiculturists and those contracting for pollination services. Thirdly, a better understanding of pollinator epidemiology is a priority. Future work should investigate pathogen prevalence in arthropods outside the Apis genus, viral life cycles, virulence and disease emergence (Manley et al., 2015). Finally, international cooperation is required. The World Organisation for Animal Health and the International Plant Protection Convention are the two bodies responsible for setting standards to reduce the risk of movement of plants and animals in trade. Emerging infectious diseases of wildlife, including honey bees, requires an international monitoring body with functions synonymous to the World Health Organization (Voyles et al., 2014).

To our knowledge, this is the first study suggesting that a globally widespread invasive ant may be associated with honey bee hive mortality. When observing invasive species interacting with native fauna it is typically concluded that effects are largely via predation and competition. Our data show the relationship may be more complex: honey bee hives impacted in the presence of 
Argentine ants are associated with levels of disease that are orders of magnitude higher than in bees without these ants. Similar results may be observed for other non-native species that become abundant and widespread in their invaded ranges. Emerging infectious diseases are a threat to global biodiversity, human health and agriculture. Our results suggest invasive species may have a significant role in disease dynamics, representing a hidden, but possibly substantial global ecological cost. 


\section{Chapter 5: The origins of global invasions of the German wasp (Vespula germanica) and its infection with four honey bee viruses}

\subsection{Abstract}

A successful control or eradication programme using biological control or geneticallymediated methods requires knowledge of the origin and the extent of wasp genetic diversity. Mitochondrial DNA variation in the native and invaded range of the social wasp Vespula germanica was used to examine intra-specific genetic variation and invasive source populations. We also examined wasps for the presence of honey bee viruses. German wasps showed reduced genetic diversity in the invaded range compared to that of their native range. Populations in the introduced range are likely to have arrived from different source populations. All four viral honey bee pathogens assayed for were found in $V$. germanica, although they varied in their distribution and strain. Multiple introductions have occurred for most invaded regions, though some populations are genetically homogenous. The differing locations of origin will guide researchers searching for biocontrol agents. Reduced genetic diversity makes these wasps a potential target for control via gene drives. Vespula germanica is capable of carrying honey bee pathogens that may directly affect wasp fitness or influence other hostpathogen interactions - including in honey bees.

\subsection{Introduction}

Many authors have lamented the difficulty of controlling well-established biological invasions (Silverman \& Brightwell, 2008; Hoffmann, 2011; Dearden et al., 2017). Eradication of invasive species is a frequently-sought ideal but is even more difficult than control, particularly in the case of plants and animals with short generation times, high reproductive output and effective dispersal (Rejmánek \& Pitcairn, 2002). Current and historical approaches to control or eradication typically utilise chemical or mechanical methods such as herbicides, pesticides, lethal baits or mechanical removal. These methods are expensive as they require ongoing investment, and can result in environmental contamination as well as non-target effects (Bergstrom et al., 2009). Another approach is the implementation of classical biological control, which involves the introduction of a co-evolved natural enemy from the native range into the area that the invasive pest now occupies. Central to the efficacy of classical biological approaches is a knowledge of the home range of the pest species (Goolsby et al., 2006; Lester et al., 2014a). Many invasive species, however, have a broad geographic range. Determining 
the precise origin of invasive species is possible with genetic techniques, such as the use of mitochondrial DNA (mtDNA) (Corin et al., 2007; Lester et al., 2014a).

New genetic technologies, such as CRISPR/Cas9 gene drive systems, have the potential to revolutionise the control and eradication of invasive species (Esvelt et al., 2014; Webber et al., 2015). Gene drives are genetic systems that push engineered genes through target populations far faster than possible through natural inheritance (Burt, 2003). The CRISPR/Cas9 system is highly specific as the enzyme Cas9 can target precise sequences of DNA, guided by a short guide RNA (gRNA) sequence. This gRNA can be designed to target precise sequences in the genome to be edited. For the purposes of invasive species control or eradication this process could be used to drive deleterious target alleles to fixation. Deleterious mutations affecting individual fitness may be nuclear or mitochondrial in origin (Dowling et al., 2015; Hammond et al., 2016).

The German wasp (Vespula germanica) is a social species native to Eurasia (Archer, 1998). It has become invasive in several countries around the world including Argentina, Australia, New Zealand and South Africa (Beggs et al., 2011). Along with the closely related Vespula vulgaris, $V$. germanica has been indicted one of the most widespread and damaging of all invasive Vespidae globally and the species are a critical issue for entomology in New Zealand (Beggs et al., 2011; Lester et al., 2014b). New Zealand has the highest recorded Vespula densities in the world, with up to 370 wasps per $\mathrm{m}^{2}$ of tree trunk (Moller et al., 1991). Introduced Vespula wasps have a variety of environmental, economic and social impacts. For instance, in New Zealand the economic costs of Vespula wasps are estimated to be approximately $\$ 130$ million each year (MacIntyre \& Hellstrom, 2015). The biomass of wasps in New Zealand honeydew beech forests is estimated to be similar to, or greater than, the entire biomasses of birds, rodents and stoats in the forest area (Thomas et al., 1990). In several countries Vespula impacts and abundance have stimulated varying degrees of management, using chemical, mechanical and biocontrol techniques (Wood et al., 2006; Beggs et al., 2008; Edwards et al., 2017). However, currently utilised control options are untenable over large areas of many hundreds of thousands of hectares, as they are typically chemical based and require ongoing investment (Dearden et al., 2017). The biology and distribution of Vespula wasps mean they are likely to be amenable to control through systems such as CRISPR/Cas9 directed gene drives (Dearden et al., 2017). 
A first step in this class of genetically-mediated approaches for control or eradication of invasive species is to identify the genetic diversity in the home and invaded range of the invasive species to be targeted (Dearden et al., 2017).

Natural enemies, such as pathogens, can have major impacts on the fitness, abundance and distribution of plants and animals. These effects may be particularly detrimental for social animals due to high host density and social interactions (Anderson \& May, 1979; Potts et al., 2010). In the case of social insects, pathogen effects can be even more pronounced as these insects often spend many generations living in fixed nesting sites. Perhaps the most well-known example of the influence of social insect pathogens is their effect on honey bees. Among pathogens, viruses appear to play a key role in causing honey bee losses (Schroeder \& Martin, 2012; McMahon et al., 2016). There have been a wide variety of pathogens observed in wasps (Evison et al., 2012), including Deformed wing virus (DWV) (Santamaria et al., 2017), which has been implicated as a key driver of honey bee colony collapse (Dainat et al., 2012; McMahon et al., 2016). Kashmir bee virus has recently also been observed in wasps (Dobelmann et al., 2017) although its pathogenicity is uncertain. Given that wasps carry a range of pathogens, one approach to genetically-mediated control could be altering or blocking wasp immune responses; as has been demonstrated in silver whitefly (Bemisia tabaci) (Zhang et al., 2017). However, pathogens or key pathogen strains affecting fitness may also be absent in the invaded range, as suggested by enemy release hypothesis (Keane \& Crawley, 2002). An understanding of pathogen distributions could be central to both genetic and biological control methods.

Our first aim in this study was to use sequence variation in mtDNA to estimate the home range of global invasions of $V$. germanica and elucidate genetic diversity in the invaded range. Specifically, we examined invasive populations in Argentina, Australia, New Zealand and South Africa; as well as the possible home range of Europe. Our second aim was to survey wasps from throughout these ranges for the presence of Acute bee paralysis virus (ABPV), Deformed wing virus (DWV), Israeli acute paralysis virus (IAPV) and Kashmir bee virus (KBV). 


\subsection{Methods}

\subsubsection{Samples}

Wasps used in this study were gathered by contacting researchers in the native and invaded range, or by scientists opportunistically sampling foragers while travelling. Individual worker samples were either freshly collected for this study, or were preserved specimens (Fig. 5.1; Table App.1). In instances where wasps were collected from nests only a single worker from that nest was used in our analysis. Although we collected samples from a broad distribution, we note we will have under-sampled genetic diversity in some areas. Samples were collected alive and immediately stored in $95 \%$ ethanol, followed by storage at $-20^{\circ} \mathrm{C}$ as soon as possible after collection. 


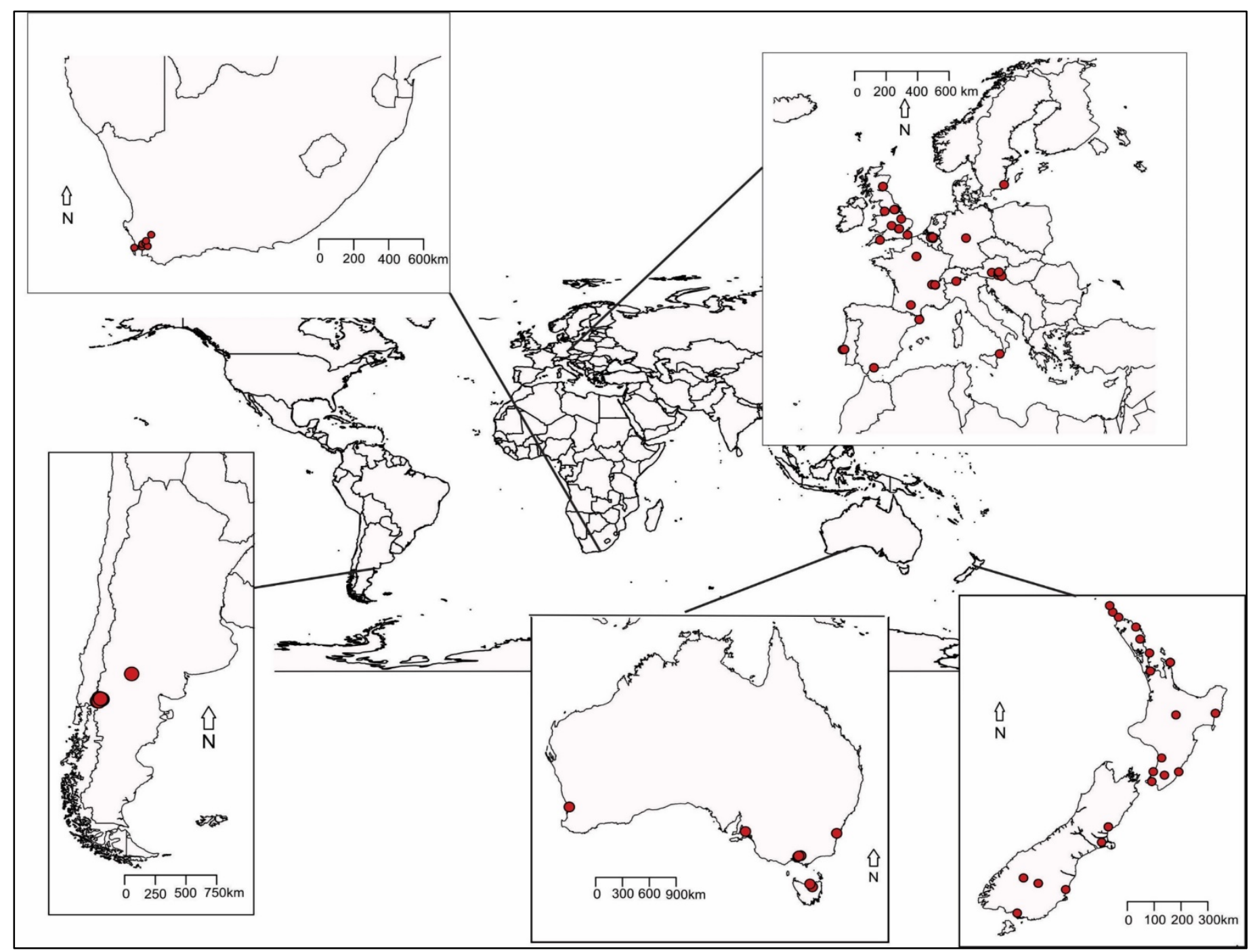

Fig. 5.1. Origin of the Vespula germanica samples used in this study. 


\subsubsection{Wasp phylogenetic relationships}

In order to elucidate the phylogenetic relationship between wasps sampled, as well as the prevalence of viral pathogens, we sequenced PCR products from DNA and RNA extracted from wasp workers sampled throughout these ranges (Fig. 5.1). DNA and RNA was extracted by bead-beating (BeadBeater 16, Biospec Products, USA) entire wasps in GENEzol reagent (Geneaid, Taiwan) and 5\% $\beta$-mercaptoethanol followed by chloroform and isopropanol purification. DNA concentrations were quantified with a NanoDrop spectrophotometer (NanoDrop/ThermoFisher Scientific, USA). $1 \mu \mathrm{g}$ /sample was used for cDNA synthesis using qScript XLT SuperMix (Quantabio, USA). Extraction products were stored at $-80^{\circ} \mathrm{C}$.

For the phylogenetic analysis we used PCR to amplify portions of the mitochondrial loci cytochrome oxidase I (CO1), cytochrome oxidase II (CO2) and cytochrome b (cytb). The mitochondrial primers were: CO1: C1-J-1718 (Sid) 5' GGA GGA TTT GGA AAT TGG CTT ATT CC-3' and C1-N-2191 (Nancy) 5' CCC GGT AAA ATT AAA ATA TAA ACT TC - 3' (Simon et al., 1994) as well as COlb C1-1901 5' TAC CAG TTC TTG CAG GAG CAA T 3' and C1-2820 5' GTG GCG TAA GGA ATT TGT TCA-3' (Dobelmann et al., 2017); CO2 C22604 5’ ATC TGG TTT TCC TCG ACG ATA CT - 3' and C1-3437 5' TAC GTC CAG GGG TAG CAT CA- 3' (Dobelmann et al., 2017); cytb: CB1 50- TAT GTA CTA CCA TGA GGA CAA ATA TC-30 and CB2 50- ATT ACA CCT CCT AAT TTA TTA GGA AT-30 (Simon et al., 1994). Each 15- $\mu 1$ PCR reaction consisted of: 1 x PCR buffer, $0.4 \mathrm{mg} / \mathrm{mL}$ bovine serum albumin (BSA), 200 um of each dNTP, 0.4um of each primer and 0.1 unit of taq DNA polymerase (Thermofisher). Thermal cycling conditions for the primer sets were as follows: Sid/Nancy (CO1) and CB1/CB2 (cytb): Initial denaturation at $94^{\circ} \mathrm{C}$ for $2 \mathrm{~min}$, followed by 40 cycles of denaturing at $94^{\circ} \mathrm{C}$ for $30 \mathrm{~s}$, annealing for $40 \mathrm{~s}$ at $45^{\circ} \mathrm{C}$ and extension at $72^{\circ} \mathrm{C}$ for 1 min, followed by a final extension at $72^{\circ} \mathrm{C}$ for $10 \mathrm{~min}$. $\mathrm{CO} 1 \mathrm{~b}$ and $\mathrm{CO}$ : Initial denaturation at $94^{\circ} \mathrm{C}$ for $2 \mathrm{~min}$, followed by 35 cycles of denaturing at $94^{\circ} \mathrm{C}$ for $30 \mathrm{~s}$, annealing for $30 \mathrm{~s}$ at $47^{\circ} \mathrm{C}$ and extension at $72^{\circ} \mathrm{C}$ for $1 \mathrm{~min}$, followed by a final extension at $72^{\circ} \mathrm{C}$ for $10 \mathrm{~min}$. All PCR assays were run using positive and negative controls.

Amplified products were purified using ExoSAP-IT (Affymetrix) and sequenced directly using Sanger sequencing by Macrogen Korea. Mitochondrial DNA was sequenced from 112 samples. We manually checked for quality, edited and aligned the sequences using MEGA7 
(Kumar et al., 2015). We used BLASTn searches of the NCBI (Genbank) nucleotide (nr) database to confirm the authenticity of our 112 samples as $V$. germanica. The same method was followed for the outgroup species of $V$. vulgaris.

For our phylogenetic analysis we assessed the CO1 (1372 bases), CO2 (172 bases) and cytb (413 bases) datasets separately and as a concatenated dataset (1957 bases; note that there was overlap between some primer pairs). To determine the most appropriate model of sequence evolution we used Bayesian Information Criterion (BIC) scores derived in MEGA7, which also estimated base frequencies, substitution rates, the proportion of invariable sites (I) and the uniformity of substitution rates among sites (G) (Table App. 2). The models of evolution selected as best-fitting were slightly different across the three datasets, but the best-fitting model for the concatenated mtDNA dataset also ranked among the four best models for the CO1, CO2 and cytb datasets using BIC and Akaike information criterion scores (Table App. 2). Therefore, we considered the patterns of sequence evolution to be comparable and used the Hasegawa-Kishino-Yano (HKY) (Hasegawa et al., 1985) model in our phylogenetic analyses. Our selected model and its parameters were then used to build a maximum composite likelihood tree. The level of support for this tree was assessed using 1000 bootstrap replicates. MEGA7 was also used to calculate percentage genetic distance and standard errors (S.E) among groups of individuals.

The relationship between mitochondrial haplotypes and regions of origin were visualised by creating a spatially structured haplotype network in the package TempNet (Prost \& Anderson, 2011) using $\mathrm{R}$ version 3.2.2 (R Core Development Team 2017). We grouped samples into six geographic regions. United Kingdom (England, Scotland), Europe (Austria, Belgium, France, Germany, Italy, Portugal, Spain, Sweden, Switzerland), Argentina, Australia, New Zealand and South Africa. The United Kingdom was separated from Europe for two reasons: First, it is geographically separated from mainland and second given historical patterns of trade we thought it the most likely origin of New Zealand's wasp populations. To investigate the closest genetic relationships of samples from individual regions to our invaded regions (Argentina, Australia, South Africa and New Zealand), we used a maximum composite likelihood model (Tamura et al., 2004). The analysis was conducted in MEGA7. 
The R package vegan was used to perform the rarefaction analysis (Oksanen et al., 2016).

\subsubsection{Viral infection and diversity}

We used PCR to detect the presence or absence of viruses in all 112 samples used in this study. The primers used were: Deformed wing virus: DWV 1848f 5' TAA CAA CTC AGC GAG ATC CT-3' and DWV 2364r 5' GTA GTC CAA TCT GGC ACA AT-3' (Berényi et al., 2007); Dicistroviridae complex: Acute bee paralysis virus/Israeli acute paralysis virus/Kashmir bee virus: 6201f 5' AAT TGG TGT CGA GGA GGA CT-3' and 6844r 5' ATG AGA ACG GGG CGT TGT AG-3' (Gruber et al., 2017). We used the same DNA/RNA extractions as were used for the mtDNA analysis. PCR recipes were also identical. Cycling conditions for DWV amplicons were $94^{\circ} \mathrm{C}$ × $2 \mathrm{~min}$, followed by 37 cycles $94^{\circ} \mathrm{C}$ for $30 \mathrm{~s}$ denaturing, annealing at $55^{\circ} \mathrm{C}$ for $50 \mathrm{~s}$, and extension at $72^{\circ} \mathrm{C}$ for $1 \mathrm{~min}$, with a final extension step of $72^{\circ} \mathrm{C}$ for $7 \mathrm{~min}$. Dicistroviridae cycling conditions were: Initial denaturing of $94^{\circ} \mathrm{C}$ for $2 \mathrm{~min}$, followed by 35 cycles of $94^{\circ} \mathrm{C}$ for $30 \mathrm{~s}$ denaturing, annealing at $60^{\circ} \mathrm{C}$ for $45 \mathrm{~s}$, and extension at $72^{\circ} \mathrm{C}$ for $1 \mathrm{~min}$, with a final extension step of $72^{\circ} \mathrm{C}$ for $10 \mathrm{~min}$. All assays were run using positive and negative controls. Amplified products of virus-positive PCR assays were purified and sequenced in the same manner as mtDNA samples $(n=22)$.

For our phylogenetic analysis of viral strain diversity, we assessed a structural polyprotein gene (330 bases). We used the same process to estimate the appropriate model of sequence evolution as the wasp phylogenetic relationships (Table App. 3 - App.4).

\subsection{Results}

\subsubsection{Wasp phylogenetic relationships}

Our sequencing revealed 36 unique $V$. germanica haplotypes among the 112 samples collected for this study across the native and invaded range (Fig. 5.2, Table 5.1). Our maximum composite likelihood model revealed overall genetic similarities between certain populations (Fig. App.1, Table App.5). In particular, the samples from New Zealand, Australia and the United Kingdom shared a number of haplotypes and the populations were most closely related to each other (Fig. 5.2, Fig 5.3. Fig. App.1, Table App.5). Only two haplotypes were detected from the 33 New Zealand specimens (Fig. 5.2, Table 5.1); one was common $(n=31)$ and one 
rare $(n=2)$. The common haplotype was an exact match to the most common haplotype in the United Kingdom. The rare wasp haplotype was only found in Auckland and is genetically similar to populations from central Europe (Fig. 5.2, Fig. 5.3).

Three haplotypes were sampled from the 11 Australian specimens. The most common $(n=$ 7/11) was the most frequently found haplotype in New Zealand and the United Kingdom (Fig. 5.2). The second haplotype ( $n=1 / 11)$ clustered with samples from the United Kingdom in our maximum composite likelihood phylogenetic analysis (Fig. 5.2, Fig. 5.3). While the third haplotype $(n=3 / 11)$ was only found in Western Australia and was an exact match to samples from central Europe.

The Argentinian population sampled only contained one haplotype which was also found in a wasp from the south of France, near the border of Spain. This population therefore clustered within Europe and most closely with French samples (Fig. 5.2, Fig. 5.3, Fig. App.1).

The home range of Europe was the most genetically diverse region sampled. A total of 31 specimens from nine countries revealed 20 unique haplotypes. Exact matches to European haplotypes were found in Argentina and Australia; but surprisingly not the United Kingdom (Fig. 5.2). We sampled nine specimens in South Africa, revealing a total of four unique haplotypes. None of these proved an exact match to our samples from Europe. However, our maximum likelihood phylogenetic analysis places them with samples from mainland Europe (Fig. 5.3; Fig App.1). 
Table 5.1. Summary of number of $V$. germanica specimens sampled and the unique haplotypes found in each range.

\begin{tabular}{|l|l|l|}
\hline Region & Specimens sampled & Unique haplotypes \\
\hline Europe & 31 & 20 \\
\hline United Kingdom & 16 & 6 \\
\hline Australia & 11 & 3 \\
\hline New Zealand & 33 & 2 \\
\hline Argentina & 12 & 1 \\
\hline South Africa & 9 & 4 \\
\hline Totals & $\mathbf{1 1 2}$ & $\mathbf{3 6}$ \\
\hline
\end{tabular}




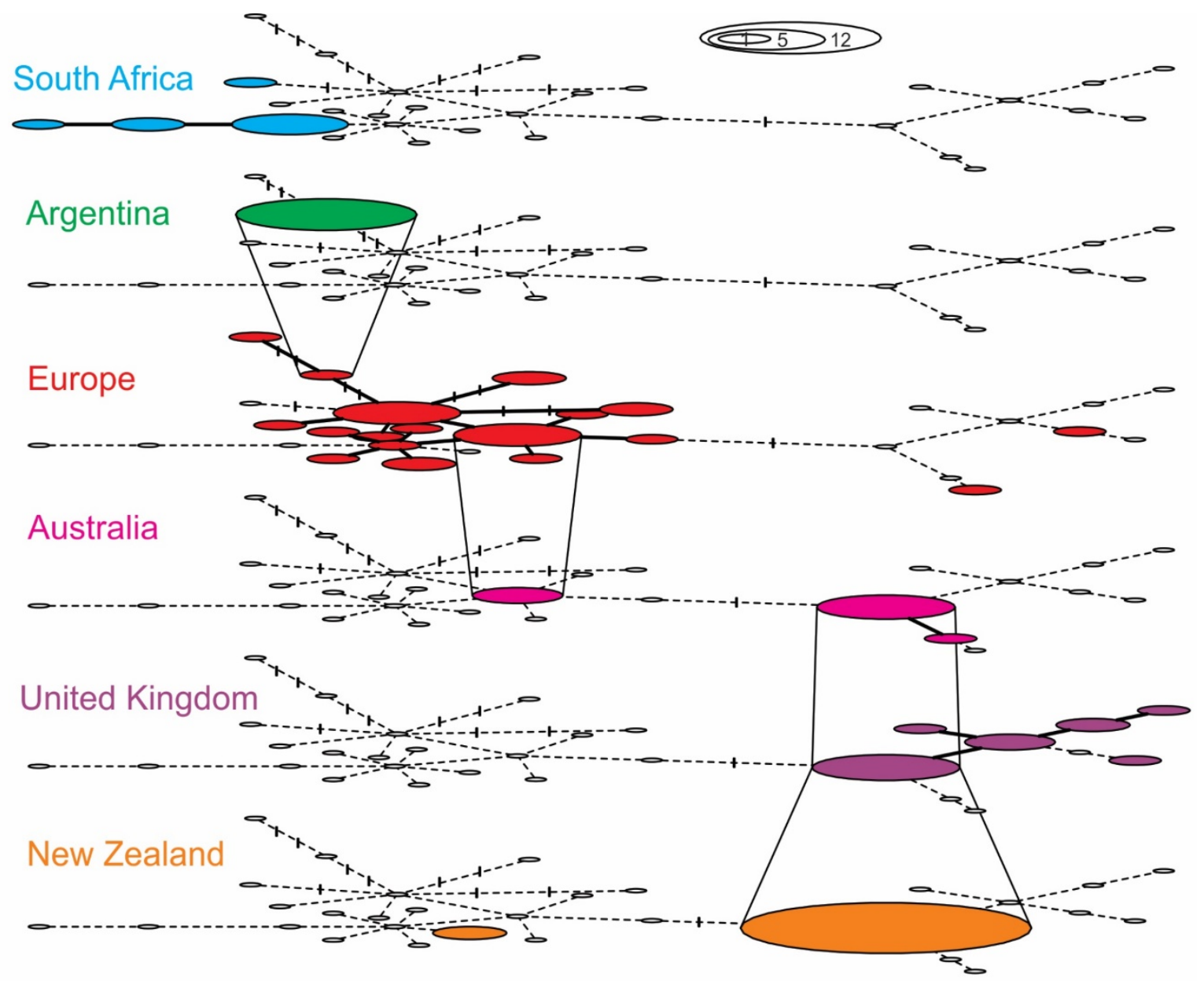

Fig. 5.2. Spatially structured haplotype network of Vespula germanica constructed in

TempNet. Lines between haplotype groups in adjacent layers indicate identical haplotypes between the groups. Filled ellipses indicate a positive sample and the relative number of samples for each haplotype. Empty ellipses show the absence of a haplotype in a particular region. Each point along the lines between haplotypes indicates base substitution. Regional groupings are: South Africa $(n=9)$, Argentina $(n=12)$, Europe (Austria, Belgium, France, Germany, Italy, Portugal, Spain, Switzerland, Sweden, $n=31)$, Australia $(n=11)$, United Kingdom (England, Scotland, $n=16)$, New Zealand $(n=33)$. 


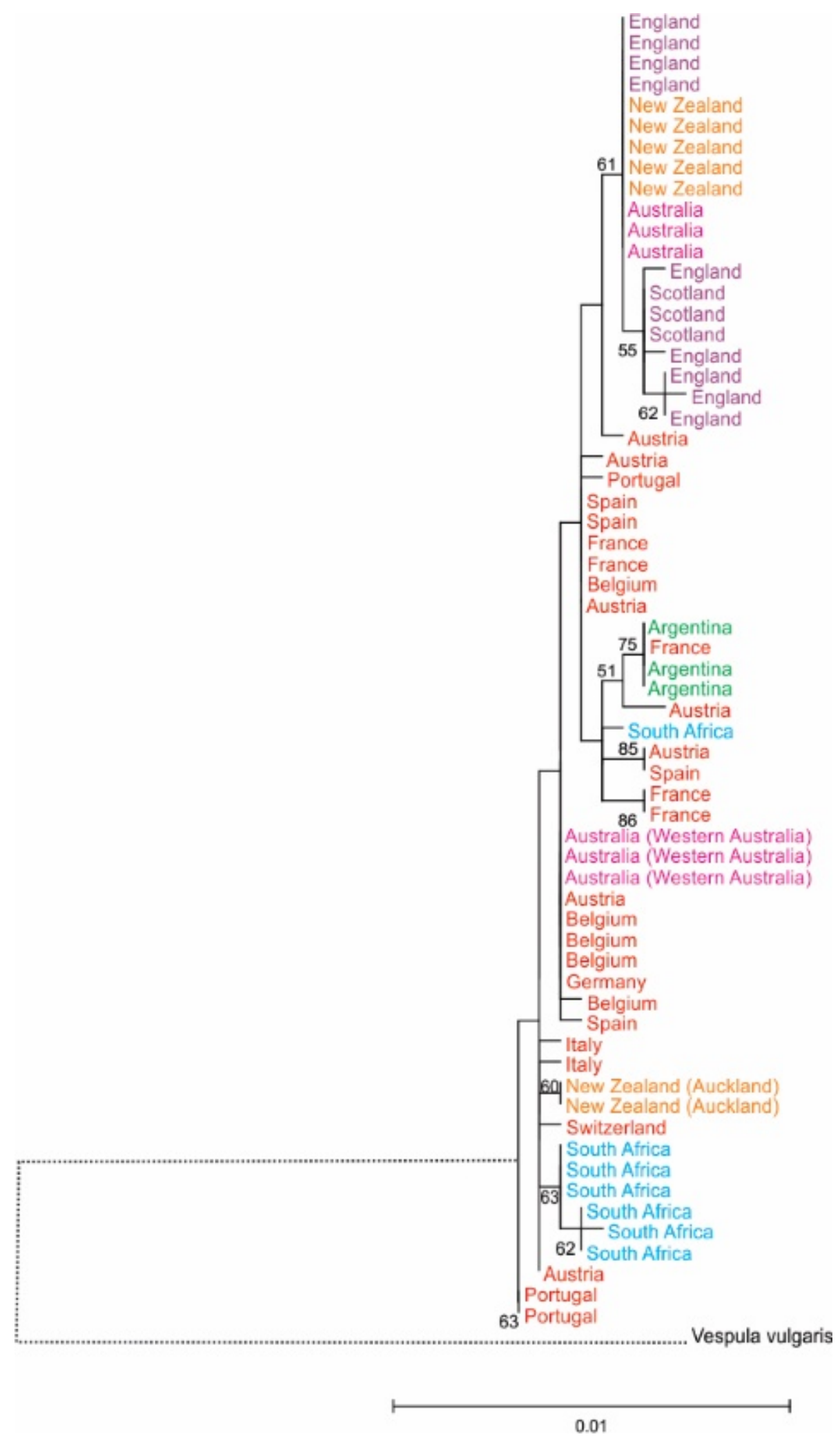

Fig. 5.3. Maximum composite likelihood tree for Vespula germanica sampled throughout the native and introduced range. $V$. vulgaris was used to root the evolutionary tree. The tree was based on 1000 bootstraps of a Hasegawa-Kishino-Yano model using a concatenated dataset of CO1, CO2 and $c y t b$ mt DNA sequences. Colours identify different regional groupings (see Fig. 2) The line connecting the outgroup $V$. vulgaris is not to scale. 
We performed a rarefaction analysis (Fig. 5.4), which suggests we have sampled much of the genetic diversity in Argentina, New Zealand and potentially Australia. Conversely, South Africa, the United Kingdom, and especially Europe likely have haplotypes that have not been sampled (Fig. 5.4); which may explain the lack of matches to haplotypes in South Africa and the United Kingdom. Our data suggest the native range of Eurasia harbours more genetic variability than the introduced range (Fig. 5.4, Table 5.1).

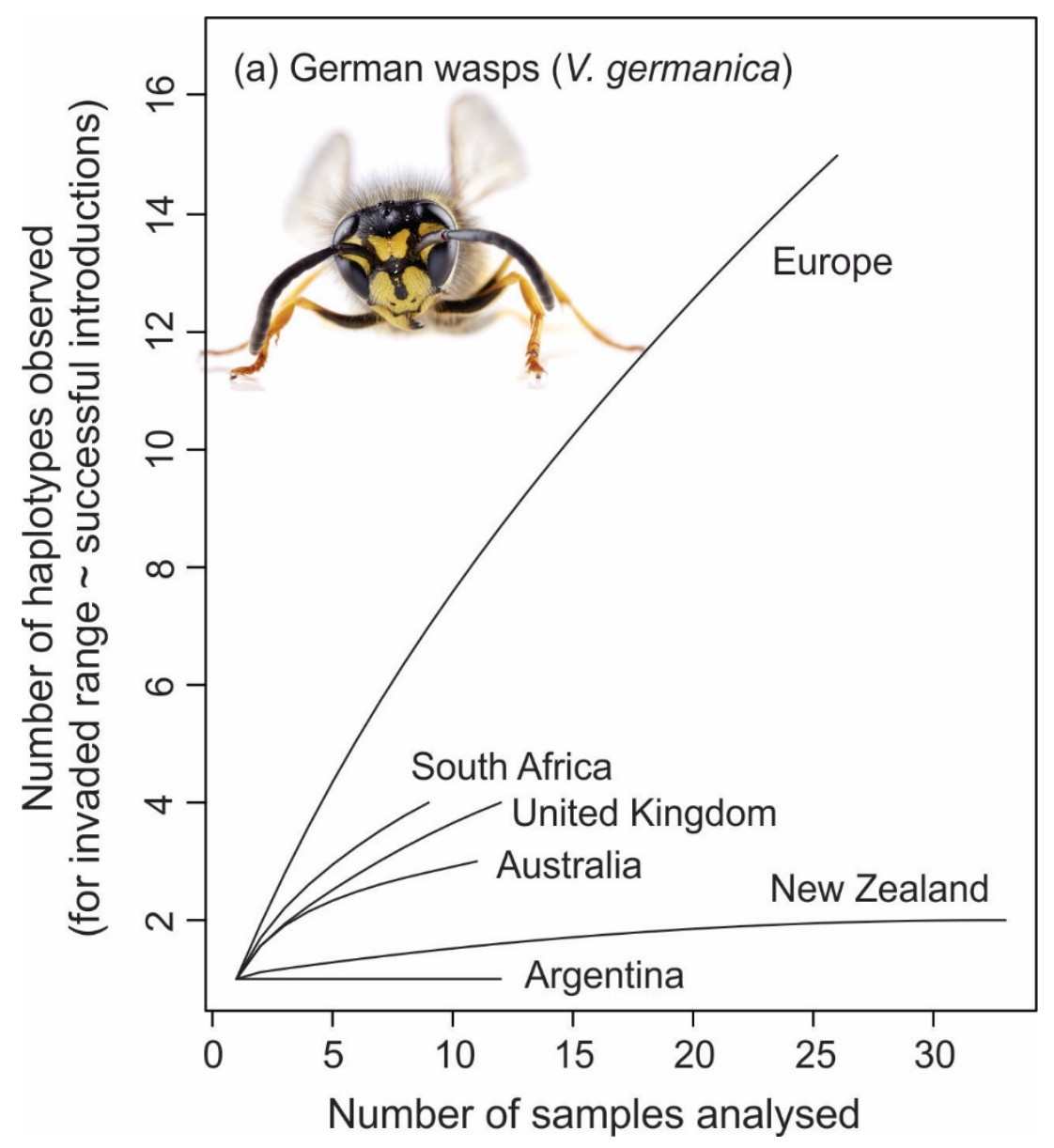

Fig. 5.4. Haplotype discovery curves from the six population areas sampled. These curves show that the full diversity of haplotypes was likely sampled from New Zealand and Argentina and Australia. Full haplotype diversity was not captured from the three other populations. 


\subsubsection{Wasp virus pathogen presence}

Three viruses in the Dicistroviridae family were observed: the Acute bee paralysis virus (ABPV), the Kashmir bee virus (KBV), and the Israeli acute paralysis virus (IAPV). ABPV presence in $V$. germanica was confirmed only in the United Kingdom $(n=5 / 16)$. Percentage cover of sequences was $100 \%$ with identity of $96-99 \%$. The phylogenetic analysis demonstrated that the ABPV sequences from the United Kingdom were more closely related to each other than to global sequences from GenBank (Fig. 5.5). Our sampling revealed that each of the five positive samples of ABPV were distinct viral genotypes (Fig. 5.5). KBV presence was confirmed in New Zealand $(n=5 / 33)$ and England $(n=1 / 16$. Percentage cover of sequences was $100 \%$ with identity of $96-99 \%(n=6)$. These samples had a comparatively low strain diversity with only two KBV genotypes sampled. Four of the New Zealand samples and one English sample were the same haplotype; while the second haplotype was discovered once in Northland, New Zealand (Fig. 5.5). IAPV presence was only confirmed once $(n=$ 1/31) in a sample from France, which was part of our European population. Percentage cover of the sequence was $99 \%$ with identity of $98 \%$. Our sequence formed a distinct branch relative to the ABPV and KBV samples (Fig. 5.5).

We detected Deformed wing virus (DWV) which is in the Iflaviridae family. DWV was present in $V$. germanica in New Zealand $(n=8 / 33)$ and Europe $(n=3 / 31)$. Percentage cover of sequences was $100 \%$ with identity of $97-99 \%$ in all cases $(n=11)$. The positive sequences from New Zealand clustered with other New Zealand samples (Fig. 5.6). Positive European samples clustered with other samples from central Europe; although the relationships within Europe were poorly resolved (Fig. 5.6). Across the two populations only two samples showed evidence of co-infection with these any of these viruses. The first was a French sample, which was positive for both DWV and IAPV; the second a New Zealand sample which was positive for both DWV and KBV.

No samples testing-positive for the viruses assayed for were collected in Argentina $(n=0 / 11)$ Australia $(n=0 / 11)$ or South Africa $(n=0 / 9)$. Viral presence and absence data are summarised in Table 5.2. 


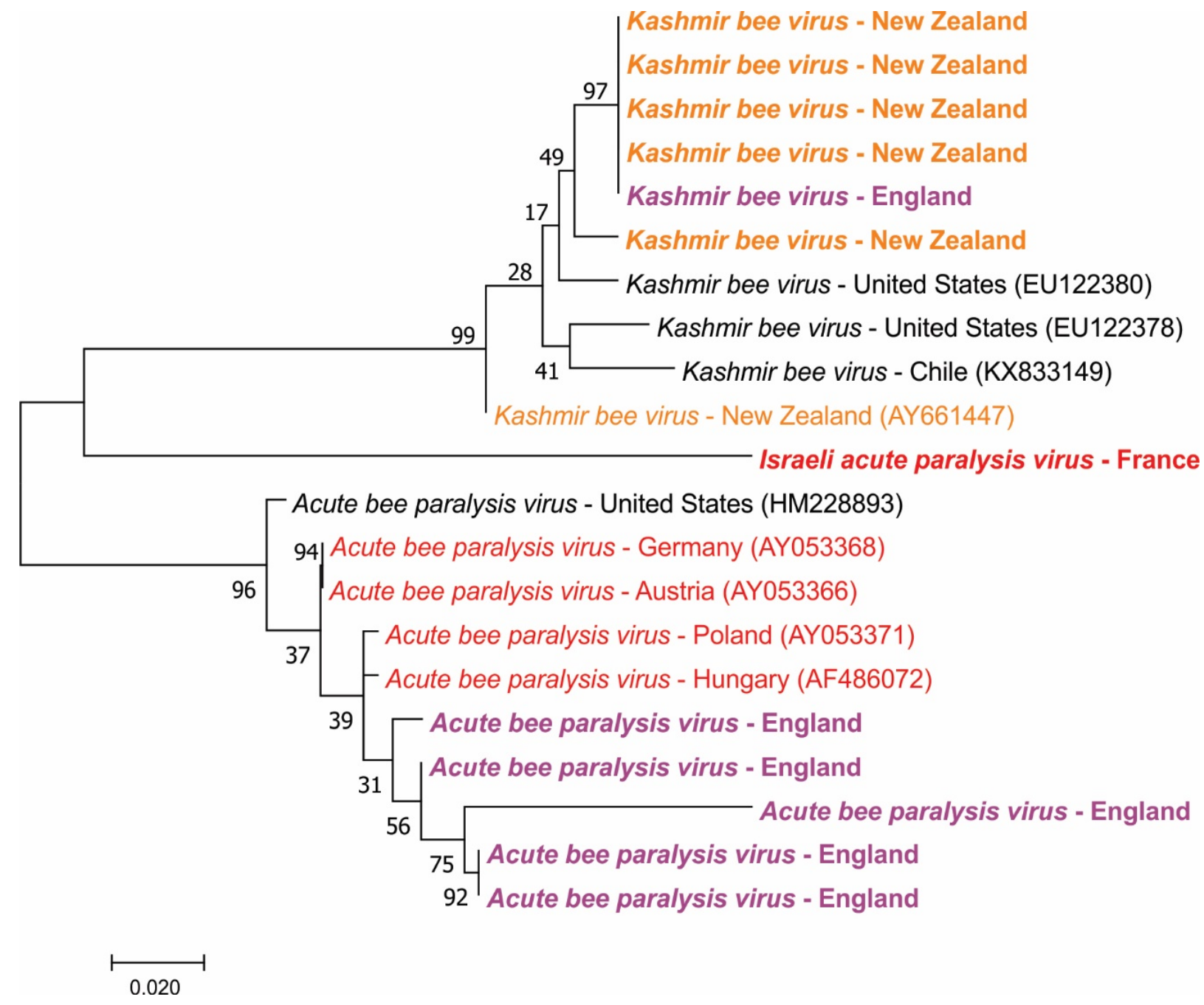

Fig. 5.5. Maximum composite likelihood tree for Dicistroviridae sequences sampled, as well as samples from utilised from GenBank. The tree was based on 1000 bootstraps of a Kimura-2 parameter model. Samples in bold are from this study. Colours indicate geographic origin (see Fig. 5.3) 


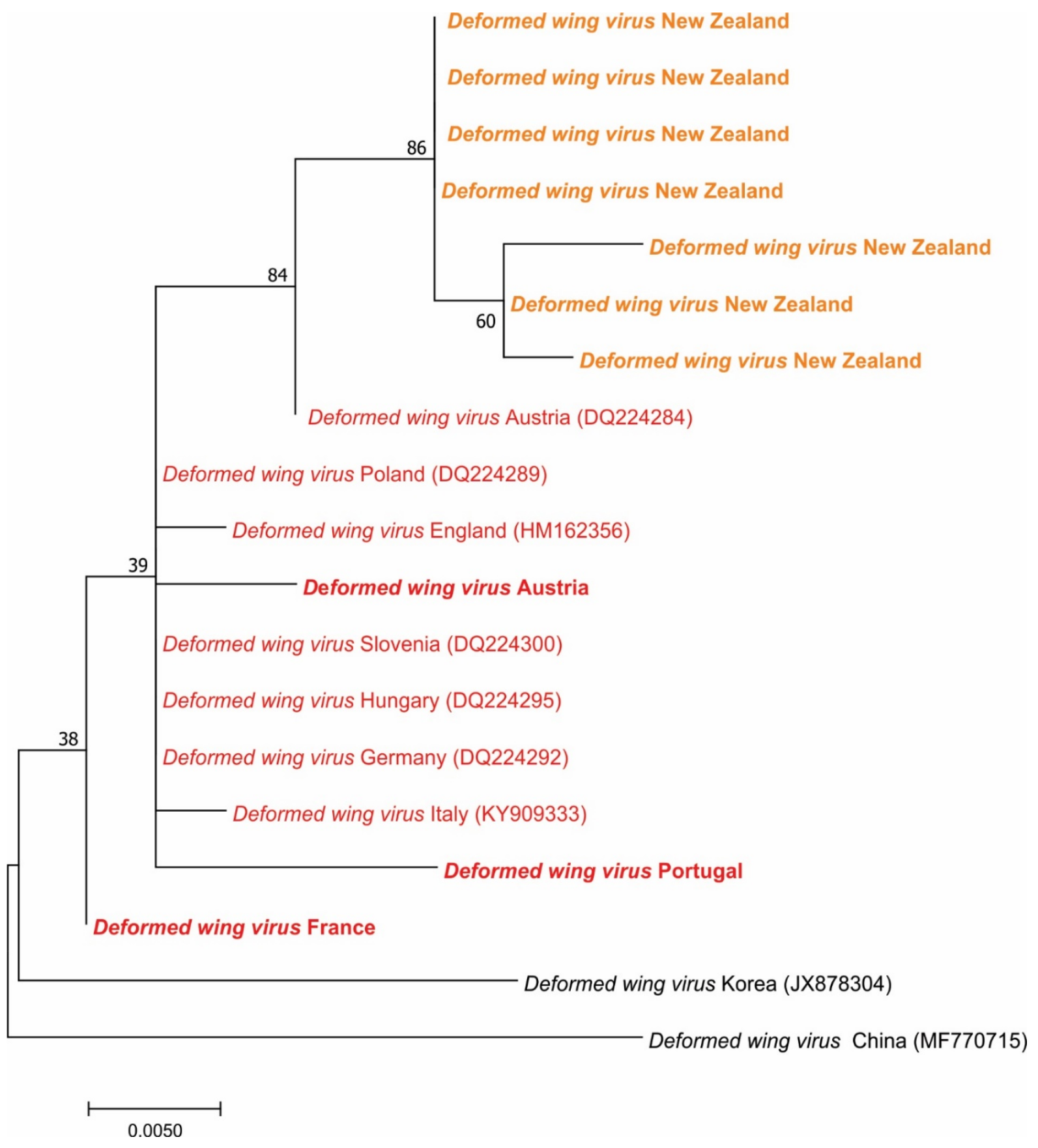

Fig. 5.6. Maximum composite likelihood tree for DWV sequences sampled, as well as samples from utilised from GenBank. The tree was based on 1000 bootstraps of a Kimura-2 parameter model. Samples in bold are from this study. Colours indicate geographic origin (see Fig. 5.3) 


\begin{tabular}{|c|c|c|c|c|c|c|}
\hline \multirow[b]{2}{*}{ Virus } & \multicolumn{6}{|l|}{ Region } \\
\hline & Argentina & Australia & Europe & $\begin{array}{l}\text { New } \\
\text { Zealand }\end{array}$ & $\begin{array}{l}\text { South } \\
\text { Africa }\end{array}$ & $\begin{array}{l}\text { United } \\
\text { Kingdom }\end{array}$ \\
\hline ABPV & - & - & - & - & - & $31 \%$ \\
\hline DWV & - & - & $10 \%$ & $24 \%$ & - & - \\
\hline IAPV & - & - & $3 \%$ & - & - & - \\
\hline $\mathrm{KBV}$ & - & - & - & $15 \%$ & - & $6 \%$ \\
\hline
\end{tabular}

\subsection{Discussion}

A first step in utilising biological control or technologies such as CRISPR/Cas9 gene drive systems for the control or eradication of invasive species is knowledge of the genetic diversity of populations in the native and invaded range (Dearden et al., 2017). Entrainment in an invasion pathway may lead to reduced genetic diversity in founding populations (Tsutsui et al., 2000; Corin et al., 2007; Lester et al., 2014a). Genetic diversity may be especially reduced where invasive populations are extremely geographically distant. Our first aim in this study was to use variation in mtDNA to estimate the home range of global invasions of $V$. germanica and elucidate genetic diversity in the invaded range. The three mitochondrial genes investigated suggest high levels of genetic diversity in the home range of Europe (Fig. 5.2, Table 5.1). We sampled 31 wasps from their European range and found 20 haplotypes. Indeed, it is likely that we under-sampled genetic diversity in this region (Fig. 5.4). Our sampling showed that, from this data, wasps in Europe are genetically diverse and appear to lack the clear haplotype boundaries found in the invaded populations.

We demonstrate reduced genetic diversity in each of the four invaded ranges (Fig. 5.2, Table 5.1). Our data have captured the likely donor regions to the invaded ranges (Table 5.3). However, the resolution with which we can pinpoint areas of origin varies. Our results from sampling of the invaded range indicates that the southern hemisphere invasions of this species may have potentially diverse origins (Table 5.3). Ultimately, however, they largely match haplotypes found in Western Europe (Fig. 5.2, Fig. 5.3, Fig. App. 1, Table A5). As German wasp nests are founded by a single queen and mtDNA is maternally inherited, the presence of 
several mitochondrial haplotypes in a region indicates the successful introduction and establishment of multiple queens. Vespid wasp queens have been found to hibernate in an array of human commodities and structures such as, under roofing eaves, within wood piles and inbetween books in shelves (personal observations). Given findings of long-range intra-country movement of Vespid wasps by humans (Crosland, 1991; Masciocchi \& Corley, 2013; Masciocchi et al. 2016) it appears likely that fertilised queens are probably moved internationally subsequent to finding a suitable overwintering habitat. Ultimately, this work unravelling the likely origins of invasions could be used to highlight where to look for coevolved natural enemies, such as parasitoids. 


\begin{tabular}{|c|c|c|}
\hline $\begin{array}{l}\text { Invaded } \\
\text { range }\end{array}$ & $\begin{array}{l}\text { Date of first report and location of } \\
\text { origin previous literature }\end{array}$ & Closest haplotypes (this study) \\
\hline Argentina & $\begin{array}{l}\text { Adults first reported during 1980s } \\
\text { (Willink, 1980). Hypothesised donor } \\
\text { region of Chile (Beggs et al., 2011). } \\
\text { Present across much of central } \\
\text { Argentina (Masciocchi \& Corley, } \\
\text { 2013). }\end{array}$ & $\begin{array}{l}\text { We discovered one haplotype in Argentina. It was most similar to a sample from the } \\
\text { south of France on the border with Spain (Fig. 5.2). Given this finding the Argentinian } \\
\text { population clusters with French and Spanish haplotypes (Fig. 5.3). Although our } \\
\text { haplotype discovery curve suggests we have sampled the full mitochondrial diversity in } \\
\text { Argentina (Fig. 5.4); our geographic sampling area does not encompass the entire range } \\
\text { of the species in South America. We cannot therefore exclude incursions from } \\
\text { elsewhere. }\end{array}$ \\
\hline Australia & $\begin{array}{l}\text { Reported in Tasmania } 1959 \\
\text { (Crosland, 1991). Recorded on } \\
\text { mainland in 1975 (Spradbery \& } \\
\text { Maywald, 1992). Hypothesised donor } \\
\text { pathway and region of origin: Cargo } \\
\text { from New Zealand (Spradbery \& } \\
\text { Maywald, 1992). }\end{array}$ & $\begin{array}{l}\text { Three haplotypes were sampled in Australia. The most common }(n=7 / 11) \text { was the most } \\
\text { frequently found haplotype in New Zealand and the United Kingdom (Fig. 5.2). The } \\
\text { second haplotype ( } n=1 / 11) \text { clustered with samples from the United Kingdom (Fig. 5.2; } \\
\text { Fig. 5.3). While the third haplotype, found in Western Australia }(n=3 / 11) \text {, was an exact } \\
\text { match to samples from central Europe (Fig. 5.2, Fig. 5.3); and this haplotype was not } \\
\text { found elsewhere in Australia. There have likely been multiple introduction events in } \\
\text { Australia. These have likely been from New Zealand, the United Kingdom and central } \\
\text { Europe. Our haplotype discovery curve (Fig. 5.4) suggests we have sampled most of the } \\
\text { diversity present in Australia. }\end{array}$ \\
\hline New Zealand & $\begin{array}{l}\text { First reported } 1945 \text { (Thomas, 1960). } \\
\text { Hypothesised to have arrived with } \\
\text { crates of equipment flown from }\end{array}$ & $\begin{array}{l}\text { The majority of New Zealand's samples }(n=31 / 33) \text { belonged to a single haplotype, } \\
\text { identical to the most common haplotype in the United Kingdom and Australia (Fig. 5.2). } \\
\text { This haplotype was spread across the country. A second rare haplotype was discovered }\end{array}$ \\
\hline
\end{tabular}




\begin{tabular}{|l|l|l|}
\hline & $\begin{array}{l}\text { Europe to New Zealand (Thomas, } \\
\text { 1960). }\end{array}$ & $\begin{array}{l}\text { in Auckland and is most similar to central European haplotypes (Fig. 5.3). There appear } \\
\text { to have been at least two introduction events to New Zealand. The 1945 introduction } \\
\text { from the United Kingdom, which became widespread; and a more recent introduction, } \\
\text { potentially from central Europe, which at present only found in Auckland. Our haplotype } \\
\text { discovery curve suggests we have sampled most of the diversity present in New Zealand } \\
\text { (Fig. 5.4). }\end{array}$ \\
\hline South Africa & $\begin{array}{l}\text { First reported 1974 (Whitehead \& } \\
\text { Prins, 1975) at a container depot } \\
\text { (Tribe \& Richardson, 1994). }\end{array}$ & $\begin{array}{l}\text { We detected the presence of four haplotypes in South Africa and sampled across the full } \\
\text { invaded range (Veldtman et al., 2012). None of these proved an exact match to our } \\
\text { samples from Europe. However, our maximum likelihood phylogenetic analysis places } \\
\text { them within samples from mainland Europe (Fig. 5.3). The presence of four haplotypes } \\
\text { may indicate one introduction event with several queens, or alternatively, multiple } \\
\text { introductions. Our haplotype discovery curve suggests we have not sampled the full } \\
\text { mitochondrial diversity in South Africa (Fig. 5.4). }\end{array}$ \\
\hline
\end{tabular}


Our work highlighting the likely region of origin of invasive propagules of $V$. germanica could aid in the discovery of biological control agents. Biological control agents such as parasitoids coevolve with their host prey, which can lead to distinct host-strain relationships that vary geographically (Dupas et al., 2003). The failure of biological control agents to affect prey densities has previously been hypothesised as due to a mismatch between prey strain and predator (Grodowitz et al., 1997). Wasp biological control has previously been attempted in New Zealand by the importation of the Holarctic parasitoid Sphecophaga vesparum (Hymenoptera: Ichneumonidae). Populations of S. vesparum burra (Cresson) were sourced from Washington State in the USA, and S. vesparum vesparum were sourced from Austria, Germany and Switzerland (Donovan \& Read, 1987). Populations of S. vesparum have established in New Zealand but have offered no evidence of social wasp control (Beggs et al., 2008). There is no evidence of $S$. vesparum burra establishment (Beggs et al., 2002). Part of the reason for the failure of these biological control attempts may be a mismatch between the geographically distinct social wasp and parasitoid strain. Our results could guide future searches for biological control agents. For example, we would recommend the UK or western Europe as a source of coevolved natural enemies for strains of $V$. germanica found in Australia and New Zealand. Similarly, central Europe appears to be the location for invasive strains of German wasps in South Africa. Natural enemies that might be effective for New Zealand strains may not have similar results in South Africa.

Current techniques used to control invasive species such as wasps rely heavily on chemical and mechanical treatment, as well as requiring ongoing investment. Traditional methods of invasive species control across large land areas of many thousands of hectares is untenable. Biological control is one potential method to reduce wasp densities at a large scale. Genetically-mediated pest-management technologies such as gene drives also have the potential for large-scale control, and may revolutionise the control or eradication of invasive species (Esvelt et al., 2014; Webber et al., 2015).

The utilisation of this class of control techniques requires knowledge of the genetic diversity within native and invaded populations (Dearden et al., 2017). Entrainment in an invasion pathway may lead to reduced genetic diversity in the founding population, particularly in geographically isolated populations (Tsutsui et al., 2000; Sakai et al., 2001; Corin et al., 2007; 
Lester et al., 2014a). Pest populations with high levels of genetic diversity can contain genetic variants that render certain genotypes immune to CRISPR/Cas9 gene drive systems (Drury et al., 2017). Our data have demonstrated that populations of the invasive $V$. germanica appear to harbour reduced mitochondrial genetic diversity relative to the home range of Eurasia (Fig. 5.2, Table 5.1). This reduced genetic diversity in the invaded range may act as a safeguard for the use of a gene drive system in these populations, because if any genetically modified individuals were re-introduced back to their native range, it would be likely that most haplotypes will be unaffected (Dearden et al., 2017). Further sequencing of genes proposed as targets in a gene drive would need to be undertaken to confirm this hypothesis. The likelihood of gene drive 'escape' is further reduced by the geographical isolation of New Zealand relative to the United Kingdom where a matching mitochondrial haplotype is found. However, genetically-mediated pest control technologies are nascent and are of concern to regulators, the public and scientists (Esvelt \& Gemmell, 2017). For a discussion of the issues relating to the use of genetically-mediated pest-control internationally and within New Zealand see Esvelt et al. 2014, and Dearden et al. 2017 respectively.

Our second aim in this study was to survey wasps from throughout the native and invaded range for the presence of viruses commonly found in honey bees, as these pathogens have been implicated as key contributors to the fitness of honey bees and even colony collapse disorder (Schroeder \& Martin, 2012; McMahon et al., 2016). We confirmed the presence of each virus tested for (Table 5.2) and that there was evidence of replication within wasps (i.e. that wasps were being parasitised by the viruses). The presence and infection rates appeared to vary between ranges, although we recognise the limited amount of samples for such a comparative analysis. Each virus detected showed distinct geographic clustering based on our maximum composite likelihood trees (Figs. 5.5-5.6). This finding can potentially be explained by the large geographic distances between populations and the high mutation rates of viruses. If these results are, in fact, indicative of a low pathogen infection rate any biological control or modification of immune systems to increase the effects of viruses on wasps may have low efficacy.

Previous work has found that Vespula wasps carry a range of honey bee pathogens (Evison et al., 2012; Lester et al., 2014a, 2015; Dobelmann et al., 2017). Wasps forage in the same habitat 
as honey and bumble bees, as well as raiding honey bee hives (Clapperton et al., 1989), increasing opportunities for pathogen sharing. Honey bee viruses have been found actively replicating in a range of arthropods (Levitt et al., 2013). From our data we cannot conclude that any viruses tested for are definitively absent from the populations in which they were not found, though the absence of viruses such as IAPV from New Zealand is in agreement with extensive sampling from honey bees (McFadden et al., 2014). Our viral pathogen assays instead indicate that $V$. germanica is a globally widespread invasive species capable of carrying honey bee viruses. However, the biological relevance of these pathogens in wasps and other arthropods is unknown and is an important avenue for future research. An increasing number of studies reveal that ostensible 'honey bee' pathogens may in fact be generalist pathogens found in a wide number of arthropods (Evison et al., 2012; Levitt et al., 2013; Lester et al., 2014a, 2015; Sébastien et al., 2015; Gruber et al., 2017). Given $V$. germanica carry these diseases, one potential avenue of control could be the use of a gene silencing approach to alter wasp immune responses to these pathogens - increasing pathogen efficacy as a biocontrol. Such an approach has been demonstrated in a major agricultural pest, the silver whitefly (Bemisia tabaci) (Zhang et al., 2017). Further, differential immune gene expression has been demonstrated in other Hymenoptera in response to virulent and avirulent virus infections (Niu et al., 2016), providing potential target genes for such approaches. This approach may, however, differ in its efficacy between countries based on the distribution and prevalence of viral pathogens. Immune gene silencing in invasive wasps may also be of concern if it significantly increases the local abundance of viruses causing spillover to other species including honey bees.

Controlling well-established biological invasions is extremely difficult (Silverman \& Brightwell, 2008; Hoffmann, 2011; Dearden et al., 2017). The control or eradication of widespread invaders is extremely difficult and not without risk. An understanding of the intraspecific genetic diversity is critical for successful control programmes involving biological control or emerging genetic methods such as gene drives or gene silencing. We have demonstrated that the Southern hemisphere populations of invasive wasps are likely to have arrived from a small number of introductions from European source populations. This is a first and important step in developing novel ways of reducing populations of German wasps in the Southern hemisphere. 


\section{Chapter 6: Full genome genetic diversity and regional grouping of Kashmir bee virus in three non-native Hymenoptera in New Zealand}

\subsection{Abstract}

Parts of the industrialised world have experienced widespread declines in pollinator abundance. Research has focused largely on honey bees. Although several causative agents have been proposed, pathogens appear to be a key driver. Increasing evidence suggests these honey bee diseases may be generalist pathogens. Here we survey for the presence of Kashmir bee virus $(\mathrm{KBV})$ in three species of Hymenoptera in New Zealand: Argentine ants (Linepithema humile) the common wasp (Vespula vulgaris) and honey bees (Apis mellifera). We sequence entire KBV genomes to elucidate local and regional diversity. We show that: (1) All three species carry KBV; (2) KBV strains are genetically diverse both locally and regionally; and (3) Sequencing small parts of the genome gives different results of KBV diversity than when entire genomes are assembled. This work has implications for pollinator management because as Hymenoptera are moved around landscape so too are their pathogen communities. The effects of the pathogens, especially viruses, on pollinator communities can be severe. Vectoring of novel pathogens and pathogen strains across the landscape could negatively impact agricultural security through a decrease in pollinators; as well as damage specific industries such as apiculture that rely entirely on honey bees for production.

\subsection{Introduction}

\subsubsection{Pathogens and diseases in pollinators}

In 2016, the UNEP's Intergovernmental Science-Policy Platform on Biodiversity and Ecosystem Services produced the first global thematic assessment evaluating the state of knowledge about pollinators and pollination (IPBES, 2016). This study confirmed widespread declines in pollinator abundance in North America and Western Europe. Although the report implicates several causative factors, one key driver in the decline of pollinators globally appears to be viral pathogens (Dainat et al., 2012; McMahon et al., 2016). Many of these pathogens such as the Deformed wing virus (DWV) and Kashmir bee virus (KBV) were first identified in honey bees (Bailey et al., 1976, 1979; Allen \& Ball, 1996), but have been 
increasingly shown to infect a range of insects (Sebastien et al., 2011; Evison et al., 2012; Levitt et al., 2013; Gruber et al., 2017; Santamaria et al., 2017).

As is the case in many non-native plants and animals, the vectoring of pathogenic microorganisms such as DWV or Varroa has largely been as a by-product of human trade (Murilhas, 2004; Mutinelli, 2011; Wilfert et al., 2016). Many countries actively export live pollinators such as bumble and honey bees, as well as primary products such as honey (Table $6.1-6.2$ ). Internationally, over one million commercially produced bumblebee colonies are traded annually (Velthuis \& van Doorn, 2006). Pathogens have been found to have been vectored around the world through direct trade in bee associated products (Murilhas, 2004; Mutinelli, 2011; Graystock et al., 2013; Murray et al., 2013; Wilfert et al., 2016). Viable American foulbrood (Paenibacillus larvae ssp. larvae) spores have been found in honey (Hansen, 1984). Honey is also often contaminated with European foulbrood (Melissococcus plutonius) (McKee et al., 2003). Managed populations of pollinators have been shown to be the likely source of infectious pathogens in native pollinator communities (Murray et al., 2013; Fürst et al., 2014). Identical strains of DWV have been found in sympatric honey bees (Apis mellifera) and bumble bees (Bombus terrestris) (Fürst et al., 2014). Invasive species too may act as reservoirs from which pathogens may spill into pollinator communities (Sébastien et al., 2015). In Chapter 3, we show evidence that Argentine ants may contribute to local honey bee decline. In Chapter 4 we demonstrate that the globally invasive $V$. germanica carries actively replicating copies of a range of honey bee viruses. 


\begin{tabular}{|c|c|c|c|c|c|}
\hline Rank & Country & $\begin{array}{l}\text { Netweight } \\
(\mathrm{kg})\end{array}$ & Value (US\$) & Price/kg & $\begin{array}{l}\text { Total bee } \\
\text { hives }\end{array}$ \\
\hline 1 & China & $128,329,582$ & $276,556,078$ & 2.16 & $9,025,627$ \\
\hline 2 & Argentina & $81,182,571$ & $168,867,877$ & 2.08 & $3,014,159$ \\
\hline 3 & India & $35,792,690$ & $70,761,029$ & 1.98 & $12,468,881$ \\
\hline 4 & Mexico & $29,098,347$ & $93,725,125$ & 3.22 & $1,858,000$ \\
\hline 5 & Spain & $26,873,972$ & $109,018,704$ & 4.06 & $2,809,500$ \\
\hline 6 & Germany & $25,325,270$ & $144,867,948$ & 5.72 & 742,968 \\
\hline 7 & Brazil & $24,203,371$ & $92,029,508$ & 3.80 & $1,009,680$ \\
\hline 8 & Belgium & $20,816,300$ & $72,369,340$ & 3.48 & 32,861 \\
\hline 9 & Hungary & $18,804,973$ & $74,169,900$ & 3.94 & 772,000 \\
\hline 10 & Canada & $17,954,499$ & $54,591,901$ & 3.04 & 686,733 \\
\hline 11 & Viet Nam & $17,250,326$ & $73,055,213$ & 4.24 & 277,112 \\
\hline 12 & Poland & $13,730,932$ & $33,596,358$ & 2.45 & $1,560,605$ \\
\hline 13 & Romania & $10,371,225$ & $41,491,608$ & 4.00 & $1,392,846$ \\
\hline 14 & New Zealand & $9,626,441$ & $206,136,137$ & 21.41 & 684,046 \\
\hline 15 & Bulgaria & $8,893,972$ & $31,901,428$ & 3.59 & 747,434 \\
\hline \multicolumn{6}{|c|}{$\begin{array}{l}\text { Data on honey volumes was sourced from UN Comtrade } 2016 \text { data using commodity code } \\
0409 \text { (Honey;natural). Data on total bee hives was sourced from UN FAO AgStat Data using } \\
\text { Item Code 1181:Beehives. Only five of the top } 15 \text { producers kept official records of bee hive } \\
\text { numbers (bold). The non-bold numbers are FAO extrapolations. }\end{array}$} \\
\hline
\end{tabular}


Table 6.2. Top 15 global live bee exporters by US\$ value (2016). There is substantial potential for internationally exported bees to carry diseases (Murilhas, 2004; Mutinelli, 2011).

\begin{tabular}{|c|c|c|}
\hline Rank & Country & Value (US\$) \\
\hline 1 & Canada & $19,535,542$ \\
\hline 2 & Slovakia & $12,155,022$ \\
\hline 3 & USA & $67,89,058$ \\
\hline 4 & Netherlands & $2,939,098$ \\
\hline 5 & New Zealand & $2,658,617$ \\
\hline 6 & Belgium & $1,115,677$ \\
\hline 7 & Israel & $1,113,000$ \\
\hline 8 & Turkey & 898,405 \\
\hline 9 & Australia & 849,559 \\
\hline 10 & Spain & 662,413 \\
\hline 11 & Italy & 533,535 \\
\hline 12 & Pakistan & 403,961 \\
\hline 13 & Argentina & 184,837 \\
\hline 14 & Chile & 167,021 \\
\hline 15 & Germany & 73,293 \\
\hline
\end{tabular}

Data on live bee export volumes were sourced from UN FAO AgStat Data using Item Code 10641: Insects; live, bees 


\subsubsection{Regulation of pollinators}

The presence or absence of pathogens and pests has important implications for market access of countries' exports, including bee products. International and domestic regulatory systems have been developed with the explicit goal of restricting the movement of honey bee pathogens. These systems largely rely on trade partners to survey for, and report, the presence of honey bee pathogens in their territories (e.g. McFadden et al., 2014). For instance, New Zealand has had a specific Import Health Standard (IHS) for specified bee products since November 2006. The IHS specifies the minimum requirements that must be met when importing bee products into New Zealand. Recently, a new IHS has been proposed and is under consultation. The specific goal of the IHS is to manage the biosecurity risks posed by European foulbrood (Melissococcus plutonius), American foulbrood, (Paenibacillus larvae spp larvae), and small hive beetle (Aethina tumida). The IHS aims to achieves its objective by prescribing approved treatments bee products must be subject to before import to New Zealand. Many countries have implemented comparable import requirements in an attempt to restrict the movement of honey bee diseases into their territories.

Whilst international regulations exist, the domestic movement of bees globally is largely unregulated. In the United States, the Animal and Plant Health Inspection Services (APHIS) is responsible for protecting animal health, animal welfare and plant health. APHIS does not regulate the interstate movement of bees in the continental states. Honey bees are the primary pollinators in the United States and provide services of around \$11 billion USD annually (Calderone, 2012). Bees in the United States are moved en masse to service particular crops requiring pollination at particular times. The majority of commercially managed hives are transported at some stage during the year (Cavigli et al., 2016). For instance, $\sim 80 \%$ of the world's almonds are produced in California (California ABO Almond Almanac 2014). Honey bees are critical to almond production and over $60 \%$ of commercially managed colonies in the US are involved in almond pollination from late February to early March (Cavigli et al., 2016). Colonies are transported to California from as far away as Texas and Louisiana, a journey of almost 3,000km (Smith, 2017). Few colony monitoring studies have occurred associated with these pollination events. However, data that do exist suggest that pathogen prevalence in colonies is highest in honey bee samples from colonies immediately after the almond population event (Cavigli et al., 2016). Likewise, many countries including New Zealand have few restrictions on the movement of pollinators domestically. 
Such a relaxed approach towards the domestic regulation of pollinators is potentially problematic. In the US and New Zealand pollinators are frequently moved across large distances within the domestic landscape (Smith, 2017). The rate at which they move is far faster than achievable through natural dispersal. Bees that are moved carry an array of microbial symbionts, including pathogens. An increasing number of studies are demonstrating that ostensible 'honey bee pathogens' infect a range of arthropod species (Levitt et al., 2013; Lester et al., 2014c, 2015; Sébastien et al., 2015; Gruber et al., 2017; Santamaria et al., 2017). Pathogen dynamics may vary depending on factors such as the presence of a species acting as a vector (Martin et al., 2012) or priority effects and virus-virus interactions within the cells of the host species (Carrillo-Tripp et al., 2016).

However, questions of how arthropod pathogens vary geographically within a country are not well-explored, although they are present in the literature (Sébastien et al., 2015). It seems likely that as pollinators and other arthropods are vectored around the landscape they carry with them a microbial and pathogen community significantly different from the area to which they are being transported. Such movement is particularly problematic when, as is often the case, landborders provide no barrier to dispersal (Schmid-Hempel et al., 2014; Aizen et al., 2018).

\subsubsection{Pathogen strain variation and Kashmir bee virus}

Kashmir bee virus is part of a group of closely related viruses from the Family Dicistroviridae (de Miranda et al., 2010). The virus is little studied relative to pathogens such as $D W V$, but it has been found to infect a range of Hymenoptera (Levitt et al., 2013; Dobelmann et al., 2017; Gruber et al., 2017) and has a global distribution. The biological relevance of this disease is largely unknown. In one study it was shown that high viral loads of the disease resulted in upregulated immune gene expression, but that the pathogen did not affect the fitness parameters investigated by the authors (Dobelmann et al., 2017). In another study sub-lethal effects in terms of slower colony start up and offspring product were shown in a laboratory setting (Meeus et al., 2014). Research on arthropod epidemiology has provided an understanding that pathogens strains vary both in terms of their genetics and virulence (McMahon et al., 2016). For instance the $D W V$ genotype-B has been shown to be more virulent than genotype-A and has been linked to overwinter decline of honeybees in the field (Natsopoulou et al., 2017). It is 
possible that strains of other viruses, such as $K B V$, will also vary in virulence and transmissibility.

Our aims in this study were to: (1) survey the differences in full genome strain diversity in a little studied 'honey bee virus' in two spatially separated areas of New Zealand; (2) Survey to see whether the virus is present in Hymenoptera species that are not honey bees; and (3) To elucidate whether different sequence lengths give a different indication of viral strain diversity.

\subsection{Methods}

\subsubsection{Samples}

Three species of Hymenopteran were collected especially for this study: the Common wasp (Vespula vulgaris), the Argentine ant (Linepithema humile) and the Western honey bee (Apis mellifera). Wasps, ants and bees collected for this study were sampled foraging in the field and immediately stored in liquid nitrogen at $-196^{\circ} \mathrm{C}$. Samples were then stored in the laboratory at $-80^{\circ} \mathrm{C}$. Honey bee and ant samples were collected in Northland, New Zealand (Fig. 6.1; Table 6.1). Vespula vulgaris samples were collected in Nelson Lakes Regional Park, New Zealand (Fig. 6.1; Table 6.1). We also utilised KBV positive Vespula germanica specimens utilised in Chapter 4, but they were only used for a minor part of the analysis. 


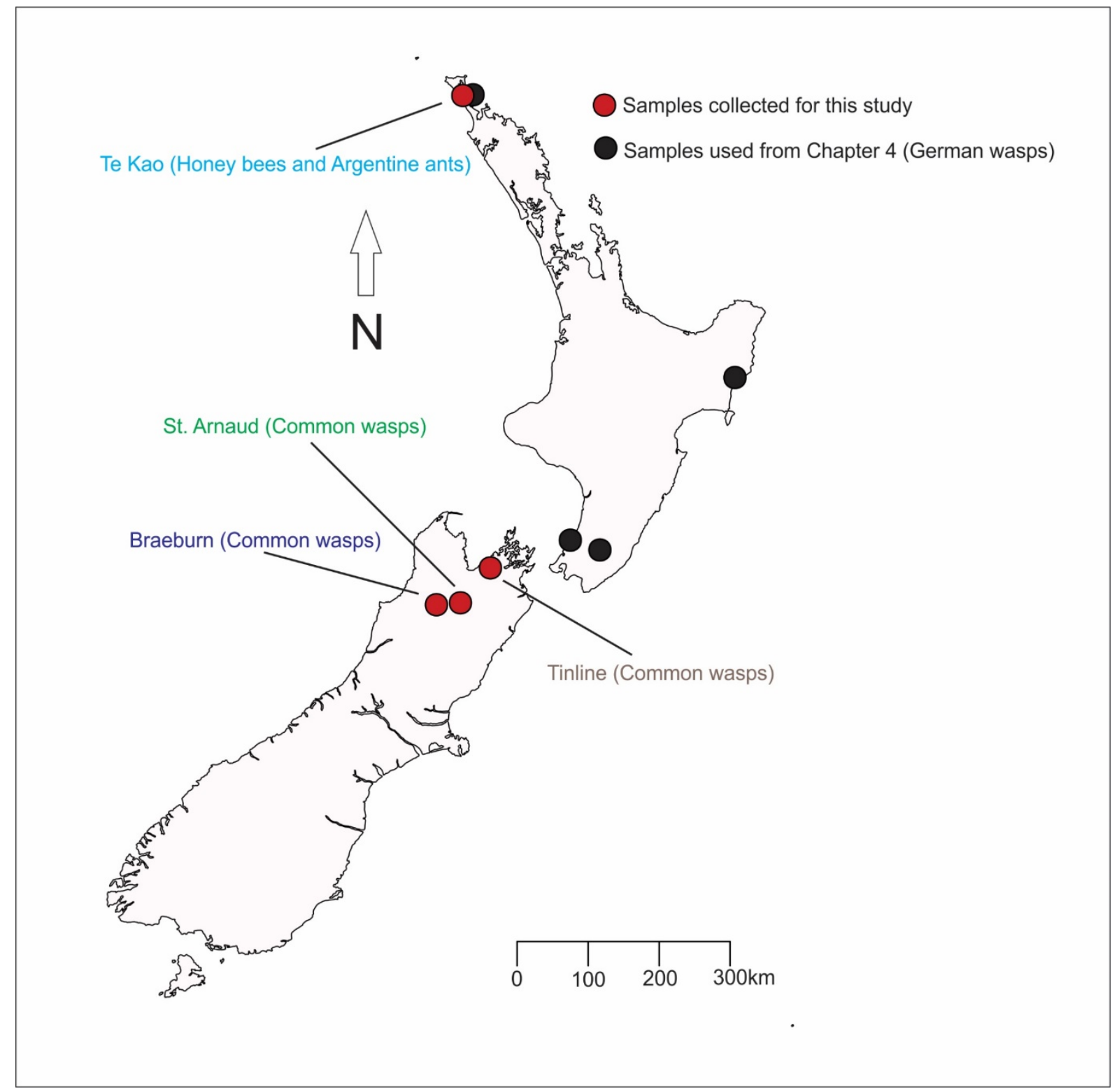

Fig. 6.1. Map showing the locations of the specimens used in this study. 


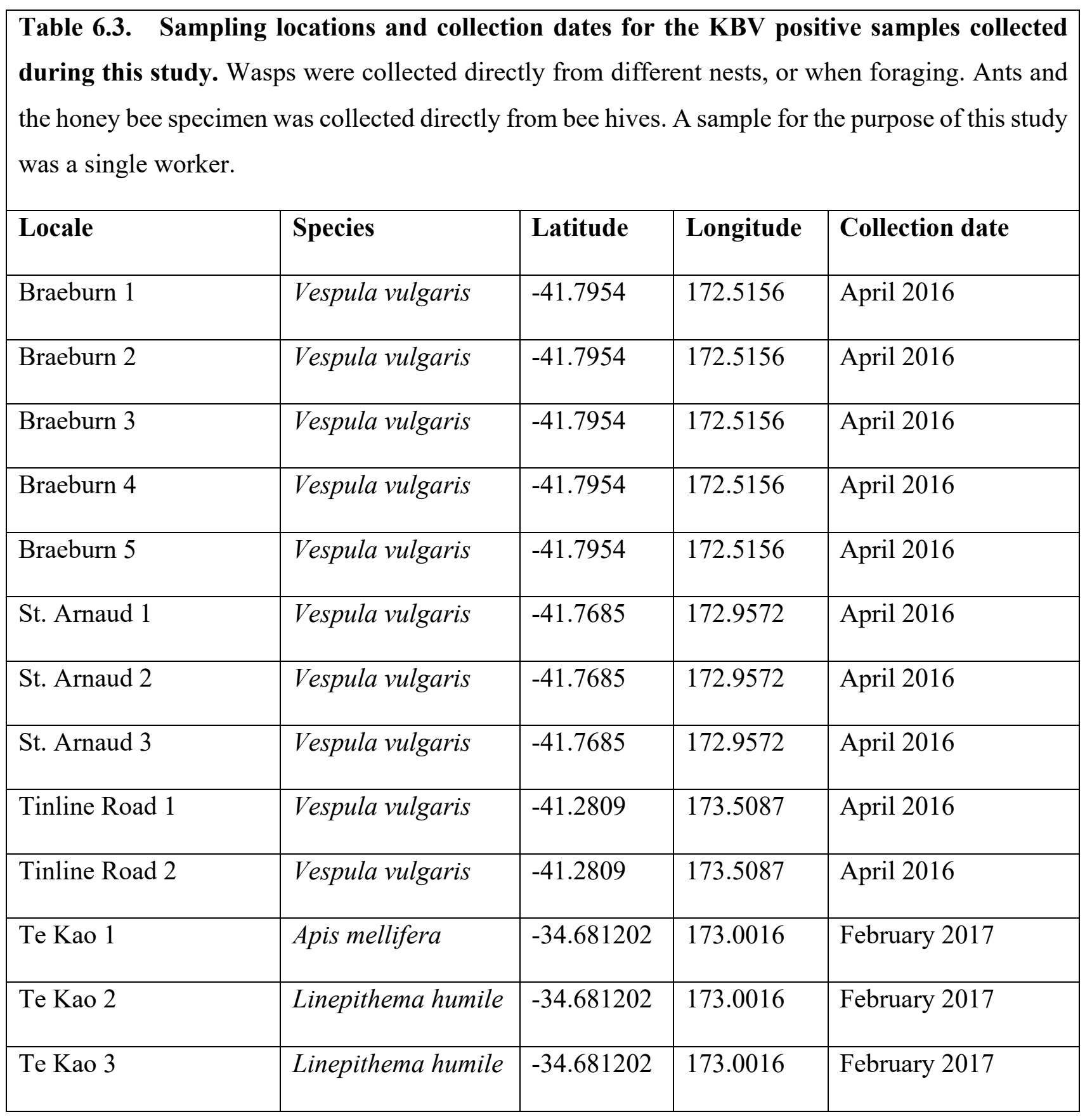

\subsubsection{Kashmir bee virus phylogenetic relationships}

In order to reveal the phylogenetic relationships between KBV carried by Hymenoptera in different parts of New Zealand we sequenced PCR products from DNA and RNA extracted from specimens sampled from throughout New Zealand (Fig. 6.1; Table 6.1). DNA and RNA was extracted by bead-beating (BeadBeater 16, Biospec Products, USA) entire specimens in GENEzol reagent (Geneaid, Taiwan) and 5\% $\beta$-mercaptoethanol followed by chloroform and isopropanol purification. DNA concentrations were quantified with a NanoDrop spectrophotometer (NanoDrop/ThermoFisher Scientific, USA). $1 \mu \mathrm{g} / \mathrm{sample}$ was used for 
cDNA synthesis using a ThermoFisher SuperScript First-Strand Synthesis System (ThermoFisher, USA). Extraction products were stored at $-80^{\circ} \mathrm{C}$.

In order to undertake a phylogenetic analysis we used PCR to amplify partial genomes to confirm the presence of absence of KBV. For samples that were positive for KBV we attempted to recover almost the entire KBV genome using the 20 primer pairs described by Gruber et al. 2017.

\begin{tabular}{|c|c|c|c|c|}
\hline $\begin{array}{l}\text { Primer } \\
\text { pairs }\end{array}$ & Sense & Sequence 5'-3' & $\begin{array}{l}\text { Product } \\
\text { length } \\
\text { (bases) }\end{array}$ & $\begin{array}{l}\text { Annealing } \\
\text { temperature } \\
{ }^{\circ} \mathrm{C}\end{array}$ \\
\hline $10 \mathrm{~F}$ & $\mathrm{~F}$ & CCCTACGTACAATTTTGACGCTT & & \\
\hline $365 \mathrm{R}$ & $\mathrm{R}$ & AGCCTCACGTCTTTAAATAGAGC & 356 & 57 \\
\hline $251 \mathrm{~F}$ & $\mathrm{~F}$ & AACACAACCGGATTACGAACC & & \\
\hline $796 \mathrm{R}$ & $\mathrm{R}$ & ACATGTGAAAAGCGTATTGGTC & 546 & 57 \\
\hline $579 \mathrm{~F}$ & $\mathrm{~F}$ & GTGTCGGAGCAGTGGTAATG & & \\
\hline 1290R & $\mathrm{R}$ & CTTGGGTTTTGTCTGGTGGG & 712 & 63 \\
\hline $1133 \mathrm{~F}$ & $\mathrm{~F}$ & AATTGAACCCAGGACCCACT & & \\
\hline $2022 \mathrm{R}$ & $\mathrm{R}$ & AGCTCTTACTTCATCGCACCAA & 890 & 60 \\
\hline $1854 \mathrm{~F}$ & $\mathrm{~F}$ & AGATCTAGGACGTGCTGCAAA & & \\
\hline $2802 \mathrm{R}$ & $\mathrm{R}$ & TCCTGTCAACTTCTGCACCT & 949 & 60 \\
\hline $2653 \mathrm{~F}$ & $\mathrm{~F}$ & TCGCTTACTTTCCCCGATGC & & \\
\hline $3156 \mathrm{R}$ & $\mathrm{R}$ & ACAATCATAAACAACACCTGTGC & 504 & 57 \\
\hline $3006 \mathrm{~F}$ & $\mathrm{~F}$ & CCATCCTGAACCCGAATACGA & & \\
\hline $3520 \mathrm{R}$ & $\mathrm{R}$ & TGAGGTCTCGGTGTGGTATG & 515 & 63 \\
\hline $3344 \mathrm{~F}$ & $\mathrm{~F}$ & ATGTGCAGGAACACCCTTGG & & \\
\hline $3795 \mathrm{R}$ & $\mathrm{R}$ & AAGCGATTCCGGGTCTTCTTC & 452 & 63 \\
\hline
\end{tabular}




\begin{tabular}{|c|c|c|c|c|}
\hline $\begin{array}{l}3560 \mathrm{~F} \\
4389 \mathrm{R}\end{array}$ & $\mathrm{F}$ & $\begin{array}{l}\text { ACATGCGTGTTGGAGATGTTG } \\
\text { GCATACGAACTTAGGGAACGC }\end{array}$ & 830 & 57 \\
\hline $\begin{array}{l}4152 \mathrm{~F} \\
4931 \mathrm{R}\end{array}$ & $\mathrm{F}$ & $\begin{array}{l}\text { AGTAAACGACGACGACACAGT } \\
\text { AATAGGGGTTCGGGAAGTCG }\end{array}$ & 780 & 60 \\
\hline $\begin{array}{l}4704 \mathrm{~F} \\
5200 \mathrm{R}\end{array}$ & $\mathrm{F}$ & $\begin{array}{l}\text { ATGTGGCCGAGCTTATGCAG } \\
\text { AGCCACAAATGGCTTCCTCA }\end{array}$ & 497 & 57 \\
\hline $\begin{array}{l}4911 \mathrm{~F} \\
5839 \mathrm{R}\end{array}$ & $\mathrm{F}$ & $\begin{array}{l}\text { TCGACTTCCCGAACCCCTAT } \\
\text { GGTTTCCTGAGGGTTGGCTA }\end{array}$ & 929 & 63 \\
\hline $\begin{array}{l}5704 \mathrm{~F} \\
6391 \mathrm{R}\end{array}$ & $\mathrm{F}$ & $\begin{array}{l}\text { TTTACGATGACGGACCGGAA } \\
\text { TACCGCTCCTGAGCATATCCA }\end{array}$ & 688 & 60 \\
\hline $\begin{array}{l}6201 \mathrm{~F} \\
6844 \mathrm{R}\end{array}$ & $\mathrm{F}$ & $\begin{array}{l}\text { AATTGGTGTCGAGGAGGACT } \\
\text { ATGAGAACGGGGCGTTGTAG }\end{array}$ & 644 & 63 \\
\hline $\begin{array}{l}6662 \mathrm{~F} \\
7169 \mathrm{R}\end{array}$ & $\mathrm{R}$ & $\begin{array}{l}\text { ACATAACACGAAACTCGCGTC } \\
\text { TTCGACTCCCGGATAACCTGT }\end{array}$ & 508 & 57 \\
\hline $\begin{array}{l}6971 \mathrm{~F} \\
7758 \mathrm{R}\end{array}$ & $\mathrm{R}$ & $\begin{array}{l}\text { AGCTGGTGGAAAAGCCCAAA } \\
\text { TGGCTGCTACACCTCCTACA }\end{array}$ & 788 & 63 \\
\hline $\begin{array}{l}7620 \mathrm{~F} \\
8229 \mathrm{R}\end{array}$ & $\mathrm{R}$ & $\begin{array}{l}\text { GGACCAATTTCCGAAGTGGC } \\
\text { TTTCCAACCTGCCTGTGTGA }\end{array}$ & 610 & 60 \\
\hline $\begin{array}{l}8015 \mathrm{~F} \\
8856 \mathrm{R}\end{array}$ & $\mathrm{F}$ & $\begin{array}{l}\text { TAACGGAGATGATTGGGGCG } \\
\text { TCGGTGTCTTGGTGTTTGCT }\end{array}$ & 842 & 63 \\
\hline $\begin{array}{l}8709 \mathrm{~F} \\
9263 \mathrm{R}\end{array}$ & $\mathrm{F}$ & $\begin{array}{l}\text { TTCTTTGACTCAGGCGACCC } \\
\text { TTGCGGAGTGCCTATCATCC }\end{array}$ & 555 & 63 \\
\hline $\begin{array}{l}9040 \mathrm{~F} \\
9493 \mathrm{R}\end{array}$ & $\mathrm{F}$ & $\begin{array}{l}\text { TTAACACCGACGGACCATCTC } \\
\text { TTCCGAAATTTTGCCGTAGTC }\end{array}$ & 454 & 57 \\
\hline
\end{tabular}

Each 15- $\mu$ l PCR reaction consisted of: 7.5 $\mu 1$ MyTaq DNA Polymerase Master Mix (Bioline, USA), $6.1 \mu 1 \mathrm{ddH}_{2} \mathrm{O}, 1.2 \mu \mathrm{l} \mathrm{cDNA}$ and $1.2 \mu \mathrm{l}$ of forward and reverse primers. Thermal cycling conditions were: Initial denaturation at $95^{\circ} \mathrm{C}$ for $2 \mathrm{~min}$, followed by 35 cycles of denaturing at $95^{\circ} \mathrm{C}$ for $20 \mathrm{~s}$, annealing for $10 \mathrm{~s}$ at 63,60 or $57^{\circ} \mathrm{C}$ depending on the primer pair and extension 
at $72^{\circ} \mathrm{C}$ for $30 \mathrm{~s}$; followed by a final extension at $72^{\circ} \mathrm{C}$ for $5 \mathrm{~min}$. Amplified products were purified using ExoSAP-IT (Affymetrix) and sequenced directly using Sanger sequencing. A total of $25 \mathrm{KBV}$ positive specimens were attempted with the recovery of $98.5 \%$ complete genomes from eight individuals $(n=8)$. $82.5 \%$ complete genomes were recovered from a further five individuals $(n=13)$. We also attempted to amplify genomes from KBV positive Vespula germanica specimens used in Chapter 4. None of these samples yielded mostly full genomes. This result is likely because, unlike the other samples, these specimens were stored at ambient temperatures in ethanol.

I manually checked for quality, edited and aligned the sequences using MEGA7 (Kumar et al., 2015). We used BLASTn searches of the NCBI (Genbank) nucleotide (nr) database to confirm the authenticity of our samples as KBV.

For our phylogenetic analysis we assessed our dataset in three parts. The first dataset included the $98.5 \%$ complete genomes $(n=8)$, as well as the full KBV genome from GenBank (de Miranda et al., 2004). The second dataset included the $82.5 \%$ complete genomes with the $98.5 \%$ complete genomes edited to match the $82.5 \%$ complete genomes $(n=13)$ (Fig. 6.2.) The third dataset included 327bp amplicons taken from the above sequences. An additional amplicon was added from this study, as well as the five KBV positive samples from $V$. germanica in Chapter $4(n=19)$. 


\section{Genome trimming method}

$98.5 \%$ complete genomes $82.5 \%$ complete genomes

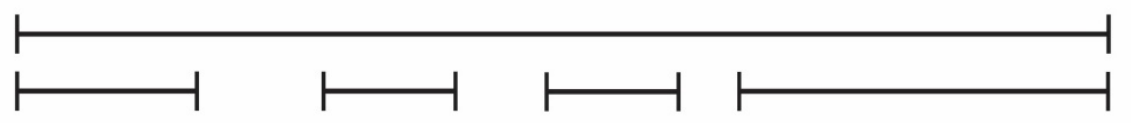

$98.5 \%$ complete genomes

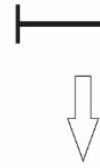

Remove sections not present in $82.5 \%$ complete genomes

$82.5 \%$ complete genomes
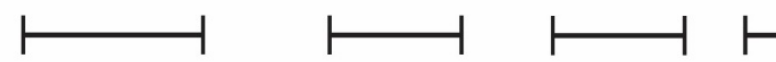

Remove gaps to combine into single sequence

$82.5 \%$ complete genomes

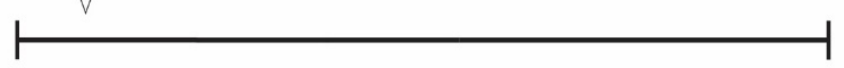

Fig. 6.2. Process used to trim $98.5 \%$ complete genomes to match $82.5 \%$ complete genomes. $98.5 \%$ complete genomes were assembled using overlapping PCR amplicons. Of those sequences that amplified incompletely, I was able to build $82.5 \%$ complete genomes from amplicons amplified successfully for each $82.5 \%$ complete genome. For my $82.5 \%$ complete genome phylogenetic analysis I trimmed the sections not present in the $82.5 \%$ genomes from the $98.5 \%$ genomes and combined the dataset.

To determine the most appropriate model of sequence evolution we used Bayesian Information Criterion (BIC) scores derived in MEGA7 (Kumar et al., 2015), which also estimated base frequencies, substitution rates, the proportion of invariable sites (I) and the uniformity of substitution rates among sites $(\mathrm{G})$ (Tab. 6.3). The top three models of evolution selected as best-fitting were identical across the two most complete datasets, with slightly different gamma distributions (Tab. 6.3). The best fitting model for the $327 \mathrm{bp}$ dataset differed from the more complete datasets (Tab. 6.3). Our selected model and its parameters were then used to build a maximum composite likelihood tree. The level of support for this tree was assessed using 1000 bootstrap replicates. MEGA7 was also used to calculate percentage genetic distance and standard errors (S.E) within and among geographic groups. 
The $\mathrm{R}$ package vegan was used to perform the rarefaction analysis (Oksanen et al., 2007; Team, 2016). Summary statistics on sequences were generated using DnaSP (Rozas et al., 2017).

Table 6.5. The maximum likelihood fits for the five best-fitting models of the 24 different nucleotide substitution models calculated in MEGA7 for the three datasets of KBV sequences. Models are shown in BIC order. Model abbreviations: TN93=Tamura-Nei, GTR= General Time Reversible, HKY = Hasegawa-Kishino-Yano, K2 = Kimura. The best-fitting substitution model was selected based on Bayesian Information Criterion scores (BIC). For each model the corrected Akaike Information Criterion value (AICc), Maximum Likelihood value $(\operatorname{lnL})$, and the number of parameters are also presented. Models with the lowest BIC, AICc and $\operatorname{lnL}$ scores describe the substitution pattern the best. Variable model parameters included nonuniformity of evolutionary rates among sites (a discrete Gamma distribution $(+G)$ with 5 rate categories) and the assumption that a certain fraction of sites are evolutionarily invariable $(+\mathrm{I})$. Where applicable the estimates of $+\mathrm{G}$ and $+\mathrm{I}$ are shown. The number of parameters in the model $(\#)$, and the assumed or estimated values of transition/transversion bias (R) are also shown.

\begin{tabular}{|c|c|c|c|c|c|c|c|c|}
\hline Dataset & Model & $\#$ & BIC & AICc & $\ln L$ & $+\mathbf{I}$ & $+\mathbf{G}$ & $\mathbf{R}$ \\
\hline \multirow{5}{*}{$\begin{array}{l}98.5 \% \\
\text { Complete } \\
\text { genomes }\end{array}$} & TN93+G & 21 & 35716.004 & 35519.753 & -17738.871 & - & 0.05 & 4.50 \\
\hline & $\mathrm{TN} 93+\mathrm{G}+\mathrm{I}$ & 22 & 35727.266 & 35521.671 & -17738.829 & 0.02 & 0.06 & 4.50 \\
\hline & $\mathrm{GTR}+\mathrm{G}$ & 24 & 35742.377 & 35518.092 & -17735.039 & - & 0.07 & 4.52 \\
\hline & $\mathrm{GTR}+\mathrm{G}+\mathrm{I}$ & 25 & 35749.873 & 35516.244 & -17733.114 & 0.61 & 0.64 & 4.59 \\
\hline & $\mathrm{HKY}+\mathrm{G}$ & 20 & 35780.576 & 35593.670 & -17776.830 & - & 0.05 & 5.80 \\
\hline Dataset & Model & \# & BIC & AICc & $\ln L$ & $+\mathbf{I}$ & $+\mathbf{G}$ & $\mathbf{R}$ \\
\hline \multirow{5}{*}{$\begin{array}{l}82.5 \% \\
\text { Complete } \\
\text { genomes }\end{array}$} & TN93+G & 31 & 31958.225 & 31660.384 & -15799.183 & - & 0.05 & 3.92 \\
\hline & TN93+G+I & 32 & 31968.134 & 31660.686 & -15798.333 & 0.08 & 0.06 & 3.94 \\
\hline & $\mathrm{GTR}+\mathrm{G}$ & 34 & 31989.694 & 31663.032 & -15797.505 & - & 0.05 & 3.94 \\
\hline & $\mathrm{HKY}+\mathrm{G}$ & 30 & 31992.036 & 31703.803 & -15821.893 & - & 0.05 & 4.01 \\
\hline & $\mathrm{T} 92+\mathrm{G}$ & 28 & 31993.037 & 31724.018 & -15834.002 & - & 0.05 & 3.94 \\
\hline
\end{tabular}




\begin{tabular}{|lllllllll|}
\hline Dataset & Model & $\#$ & BIC & AICc & InL & + I & + G & R \\
\hline 327bp & K2 & 36 & 1999.506 & 1757.499 & -842.534 & - & - & 1.37 \\
amplicon & $\mathrm{K} 2+\mathrm{G}$ & 37 & 2001.966 & 1753.249 & -839.397 & - & 0.57 & 1.47 \\
& $\mathrm{~T} 92$ & 37 & 2003.379 & 1754.662 & -840.103 & - & - & 1.37 \\
& $\mathrm{~T} 92+\mathrm{G}$ & 38 & 2006.043 & 1750.616 & -837.068 & - & 0.58 & 1.47 \\
& $\mathrm{~K} 2+\mathrm{I}$ & 37 & 2006.828 & 1758.111 & -841.828 & 0.11 & - & 1.38 \\
& & & & & & & & \\
\end{tabular}

\subsection{Results}

\subsubsection{Kashmir bee virus phylogenetic relationships}

The complete published KBV genome is 9,524bp (de Miranda et al., 2004). We managed to recover eight $9,380 \mathrm{bp}$ genomes which represents $98.5 \%$ of the full published genome. In these eight samples our sequencing revealed eight unique KBV haplotypes. In addition, we recovered an additional five $7,858 \mathrm{bp}$ fragments which represents $82.5 \%$ of the full published genome. We analysed the two datasets separately and the analyses indicated highly similar trends that became more pronounced as sequence length increased.

\begin{tabular}{|l|l|l|l|}
\hline \multicolumn{2}{|l|}{ Table 6.6. Summary statistics on nucleotide variation within datasets } \\
\hline & $327 \mathrm{bp}$ amplicons & $\begin{array}{l}82.5 \% \text { complete } \\
\text { genomes }\end{array}$ & $\begin{array}{l}98.5 \% \text { complete } \\
\text { genomes } \\
n=19\end{array}$ \\
& & $7858 \mathrm{bp}$ & $n=9$ \\
& & $9449 \mathrm{bp}$ \\
\hline Conserved sites & $261(79.8 \%)$ & $7202(91.6 \%)$ & $8695(92.0 \%)$ \\
\hline Variable sites & $66(20.2 \%)$ & $656(8.3 \%)$ & $706(7.5 \%)$ \\
\hline
\end{tabular}




\begin{tabular}{|l|l|l|l|}
\hline $\begin{array}{l}\text { Parsimony informative } \\
\text { sites }\end{array}$ & $31(9.5 \%)$ & $400(5.1 \%)$ & $432(4.6 \%)$ \\
\hline Singleton sites & $35(10.7 \%)$ & $256(3.3 \%)$ & $274(2.9 \%)$ \\
\hline $\begin{array}{l}\text { Average number of } \\
\text { nucleotide differences per } \\
\text { sequence }\end{array}$ & $12.04(3.6 \%)$ & $186.68(2.4 \%)$ & $273.14(2.9 \%)$ \\
\hline Unique haplotypes & 9 & 14 & 9 \\
\hline
\end{tabular}

Our phylogenetic trees built using the $98.5 \%$ and $82.5 \%$ complete genomes (Fig. 6.2a-b) demonstrate that these populations cluster geographically and have less genetic distance within populations than between populations (Fig. 6.3). If $327 \mathrm{bp}$ fragments of the same sequences are used to build a phylogenetic tree, many of the sequences are identical and geographic patterns are lost (Fig. 6.2c).

The $98.5 \%$ complete genomes resolved genetic patterns with the greatest resolution (Fig. 6.2a). The $98.5 \%$ complete tree indicates a geographic grouping of KBV strains. This grouping changes little as fewer base pairs are used in the analysis as is the case in the $82.5 \%$ complete tree (Fig. 6.2b). If the additional samples are removed the phylogenetic trees are identical. (Fig. $6.2 \mathrm{a}-\mathrm{b}$ ) The tree was built using $327 \mathrm{bp}$ amplicons groups viral strains with a much lower degree of resolution (Fig. 6.2c).

We performed three rarefaction analyses (Fig. 6.4) which suggest that we have not sampled the full genetic diversity of KBV in either of the regions sampled.

Unfortunately our Vespula germanica samples utilised from Chapter 4 amplified poorly and were not used except in the $327 \mathrm{bp}$ amplicon analysis. 


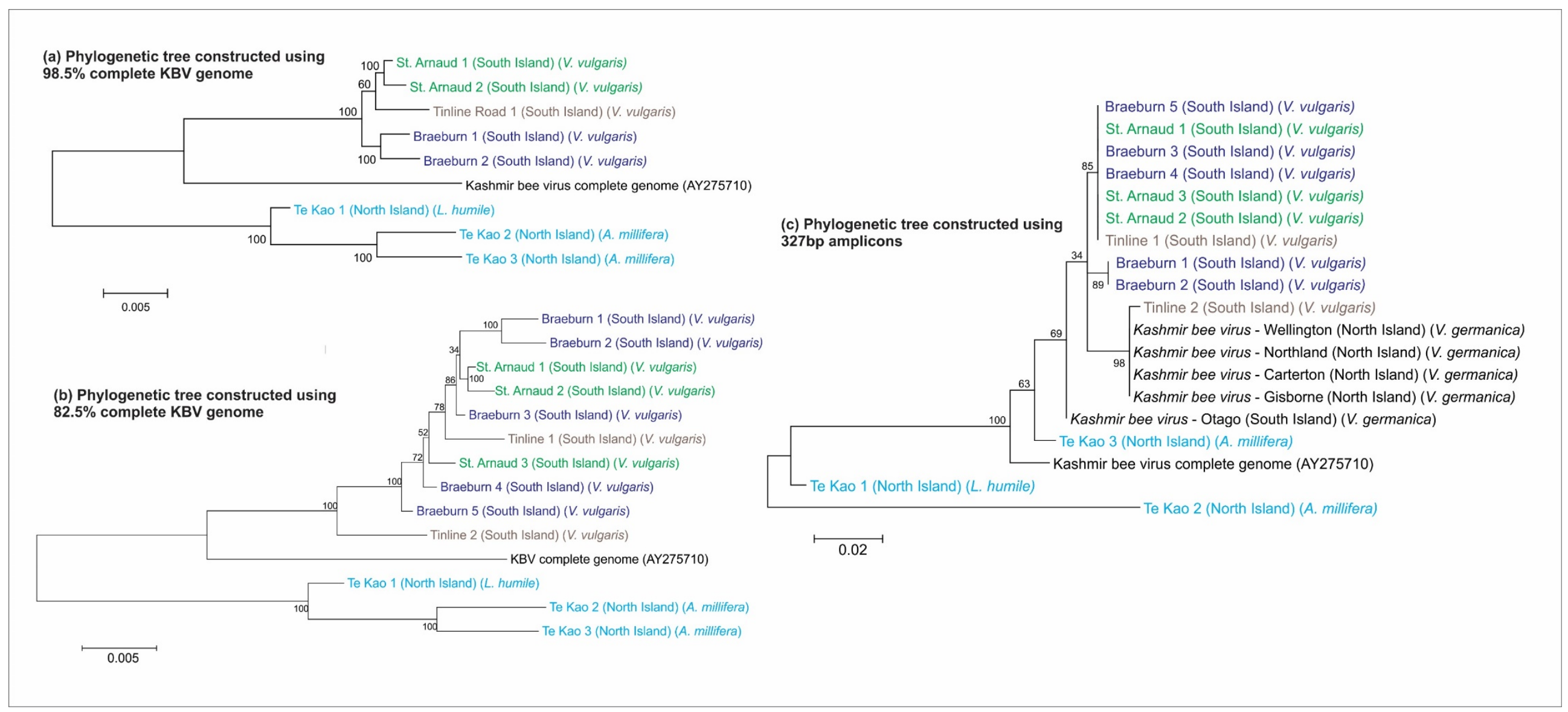

Figure 6.2. (a)-(c). Maximum composite likelihood trees for $98.5 \%$ and $82.5 \%$ complete KBV genome sequences sampled, as well as the 327bp amplicons and samples from utilised from GenBank. The trees were based on 1000 bootstraps of a Tamura-Nei model with a gamma distribution. Samples in bold are from this study. Colours indicate geographic origin 


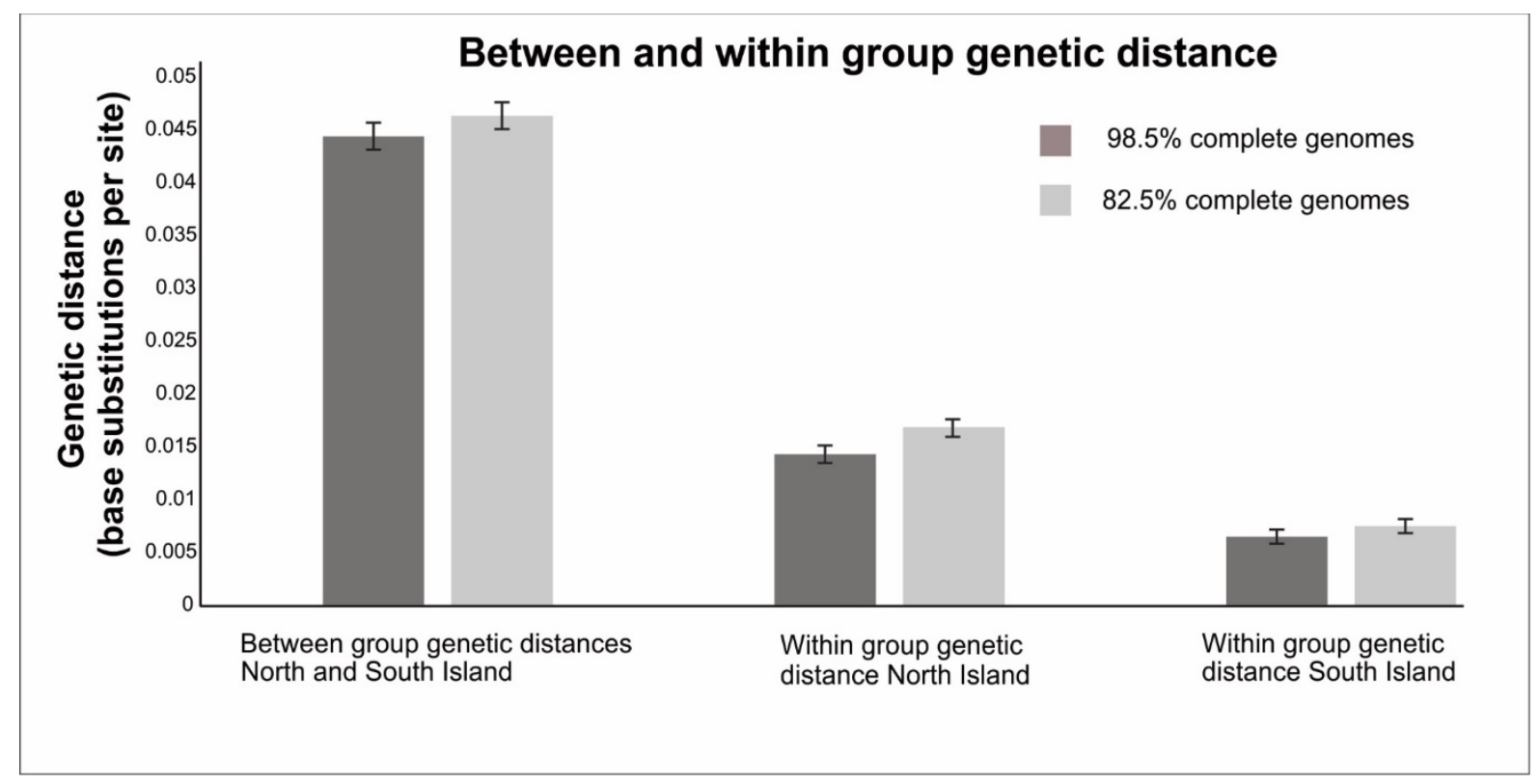

Fig. 6.3. Between and within group genetic distance of the $98.5 \%$ and $82.5 \%$ complete genomes sampled. Total genetic distance and standard errors shown. Analyses were conducted using 1000 bootstraps of a maximum composite likelihood model (Tamura et al., 2004). Between group genetic distance is the distance between the North and South Island populations. Within group genetic distance is the genetic distance within populations from either the North or the South Island. 


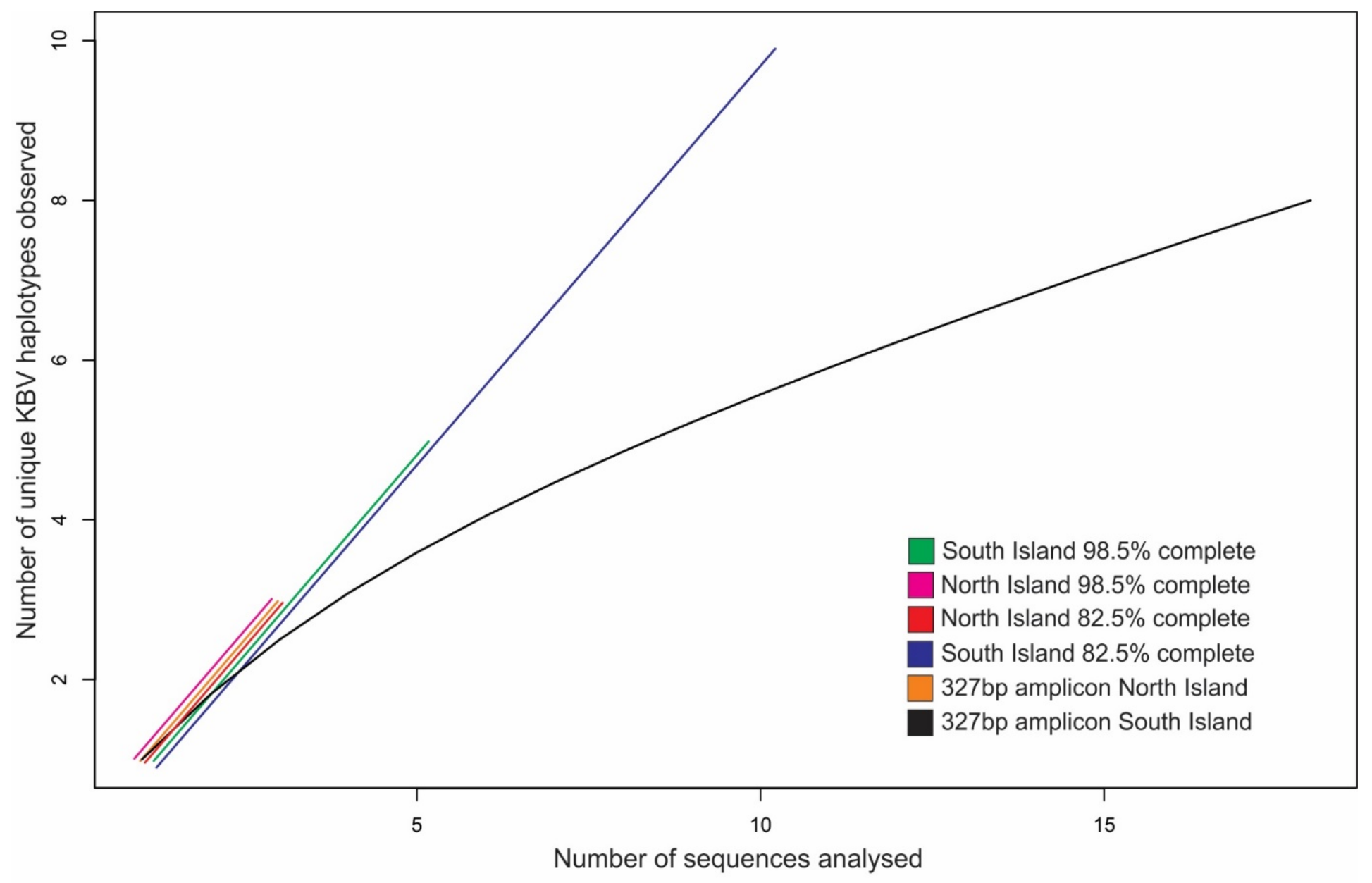

Fig. 6.4. Haplotype discovery curve of the three datasets. The curves show that it is very unlikely the full viral diversity was sampled from these regions. 


\subsection{Discussion}

My aims in this study were: First, to survey the differences in full genome strain diversity of KBV across two spatially separated areas of New Zealand. Second, to elucidate whether the virus is present in Hymenoptera species that are not honey bees. I show that all four species tested - Argentine ants, common wasps, German wasps and honey bees - carry KBV. The KBV strains carried are genetically diverse, both locally and regionally. When sequencing KBV strains, longer sequences capture greater genetic diversity and provide greater data with which to inform models building phylogenetic trees. My third goal was to investigate whether differences in sequence length give a different indication of viral strain diversity.

Pollinator declines globally have been linked to a range of biotic and abiotic factors such as pathogens, agricultural chemicals, food availability and diversity, as well as management practices (Berthoud et al., 2010; Potts et al., 2010; VanEngelsdorp \& Meixner, 2010; Dainat et al., 2012; Owen, 2017). Little consensus exists as to the causative agent of declines, instead it is likely an interplay of the above factors. Particular emphasis has been placed upon elucidating the role of parasites and pathogens in this phenomenon. (Martin et al., 2012; Fürst et al., 2014; Wilfert et al., 2016). The focus of pollinator pathogen related research has been primarily on honey bees, resulting in the labelling of a range of viruses such as Black queen cell virus, Deformed wing virus, Israeli acute paralysis virus and Kashmir bee virus as honey bee pathogens.

Evidence against these pathogens' eponymous classification as 'honey bee' diseases is the fact that when studies are performed assaying for the presence of these pathogens in other insect groups, they are often found (Evison et al., 2012; Levitt et al., 2013; Sébastien et al., 2015; Dobelmann et al., 2017; Gruber et al., 2017; Santamaria et al., 2017). Here we observed the presence of KBV in Argentine ants, common wasps, German wasps and honey bees. This analysis confirms that several different Hymenopteran hosts can carry KBV, and when an invasive species arrives in a recipient environment it may carry a new strain of such diseases. Vespula wasps and Argentine ants are included in the IUCN's list of 100 of the world's worst invasive species (Lowe et al., 2000). Like many invasive species they are generalists and quickly secure and dominate resources (Holway, 1999; Grangier \& Lester, 2011; Flanagan et al., 2013; Santoro et al., 2015). Both species of wasps and Argentine ants have been observed 
raiding honey bee hives (Chapter 3; Clapperton et al., 1989; MacIntyre \& Hellstrom, 2015). All three of these species also have a global distribution (Suarez et al., 2001; Lester \& Beggs, 2018) as well as being present across much of New Zealand (Ward et al., 2010; Lester et al., 2014b). Here we have shown that there is a high degree of genetic variability in KBV carried by these Hymenoptera. Further, this variability is less within populations than between populations (Figs. $6.2-6.3$ ). The potential implication of the frequent movement of these species is that every entrainment event represents the movement of not just the species, but also a range of microbes, including pathogens. Further, the species in this study are social insects that engage in both inter- and intraspecific interactions; such as grooming or hive robbing (Clapperton et al., 1989; MacIntyre \& Hellstrom, 2015). These sorts of behaviours provide ample opportunity for horizontal pathogen transfer.

As a further implication, the fact that a disease such as KBV might already exist in an area does not mean the introduction of Hymenoptera infected with the same virus is of no concern. Each of the species investigated in this study carried different strains of the same virus, both within and between regions. Differences in pathogen genetics can impact factors such as their transmissibility and virulence (McMahon et al., 2016; Natsopoulou et al., 2017). For instance, the DWV genotype-B has been shown to be more virulent than genotype-A and has been linked to overwintering declines of honey bees (Natsopoulou et al., 2017). Individual hosts can also host more than one pathogen strain, with potentially substantial differences in levels of virulence (Martin et al., 2012).

Pathogens may circulate in host populations at low levels for some time before causing detectable outbreaks (Longdon et al., 2014). Lack of outbreaks does not mean lack of risk. In the case of viruses introduced to novel host communities in the recipient range, lack of outbreaks may simply be a lag caused by ongoing viral adaptation to maximise fitness in the novel host (Longdon et al., 2014). Latent infections in asymptomatic hosts can eventually result in deleterious impacts (Speck \& Ganem, 2010). Apparently mild illnesses can reduce fitness by influencing interspecific interactions and community composition (Vincent et al., 2014; Jones \& Coutts, 2015). Little work has been done on the biological impacts of KBV. To our knowledge, no studies have been published demonstrating causative impacts of KBV on honeybee mortality. However, one study of laboratory infection did demonstrate sub-lethal 
effects of significantly slower colony startup and offspring production in bumblebees (Meeus et al., 2014).

Our phylogenetic analyses and measures of genetic distance provide evidence for strong regional grouping of this pathogen (Fig. 6.2a-c, Fig. 6.3). As data in the form of base pairs were added to the model building our phylogenetic trees, the regional groupings became more resolved (Fig. 6.2a-c). These results are perhaps unsurprising as a genome that is $98.5 \%$ percent complete will likely capture more variability than a relatively short PCR amplicon. It is unlikely we overestimate sequencing diversity due to sequence error as the error rate of Sanger sequencing is $0.001 \%$ (Rhoads \& Au, 2015).

With respect to the differences in South and North Island KBV strain diversity, the genetic separation seems to be an intuitive result given the approximately $1,200 \mathrm{~km}$ between the two locales. However, the three South Island sampling locations are relatively close to one another with only $\sim 25 \mathrm{~km}$ between Six Mile and Braeburn, and an additional $\sim 70 \mathrm{~km}$ to Tinline (Fig. 6.1). Even given these small distances there was still strong geographic grouping of genomes in the $98.5 \%$ complete tree (Fig. 6.2a). Effects of sociality, geographic distance and hostdensity have been shown to impact upon strain diversity and admixture (Wilson et al., 2002; Langwig et al., 2012). Densities of $V$. vulgaris in New Zealand's upper South Island are amongst the highest in the world with up to 370 wasps per $\mathrm{m}^{2}$ of tree trunk (Moller et al., 1991). The $V$. vulgaris samples used in this study were collected in autumn during the apogee of wasp density. Given this timing, there had been an entire season for wasps to interact with one another and exchange pathogens. It has been shown that wasps directly physically interact with other Hymenoptera in this environment (Grangier \& Lester, 2011), providing another potential host for disease transfer, and further biomass in which pathogens may exist.

Patterns in the North Island require further exploration. Unlike the South Island sites, a wide range of introduced and invasive Hymenoptera are present in the upper North Island. These species include the four species used in this study, as well as a wide range of other wasp and ant species (personal observation). Further, honey bee hives in the Northland/Auckland region have increased from 64,376 in 2012 to 149,332 in 2017 (MPI, 2012, MPI, 2017). In Chapter 3 
we observed high densities of Argentine ants living within and in proximity to bee hives. Given the Hymenopteran diversity in the region, disease dynamics may operate differently. Unfortunately, we only have three KBV complete samples from Northland therefore we can draw no firm conclusions from these data. Perhaps all we can conclude is that it is clear that the KBV from the North Island formed a distinct geographic grouping relative to our South Island samples (Figs 6.2(a)-(c) - 6.3).

Our rarefaction analysis indicates that it is very unlikely that we sampled the full KBV diversity in these regions (Fig. 6.4). Together with our phylogenetic trees, our rarefaction analysis suggests that analyses using short sequences will tend to underestimate biological diversity in viruses. Such issues will be particularly acute using qPCR methodologies typically utilised in pathogen presence/absence trials. This acuity is because qPCR assays typically amplify short amplicon lengths. Overall, this result highlights the necessity of choosing appropriate genetic tools and analyses to answer research questions. For instance, the use of high resolution melt analysis could be used in tandem with qPCR to estimate strain diversity as utilised by Martin et al. 2012. Alternatively, Next Generation Sequencing technologies could be used to provide data on strain diversity and prevalence within single individuals.

Honey bees are frequently moved to provide pollination services to agricultural industries. In the United States over $60 \%$ of commercially managed colonies are involved in almond pollination from late February to early March (Cavigli et al., 2016). Colonies are transported to California from as far away as Texas and Louisiana, a journey of almost 3,000km (Smith, 2017). In New Zealand honey bee colonies have increased from 422,728 in 2012 to 795,578 in 2017 (MPI, 2012; MPI, 2017). Hives are frequently moved hundreds of kilometres for pollination purposes (personal observation). Vespid wasp queens are estimated to naturally disperse in the range of hundreds of metres per year (Thomas, 1960; Masciocchi \& Corley, 2013). Patterns of rapid long-range dispersal (hundreds of kilometres) have occurred in Australia, probably due to the accidental transport of hibernating queens (Crosland, 1991). Argentine ants are a globally distributed invasive species that are likely vectored around domestic landscapes in a range of conveyances, including honey bee hives as observed in Chapter 3. When these species are moved, their microbial communities - including pathogens - move also. 
The implications of this frequent long-range intentional movement and dispersal are unknown, but potentially substantial. Viruses have the potential to rapidly adapt to infect novel species encountered during range shifts. RNA viruses, such as DWV and KBV, in particular have high mutation and nucleotide substitution rates, allowing them to adapt quickly to new species and environments (Duffy et al., 2008; Sanjuan et al., 2010). In some cases a viral host shift may occur with only a single mutation that alters a viral surface protein enabling it to bind to a host receptor protein (Longdon et al., 2014). DWV is carried by a range of Hymenopteran species (Evison et al., 2012; Lester et al., 2015; Sébastien et al., 2015) and different strains display variable virulence (Natsopoulou et al., 2017). It is therefore possible that variable KBV strains, and other pathogens, are constantly vectored across the landscape by human activity. Our results indicate that it is likely that as these species are vectored across landscapes, they carry with them a range of strains of KBV that may have variable impacts.

In New Zealand the relevant legislation regulating the management of established invasive species are Regional Pest Management Plans promulgated under the Biosecurity Act (Chapter 3 ). However, there are few practical controls in place to restrict the movement of already wellestablished and widely distributed invasive species such as Argentine ants and Vespula wasps. Honey bees, which are non-native but not invasive, also have few controls on their movement. This approach is in line with global biosecurity efforts that allocate resources based on the prioritisation of the prevention of new invasions (Leung et al., 2002; Finnoff et al., 2007; Evison et al., 2012; Kumschick \& Richardson, 2013; Keller \& Springborn, 2014). We do not know whether the potential admixture of pathogen strains through the domestic movement of Hymenoptera has a biological impact. However, managed pollinators have been shown to influence pathogen presence in native pollinator communities (Fürst et al., 2014). Therefore, it is possible that widespread pathogen sharing occurs in these Hymenopteran communities. This possible spill-over and spill-back of pathogens that may vary in virulence between host species likely complicates community dynamics, particularly over large scales that may have variable environmental and ecological communities (Lester et al., 2015).

There have been widespread declines in pollinator abundance in certain areas of the developed world (IPBES, 2016). Although several causes have been implicated, a key driver appears to 
be viral pathogens (Dainat et al., 2012; Fürst et al., 2014; McMahon et al., 2016). Research on pollinator decline has focused on honey bees, resulting in the labelling of many pathogens as honey bee diseases. However, it is becoming increasingly apparent that these diseases are present in a wide range of arthropods (Sebastien et al., 2011; Evison et al., 2012; Levitt et al., 2013; Dobelmann et al., 2017; Gruber et al., 2017; Santamaria et al., 2017). Invasive social insects are a major problem in many countries (Beggs et al., 2011; Bradshaw et al., 2016). Once well-established in a country they spread rapidly and have proved mostly impossible to eradicate. Studies of the impact of invasive species generally focus on obvious effects such as economic impacts (MacIntyre \& Hellstrom, 2015) or direct effects through competition or predation (Beggs, 2001). Spill-over and spill-back of pathogens that vary in virulence will affect community dynamics. In the case of the species investigated here this pattern is further complicated by the fact that honey bees are frequently intentionally moved across the landscape. Future work towards understanding the generality and variability of 'honey bee pathogens' should focus on elucidating whether there is active exchange of strains between different species and whether this exchange results in sub-lethal or lethal effects. 


\section{Chapter 7: General Discussion}

Many international and domestic regulations have been promulgated with the intention to manage the spread and impacts of invasive species (McGeoch et al., 2010). My overall aims in this thesis were twofold:

(1) First, to review a subset of international and domestic level regulations targeting invasive species with a view to commenting on their fitness for purpose and suggesting potential improvements to regulatory regimes; and

(2) Second, to use the example of non-native and invasive Hymenoptera, as well as their pathogens, to illustrate both the risks posed by invasive species and gaps in their management.

\subsection{Synthesis}

Humans have been transporting non-native species around the world for millennia (Druett, 1983; Crosby, 1986; Yan et al., 2001; Savolainen et al., 2004). However, the degree of interconnectivity between human population centres, and the speed at which movement occurs, is unparalleled throughout history. International trade is now cited as the primary driver of the spread of non-native species (Levine \& D'Antonio, 2003; Kobelt \& Nentwig, 2008; Westphal et al., 2008; Hulme, 2009; Bertelsmeier et al., 2017; Seebens et al., 2018). As non-native species are transported and establish in novel regions, a small percentage become invasive (Williamson \& Fitter, 1996). Those species that do become invasive can have a substantial effect on a recipient area's economy, environment and society (MacIntyre \& Hellstrom, 2015; Yap et al., 2015; Bradshaw et al., 2016). As a response, many regulations have been promulgated internationally and domestically intended to manage risks and impacts associated with invasive species (McGeoch et al., 2010).

As illustrated in Chapter 2, the World Trade Organization's (WTO) Agreement on Sanitary and Phytosanitary Measures (SPS Agreement) allows WTO members to manage the risk of invasive species in trade. Given the key role trade plays in driving the spread of non-native species, the SPS Agreement is arguably the most important global regulation controlling the spread of invasive species. However, it has been critiqued from various perspectives as being 
imperfect in this regard (Campbell, 2001; Riley, 2005, 2011; Simberloff, 2005; Brasier, 2008; Roy et al., 2014). In particular, critiques focus on the requirement that species be identified as a pest and undergo a risk assessment. Offering a different point of view, a minority of authors have advocated that management is possible within the paradigm of the current WTO system (Jenkins, 2005, 2007, Du, 2010a, 2011). In Chapter 2, I agree with the perspective that the SPS Agreement is not inimical to the management of invasive species. To my knowledge, Chapter 2 is the first paper that argues that invasive species can largely be adequately managed by domestic regulators through the tool of an appropriate level of protection (ALOP). This is particularly so for notorious global invaders, the impacts of which are well-known. The critique that species must be identified to be subject to risk assessment is valid. However, domestic regulators may choose to impose extremely restrictive ALOPs in which the risks posed by any species may result in the barring of imports. The reason that no state implements such an approach is that the broader outcome would be to sever ties with the global trading system. No modern progressive state exists in a state of autarky and a policy of absolute trade isolationism would be untenable for most societies.

Commentators who wish to change the manner in which invasive species associated with trade are managed internationally should focus on changing the policies of their mandated national authorities. Some authors are cognisant of this requirement and have written eloquently on the topic (Simberloff, 2005). From a broader perspective, the issue of regulation of invasive species under the SPS Agreement is an example of the well-worn discussion of the ceding of domestic regulatory autonomy when entering into international agreements (Wagner, 1998, 2000; Davey, 2001; Jackson, 2006; Trebilcock et al., 2013). This discussion in turn is a subset of the recent populist discontent with modern trade and globalisation. When discussing these issues it should be remembered that WTO Members have, in pursuit of their own national interests, agreed to exercise their sovereignty circumscribed by the commitments they have made in the WTO Agreement. This circumscription includes the manner in which they may restrict imports based on the risk posed by potentially invasive species. Those that would argue for far more stringent approaches should be cognisant of the concomitant costs such changes would impose in other areas such as market access for exports, as well as reduced choice and increased prices for domestic consumers. The WTO has a mandate as a trade regulator, not a protector of the environment. The task of risk management, including risk to the environment, sits with domestic regulatory authorities. Any change designed or initiated to manage invasive species 
in international trade is unlikely to occur through structural change to the WTO. It could, or should, instead be pursued via domestic biosecurity policy.

Regulations managing incoming commodities promulgated by domestic authorities in compliance with the SPS Agreement represent pre-border management. Pre-border management of invasive species is generally agreed upon to be the most effective and economical method of preventing the introduction of invasive species (Leung et al., 2002; Springborn et al., 2011; Kumschick \& Richardson, 2013). New Zealand's management and assessment of pre-border invasive species risk has been hailed as world-leading (Jenkins, 2005; Simberloff, 2013). Essentially, New Zealand's pre-border regime is relatively risk intolerant and takes a 'guilty until proven innocent' approach towards introductions. Imports of new organisms are subject to risk assessment under the Biosecurity Act 1993 and Hazardous Substances and New Organisms Act 1996; and are not permitted to be imported until an assessment has occurred.

Whilst New Zealand's pre-border approach has been heralded, post-border management has been subject to less scrutiny. Elsewhere, internal regulatory management of invasive species has been found to be fragmented and to differ across internal domestic jurisdictions (McCubbins et al., 2013; Riley, 2013; Smith et al., 2014). Systems which utilise a federal as opposed to unitary approach - such as Australia, Canada and the United States - have been the subject of particular focus (McCubbins et al., 2013; Smith et al., 2014). Under a federal system, such as the United States, powers are shared between the federal government and the states. This devolution of power has been observed to fragment invasive species policy and to complicate the development of a co-ordinated approach to the problem (Riley, 2012, 2013; McCubbins et al., 2013; Smith et al., 2014). In contrast, a unitary state - such as New Zealand - is governed as a single power in which central government is supreme and any sub-national units only have power that the government chooses to delegate. Chapter 3 narrows the focus of the thesis, from global risk management to the approach of New Zealand. Here, I outlined New Zealand's pre- and post-border approach to managing invasive species. I analysed the domestic management of invasive species in New Zealand and found similar patterns to those of the aforementioned federal jurisdictions, though not as acute. I recognised that from a conservation perspective the current paradigm of pre-border risk assessment in international 
trade could be seen as imperfect. However, it is ameliorated significantly by New Zealand's strong response capacity that is able to be utilised if a high priority invasive species is detected.

Although New Zealand is a unitary state, its internal management of many invasive species has been delegated under the Biosecurity Act to sub-national units - regional councils. These regional councils manage invasive species via Regional Pest Management Plans (RPMPs). My analysis found substantial differences in regional council's RPMPs; both in the pest plant and animal species regulated, as well as the annual council spend per unit area. This result was consistent across geographically contiguous regions such as Auckland, Bay of Plenty and Waikato that share broadly similar environmental conditions. This inconsistency is potentially problematic given the interconnectedness of these regions. Transport corridors such as roads and railways have been shown to facilitate the spread of non-native species across landscapes (Müllerová et al., 2005; Wangen \& Webster, 2006; von der Lippe \& Kowarik, 2007). All three of these regions are strongly interconnected via road, rail and commercial enterprises. Further, two of these regions are home to New Zealand's largest seaports - Auckland and Tauranga. Maintaining a consistent list of pests and biosecurity issues across such geographically similar regions could be of mutual benefit to regions as well as of national interest.

Invasions are not only terrestrial; aquatic invasive species are of increasing concern globally (Rahel \& Olden, 2008; Tsolaki \& Diamadopoulos, 2010). For instance, introduced bivalves have driven large-scale changes in ecosystem structure and function in freshwater waterways in the United States (Strayer et al., 1999). A key pathway of aquatic invasive species introduction is through ballast water or hitchhiking via hull fouling (Roman \& Darling, 2007; Williams \& Smith, 2007). Aquatic transport hubs have been found to be important centres of invasion (Floerl et al., 2009). At the time of writing only four of New Zealand's 15 regional councils had publicly available marine pest management strategies - this list did not include New Zealand's biggest seaport of Auckland. Given the risks posed by invasive marine species, the absence of such strategies was a surprising result. It may, however, simply represent a choice by regional councils to direct limited funding towards terrestrial environments where risks appear more manageable. Regardless, given evidence elsewhere of the impacts of aquatic invasive species, aquatic invasions appear to be a risk that should be managed. 
Since the publication of Chapter 3, New Zealand's biosecurity system has entered a state of significant flux. In November 2016 New Zealand's Ministry for Primary Industries instituted the Biosecurity 2025 project, the intention of which is to strengthen New Zealand's biosecurity system. This project is ongoing, but it is clear that significant changes are underway. It is likely that the outcomes of this project will affect or ameliorate many of the findings of this paper.

The first two substantive chapters of this thesis discussed invasive species in an expansive sense, seeking to provide a broad platform for the following empirical studies. Chapter 2 addressed world issues, Chapter 3, those specific to New Zealand. In Chapters 4-6 I sought to drill down further to the level of specific industries, species and pathogens. Research prompted by pollinator decline globally has resulted in an increase in knowledge of the role pathogens play in pollinator, especially honey bee, population dynamics (Dainat et al., 2012; Fürst et al., 2014; McMahon et al., 2016; Wilfert et al., 2016). The majority of this research has focussed on exchange of pathogens between commercial pollinators, such as honey bees and bumblebees (Potts et al., 2010; Fürst et al., 2014; Dicks et al., 2016). However, recent research into other Hymenopteran and insect species is suggesting that these honey bee pathogens may in fact be general to a range of arthropods (Evison et al., 2012a; Levitt et al., 2013; Lester et al., 2014c, 2015; Sébastien et al., 2015; Dobelmann et al., 2017; Gruber et al., 2017).

In Chapter 4 the focal point of the thesis resolves further, to the apiculture industry and risks posed by invasive species. This chapter is alive to the potential generality of honey bee pathogens. To our knowledge it is the first study that seeks to elucidate the role a globally distributed invasive ant may play in the mortality and disease dynamics of honey bees where they occur sympatrically. Honey bee pathogens had been found in Argentine ants prior to this study (Sébastien et al., 2015; Gruber et al., 2017). Chapter 4 provides a further example of Argentine ants carrying actively replicating copies of honey bee pathogens. It builds on prior research by demonstrating that this infection may have implications for other species. Over a six month period, hive survival in apiaries with Argentine ants was reduced compared to apiaries without ants. Also, we showed that Deformed wing virus (DWV) levels were always higher in bees when Argentine ants were present. These patterns represent novel scientific findings and are relevant to both the management of invasive species and honey bees. 
Levels of DWV infection in our study varied by orders of magnitude across time and apiary. Argentine ants have been shown to carry actively replicating copies of DWV (Sébastien et al., 2015; Chapter 4). Elsewhere, there is evidence suggesting that DWV plays a key role in honey bee decline in some circumstances (Schroeder \& Martin, 2012; Wilfert et al., 2016; Natsopoulou et al., 2017). The role introduced Hymenoptera play in transporting pathogens across landscapes is relatively poorly explored, but the little research that does exist has shown that in some circumstances there are negative consequences for native Hymenopteran species resulting from such movement (Schmid-Hempel et al., 2014). New Zealand has a diverse native and non-native Hymenopteran biota that interact with one another (Grangier \& Lester, 2011) which could potentially result in the sharing of disease, as has occurred elsewhere (SchmidHempel et al., 2014).

Pathogens may circulate in host populations at low levels for some time before causing detectable outbreaks (Longdon et al., 2014). The lack of outbreaks does not mean a lack of risk. In the case of viruses introduced to novel host communities in the recipient range, lack of outbreaks may simply be a lag caused by ongoing viral adaptation to maximise fitness in the novel host (Longdon et al., 2014). Some honey bee pathogens such as Kashmir bee virus (KBV) have not been demonstrated to have causative lethal effects on pollinators. However, sub-lethal effects in terms of slower colony start up and offspring product have been shown in a laboratory setting (Meeus et al., 2014). Latent infections in asymptomatic hosts can eventually result in deleterious impacts (Speck \& Ganem, 2010). Apparently mild illnesses can reduce fitness by influencing interspecific interactions and community composition (Vincent et al., 2014; Jones \& Coutts, 2015). In Chapter 6, I demonstrated that there is genetic variation in KBV strains both within small geographic areas and across large distances. Such a finding is in keeping with the observation that viral variation exists within Hymenopteran communities (Martin et al., 2012; Schroeder \& Martin, 2012).

New Zealand authorities have very few regulatory control measures for the domestic movement of non-native Hymenoptera across the landscape. Bee hives are often intentionally moved hundreds of kilometres for pollination purposes, or to access new sites for honey production (personal observation). In Chapter 4, we showed that hives may contain entire nests of Argentine ants, including reproductives. The rapid spread of Argentine ants across New 
Zealand since introduction provides indirect evidence of the ease with which this species is transported (Lester et al., 2003; Ward et al., 2010). Because these ants are associated with beehives, the movement of honey bees for pollination may help to spread pest species such as the Argentine ant, as was the case with the red imported fire ant (Solenopsis invicta) in the United States (Dowell et al., 1997). Movement of beehives may also facilitate movement of diseases pest species and bees carry. Further, species such as common and German wasps frequently rob beehives (Clapperton et al., 1989; MacIntyre \& Hellstrom, 2015), providing another opportunity for pathogen transfer.

In Chapters 4-6 I demonstrate that all the Hymenopteran species tested (Argentine ants, common wasps, German wasps and honey bees) carried viruses once only described from honey bees. Generalist viruses have been found to pose a greater threat to native biodiversity than specialist viruses (Vincent et al., 2014). Viruses have the potential to rapidly adapt to infect novel species encountered during biological invasions. RNA viruses, such as DWV and $\mathrm{KBV}$, have high mutation and nucleotide substitution rates, allowing them to adapt quickly to new species and environments (Duffy et al., 2008; Sanjuan et al., 2010). In some cases a viral host shift may occur with only a single mutation that alters a viral surface protein enabling it to bind to a host receptor protein (Longdon et al., 2014). The more successful an invasive species, the more host biomass is available for pathogens to infect. This effect is probably magnified in social species such as many Hymenoptera, especially in areas of extremely high population density, such as with common wasp densities in honeydew beech forests in New Zealand (Moller et al., 1991; Beggs et al., 1998). The effect of honey bee diseases on Hymenopterans such as wasps and ants is unknown and deserving of further research. I do not explicitly recommend an embargo on the movement of honey bees or other Hymenoptera, but cognisance of potential harm involved is prudent when managing risk.

My finding that several Hymenoptera species carry honey bee diseases is not confined to New Zealand. In Chapter 5 I showed that the globally distributed German wasp carries different strains of honey bee diseases in a variety of regions. Other studies have demonstrated a range of Hymenoptera carry honey bee pathogens elsewhere in the world (Evison et al., 2012a; Santamaria et al., 2017). Using variation in mitochondrial DNA in the invaded and native range of the German wasp I also demonstrated that invasive German wasp populations in 
different areas of the world came from different source populations and multiple introductions are likely to have occurred. Our findings are consistent with the literature on introductions of other invasive species. That is, invasive populations may contain many haplotypes that indicate multiple or single invasion events (Corin et al., 2007a; Lester et al., 2014b; Tsuchida et al., 2014; Valentin et al., 2017). In Chapter 6, whether the invaded German wasp populations were genetically homogenous or diverse, the wasps consistently carried honey bee diseases. In the case of honey bees, the global DWV strain landscape has been altered by the movement of the parasitic Varroa mite together with honey bees (Martin et al., 2012). What the effects of global admixture of pathogens carried by non-native Hymenoptera are is unknown, and requires further research.

Chapter 6 is the culmination of the iterative narrowing of focus of each chapter of this thesis. In this chapter I focussed on a single honey bee virus. I sequenced near entire genomes of KBV present in three different Hymenopteran species. I demonstrated that there is significant regional variation in $\mathrm{KBV}$ diversity across New Zealand and that this relatedness is higher within regions than between regions. Further, that all four Hymenopteran species tested in that study (Argentine ants, common wasps, German wasps, honey bees) carry KBV. This result demonstrates that the intentional or unintentional vectoring of Hymenopteran species across the landscape may result in the admixture of novel pathogen strains. As a second finding, I also showed that as sequence length increases, so does diversity between sequences. This highlights that approaches using short sequence reads to investigate strain diversity may be limited.

The human driven movement of animals, plants and microbes around the world has many impacts, both obvious and unseen. Legal regulation is usually a post-hoc response once a problem is, at best, incipient; or at worst, fully arisen. Biological systems are complex and poorly understood, therefore managing risks is challenging. My thesis has demonstrated that internationally, domestic regulators have substantial freedom to impose the level of protection they deem acceptable. At a national level, management is complicated by the devolution of power to sub-national units, which fragments national planning. I recommend that this fragmentation should be addressed in New Zealand, particularly in geographically contiguous areas that share environmental conditions. At the level of particular industries, species and pathogens, significant uncertainty exists. My thesis has shed some light on the presence of 
honey bee pathogens in various insect species, and the role these pathogens may play. However, there are many questions to be answered in relation to the role played by pathogens in insect community dynamics; as well as what impact humans have in this system. It is an exciting, fascinating and important area, in which it has been my privilege to work.

\subsection{Constraints and future research}

During the course of my research I encountered several constraints that prevented me from following certain research avenues and present fecund areas for further investigation.

In Chapter 2, I qualitatively evaluated the SPS Agreement and the ability of domestic regulators to manage risks posed by invasive species under its rules. However, empirical data validating my arguments would add strength to my propositions. Demonstrating causation of regulations in reducing the movement of invasive species is extremely difficult. Such a demonstration would require the analysis of large longitudinal datasets, usually held by domestic animal and plant protection authorities (e.g. Work et al., 2005; McCullough et al., 2006; Brenton-Rule et al., 2016). Unfortunately, these data are not recorded consistently between jurisdictions, making comparisons difficult. Further, when these data are made available there are often caveats attached to what they may be used for (McCullough personal communication ${ }^{194}$ ); usually relating to political considerations with regard to international trade. That said, elegant studies have been designed teasing out patterns in such datasets (Capinha et al., 2015; Bertelsmeier et al., 2017; Seebens et al., 2017, 2018). The efficacy of the SPS Agreement or other sanitary and phytosanitary regulations such as International Standards for Phytosanitary Measures could be investigated using such longitudinal datasets. For instance, pest interceptions associated with certain categories of commodity could be compared before and after implementation of targeted regulations. However, demonstrating causation instead of correlation would still prove challenging. The benefits of such a project could be substantial in terms of informing what improves biosecurity regulation and outcomes.

\footnotetext{
${ }^{194}$ Deborah McCullough is a Professor of Forest Entomology at Michigan State University. She was an author on two papers published in Biological Invasions that extensively used US APHIS border interception data (Work et al., 2005; McCullough et al., 2006).
} 
Chapter 4 hints at pathogen exchange between Argentine ants and honey bees, potentially contributing to honey bee mortality. This was the most novel finding of my thesis. However, a flaw in the study was the absence of data on Varroa abundance given the role Varroa play in vectoring DWV. The reason for this apparent oversight was that this was an opportunistic study of commercial hives prompted by dialogue with beekeepers. I could not control acaricidal treatment of the hives and beekeeper records of treatment were lacking - although the presence of Varroa strips in hives indicated treatment had occurred. Standard Varroa abundance monitoring methods require measurement of mite fall rates before, during and after acaricide treatment, as well as near daily access to the hives over a period of weeks (Branco et al., 2006). The only hives to which I was granted access where Argentine ants and bees occur sympatrically were in Northland, which meant daily access over a long period was prohibitively expensive. A further complication was that ants will often scavenge dead Varroa from bottom boards resulting the disappearance of dead mites before they can be counted (Dainat et al., 2011), although this issue may be managed through the use of ant traps where bottom board counts are used for Varroa diagnosis. Counts of phoretic mites are an antindependent measure, but this approach is invasive and could not be implemented as the hives were not our own. These constraints also confounded our ability to measure colony strength. Given these restrictions I could not evaluate Varroa abundance as is standard practice in the literature. Further, the data I presented are correlational not experimental.

To address many of these issues, it would be interesting to undertake an experimental assay to attempt to tease apart the observed patterns. Such an approach could introduce DWV-free Apis colonies - if DWV-free colonies exist - into areas with and without Argentine ants to test for the potential of viral transmission and to assess colony performance and survival over time. More data, such as measures of colony strength, could be assessed and differences measured over time. Additionally, the number of colonies analysed was limited. Some studies in this space analyse dozens or hundreds of hives to elucidate trends (e.g. Woodcock et al., 2017). Finally, abiotic factors such as temperature and rainfall were not analysed. These study limitations are able to be overcome and experimental field trials are planned in the future.

In Chapter 5 my original intent was to sample specimens from a broader distribution in the native range. However, some collaborators who had committed to sending samples took many 
months, and in some cases years, to send specimens. When samples did arrive some were labelled as having been collected decades previously. I attempted various techniques to extract quality RNA and DNA, but all PCR amplicons from these aged samples successfully sequenced were highly degraded and were discarded from analysis. Also, invasive populations of $V$. germanica have been reported from North America (Lester \& Beggs, 2018). I did not manage to obtain $V$. germanica specimens from this region, though received various other wasp species for which I am still grateful for the effort expended by collectors. It would be interesting and worthwhile to obtain North American samples to add to the dataset. Additionally, a broader sampling distribution within Argentina would strengthen my conclusion that the populations there are genetically homogenous. Finally, I did not manage to identify an identical haplotype within Europe that matched haplotypes within South Africa. Whilst our analyses suggest a western European origin, it was frustrating not to find an exact match. Further sampling in the native range would have proved useful.

Chapter 6 is novel as I amplify entire genomes of KBV from various Hymenoptera. Our approach used Sanger sequencing, which is extremely accurate (Rhoads \& Au, 2015), but gives no data as to strain diversity within individual wasps. To address this issue, using the DNA/RNA extractions from this chapter I have prepared samples for next generation sequencing. In theory, the resulting data should be able to be analysed to quantify the KBV strain variability within individual wasp specimens. This analysis is ongoing and will be completed for manuscript preparation. In Chapter $3 \mathrm{I}$ demonstrated that there is variation in viral load across seasons. In New Zealand's honeydew beech forests wasp densities are the highest in the world. It would be interesting to examine whether viral-load or strain diversity varies across the year in wasp populations; particularly during autumn which is the period of highest wasp density. A similar technique could be used in bee hives to analyse whether Argentine ants not only increase viral loads overall, but change viral strain frequency as has been observed in Varroa-Apis interactions (Martin et al., 2012).

From an even broader perspective it would be fascinating to use next generation sequencing approaches to elucidate how changes in insect species assemblage - such as after the introduction of an invasive species - changes pathogen dynamics within that community. As 
density-dependence plays a critical role in the survival and transmission of pathogens, areas such as New Zealand's honeydew beech forest would provide an ideal system for such a study.

It has been a wonderful privilege to spend time working on these questions. Few people are afforded the luxury to think and delve into research. I am extremely grateful for the opportunity, and hope whoever follows me has a similar experience. 


\section{References}

Aikio, S., Duncan, R.P., \& Hulme, P.E. (2010) Lag-phases in alien plant invasions: separating the facts from the artefacts. Oikos, 119, 370-378.

Aizen, M.A. \& Harder, L.D. (2009) The Global Stock of Domesticated Honey Bees Is Growing Slower Than Agricultural Demand for Pollination. Current Biology, 19, 915918.

Aizen, M.A., Smith-Ramírez, C., Morales, C.L., Vieli, L., Sáez, A., Barahona-Segovia, R.M., Arbetman, M.P., Montalva, J., Garibaldi, L.A., Inouye, D.W., \& Harder, L.D. (2018) Coordinated species importation policies are needed to reduce serious invasions globally: The case of alien bumblebees in South America. Journal of Applied Ecology, $1-7$.

Allen, M. \& Ball, B. V (1996) The incidence and world distribution of honeybee viruses. Bee World, 77, 141-162.

Andersen, M.C., Adams, H., Hope, B., \& Powell, M. (2004) Risk assessment for invasive species. Risk Analysis, 24, 787-793.

Anderson, R.M. \& May, R.M. (1979) Population biology of infectious disease: Part I. Nature, 280, 361-367.

Archer, M.E. (1998) The world distribution of the Euro-Asian species of Paravespula (Hym., Vespinae). Entomologists’ Montly Magazine, 134, 279-284.

Atik, J. (2004) The Weakest Link: Demonstrating the Inconsistency of "Appropriate Levels of Protection" in Australia-Salmon. Risk Analysis, 24, 483-490.

Aukema, J.E., Leung, B., Kovacs, K., Chivers, C., Britton, K.O., Englin, J., Frankel, S.J., Haight, R.G., Holmes, T.P., Liebhold, A.M., McCullough, D.G., \& von Holle, B. (2011) Economic impacts of Non-Native forest insects in the continental United States. PLoS ONE, 6, e24587.

Avila, G.A., Berndt, L.A., \& Holwell, G.I. (2013) Dispersal behavior of the parasitic wasp Cotesia urabae (Hymenoptera: Braconidae): A recently introduced biocontrol agent for the control of Uraba lugens (Lepidoptera: Nolidae) in New Zealand. Biological Control, 66, 166-172.

Bailey, L., Ball, B. V, \& Woods, R.D. (1976) An Iridovirus from Bees. Journal of General 
Virology, 43, 641-647.

Bailey, L., Ball, B. V, \& Woods, R.D. (1979) Egypt Bee Virus and Australian Isolates of Kashmir Bee Virus. Journal of General Virology.

Banks, P.B. \& Dickman, C.R. (2007) Alien predation and the effects of multiple levels of prey naivete. Trends in Ecology and Evolution, 22, 229-230.

Beggs, J. (2001) The ecological consequences of social wasps (Vespula spp.) invading an ecosystem that has an abundant carbohydrate resource. Biological Conservation, 99, 1728.

Beggs, J.R., Brockerhoff, E.G., Corley, J.C., Kenis, M., Masciocchi, M., Muller, F., Rome, Q., \& Villemant, C. (2011) Ecological effects and management of invasive alien Vespidae. BioControl, 56, 505-526.

Beggs, J.R., Rees, J.S., \& Harris, R.J. (2002) No evidence for establishment of the wasp parasitoid, Sphecophaga vesparum burra (Cresson) (Hymenoptera: Ichneumonidae) at two sites in New Zealand. New Zealand Journal of Zoology, 29, 205-211.

Beggs, J.R., Rees, J.S., Toft, R.J., Dennis, T.E., \& Barlow, N.D. (2008) Evaluating the impact of a biological control parasitoid on invasive Vespula wasps in a natural forest ecosystem. Biological Control, 44, 399-407.

Beggs, J.R., Toft, R.J., Malham, J.P., Rees, J.S., Tilley, J.A. V., Moller, H., \& Alspach, P. (1998) The Difficulty of Reducing Introduced Wasp (Vespula vulgaris) Populations for Conservation Gains. New Zealand Journal of Ecology, 22, 55-63.

Bellingham, P.J., Towns, D.R., Cameron, E.K., Davis, J.J., Wardle, D.A., Wilmshurst, J.M., \& Mulder, C.P.H. (2010) New Zealand island restoration: Seabirds, predators, and the importance of history. New Zealand Journal of Ecology, 34, 115-136.

Berényi, O., Bakonyi, T., Derakhshifar, I., Köglberger, H., Topolska, G., Ritter, W., Pechhacker, H., \& Nowotny, N. (2007) Phylogenetic analysis of deformed wing virus genotypes from diverse geographic origins indicates recent global distribution of the virus. Applied and Environmental Microbiology, 73, 3605-3611.

Bergstrom, D.M., Lucieer, A., Kiefer, K., Wasley, J., Belbin, L., Pedersen, T.K., \& Chown, S.L. (2009) Indirect effects of invasive species removal devastate World Heritage Island. Journal of Applied Ecology, 46, 73-81. 
Bertelsmeier, C., Ollier, S., Liebhold, A., \& Keller, L. (2017) Recent human history governs global ant invasion dynamics. Nature Ecology and Evolution, 1, 0184.

Berthoud, H., Imdorf, A., Haueter, M., Radloff, S., \& Neumann, P. (2010) Virus infections and winter losses of honey bee colonies (Apis mellifera). Journal of Apicultural Research, 49, 60-65.

Blackburn, T.M., Essl, F., Evans, T., et al. (2014) A Unified Classification of Alien Species Based on the Magnitude of their Environmental Impacts. PLoS Biology, e1001850 12.

Blackburn, T.M., Pyšek, P., Bacher, S., Carlton, J.T., Duncan, R.P., Jarošík, V., Wilson, J.R.U., \& Richardson, D.M. (2011) A proposed unified framework for biological invasions. Trends in Ecology \& Evolution, 26, 333-9.

Bohanes, J. (1999) The WTO's interpretation of the SPS Agreement has undermined the right of governments to establish appropriate levels of protection against risk. Law and Policy in International Business, 31, 855-859.

Bohanes, J. (2002) Risk regulation in WTO law: a procedure-based approach to the precautionary principle. Columbia Journal of Transnational Law, 40, 323-389.

Bohanes, J. \& Lockhart, N. (2009) Standards of Review in WTO Law. The Oxford Handbook of International Economic Law (ed. by R. Neufeld and I. Van Damme), Oxford University Press, Oxford.

Bradshaw, C.J.A., Leroy, B., Bellard, C., Albert, C., Roiz, D., Barbet-Massin, M., Fournier, A., Salles, J.-M., Simard, F., \& Courchamp, F. (2016) Massive yet grossly underestimated global costs of invasive insects. Nature Communications, 7, 12986.

Branco, M.R., Kidd, N.A.C., \& Pickard, R.S. (2006) A comparative evaluation of sampling methods for Varroa destructor (Acari: Varroidae) population estimation. Apidologie, 37, $558-565$.

Brasier, C.M. (2008) The biosecurity threat to the UK and global environment from international trade in plants. Plant Pathology, 57, 792-808.

Brenton-Rule, E.C., Barbieri, R.F., \& Lester, P.J. (2016) Corruption, development and governance indicators predict invasive species risk from trade. Proceedings of the Royal Society B: Biological Sciences, 283, 20160901. 
Briggs, J.C. (2017) Rise of Invasive Species Denialism? A Response to Russell and Blackburn. Trends in Ecology and Evolution, 32, 231-232.

Burgess, T. \& Wingfield, M.J. (2001) Exotic pine forestry in the Southern Hemisphere: A brief history of establishment and quarantine practices. Southern African Forestry Journal, 192, 79-83.

Burgiel, S. (2015) From Global to Local: Integrating Policy Frameworks for the Prevention and Management of Invasive Species. Invasive Species in a Globalized World (ed. by R.P. Keller, M.W. Cadotte, and G. Sandiford), pp. 283-302. University of Chicago Press.

Burrill, A.C. (1926) Ants that infest beehives. American Bee Journal, 66, 29-31.

Burt, A. (2003) Site-specific selfish genes as tools for the control and genetic engineering of natural populations. Proceedings of the Royal Society B: Biological Sciences, 270, 921928.

Button, C. (2004) The Power to Protect: Trade, Health and Uncertainty in the WTO. Hart Publishing, Oregon.

Calderone, N.W. (2012) Insect pollinated crops, insect pollinators and US agriculture: Trend analysis of aggregate data for the period 1992-2009. PLOS ONE, 7, 24-28.

Cameron, R.C., Duncan, E.J., \& Dearden, P.K. (2013) Stable reference genes for the measurement of transcript abundance during larval caste development in the honeybee. Apidologie, 44, 357-366.

Campbell, F.T. (2001) The Science of Risk Assessment for Phytosanitary Regulation and the Impact of Changing Trade Regulations. BioScience, 51, 148-153.

Capinha, C., Essl, F., Seebens, H., Moser, D., \& Pereira, H.M. (2015) The dispersal of alien species redefines biogeography in the Anthropocene. Science, 348, 1248-1251.

Carlsson, N., Brönmark, C., \& Hansson, L. (2004) Invading herbivory: the golden apple snail alters ecosystem functioning in Asian wetlands. Ecology, 85, 1575-1580.

Carrillo-Tripp, J., Dolezal, A.G., Goblirsch, M.J., Miller, W.A., Toth, A.L., \& Bonning, B.C. (2016) In vivo and in vitro infection dynamics of honey bee viruses. Scientific Reports, 6, 22265 . 
Cavigli, I., Daughenbaugh, K.F., Martin, M., Lerch, M., Banner, K., Garcia, E., Brutscher, L.M., \& Flenniken, M.L. (2016) Pathogen prevalence and abundance in honey bee colonies involved in almond pollination. Apidologie, 47, 251-266.

Chen, Y., Pettis, J.S., \& Feldlaufer, M.F. (2005) Detection of multiple viruses in queens of the honey bee Apis mellifera L. Journal of Invertebrate Pathology, 90, 118-121.

Clapperton, B.K., Alspach, P.A., Moller, H., \& Matheson, A.G. (1989) The impact of common and German wasps (Hymenoptera: Vespidae) on the New Zealand beekeeping industry. New Zealand Journal of Zoology, 16, 325-332.

Colautti, R.I., Ricciardi, A., Grigorovich, I.A., \& MacIsaac, H.J. (2004) Is invasion success explained by the enemy release hypothesis? Ecology Letters, 7, 721-733.

Cook, D., Henry, D., Sheppard, A., \& Lonsdale, M. (2008) Transition to resilient social communities and cities: Biosecurity. CSIRO, Canberra.

Cooling, M., Sim, D.A., \& Lester, P.J. (2015) Density-dependent effects of an invasive ant on a ground-dwelling arthropod community. Environmental Entomology, 44, 44-53.

Cooney, R. \& Lang, A.T.F. (2007) Taking Uncertainty Seriously: Adaptive Governance and International Trade. The European Journal of Environmental Law, 18, 523-551.

Corin, S.E., Lester, P.J., Abbott, K.L., \& Ritchie, P. a. (2007a) Inferring historical introduction pathways with mitochondrial DNA: the case of introduced Argentine ants (Linepithema humile) into New Zealand. Diversity and Distributions, 13, 510-518.

Courchamp, F., Fournier, A., Bellard, C., Bertelsmeier, C., Bonnaud, E., Jeschke, J.M., \& Russell, J.C. (2017) Invasion Biology: Specific Problems and Possible Solutions. Trends in Ecology and Evolution, 32, 13-22.

Cox, J.G. \& Lima, S.L. (2006) Naiveté and an aquatic-terrestrial dichotomy in the effects of introduced predators. Trends in Ecology and Evolution, 21, 674-680.

Covelli, N. \& Hohots, V. (2003) The Health Regulation of Biotech Foods Under the WTO Agreements. Journal of International Economic Law, 6, 773-795.

Crosby, A. (1986) Ecological Imperialism - The Biological Expanasion of Europe, 900-1900. Cambridge University Press, Cambridge.

Crosland, M.W. (1991) The spread of the social wasp, Vespula germanica, in Australia. New 
Zealand Journal of Zoology, 18, 375-388.

Crowley, S.L., Hinchliffe, S., Redpath, S.M., \& McDonald, R.A. (2017) Disagreement About Invasive Species Does Not Equate to Denialism: A Response to Russell and Blackburn. Trends in Ecology and Evolution, 32, 228-229.

Dahlstrom, A., Hewitt, C.L., \& Campbell, M.L. (2011) A review of international, regional and national biosecurity risk assessment frameworks. Marine Policy, 35, 208-217.

Dainat, B., Evans, J.D., Chen, Y.P., Gauthier, L., \& Neumann, P. (2012) Dead or alive: Deformed Wing Virus and Varroa Destructor Reduce the Life Span of Winter Honeybees. Applied and Environmental Microbiology, 78, 981-987.

Dainat, B., Kuhn, R., Cherix, D., \& Neumann, P. (2011) A scientific note on the ant pitfall for quantitative diagnosis of Varroa destructor. Apidologie, 42, 740-742.

Daszak, P., Cunningham, A.A., \& Hyatt, A.D. (2000) Emerging Infectious Diseases of Wildlife - Threats to Biodiversity and Human Health. Science, 287, 443-449.

Davey, W.J. (2001) Has the WTO dispute settlement system exceeded its authority? A consideration of deference shown by the system to member government decisions and its use of issue-avoidance techniques. Journal of International Economic Law, 4, 79110.

Davidson, A.D., Hewitt, C.L., \& Kashian, D.R. (2015) Understanding Acceptable Level of Risk: Incorporating the Economic Cost of Under-Managing Invasive Species. PLoS ONE, 10, e0141958.

Dearden, P.K., Gemmell, N.J., Mercier, O.R., \& Lester, P.J. (2017) The potential for the use of gene drives for pest control in New Zealand: a perspective. Journal of the Royal Society of New Zealand, 1-20.

Dicks, L. V., Viana, B., Bommarco, R., Brosi, B., Arizmendi, C., Cunningham, S.A., Galetto, L., Hill, R., Lopes, V., Pires, C., \& Taki, H. (2016) Ten policies for pollinators - What governments can do to safeguard pollination services. Science, 354, 14-15.

DiTomaso, J. (2000) Invasive weeds in rangelands: Species, impacts, and management. Weed Science, 48, 255-265.

Dobelmann, J., Loope, K.J., Wilson-Rankin, E., Quinn, O., Baty, J.W., Gruber, M.A.M., \& 
Lester, P.J. (2017) Fitness in invasive social wasps: the role of variation in viral load, immune response and paternity in predicting nest size and reproductive output. Oikos, 126, 1208-1218.

Don, W. (2007) Ants of New Zealand. Otago University Press, Dunedin.

Donovan, B.J. (1983) The common wasp is here. New Zealand Beekeeper, 180, 9-10.

Donovan, B.J. \& Read, P.E.C. (1987) Attempted biological control of social wasps, Vespula spp., (Hymenoptera: Vespidae) with Sphecophaga vesparum (curtis) (Hymenoptera: Ichneumonidae) in New Zealand. New Zealand Journal of Zoology, 14, 329-335.

Dowell, R. V, Gilbert, A., \& Sorensen, J. (1997) Red Imported Fire Ant Found in California. California Plant Pest and Disease Report, June-Septe, .

Dowling, D.K., Tompkins, D.M., \& Gemmell, N.J. (2015) The Trojan Female Technique for pest control: A candidate mitochondrial mutation confers low male fertility across diverse nuclear backgrounds in Drosophila melanogaster. Evolutionary Applications, 8, $871-880$

Druett, J. (1983) Exotic Intruders. Heinemann Publishers, Auckland.

Drury, D.W., Dapper, A.L., Siniard, D.J., Zentner, G.E., \& Wade, M.J. (2017) CRISPR/Cas9 gene drives in genetically variable and nonrandomly mating wild populations. Science Advances, 3, e1601910.

Du, M.M. (2010a) Autonomy in setting appropriate level of protection under the WTO law: Rhetoric or reality? Journal of International Economic Law, 13, 1077-1102.

Du, M.M. (2010b) Standard of Review Under the SPS Agreement After EC-Hormones II. International and Comparative Law Quarterly, 59, 441-459.

Du, M.M. (2011) The Rise of National Regulatory Autonomy in the GATT/WTO Regime. Journal of International Economic Law, 14, 639-675.

Duffy, S., Shackelton, L.A., \& Holmes, E.C. (2008) Rates of evolutionary change in viruses: Patterns and determinants. Nature Reviews Genetics, 9, 267-276.

Dupas, S., Carton, Y., \& Poiriè, M. (2003) Genetic dimension of the coevolution of virulence-resistance in Drosophila - Parasitoid wasp relationships. Heredity, 90, 84-89.

Early, R., Bradley, B.A., Dukes, J.S., Lawler, J.J., Olden, J.D., Blumenthal, D.M., Gonzalez, 
P., Grosholz, E.D., Ibañez, I., Miller, L.P., Sorte, C.J.B., \& Tatem, A.J. (2016) Global threats from invasive alien species in the twenty-first century and national response capacities. Nature Communications, 7, 12485.

Edwards, E., Toft, R., Joice, N., \& Westbrooke, I. (2017) The efficacy of Vespex ${ }^{\circledR}$ wasp bait to control Vespula species (Hymenoptera: Vespidae) in New Zealand. International Journal of Pest Management, 63, 266-272.

Ehrenfeld, J.G. (2003) Effects of Exotic Plant Invasions on Soil Nutrient Cycling Processes. Ecosystems, 6, 503-523.

Eldridge, R.H. \& Simpson, J.A. (1987) Development of contingency plans for use against exotic pests and diseases of trees and timber - Histories of control measures against some introduced pests and diseases of forests and forest products in Australia. Australian Forestry, 50, 24-36.

Ellender, B.R., Woodford, D.J., Weyl, O.L.F., \& Cowx, I.G. (2014) Managing conflicts arising from fisheries enhancements based on non-native fishes in southern Africa. Journal of Fish Biology, 85, 1890-1906.

Ellstrand, N.C. \& Schierenbeck, K.A. (2006) Hybridization as a stimulus for the evolution of invasiveness in plants? Euphytica, 148, 35-46.

Epps, T. (2012) Recent Developments in WTO Jurisprudence: Has the Appellate Body Resolved the Issue of an Appropriate Standard of Review in SPS Cases? University of Toronto Law Journal, 62, 201-227.

Errard, C., Delabie, J., Jourdan, H., \& Hefetz, A. (2005) Intercontinental chemical variation in the invasive ant Wasmannia auropunctata (Roger) (Hymenoptera Formicidae): A key to the invasive success of a tramp species. Naturwissenschaften, 92, 319-323.

Esvelt, K.M. \& Gemmell, N.J. (2017) Conservation demands safe gene drive. PLoS Biology, $15,1-8$.

Esvelt, K.M., Smidler, A.L., Catteruccia, F., \& Church, G.M. (2014) Concerning RNAguided gene drives for the alteration of wild populations. eLife, 3, 1-21.

Evison, S.E.F., Roberts, K.E., Laurenson, L., Pietravalle, S., Hui, J., Biesmeijer, J.C., Smith, J.E., Budge, G., \& Hughes, W.O.H. (2012a) Pervasiveness of parasites in pollinators. PloS one, 7, e30641. 
Evison, S.E.F., Roberts, K.E., Laurenson, L., Pietravalle, S., Hui, J., Biesmeijer, J.C., Smith, J.E., Budge, G., \& Hughes, W.O.H. (2012b) Pervasiveness of parasites in pollinators. PloS one, 7, e30641.

Finnoff, D., Shogren, J.F., Leung, B., \& Lodge, D. (2007) Take a risk: Preferring prevention over control of biological invaders. Ecological Economics, 62, 216-222.

Flanagan, T.P., Pinter-Wollman, N.M., Moses, M.E., \& Gordon, D.M. (2013) Fast and Flexible: Argentine Ants Recruit from Nearby Trails. PLoS ONE, 8, e70888.

Floerl, O., Inglis, G.J., Dey, K., \& Smith, A. (2009) The importance of transport hubs in stepping-stone invasions. Journal of Applied Ecology, 46, 37-45.

Forseth, I.N. \& Innis, A.F. (2004) Kudzu (Pueraria montana): History, Physiology, and Ecology Combine to Make a Major Ecosystem Threat. Critical Reviews in Plant Sciences, 23, 401-413.

Foster, C.E. (2008) Public Opinion and the Interpretation of the World Trade Organisation's Agreement on Sanitary and Phytosanitary Measures. Journal of International Economic Law, 11, 427-458.

Foucaud, J., Orivel, J., Loiseau, A., Delabie, J.H.C., Jourdan, H., Konghouleux, D., Vonshak, M., Tindo, M., Mercier, J.L., Fresneau, D., Mikissa, J.B., McGlynn, T., Mikheyev, A.S., Oettler, J., \& Estoup, A. (2010) Worldwide invasion by the little fire ant: routes of introduction and eco-evolutionary pathways. Evolutionary Applications, 3, 363-374.

Francis, R.M., Nielsen, S.L., \& Kryger, P. (2013) Varroa-Virus Interaction in Collapsing Honey Bee Colonies. PLoS ONE, 8, e57540.

Fürst, M.A., McMahon, D.P., Osborne, J.L., Paxton, R.J., \& Brown, M.J.F. (2014) Disease associations between honeybees and bumblebees as a threat to wild pollinators. Nature, 506, 364-366.

Gallai, N., Salles, J.-M., Settele, J., \& Vaissière, B.E. (2009) Economic valuation of the vulnerability of world agriculture confronted with pollinator decline. Ecological Economics, 68, 810-821.

Goodisman, M.A.D., Matthews, R.W., \& Crozier, R.H. (2001) Hierarchical genetic structure of the introduced wasp Vespula germanica in Australia. Molecular Ecology, 10, 14231432. 
Goolsby, J.A., De Barro, P.J., Makinson, J.R., Pemberton, R.W., Hartley, D.M., \& Frohlich, D.R. (2006) Matching the origin of an invasive weed for selection of a herbivore haplotype for a biological control programme. Molecular Ecology, 15, 287-297.

Gordon, D.R., Onderdonk, D.A., Fox, A.M., \& Stocker, R.K. (2008) Consistent accuracy of the Australian weed risk assessment system across varied geographies. Diversity and Distributions, 14, 234-242.

Grangier, J. \& Lester, P.J. (2011) A novel interference behaviour: Invasive wasps remove ants from resources and drop them from a height. Biology Letters, 7, 664-667.

Graystock, P., Yates, K., Evison, S.E.F., Darvill, B., Goulson, D., \& Hughes, W.O.H. (2013) The Trojan hives: pollinator pathogens, imported and distributed in bumblebee colonies. Journal of Applied Ecology, 50, 1207-1215.

Grodowitz, M.J., Center, T.D., Cofrancesco, A.F., \& Freedman, J.E. (1997) Release and establishment of Hydrellia balciunasi (Diptera: Ephydridae) for the biological control of the submersed aquatic plant Hydrilla verticillata (Hydrocharitaceae) in the United States. Biological Control, 9, 15-23.

Groffman, P.M., Stylinski, C., Nisbet, M.C., Duarte, C.M., Jordan, R., Burgin, A., Andrea Previtali, M., \& Cary, J.C. (2010) Restarting the conversation: Challenges at the interface between ecology and society. Frontiers in Ecology and the Environment, 8, 284-291.

Gruber, M.A.M. Pacific Biosecurity, www.pacificbiosecurity.org (2018)

Gruber, M.A.M., Cooling, M., Baty, J.W., Buckley, K., Friedlander, A., Quinn, O., Russell, J.F.E.J., Sébastien, A., \& Lester, P.J. (2017) Single-stranded RNA viruses infecting the invasive Argentine ant, Linepithema humile. Scientific Reports, 7, 3304.

Gruszczynski, L. (2010) Regulating health and environmental risks under WTO law: A critical analysis of the SPS agreement.

Gurr, L. (1972) The introduction of bumblebees into North Island, New Zealand. New Zealand Journal of Agricultural Research, 15, 635-638.

Hammond, A., Galizi, R., Kyrou, K., Simoni, A., Siniscalchi, C., Katsanos, D., Gribble, M., Baker, D., Marois, E., Russell, S., Burt, A., Windbichler, N., Crisanti, A., \& Nolan, T. (2016) A CRISPR-Cas9 gene drive system targeting female reproduction in the malaria 
mosquito vector Anopheles gambiae. Nature Biotechnology, 34, 78-83.

Hansen, H. (1984) The incidence of the foulbrood bacterium Bacillus larvae in honey retailed in Denmark. Danish Journal of Plant and Soil Science, 88, 329-336.

Hartley, S., Harris, R., \& Lester, P.J. (2006) Quantifying uncertainty in the potential distribution of an invasive species: climate and the Argentine ant. Ecology Letters, 9, 1068-1079.

Hartley, S. \& Lester, P.J. (2003) Temperature-dependent development of the Argentine ant, Linepithema humile (Mayr) (Hymenoptera: Formicidae): A degree-day model with implications for range limits in New Zealand. New Zealand Entomologist, 26, 91-100.

Haseeb Ansari, A. \& Wartini, S. (2014) Application of precautionary principle in international trade law and international environmental law. Journal of International Trade Law and Policy, 13, 19-43.

Hasegawa, M., Kishino, H., \& Yano, T. Aki (1985) Dating of the human-ape splitting by a molecular clock of mitochondrial DNA. Journal of Molecular Evolution, 22, 160-174.

Hastings, A., Cuddington, K., Davies, K.F., Dugaw, C.J., Elmendorf, S., Freestone, A., Harrison, S., Holland, M., Lambrinos, J., Malvadkar, U., Melbourne, B.A., Moore, K., Taylor, C., \& Thomson, D. (2005) The spatial spread of invasions: New developments in theory and evidence. Ecology Letters, 8, 91-101.

Hoffmann, B.D. (2011) Eradication of populations of an invasive ant in northern Australia: successes, failures and lessons for management. Biodiversity and Conservation, 20, 3267-3278.

Holway, D. (1999) Competitive mechanisms underlying the displacement of native ants by the invasive Argentine ant. Ecology, 80, 238-251.

Holway, D.A., Lach, L., Suarez, A. V., Tsutsui, N.D., \& Case, T.J. (2002) The Causes and Consequences of Ant Invasions. Annual Review of Ecology and Systematics, 33, 181233.

Hulme, P.E. (2009) Trade, transport and trouble: managing invasive species pathways in an era of globalization. Journal of Applied Ecology, 46, 10-18.

Hulme, P.E. (2011) Addressing the threat to biodiversity from botanic gardens. Trends in 
Ecology \& Evolution, 26, 168-74.

Hulme, P.E., Bacher, S., Kenis, M., Klotz, S., Kühn, I., Minchin, D., Nentwig, W., Olenin, S., Panov, V., Pergl, J., Pyšek, P., Roques, A., Sol, D., Solarz, W., \& Vilà, M. (2008) Grasping at the routes of biological invasions: a framework for integrating pathways into policy. Journal of Applied Ecology, 45, 403-414.

IPBES (2016) The assessment report of the Intergovernmental Science-Policy Platform on Biodiversity and Ecosystem Services on pollinators, pollination and food production.

IPBES (2016) Summary for policymakers of the assessment report of the Intergovernmental Science-Policy Platform on Biodiversity and Ecosystem Services on pollinators, pollination, and food production.

Jackson, J.H. (1997) The Great 1994 Sovereignty Debate: United States Acceptance and Implementation of the Uruguay Round Results. Columbia Journal of Transnational Law, .

Jackson, J.H. (2006) Sovereignty, the WTO and Changing Fundamentals of International Law. Cambridge University Press.

Jenkins, P. (2007) International Law on Precautionary Approaches To National Regulation of Live Animal Imports.

Jenkins, P.T. (2005) International Law Related to Precautionary Approaches to National Regulation of Plant Imports. Journal of World Trade, 39, 895-906.

Jones, K.E., Patel, N.G., Levy, M.A., Storeygard, A., Balk, D., Gittleman, J.L., \& Daszak, P. (2008) Global trends in emerging infectious diseases. Nature, 451, 990-994.

Jones, R.A.C. \& Coutts, B.A. (2015) Spread of introduced viruses to new plants in natural ecosystems and the threat this poses to plant biodiversity. Molecular Plant Pathology, 16, 541-545.

Juliano, S.A. \& Lounibos, P.L. (2005) Ecology of invasive mosquitoes: effects on resident species and on human health. Ecology Letters, 8, 558-574.

Karesh, W.B., Cook, R. a, Bennett, E.L., \& Newcomb, J. (2005) Wildlife trade and global disease emergence. Emerging Infectious Diseases, 11, 1000-2.

Keane, R.M. \& Crawley, M.J. (2002) Exotic plant invasions and the enemy release 
hypothesis. Trends in Ecology \& Evolution, 17, 164-170.

Keller, R.P., Lodge, D.M., \& Finnoff, D.C. (2007) Risk assessment for invasive species produces net bioeconomic benefits. Proceedings of the National Academy of Sciences of the United States of America, 104, 203-207.

Keller, R.P. \& Springborn, M.R. (2014) Closing the screen door to new invasions. Conservation Letters, 7, 285-292.

Klein, A.-M., Vaissière, B.E., Cane, J.H., Steffan-Dewenter, I., Cunningham, S.A., Kremen, C., \& Tscharntke, T. (2007) Importance of pollinators in changing landscapes for world crops. Proceedings of the Royal Society B: Biological Sciences, 274, 303-313.

Kobelt, M. \& Nentwig, W. (2008) Alien spider introductions to Europe supported by global trade. Diversity and Distributions, 14, 273-280.

Kraus, F.B., Neumann, P., \& Moritz, R.F.A. (2005) Genetic variance of mating frequency in the honeybee (Apis mellifera). Insectes Sociaux, 52, 1-5.

Kumar, S., Stecher, G., \& Tamura, K. (2015) MEGA7: Molecular Evolutionary Genetics Analysis version 7.0 for bigger datasets.

Kumschick, S. \& Richardson, D.M. (2013) Species-based risk assessments for biological invasions: advances and challenges. Diversity and Distributions, 19, 1095-1105.

Langwig, K.E., Frick, W.F., Bried, J.T., Hicks, A.C., Kunz, T.H., \& Marm Kilpatrick, A. (2012) Sociality, density-dependence and microclimates determine the persistence of populations suffering from a novel fungal disease, white-nose syndrome. Ecology Letters, 15, 1050-1057.

Lester, P.J. (2005) Determinants for the successful establishment of exotic ants in New Zealand. Diversity and Distributions, 11, 279-288.

Lester, P.J. (2018) The Vulgar Wasp. Victoria Univesity Press, Wellington.

Lester, P.J., Baring, C.W., Longson, C.G., \& Hartley, S. (2003) Argentine and other ants (Hymenoptera: Formicidae) in New Zealand horticultural ecosystems: Distribution, Hemipteran hosts, and review. New Zealand Entomologist, 26, 79-89.

Lester, P.J., Beggs, J., \& Brown, R.L. (2013) The outlook for control of New Zealand's most abundant, widespread and damaging invertebrate pests: social wasps. New Zealand 
Science Review, 70, 56-62.

Lester, P.J. \& Beggs, J.R. (2018) Vespula wasp review. Annual Review of Entomology, .

Lester, P.J., Bosch, P.J., Gruber, M.A.M., Kapp, E.A., Peng, L., Brenton-Rule, E.C., Buchanan, J., Stanislawek, W.L., Archer, M., Corley, J.C., Masciocchi, M., Van Oystaeyen, A., \& Wenseleers, T. (2015) No evidence of enemy release in pathogen and microbial communities of common wasps (Vespula vulgaris) in their native and introduced range. PLoS ONE, 10, e 0121358.

Lester, P.J., Brown, S.D.J., Edwards, E.D., Holwell, G.I., Pawson, S.M., Ward, D.F., \& Watts, C.H. (2014a) Critical issues facing New Zealand entomology. New Zealand Entomologist, 37, 1-13.

Lester, P.J., Gruber, M.A.M., Brenton-Rule, E.C., Archer, M., Corley, J.C., Dvořák, L., Masciocchi, M., \& Van Oystaeyen, A. (2014b) Determining the origin of invasions and demonstrating a lack of enemy release from microsporidian pathogens in common wasps (Vespula vulgaris). Diversity and Distributions, 20, 964-974.

Lester, P.J., Haywood, J., Archer, M.E., \& Shortall, C.R. (2017) The long-term population dynamics of common wasps in their native and invaded range. Journal of Animal Ecology, 86, 337-347.

Leung, B., Lodge, D.M., Finnoff, D., Shogren, J.F., Lewis, M. A, \& Lamberti, G. (2002) An ounce of prevention or a pound of cure: bioeconomic risk analysis of invasive species. Proceedings of the Royal Society B: Biological Sciences, 269, 2407-13.

Leung, B., Roura-Pascual, N., Bacher, S., Heikkilä, J., Brotons, L., Burgman, M.A., DehnenSchmutz, K., Essl, F., Hulme, P.E., Richardson, D.M., Sol, D., \& Vilà, M. (2012) TEASIng apart alien species risk assessments: A framework for best practices. Ecology Letters, 15, 1475-1493.

Levan, K.E. \& Holway, D.A. (2015) Ant-aphid interactions increase ant floral visitation and reduce plant reproduction via decreased pollinator visitation. Ecology, 96, 1620-1630.

Levine, J.M. \& D’Antonio, C.M. (2003) Forecasting biological invasions with increasing international trade. Conservation Biology, 217, 322-326.

Levitt, A.L., Singh, R., Cox-Foster, D.L., Rajotte, E., Hoover, K., Ostiguy, N., \& Holmes, E.C. (2013) Cross-species transmission of honey bee viruses in associated arthropods. 
Virus Research, 176, 232-240.

von der Lippe, M. \& Kowarik, I. (2007) Long-distance dispersal of plants by vehicles as a driver of plant invasions. Conservation Biology, 21, 986-996.

Lockwood, J.L., Hoopes, M., \& Marchetti, M. (2009) An introduction to invasion ecology. In: Invasion ecology. Blackwell Publishing, Malden.

Lodge, D., Williams, S., MacIsaac, H., Hayes, K., Leung, B., Reichard, S., Mack, R., Moyle, P., Smith, M., Andow, D., Carlton, J., \& McMichael, A. (2006) Biological Invasions: Recommendations for U.S. Policy and Management. Ecological Applications, 16, 20352054.

Longdon, B., Brockhurst, M.A., Russell, C.A., Welch, J.J., \& Jiggins, F.M. (2014) The Evolution and Genetics of Virus Host Shifts. PLoS Pathogens, 10, e1004395.

Lowe, S., Browne, M., Boudjelas, S., \& De Poorter, M. (2000) 100 of the World's Worst Invasive Alien Species. A Selection from the Global Invasive Species Database. Published by the Invasive Species Specialist Group of the World Conservation Union.

MacIntyre, P. \& Hellstrom, J. (2015) An evaluation of the costs of pest wasps (Vespula species) in New Zealand. Department of Conservation and Ministry for Primary Industries, 57, .

MacLeod, A., Pautasso, M., Jeger, M.J., \& Haines-Young, R. (2010) Evolution of the international regulation of plant pests and challenges for future plant health. Food Security, 2, 49-70.

Manley, R., Boots, M., \& Wilfert, L. (2015) Emerging viral disease risk to pollinating insects: ecological, evolutionary and anthropogenic factors. Journal of Applied Ecology, 52, 331-340.

Martin, S.J., Highfield, A.C., Brettell, L., Villalobos, E.M., Budge, G.E., Powell, M., Nikaido, S., \& Schroeder, D.C. (2012) Global Honey Bee Viral Landscape Altered by a Parasitic Mite. Science, 336, 1304-1306.

Masciocchi, M. \& Corley, J. (2013) Distribution, dispersal and spread of the invasive social wasp (Vespula germanica) in Argentina. Austral Ecology, 38, 162-168.

Matsuzaki, S.-I.S., Usio, N., Takamura, N., \& Washitani, I. (2009) Contrasting impacts of 
invasive engineers on freshwater ecosystems: an experiment and meta-analysis. Oecologia, 158, 673-86.

McCubbins, J.S.N., Endres, A.B., Quinn, L., \& Barney, J.N. (2013) Frayed Seams in the "Patchwork Quilt" of American Federalism: An Empirical Analysis of Invasive Plant Species Regulation. Environmental Law, 43, 35-82.

McCullough, D.G., Work, T.T., Cavey, J.F., Liebhold, A.M., \& Marshall, D. (2006)

Interceptions of Nonindigenous Plant Pests at US Ports of Entry and Border Crossings Over a 17-year Period. Biological Invasions, 8, 611-630.

McFadden, A.M.J., Tham, K.-M., Stevenson, M., Goodwin, M., Pharo, H., Taylor, B., Munro, G., Owen, K., Peacock, L., Stanslawek, W.L., \& Stone, M. (2014) Israeli acute paralysis virus not detected in Apis mellifera in New Zealand in a national survey. Journal of Apicultural Research, 53, 520-527.

McGeoch, M.A., Butchart, S.H.M., Spear, D., Marais, E., Kleynhans, E.J., Symes, A., Chanson, J., \& Hoffmann, M. (2010) Global indicators of biological invasion: Species numbers, biodiversity impact and policy responses. Diversity and Distributions, 16, 95108.

McKee, B.A., Djordjevic, S.P., Goodman, R.D., \& Hornitzky, M.A. (2003) The detection of Melissococcus pluton in honey bees (Apis mellifera) and their products using a heminested PCR. Apidologie. Apidologie, 34, 19-27.

McMahon, D.P., Natsopoulou, M.E., Doublet, V., Fürst, M.A., Weging, S., Brown, M.J.F., Gogol-Döring, A., \& Paxton, R.J. (2016) Elevated virulence of an emerging viral genotype as a driver of honeybee loss. Proceedings of the Royal Society B: Biological Sciences, .

McNeill, M., Phillips, C., Young, S., Shah, F., Aalders, L., Bell, N., Gerard, E., \& Littlejohn, R. (2011) Transportation of nonindigenous species via soil on international aircraft passengers' footwear. Biological Invasions, 13, 2799-2815.

Meeus, I., de Miranda, J.R., de Graaf, D.C., Wäckers, F., \& Smagghe, G. (2014) Effect of oral infection with Kashmir bee virus and Israeli acute paralysis virus on bumblebee (Bombus terrestris) reproductive success. Journal of Invertebrate Pathology, 121, 6469. 
Miller, M.L. (2003) NIS, WTO, SPS, WIR - Does the WTO Substantially Limit the Ability of Countries to Regulate Harmful Nonindigenous Species. Emory International Law Review, 17, 1059-1090.

Ministry of Agriculture and Forestry (2006) Memorandum of Understanding on biosecurity activities between agencies.

Ministry of Agriculture and Forestry (2008) Horticulre and Arable Monitoring Report.

Ministry for Primary Industries (2012) Horticulture Monitoring Programme.

Ministry for Primary Industries (2015) National Policy Direction for Pest Management.

Ministry for Primary Industries (2017) Apiculture Monitoring Programme.

de Miranda, J.R., Cordoni, G., \& Budge, G. (2010) The Acute bee paralysis virus-Kashmir bee virus-Israeli acute paralysis virus complex. Journal of Invertebrate Pathology, 103, S30-S47.

de Miranda, J.R., Drebot, M., Tyler, S., Shen, M., Cameron, C.E., Stoltz, D.B., \& Camazine, S.M. (2004) Complete nucleotide sequence of Kashmir bee virus and comparison with Acute bee paralysis virus. Journal of General Virology, 85, 2263-2270.

Moller, H., Tilley, J., Thomas, B., \& Gaze, P. (1991) Effect of introduced social wasps on the standing crop of honeydew in New Zealand beech forests. New Zealand Journal of Zoology, 18, 171-179.

Molnar, J.L., Gamboa, R.L., Revenga, C., \& Spalding, M.D. (2008) Assessing the global threat of invasive species to marine biodiversity. Frontiers in Ecology and the Environment, 6, 485-492.

Motaal, D.A. (2005) Is the World Trade Organization Anti-Precaution? Journal of World Trade, 39, 483-501.

Müllerová, J., Pyšek, P., Jarošík, V., \& Pergl, J. (2005) Aerial photographs as a tool for assessing the regional dynamics of the invasive plant species Heracleum mantegazzianum. Journal of Applied Ecology, 42, 1042-1053.

Murilhas, A.M. (2004) Aethina tumida arrives in Portugal. Will it be eradicated? Eurbee Newsletter, 2, 7-9.

Murray, T.E., Coffey, M.F., Kehoe, E., \& Horgan, F.G. (2013) Pathogen prevalence in 
commercially reared bumble bees and evidence of spillover in conspecific populations. Biological Conservation, 159, 269-276.

Murray, Z.L., Keyzers, R.A., Barbieri, R.F., Digby, A.P., \& Lester, P.J. (2016) Two pathogens change cuticular hydrocarbon profiles but neither elicit a social behavioural change in infected honey bees, Apis mellifera (Apidae: Hymenoptera). Austral Entomology, 55, 147-153.

Mutinelli, F. (2011) The spread of pathogens through trade in honey bees and their products (including queen bees and semen): overview and recent developments. Revue Scientifique et Technique de l'OIE, 30, 257-271.

Natsopoulou, M.E., McMahon, D.P., Doublet, V., Frey, E., Rosenkranz, P., \& Paxton, R.J. (2017) The virulent, emerging genotype B of Deformed wing virus is closely linked to overwinter honeybee worker loss. Scientific Reports, 7, 5242.

Nisbet, M.C. \& Scheufele, D.A. (2009) What's next for science communication? Promising directions and lingering distractions. American Journal of Botany, 96, 1767-1778.

Niu, J., Meeus, I., \& Smagghe, G. (2016) Differential expression pattern of Vago in bumblebee (Bombus terrestris), induced by virulent and avirulent virus infections. Scientific Reports, 6, 1-9.

Novoa, A., Kaplan, H., Wilson, J.R.U., \& Richardson, D.M. (2016) Resolving a Prickly Situation: Involving Stakeholders in Invasive Cactus Management in South Africa. Environmental Management, 57, 998-1008.

O’Dowd, D., Green, P., \& Lake, P. (2003) Invasional "meltdown” on an oceanic island. Ecology Letters, 6, 812-817.

Oksanen, J., Kindt, R., Legendre, P., O’Hara, B., Stevens, M.H.H., Oksanen, M.J., \& Suggests, M. (2007) The vegan package. Community ecology package.

Owen, R. (2017) Role of Human Action in the Spread of Honey Bee (Hymenoptera: Apidae) Pathogens. Journal of Economic Entomology, 110, 797-801.

Peel, J. (2006) A GMO by any other name $\cdots$ Might be an SPS risk!: Implications of expanding the scope of the WTO sanitary and phytosanitary measures agreement. European Journal of International Law, 17, 1009-1031. 
Peel, J. (2007) International Law and the Legitimate Determination of Risk: Is Demonscratising Expertise the Answer? Victoria University of Wellington Law Review, 38, 363-380.

Peel, J. (2012) Of Apples and Oranges (and Hormones in Beef): Science and the Standard of Review in WTO Disputes Under the SPS Agreement. International and Comparative Law Quarterly, 61, 427-458.

Pejchar, L. \& Mooney, H. a (2009) Invasive species, ecosystem services and human wellbeing. Trends in Ecology \& Evolution, 24, 497-504.

Pheloung, P., Williams, P., \& Halloy, S. (1999) A weed risk assessment model for use as a biosecurity tool evaluating plant introductions. Journal of Environmental Management, 57, 239-251.

Phillips, B.L. \& Shine, R. (2006) An invasive species induces rapid adaptive change in a native predator: Cane toads and black snakes in Australia. Proceedings of the Royal Society B: Biological Sciences, 273, 1545-1550.

Pimentel, D., Zuniga, R., \& Morrison, D. (2005) Update on the environmental and economic costs associated with alien-invasive species in the United States. Ecological Economics, 52, 273-288.

Potts, S.G., Biesmeijer, J.C., Kremen, C., Neumann, P., Schweiger, O., \& Kunin, W.E. (2010) Global pollinator declines: trends, impacts and drivers. Trends in Ecology and Evolution, 25, 345-353.

Prost, S. \& Anderson, C.N.K. (2011) TempNet: A method to display statistical parsimony networks for heterochronous DNA sequence data. Methods in Ecology and Evolution, 2, $663-667$.

Quinn, L.D., Barney, J.N., \& Endres, A.B. (2013) Navigating the "Noxious" and "Invasive" Regulatory Landscape: Suggestions for Improved Regulation. BioScience, 63, 124-131.

R Development Team. (2016) R: a language and environment for statistical computing.

Rahel, F.J. \& Olden, J.D. (2008) Assessing the effects of climate change on aquatic invasive species. Conservation Biology, 22, 521-33.

Reichard, S., Schmitz, D., Simberloff, D.M., Morrison, D., Lehtonen, P.P., Windle, P.N., 
Chavarria, G., \& Mezitt, R. (2005) The tragedy of the commons revisited: invasive species. Frontiers in Ecology and the Environment, 3, 109-115.

Rejmánek, M. \& Pitcairn, M.J. (2002) When is eradication of exotic pest plants a realistic goal? In Veitch CR, Clout MN (eds) Turning the tide: the eradication of invasive species. IUCN Species Survival Commission, Gland. 249-253.

Rejmánek, M., Richardson, D.M., Barbour, M.G., Crawley, M.J., Hrusa, G.F., Moyle, P.B., Randall, J.M., Simberloff, D., \& Williamson, M. (2002) Biological Invasions: Politics and the Discontinuity of Ecological Terminology. Bulletin of the Ecological Society of America, 83, 131-133.

Reserve Bank, The macroeconomic impacts of a foot-and-mouth disease outbreak: an information paper for Department of the Prime Minister and Cabinet (2003).

Rhoads, A. \& Au, K.F. (2015) PacBio Sequencing and Its Applications. Genomics Proteomics and Bioinformatics, 13, 278-289.

Richardson, D.M. (2011) A compendium of essential concepts and terminology in invasion ecology. In Fifty Years of Invasion Ecology: The Legacy of Charles Elton Blackwell pp. $409-420$

Richardson, D. \& Pyšek, P. (2008) Fifty years of invasion ecology-the legacy of Charles Elton. Diversity and Distributions, 14, 161-168.

Riley, S. (2005) Invasive alien species and the protection of biodiversity: The role of quarantine laws in resolving inadequacies in the international legal regime. Journal of Environmental Law, 17, 323-359.

Riley, S. (2011) Heads I Win, Tails You Lose: Uncertainty and the Protection of Biodiversity from Invasive Alien Species. Asia Pacific Journal of Environmental Law, 14, 139-168.

Riley, S. (2012) Law is order, and good law is good order: The role of governance in the regulation of invasive alien species. Environmental and Planning Law Journal, 16, 1644.

Riley, S. (2013) Peak Coordinating Bodies and Invasive Alien Species : Is the Whole Worth More Than the Sum of Its Parts? Loyola of Los Angeles International and Comparative Law Review, 35, 453-492. 
Roman, J. \& Darling, J.A. (2007) Paradox lost: genetic diversity and the success of aquatic invasions. Trends in Ecology and Evolution, 22, 454-464.

Roy, B.A., Alexander, H.M., Davidson, J., Campbell, F.T., Burdon, J.J., Sniezko, R., \& Brasier, C. (2014) Increasing forest loss worldwide from invasive pests requires new trade regulations. Frontiers in Ecology and the Environment, 12, 457-465.

Roy, H.E., Handley, L.J.L., Schönrogge, K., Poland, R.L., \& Purse, B. V. (2011) Can the enemy release hypothesis explain the success of invasive alien predators and parasitoids? BioControl, 56, 451-468.

Rozas, J., Ferrer-Mata, A., Sanchez-DelBarrio, J.C., Guirao, S., Librado, P., Ramos-Onsins, S.E., \& Sanchez-Gracia, A. (2017) DNASP v6. DNA Sequence Polymorphism Analysis of Large Datasets. Molecular Biology and Evolution, 34, 3299-3302.

Russell, J.C. \& Blackburn, T.M. (2017a) Invasive Alien Species: Denialism, Disagreement, Definitions, and Dialogue. Trends in Ecology and Evolution, 32, 312-314.

Russell, J.C. \& Blackburn, T.M. (2017b) The Rise of Invasive Species Denialism. Trends in Ecology and Evolution, 32, 3-6.

Sakai, A.K., Allendorf, F.W., Holt, J.S., Lodge, M., Molofsky, J., With, K.A., Cabin, R.J., Cohen, J.E., Norman, C., Mccauley, D.E., Neil, P.O., Parker, M., Thompson, J.N., \& Weller, S.G. (2001) The Population Biology of Invasive Species. Annual Review of Ecology and Systematics, 32, 305-332.

Sanjuan, R., Nebot, M.R., Chirico, N., Mansky, L.M., \& Belshaw, R. (2010) Viral Mutation Rates. Journal of Virology, 84, 9733-9748.

Santamaria, J., Villalobos, E.M., Brettell, L., Nikaido, S., Graham, J.R., \& Martin, S. (2017) Evidence of Varroa-mediated Deformed Wing virus spillover in Hawaii. Journal of Invertebrate Pathology, .

Santoro, D., Hartley, S., Suckling, D.M., \& Lester, P.J. (2015) Nest-based information transfer and foraging activation in the common wasp (Vespula vulgaris). Insectes Sociaux, 62, 207-217.

Savolainen, P., Leitner, T., Wilton, A., Matisoo-Smith, E., \& Lundeberg, J. (2004) A detailed picture of the origin of the Australian dingo, obtained from the study of mitochondrial DNA. Proceedings of the National Academy of Sciences of the United States of America, 
101, 12387-12390.

Scalera, R. (2010) How much is Europe spending on invasive alien species? Biological Invasions, 12, 173-177.

Scheffer, S.J. \& Grissell, E.E. (2003) Tracing the geographical origin of Megastigmus transvaalensis (Hymenoptera: Torymidae): An African wasp feeding on a South American plant in North America. Molecular Ecology, 12, 415-421.

Schmid-Hempel, R., Eckhardt, M., Goulson, D., Heinzmann, D., Lange, C., Plischuk, S., Escudero, L.R., Salathé, R., Scriven, J.J., \& Schmid-Hempel, P. (2014) The invasion of southern South America by imported bumblebees and associated parasites. Journal of Animal Ecology, 83, 823-837.

Schmidt, J.P., Springborn, M., \& Drake, J.M. (2012) Bioeconomic forecasting of invasive species by ecological syndrome. Ecosphere, 3, Art 46.

Schroeder, D.C. \& Martin, S.J. (2012) Deformed wing virus: The main suspect in unexplained honeybee deaths. Virulence, 3, 589-598.

Scott, D.N. (2005) Nature/Culture Clash: The Transnational Trade Debate Over GMOs', Global Law Working Paper. Hauser Global Law School Program, 06/05.

Scott, J. (2000) On Kith and Kine (and Crustaceans): Trade and Environment in the EU and WTO. The EU, the WTO and the NAFTA (ed. by J.H.H. Weiler),

Sebastien, A., Gruber, M.A.M., \& Lester, P.J. (2011) Prevalence and genetic diversity of three bacterial endosymbionts (Wolbachia, Arsenophonus, and Rhizobiales) associated with the invasive yellow crazy ant (Anoplolepis gracilipes). Insectes Sociaux, 59, 33-40.

Sébastien, A., Lester, P.J., Hall, R.J., Wang, J., Moore, N.E., \& Gruber, M.A.M. (2015) Invasive ants carry novel viruses in their new range and form reservoirs for a honeybee pathogen. Biology Letters, 11, 20150610.

Secretariat of CBD (2001) Review of the efficiency and efficacy of existing legal instruments applicable to invasive alien species.

Seebens, H., Blackburn, T., Dyer, E., Genovesi, P., Hulme, P.E., Jeschke, J., Pagad, S., Pysek, P., Winter, M., Arianoutsou, M., Bacher, S., \& Essl, F. (2017) No saturation in the accumulation of alien species worldwide. 1-9. 
Seebens, H., Blackburn, T.M., Dyer, E.E., et al. (2018) Global rise in emerging alien species results from increased accessibility of new source pools. Proceedings of the National Academy of Sciences, 115, 201719429.

Sidhu, S.C. \& Wilson Rankin, E.E. (2016) Honey Bees Avoiding Ant Harassment at Flowers Using Scent Cues. Environmental Entomology, 45, 420-426.

Silverman, J. \& Brightwell, R.J. (2008) The Argentine ant: Challenges in managing an invasive unicolonial pest. Annual Reviews of Entomology, 53, 231-252.

Simberloff, D.M. (2003) Confronting introduced species: a form of xenophobia? Biological Invasions, 5, 179-192.

Simberloff, D.M. (2005) The politics of assessing risk for biological invasions: the USA as a case study. Trends in Ecology \& Evolution, 20, 216-22.

Simberloff, D.M. (2013) Invasive Species - What Everyone Needs to Know. Oxford University Press, New York.

Simberloff, D.M. \& Holle, B. Von (1999) Positive interactions of nonindigenous species: invasional meltdown? Biological invasions, 1, 21-32.

Simon, C., Frati, F., Beckenbach, A., Crespi, B., Liu, H., \& Flook, P. (1994) Evolution, weighting and phylogenetic utility of mitochondrial gene sequences and a compilation of conserved polymerase chain reaction "primers." Annals of the Entomological Society of America, 87, 651-701.

Skogstad, G. (2001) Internationalization, Democracy, and Food Safety Measures: The (Il)Legitimacy of Consumer Preferences. Global Governance, 7, 293-316.

Smith, A.L., Bazely, D.R., \& Yan, N. (2014) Are legislative frameworks in Canada and Ontario up to the task of addressing invasive alien species? Biological Invasions, 16, $1325-1344$.

Smith, K.F., Behrens, M., Schloegel, L.M., Marano, N., Burgiel, S., \& Daszak, P. (2009) Reducing the risks of the wildlife trade. Science, 324, 594-5.

Smith, R. (2017) Bees Travel Cross Country For The California Almond Harvest.

Soper, J. \& Beggs, J. (2013) Assessing the impact of an introduced bee, Anthidium manicatum, on pollinator communities in New Zealand. New Zealand Journal of 
Botany, 51, 213-228.

Speck, S.H. \& Ganem, D. (2010) Viral latency and its regulation: Lessons from the $\gamma$ Herpesviruses. Cell Host and Microbe, 8, 100-115.

Spradbery, J. \& Maywald, G. (1992) The Distribution of the European or German Wasp, Vespula germanica (F) (Hymenoptera, Vespidae), in Australia - Past, Present and Future. Australian Journal of Zoology, 40, 495-510.

Springborn, M., Romagosa, C.M., \& Keller, R.P. (2011) The value of nonindigenous species risk assessment in international trade. Ecological Economics, 70, 2145-2153.

Stirling, F. (1921) The Honeybees' Own Troubles. The Florida Entomologist, 4, 56-58.

Strauss, A., White, A., \& Boots, M. (2012) Invading with biological weapons: the importance of disease-mediated invasions. Functional Ecology, 26, 1249-1261.

Strayer, D.L., Caraco, N.F., Cole, J.J., Findlay, S., \& Pace, M.L. (1999) Transformation of freshwater ecosystems by bivalves: A case study of zebra mussels in the Hudon River. Bioscience, 49, 19-27.

Stockwell, C.A., Hendry, A.P., \& Kinnison, M.T. (2003) Contemporary evolution meets conservation biology. Trends in Ecology and Evolution, 18, 94-101.

Suarez, A., Holway, D., \& Case, T.J. (2001) Patterns of spread in biological invasions dominated by long-distance jump dispersal: Insights from Argentine ants. Proceedings of the National Academy of Sciences of the United States of America, 98, 1095-1100.

Sykes, A.O. (2002) Domestic Regulation, Sovereignty and Scientific Evidence Requirements: A Pessimistic View. Chicago Journal of International Law, 3, 353-368.

Tamura, K. (1992) Estimation of the Number of Nucleotide Substitutions When There Are Strong Transition-Transversion and G+C-Content Biases 'Molecular Biology and Evolution, 9, 678-687.

Tamura, K., Nei, M., \& Kumar, S. (2004) Prospects for inferring very large phylogenies by using the neighbor-joining method. Proceedings of the National Academy of Sciences, 101, 11030-11035.

Tatem, A.J. \& Hay, S.I. (2007) Climatic similarity and biological exchange in the worldwide airline transportation network. Proceedings of the Royal Society B: Biological Sciences, 
274, 1489-1496.

Tassin, J., Thompson, K., Carroll, S.P., \& Thomas, C.D. (2017) Determining Whether the Impacts of Introduced Species Are Negative Cannot Be Based Solely on Science: A Response to Russell and Blackburn. Trends in Ecology and Evolution, 32, 230-231.

Therneau T (2015) A package for survival analysis in $\mathrm{R}$.

Thomas, C.D., Moller, H., Plunkett, G.M., \& Harris, R.J. (1990) The prevalence of introduced Vespula vulgaris wasps in a New Zealand beech forest community. New Zealand Journal of Ecology, 13, 63-72.

Thomas, C.R. (1960) The European wasp (Vespula germanica Fab.). New Zealand Department of Scientific and Industrial Research Information Series, 27, 1-74.

Thomas, M.L., Payne-Makrisâ, C.M., Suarez, A. V., Tsutsui, N.D., \& Holway, D.A. (2006) When supercolonies collide: Territorial aggression in an invasive and unicolonial social insect. Molecular Ecology, 15, 4303-4315.

Tittensor, D.P., Walpole, M., Hill, S., Boyce, D., Britten, G.L., Burgess, N., Butchart, S.H.M., \& Reagan, E. (2014) A mid-term analysis of progress towards international biodiversity targets. Science, 346, 241-245.

Toft, R.J. \& Rees, J.S. (1998) Reducing predation of orb-web spiders by controlling common wasps (Vespula vulgaris) in a New Zealand beech forest. Ecological Entomology, 23, 90-95.

Torchin, M.E., Lafferty, K.D., Dobson, A.P., McKenzie, V.J., \& Kuris, A.M. (2003) Introduced species and their missing parasites. Nature, 421, 628-630.

Trebilcock, M. (2005) Critiquing the Critics of Economic Globalization. Journal of International Law and International Relations, 2000, 213-238.

Trebilcock, M., Howse, R., \& Eliason, A. (2012) The Regulation of International Trade. Taylor \& Francis, London.

Tribe, G.D. \& Richardson, D.M. (1994) The European Wasp, Vespula germanica (Fabricius) (Hymenoptera, Vespidae), In Southern Africa and Its Potential Distribution As Predicted By Ecoclimatic Matching. African Entomology, 2, 1-6.

Tsolaki, E. \& Diamadopoulos, E. (2010) Technologies for ballast water treatment: a review. 
Journal of Chemical Technology \& Biotechnology, 85, 19-32.

Tsuchida, K., Kudo, K., \& Ishiguro, N. (2014) Genetic structure of an introduced paper wasp, Polistes chinensis antennalis (Hymenoptera, Vespidae) in New Zealand. Molecular Ecology, 23, 4018-4034.

Tsutsui, N.D., Suarez, A. V., Holway, D.A., \& Case, T.J. (2000) Reduced genetic variation and the success of an invasive species. Proceedings of the National Academy of Sciences, 5948-5953.

Tsutsui, N.D. \& Suarez, A. V (2003) The Colony Structure and Population Biology of Invasive Ants. Conservation Biology, 17, 48-58.

Valentin, R.E., Nielsen, A.L., Wiman, N.G., Lee, D.H., \& Fonseca, D.M. (2017) Global invasion network of the brown marmorated stink bug, Halyomorpha halys. Scientific Reports, 7, 9866.

VanEngelsdorp, D. \& Meixner, M.D. (2010) A historical review of managed honey bee populations in Europe and the United States and the factors that may affect them. Journal of Invertebrate Pathology, 103, S80-S95.

Veldtman, R., Addison, P., \& Tribe, G.D. (2012) Current status and potential future impact of invasive vespid wasps (Vespula germanica and Polistes dominulus) in South Africa. IOBC/WPRS Bulletin, 75, 217-227.

Velthuis, H.H.W. \& van Doorn, A.B.. (2006) A century of advances in bumblebee domestication and the economic and environmental aspects of its commercialization for pollination. Apidologie, 37, 421-451.

Verbrugge, L.N.H., Van Den Born, R.J.G., \& Lenders, H.J.R. (2013) Exploring public perception of non-native species from a visions of nature perspective. Environmental Management, 52, 1562-1573.

Vilà, M., Basnou, C., Pyšek, P., Josefsson, M., Genovesi, P., Gollasch, S., Nentwig, W., Olenin, S., Roques, A., Roy, D., \& Hulme, P.E. (2010) How well do we understand the impacts of alien species on ecosystem services? A pan-European, cross-taxa assessment. Frontiers in Ecology and the Environment, 8, 135-144.

Vilà, M., Espinar, J.L., Hejda, M., Hulme, P.E., Jarošík, V., Maron, J.L., Pergl, J., Schaffner, U., Sun, Y., \& Pyšek, P. (2011) Ecological impacts of invasive alien plants: A meta- 
analysis of their effects on species, communities and ecosystems. Ecology Letters, 14, $702-708$.

Vincent, S.J., Coutts, B.A., \& Jones, R.A.C. (2014) Effects of introduced and indigenous viruses on native plants: Exploring their disease causing potential at the agro-ecological interface. PLoS ONE, 9, e91224.

Vitousek, P. \& D’Antonio, C. (1997) Introduced species: A significant component of humancaused global environmental change. New Zealand Journal of Ecology, 21, 1-16.

Vitousek, P., Walker, L., Whiteaker, L., Mueller-Dombois, D., \& Matson, P. (1987)

Biological Invasion by Myrica faya Alters Ecosystem Development in Hawaii. Science, 238, 802-804.

Voyles, J., Kilpatrick, A.M., Collins, J.P., Fisher, M.C., Frick, W.F., McCallum, H., Willis, C.K.R., Blehert, D.S., Murray, K.A., Puschendorf, R., Rosenblum, E.B., Bolker, B.M., Cheng, T.L., Langwig, K.E., Lindner, D.L., Toothman, M., Wilber, M.Q., \& Briggs, C.J. (2014) Moving Beyond Too Little, Too Late: Managing Emerging Infectious Diseases in Wild Populations Requires International Policy and Partnerships. EcoHealth, 12, 404-407.

Wagner, J.M. (1998) The Impact of International Trade Agreements on U.S. Food Safety and Labelling Standards. Food and Drug Law Journal, 53, 537-542.

Wagner, J.M. (2000) The WTO's interpretation of the SPS Agreement has undermined the right of governments to establish appropriate levels of protection against risk. Law and Policy in International Business, 31, 855-859.

Wangen, S.R. \& Webster, C.R. (2006) Potential for multiple lag phases during biotic invasions: Reconstructing an invasion of the exotic tree Acer platanoides. Journal of Applied Ecology, 43, 258-268.

Ward, D.F., Beggs, J.R., Clout, M.N., Harris, R.J., \& O’Connor, S. (2006) The diversity and origin of exotic ants arriving in New Zealand via human-mediated dispersal. Diversity and Distributions, 12, 601-609.

Ward, D.F., Green, C., Harris, R.J., Hartley, S., Lester, P.J., Stanley, M.C., Suckling, D.M., \& Toft, R.J. (2010) Twenty years of Argentine ants in New Zealand: past research and future priorities for applied management. New Zealand Entomologist, 33, 68-78. 
Waterhouse, D.F. (1993) The Major Arthropod Pests and Weeds of Agriculture in Southeast Asia. Canberra.

Waterhouse, D.F. (1997) The Major Invertebrate Pests and Weeds of Agriculture and Plantation Forestry in the Southern and Western Pacific. Canberra.

Webber, B.L., Raghu, S., \& Edwards, O.R. (2015) Is CRISPR-based gene drive a biocontrol silver bullet or global conservation threat? Proceedings of the National Academy of Sciences, 112, 10565-10567.

Westphal, M.I., Browne, M., MacKinnon, K., \& Noble, I. (2008) The link between international trade and the global distribution of invasive alien species. Biological Invasions, 10, 391-398.

Whitehead, V.B. \& Prins, A.J. (1975) The European wasp, Vespula germanica (F.), in the Cape Peninsula. Journal of the Entomological Society of Southern Africa, 38, 39-42.

Wilfert, L., Long, G., Leggett, H.C., Schmid-Hempel, P., Butlin, R., Martin, S., \& Boots, M. (2016) Deformed wing virus is a recent global epidemic in honeybees driven by Varroa mites. Science, 351, 594-597.

Williams, S.L. \& Smith, J.E. (2007) A Global Review of the Distribution, Taxonomy, and Impacts of Introduced Seaweeds. Annual Review of Ecology, Evolution, and Systematics, 38, 327-359.

Williamson, M. \& Fitter, A. (1996) The varying success of invaders. Ecology, 77, 16611666.

Willink, A. (1980) Sobre la presencia de Vespula germanica (Fabricius) en la Argentina. Neotropica, 26, 205-206.

Wilson, D. (2000) The appropriate level of protection. Proceedings of Quarantine and Market Access Forum, Canberra. 159-164.

Wilson, J.R.U., Dormontt, E.E., Prentis, P.J., Lowe, A.J., \& Richardson, D.M. (2009) Something in the way you move: dispersal pathways affect invasion success. Trends in Ecology \& Evolution, 24, 136-44.

Wilson, K., Thomas, M.B., Blanford, S., Doggett, M., Simpson, S.J., \& Moore, S.L. (2002) Coping with crowds: density-dependent disease resistance in desert locusts. Proceedings 
of the National Academy of Sciences of the United States of America, 99, 5471-5475.

Wood, G.M., Hopkins, D.C., \& Schellhorn, N.A. (2006) Preference by Vespula germanica (Hymenoptera: Vespidae) for Processed Meats: Implications for Toxic Baiting. Journal of Economic Entomology, 99, 263-267.

Woodcock, B.A., Bullock, J.M., Shore, R.F., Heard, M.S., Pereira, M.G., Redhead, J., Ridding, L., Dean, H., Sleep, D., Henrys, P., Peyton, J., Hulmes, S., Hulmes, L., Sárospataki, M., Saure, C., Edwards, M., Genersch, E., Knäbe, S., \& Pywell, R.F. (2017) Country-specific effects of neonicotinoid pesticides on honey bees and wild bees. Science, 356, 1393-1395.

Work, T.T., McCullough, D.G., Cavey, J.F., \& Komsa, R. (2005) Arrival rate of nonindigenous insect species into the United States through foreign trade. Biological Invasions, 7, 323-332.

Yan, X., Zhenyu, L., Gregg, W., \& Dianmo, L. (2001) Invasive species in China-an overview. Biodiversity \& Conservation, 10, 1317-1341.

Yañez, O., Jaffé, R., Jarosch, A., Fries, I., Robin, F.A.M., Robert, J.P., \& De Miranda, J.R. (2012) Deformed wing virus and drone mating flights in the honey bee (Apis mellifera): Implications for sexual transmission of a major honey bee virus. Apidologie, 43, 17-30.

Yap, T.A., Koo, M.S., Ambrose, R.F., Wake, D.B., \& Vredenburg, V.T. (2015) Averting a North American biodiversity crisis. Science, 349, 481-482.

Yue, C. \& Genersch, E. (2005) RT-PCR analysis of Deformed wing virus in honeybees (Apis mellifera) and mites (Varroa destructor). Journal of General Virology, 86, 3419-3424.

Yue, C., Schröder, M., Bienefeld, K., \& Genersch, E. (2006) Detection of viral sequences in semen of honeybees (Apis mellifera): Evidence for vertical transmission of viruses through drones. Journal of Invertebrate Pathology, 92, 93-96.

Zhang, C., Yan, S.Q., Shen, B. Bin, Ali, S., Wang, X.M., Jin, F.L., Cuthbertson, A.G.S., \& Qiu, B.L. (2017a) RNAi knock-down of the Bemisia tabaci Toll gene (BtToll) increases mortality after challenge with destruxin A. Molecular Immunology, 88, 164-173. 


\section{Appendices}

\section{Appendix for Chapter 5: The origins of global invasions of the German wasp (Vespula germanica) and its infection with four honey bee viruses}

\section{Further details on wasp introductions}

Adults of $V$. germanica were first reported in Argentina during the 1980s (Willink, 1980). It has been hypothesised that they arrived from Chile where they arrived a decade earlier (Beggs et al., 2011). Since arrival it has spread across much of central Argentina (Masciocchi \& Corley, 2013). Our data uncovered only a single haplotype in Argentina and this was identical to a European sample from the south of France near the border with Spain (Fig. 5.2). Given this finding, in our maximum parsimony tree, the Argentinian population clusters with French and Spanish haplotypes (Fig. 5.3). This outcome is unsurprising given historical trade between France/Spain and Argentina. However, although our haplotype discovery curve (Fig. 5.4) suggests we have sampled the full mitochondrial diversity in Argentina, our geographic area of sampling does not encompass the entire range of the species in Argentina as described by Masciocchi and Corley 2013. We cannot therefore exclude incursions from elsewhere in the world.

Vespula germanica was first discovered in Australia on the island of Tasmania in 1959 (Crosland, 1991). It was then not recorded on the mainland until 1975 when it was found in the southeast of the country, as well as Perth in Western Australia (Spradbery \& Maywald, 1992). We discovered three unique mitochondrial haplotypes within our Australian samples. This finding was interesting as a previous study using 141 nests and 1696 individuals only found one mitochondrial haplotype (Goodisman et al., 2001). Possible explanations for this finding could be lack of polymorphisms at the loci examined in that study; alternatively, there may have been further introductions after 2001. The most common haplotype sampled in Australia was identical to the most common haplotype in both the United Kingdom and New Zealand (Fig. 5.2). Of the other two haplotypes, one clustered strongly with the United Kingdom (Fig. 5.3), while the third was an exact match to samples collected in central Europe (Fig. 5.2, Fig. 5.3). The third haplotype was present in three samples, all from Western Australia and the 
haplotype was not found anywhere else in Australia. This finding suggests that the $V$. germanica populations in Western Australia are likely the result of an entirely separate introduction from the eastern population; as opposed to intra-Australia transport. Previous studies have suggested that it was highly likely that the introductions of $V$. germanica into Australia were associated with cargo from New Zealand rather than Europe or elsewhere (Spradbery \& Maywald, 1992). This hypothesis is supported by the most common Australian haplotype being identical to the common haplotype found across all of New Zealand (Fig. 5.2). However, the rarer haplotype found in eastern Australia $(n=1)$ was not sampled anywhere in New Zealand despite thorough sampling (Fig. 5.1). This unique haplotype is closest to populations from the United Kingdom (Fig. 5.2) and may indicate that there have been introductions from the United Kingdom to Australia prior, or subsequent, to the introduction from New Zealand. Further, the haplotype present in Perth was never sampled in New Zealand and matches samples from central Europe (Fig. 5.2, Fig. 5.3). Our haplotype discovery curve (Fig. 5.4) suggests we have sampled most of the diversity present in Australia, but as with Argentina we cannot exclude that other introduction events may have occurred.

Vespula germanica did not establish in New Zealand until 1945; likely as a result of the introduction of hibernating queens in crates of equipment flown from Europe to Hamilton (Thomas, 1960). By 1951 more than 80,000 $\mathrm{km}^{2}$ of land was infested, and by 1960 the species was well-established across both islands (Thomas, 1960). Our data broadly supports the theory of a single introduction event in 1945. New Zealand's population of $V$. germanica was geographically particularly genetically homogenous. The majority of samples $(n=31)$ belonged to a single haplotype, identical to the most common haplotype in the United Kingdom and Australia (Fig. 5.2). It appears that this haplotype from the United Kingdom has achieved widespread geographic dispersal in the 72 years since introduction. A second rare haplotype was found in Auckland. The rare haplotype sampled in Auckland clusters with samples from southern mainland Europe (Fig. 5.2; Fig. 5.3) and likely represents a more recent invasion than the widespread haplotype introduced from the United Kingdom. Auckland is New Zealand's largest city and is home to the country's largest air and seaports. Therefore, we suggest given the volume of trade arriving in Auckland propagule pressure is heightened and the rare haplotype is a much more recent introduction. Our haplotype discovery curve (Fig. 5.4) suggests that we have sampled the full genetic diversity present in New Zealand. Our widespread sampling regime (Fig. 5.1) supports this conclusion. 
Vespula germanica was first collected and identified in South Africa on the grounds of the South African Museum in Cape Town during August of 1974 (Whitehead \& Prins, 1975). However, unpublished evidence suggests the species may have been there for some time. In 1972 pest controllers delivered a mutilated specimen to the museum for identification and an entomologist at the South African Museum had sighted the species before 1970 (Whitehead \& Prins, 1975). The first positive specimen identified in 1974 was from a nest situated where a container depot is sited, indicating a possible site of entry into South Africa (Tribe \& Richardson, 1994). Range expansion of $V$. germanica has been slow in South Africa compared to other invaded areas. The wasp is still confined to a relatively small area within the Western Cape (Veldtman et al., 2012). However, some authors have suggested that further spread is likely as the species moves into areas of sub-Saharan Africa with more suitable ecoclimatic conditions (Spradbery \& Maywald, 1992; Tribe \& Richardson, 1994). Recent work demonstrating the importance of climate in the population dynamics of $V$. vulgaris lends support to this hypothesis (Lester et al., 2017). From our sampling we detected the presence of four haplotypes present in the range of $V$. germanica in South Africa. Unfortunately, we were unable to find an exact haplotype match for any of our South African samples. However, our phylogenetic analysis places the South African haplotypes within samples from central mainland Europe (Fig. 5.3). The presence of four haplotypes may indicate one introduction event with several queens, or alternatively, multiple introductions. Our haplotype discovery curve suggests we have not sampled the full mitochondrial diversity in South Africa. 


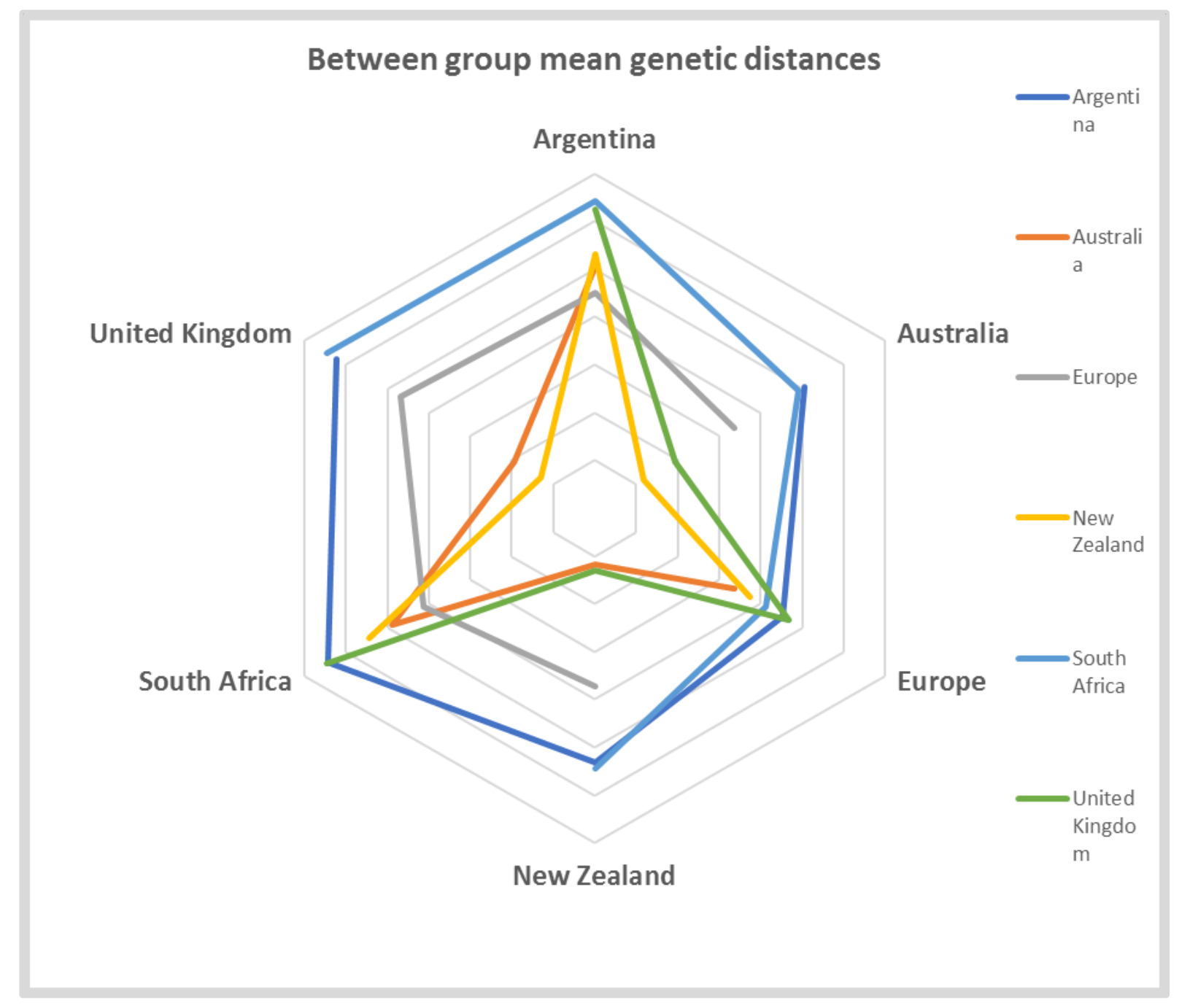

Fig. Appendix 1 Radar Graph of Estimates of Evolutionary Divergence over Sequence

Pairs between Groups. The points of the pentagon correspond with a region sampled. Each grey line within the pentagon indicates levels of genetic similarity - outer rings are the least similar; inner rings most similar. As coloured lines move around the pentagon they illustrate levels of genetic similarity between populations. 


\begin{tabular}{|c|c|c|c|c|c|}
\hline \multicolumn{6}{|c|}{$\begin{array}{l}\text { Table Appendix 1. Sampling locations and collection date for the } V \text {. germanica and } V \text {. vulgari } \\
\text { utilised in this study. Wasps were mainly collected during foraging. If wasps were collected from a nes } \\
\text { only a single individual was used in this analysis. }\end{array}$} \\
\hline Country & Locale & Latitude & Longitude & Collection date & Submitter \\
\hline Argentina 1 & Bariloche & -41.172 & -71.251 & 10 April 2017 & M. Masciocchi \\
\hline Argentina 2 & Bariloche & -41.075 & -71.568 & 10 April 2017 & M. Masciocchi \\
\hline Argentina 3 & Bariloche & -41.141 & -71.315 & 10 April 2017 & M. Masciocchi \\
\hline Argentina 4 & Bariloche & -41.138 & -71.413 & 5 April 2017 & M. Masciocchi \\
\hline Argentina 5 & Bariloche & -41.178 & -71.414 & 10 April 2017 & M. Masciocchi \\
\hline Argentina 6 & Bariloche & -41.144 & -71.376 & 15 January 2017 & M. Masciocchi \\
\hline Argentina 7 & Bariloche & -41.335 & -71.754 & 6 February 2017 & M. Masciocchi \\
\hline Argentina 8 & Bariloche & -41.350 & -71.595 & 30 January 2017 & M. Masciocchi \\
\hline Argentina 9 & Rio Negro & -41.156 & -71.363 & 2013-2016 & Carolina van Zyl \\
\hline Argentina 10 & Rio Negro & -41.133 & -71.414 & 2013-2016 & Carolina van Zyl \\
\hline Argentina 11 & Rio Negro & -41.133 & -71.414 & 2013-2016 & Carolina van Zyl \\
\hline Australia 1 & Launceston & -41.440 & 147.127 & 1 February 2013 & Tim Scott \\
\hline Australia 2 & George Town & -41.107 & 146.823 & 1 February 2013 & Tim Scott \\
\hline Australia 3 & Melbourne & -37.818 & 145.279 & 1 February 2013 & $\begin{array}{l}\text { Chris } \\
\text { Mcgrannachan }\end{array}$ \\
\hline Australia 4 & Melbourne & -37.862 & 145.286 & 4 February 2013 & $\begin{array}{l}\text { Chris } \\
\text { Mcgrannachan }\end{array}$ \\
\hline Australia 5 & Adelaide & -34.890 & 138.558 & 7 February 2013 & $\begin{array}{l}\text { Chris } \\
\text { Mcgrannachan }\end{array}$ \\
\hline & & & & & Chris \\
\hline Australia 6 & Sassafras & -35.103 & 150.256 & 11 February 2013 & Mcgrannachan \\
\hline Australia 7 & Melbourne & -37.755 & 145.653 & 4 February 2013 & $\begin{array}{l}\text { Chris } \\
\text { Mcgrannachan }\end{array}$ \\
\hline & & & & & Chris \\
\hline Australia 8 & Melbourne & -37.783 & 145.385 & 17 February 2013 & Mcgrannachan \\
\hline Australia 9 & Perth & -31.985 & 115.961 & 2013-2016 & Carolina van Zyl \\
\hline
\end{tabular}




\begin{tabular}{|c|c|c|c|c|c|}
\hline Australia 10 & Perth & -31.985 & 115.961 & 2013-2016 & Carolina van Zyl \\
\hline Australia 11 & Perth & -31.985 & 115.961 & 2013-2016 & Carolina van Zyl \\
\hline Austria 1 & Styria & 47.070 & 15.439 & 2 October 2012 & Helmut Kovac \\
\hline Austria 2 & Styria & 47.098 & 14.399 & $\begin{array}{l}25 \text { September } \\
2012\end{array}$ & Helmut Kovac \\
\hline \multirow[t]{2}{*}{ Austria 3} & Styria & 47.070 & 15.439 & $\begin{array}{l}17 \text { September } \\
2012\end{array}$ & Helmut Kovac \\
\hline & Styria & 46.782 & 15.428 & $\begin{array}{l}15 \text { September } \\
2012\end{array}$ & Helmut Kovac \\
\hline Austria 5 & Styria & 47.070 & 15.439 & $\begin{array}{l}13 \text { September } \\
2012\end{array}$ & Helmut Kovac \\
\hline Austria 6 & Styria & 46.688 & 15.990 & $\begin{array}{l}16 \text { September } \\
2012\end{array}$ & Helmut Kovac \\
\hline Austria 7 & Styria & 47.160 & 15.534 & $\begin{array}{l}15 \text { September } \\
2012\end{array}$ & Helmut Kovac \\
\hline Belgium 1 & Leuven & 50.893 & 4.722 & $\begin{array}{l}1 \text { September } \\
2017\end{array}$ & Jana Doblemann \\
\hline Belgium 2 & Leuven & 50.875 & 4.703 & $\begin{array}{l}1 \text { September } \\
2017\end{array}$ & Jana Doblemann \\
\hline Belgium 3 & Leuven & 50.797 & 4.985 & 2 August 2015 & Hendrik Munks \\
\hline Belgium 4 & Leuven & 50.885 & 4.658 & 2 August 2015 & Hendrik Munks \\
\hline Belgium 5 & Leuven & 50.926 & 4.985 & 3 August 2015 & Hendrik Munks \\
\hline France 18 & Paris & 48.843 & 2.362 & $\begin{array}{l}28 \text { September } \\
212\end{array}$ & Louis Deharveng \\
\hline France 1 & Optevoz & 45.749 & 5.330 & 31 August 2012 & Julien Grangier \\
\hline France 2 & Courtenay & 45.723 & 5.368 & $\begin{array}{l}16 \text { September } \\
2012\end{array}$ & Julien Grangier \\
\hline France 3 & Lyon & 45.773 & 4.855 & $\begin{array}{l}22 \text { September } \\
2012\end{array}$ & Julien Grangier \\
\hline France 5 & Toulouse & 43.558 & 1.469 & $\begin{array}{l}12 \text { September } \\
2012\end{array}$ & Laurent Pelozuelo \\
\hline Italy 1 & Calabria & 38.235 & 15.655 & $\begin{array}{l}9 \text { September } \\
2012\end{array}$ & Davide Santoro \\
\hline
\end{tabular}




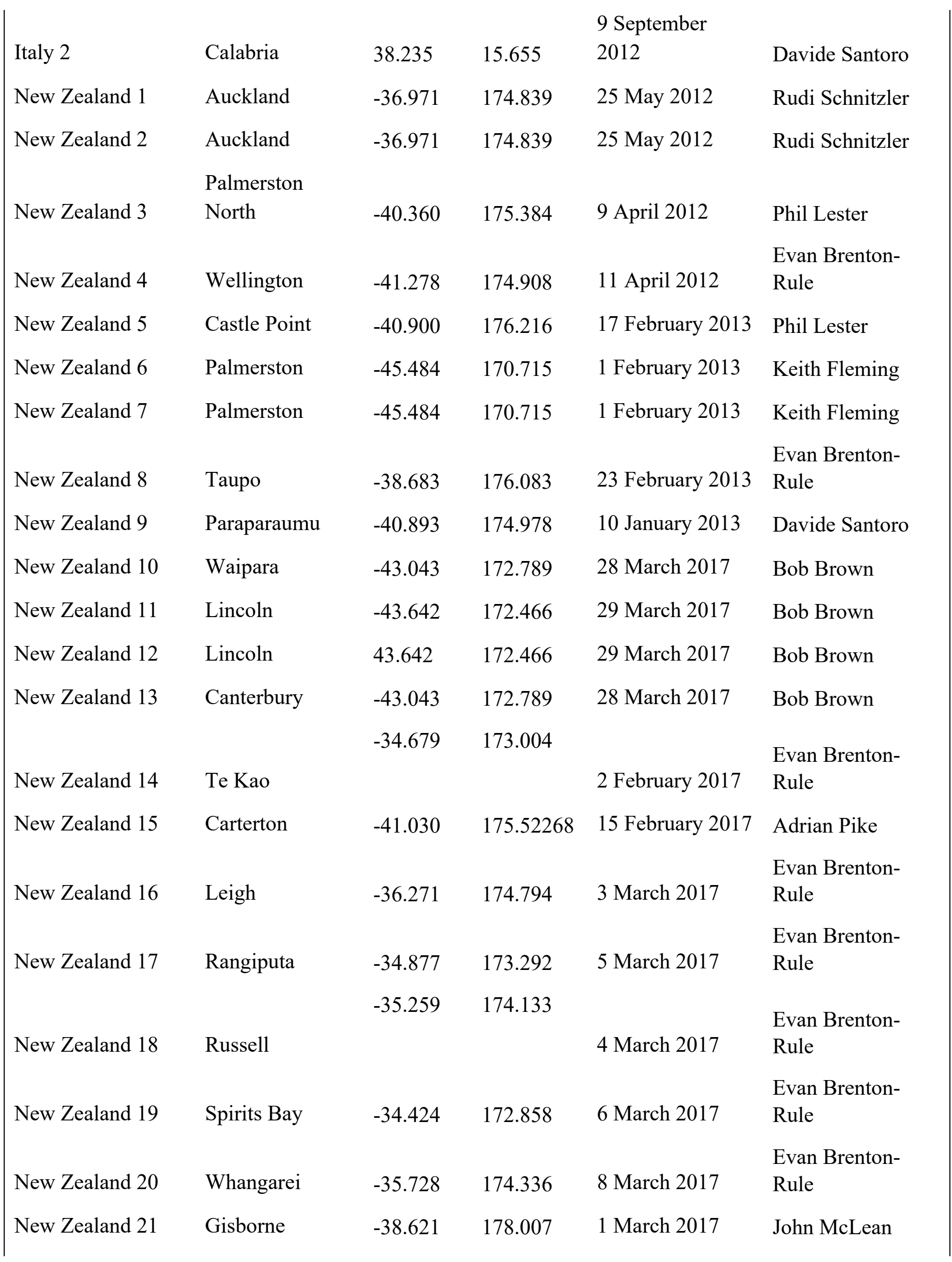




\begin{tabular}{|c|c|c|c|c|c|}
\hline New Zealand 22 & Gisborne & -38.621 & 178.007 & 1 March 2017 & John McLean \\
\hline New Zealand 23 & Gisborne & -38.621 & 178.007 & 1 March 2017 & John McLean \\
\hline New Zealand 24 & Invercargill & -46.402 & 168.354 & 5 March 2017 & Phil Lester \\
\hline New Zealand 25 & Invercargill & -46.402 & 168.354 & 5 March 2017 & Phil Lester \\
\hline \multirow[t]{2}{*}{ New Zealand 26} & Winton & 46.146 & 168.322 & 5 March 2017 & Phil Lester \\
\hline & & -45.033 & & & \\
\hline New Zealand 27 & Queenstown & & 168.661 & 6 March 2017 & Phil Lester \\
\hline New Zealand 28 & Alexandra & -45.244 & 169.379 & 7 March 2017 & Phil Lester \\
\hline New Zealand 29 & Queenstown & -45.033 & 168.661 & 6 March 2017 & Phil Lester \\
\hline New Zealand 30 & Mercury Islands & -36.636 & 175.806 & 1 March 2017 & Julia Schmack \\
\hline New Zealand 31 & Mercury Islands & -36.636 & 175.806 & 1 March 2017 & Julia Schmack \\
\hline New Zealand 32 & Mercury Islands & -36.636 & 175.806 & 1 March 2017 & Julia Schmack \\
\hline New Zealand 33 & Mercury Islands & -36.636 & 175.806 & 1 March 2017 & Julia Schmack \\
\hline Portugal 1 & Lisbon & 38.715 & -9.135 & 25 October 2017 & Helmut Kovac \\
\hline Portugal 2 & Lisbon & 38.691 & -9.425 & 27 October 2017 & Helmut Kovac \\
\hline Portugal 3 & Lisbon & 38.729 & -9.153 & 28 October 2017 & Helmut Kovac \\
\hline Portugal 4 & Lisbon & 38.729 & -9.153 & 28 October 2017 & Helmut Kovac \\
\hline South Africa 1 & Devon Valley & -33.916 & 18.816 & May 2017 & Ruan Veldtman \\
\hline South Africa 2 & Kirstenbosch & -33.991 & 18.428 & May 2017 & Ruan Veldtman \\
\hline South Africa 3 & Franschoek & -33.922 & 19.118 & May 2017 & Ruan Veldtman \\
\hline South Africa 4 & Stellenbosch & -33.948 & 18.837 & May 2017 & Ruan Veldtman \\
\hline South Africa 5 & Elsenburg & -33.820 & 18.840 & May 2017 & Ruan Veldtman \\
\hline South Africa 6 & South Paarl & -33.781 & 19.001 & May 2017 & Ruan Veldtman \\
\hline South Africa 8 & Ceres & -33.377 & 19.305 & May 2017 & Ruan Veldtman \\
\hline South Africa 9 & Wellington & -33.667 & 19.042 & May 2017 & Ruan Veldtman \\
\hline Spain 1 & Malaga & 36.721 & -4.421 & 30 August 2012 & Nuria Roura \\
\hline Spain 2 & Girona & 41.972 & 2.819 & $\begin{array}{l}30 \text { September } \\
2012\end{array}$ & Helmut Kovac \\
\hline
\end{tabular}




\begin{tabular}{|c|c|c|c|c|c|}
\hline Spain 3 & Girona & 41.972 & 2.819 & $\begin{array}{l}30 \text { September } \\
2012\end{array}$ & Helmut Kovac \\
\hline Spain 4 & Malaga & 36.721 & -4.421 & 30 August 2012 & Nuria Roura \\
\hline Sweden 1 & Kalmar & 56.663 & 16.356 & $\begin{array}{l}\text { 16 September } \\
2012\end{array}$ & Rikard Unelius \\
\hline United Kingdom 1 & Starcross & 50.626 & -3.450 & September 2017 & Chris Shortall \\
\hline United Kingdom 2 & Silwood Park & 51.409 & -0.638 & September 2017 & Chris Shortall \\
\hline United Kingdom 3 & Preston & 53.763 & -2.703 & September 2017 & Chris Shortall \\
\hline United Kingdom 4 & Wye & 51.181 & 0.937 & September 2017 & Chris Shortall \\
\hline United Kingdom 5 & Kirton & 52.926 & -0.0608 & September 2017 & Chris Shortall \\
\hline United Kingdom 6 & York & 53.955 & -1.005 & September 2017 & Chris Shortall \\
\hline United Kingdom 7 & Slip End & 51.851 & -0.448 & September 2017 & Chris Shortall \\
\hline United Kingdom 8 & York & 53.955 & -1.005 & September 2017 & Chris Shortall \\
\hline United Kingdom 9 & York & 53.955 & -1.005 & September 2017 & Chris Shortall \\
\hline $\begin{array}{l}\text { United Kingdom } \\
10\end{array}$ & York & 53.955 & -1.005 & September 2017 & Chris Shortall \\
\hline $\begin{array}{l}\text { United Kingdom } \\
11\end{array}$ & Wellesbourne & 52.196 & -1.594 & September 2017 & Chris Shortall \\
\hline $\begin{array}{l}\text { United Kingdom } \\
12\end{array}$ & Slip End & 51.851 & -0.448 & September 2017 & Chris Shortall \\
\hline $\begin{array}{l}\text { United Kingdom } \\
13\end{array}$ & Hergford & 52.049 & -2.716 & September 2017 & Chris Shortall \\
\hline Switzerland 1 & Geneva & 46.144 & 8.716 & September 2017 & Julia Schmack \\
\hline Germany 1 & Moorgrund & 50.840 & 10.275 & June 2017 & Jana Dobelmann \\
\hline Germany 2 & Moorgrund & 50.840 & 10.275 & June 2017 & Jana Dobelmann \\
\hline Scotland 1 & Dundee & 56.457 & -2.981 & August 2017 & Julia Schmack \\
\hline Scotland 2 & Dundee & 56.457 & -2.981 & August 2017 & Julia Schmack \\
\hline Scotland 3 & Dundee & 56.457 & -2.981 & August 2017 & Julia Schmack \\
\hline
\end{tabular}


Table Appendix 2 The maximum likelihood fits for the five best-fitting models of the 24 different nucleotide substitution models calculated in MEGA7 for the separate CO1, CO2 and cytb datasets and concatenated dataset (1957 bases). Model abbreviations: HKY=Hasegawa-Kishino-Yano; TN93=Tamura-Nei; T92=Tamura 3parameter. The best-fitting substitution model was selected based on Bayesian Information Criterion scores (BIC). For each model the corrected Akaike Information Criterion value (AICc), Maximum Likelihood value ( $\mathrm{lnL}$ ), and the number of parameters are also presented. Models with the lowest BIC, AICc and $\operatorname{lnL}$ scores describe the substitution pattern the best. Variable model parameters included non-uniformity of evolutionary rates among sites (a discrete Gamma distribution $(+\mathrm{G})$ with 5 rate categories) and the assumption that a certain fraction of sites are evolutionarily invariable $(+\mathrm{I})$. Where applicable the estimates of $+\mathrm{G}$ and $+\mathrm{I}$ are shown. The number of parameters in the model $(\#)$, and the assumed or estimated values of transition/transversion bias (R) are also shown.

\begin{tabular}{|lllllllll|}
\hline Dataset & Model & $\#$ & BIC & AICc & InL & $+\mathbf{I}$ & $+\mathbf{G}$ & $\mathbf{R}$ \\
\hline Composite & HKY & 225 & 8613 & 5751 & -2700 & - & - & 4.84 \\
& HKY+G & 226 & 8167 & 5846 & -2697 & - & 0.05 & 4.92 \\
& TN93 & 226 & 8172 & 5850 & -2699 & - & - & 4.84 \\
& HKY+I & 226 & 8175 & 5853 & -2700 & 0.02 & - & 4.84 \\
& TN93+G & 227 & 8177 & 5845 & -2695 & - & 0.05 & 4.92 \\
\hline COI & HKY & 225 & 6571 & 4335 & -1942 & - & - & 5.26 \\
& T92 & 223 & 6573 & 4362 & -1957 & - & - & 5.26 \\
& HKY+G & 226 & 6582 & 4335 & -1941 & - & 0.05 & 5.35 \\
& T93 & 226 & 6582 & 4336 & -1941 & - & - & 5.26 \\
& HKY+I & 226 & 6583 & 4337 & -1942 & 0.00 & - & 5.26 \\
& & & & & & & & \\
\hline CO2 & T92 & 223 & 4589 & 2642 & -1907 & - & - & 6.90 \\
& T92+I & 224 & 4598 & 2643 & -1906 & 0.03 & - & 6.94 \\
& T92+G & 224 & 4600 & 2645 & -1907 & - & 0.31 & 6.93 \\
& HKY+I & 226 & 4603 & 2629 & -1087 & 0.02 & - & 6.98 \\
& TN93 & 226 & 4603 & 2629 & -1087 & - & - & 6.93 \\
& & & & & & & & \\
\hline Cyt B & T92 & 223 & 3389 & 1467 & -510 & - & - & 1.68 \\
& HKY & 225 & 3393 & 1455 & -501 & - & - & 1.78 \\
& T92+G & 224 & 3399 & 1469 & -510 & - & 2.00 & 1.62 \\
& T92+I & 224 & 3399 & 1469 & -510 & 0.00 & - & 1.65 \\
& TN93 & 226 & 3404 & 1456 & -501 & - & - & 1.65 \\
& & & & & & & & \\
\hline
\end{tabular}


Table Appendix 3. The maximum likelihood fits for the five best-fitting models of the 24 different nucleotide substitution models calculated in MEGA7 for the ABPV, KBV and IAPV polyprotein gene sequenced (330 bases). Model abbreviations: K2=Kimura 2parameter, T92=Tamura 3-parameter. The best-fitting substitution model was selected based on Bayesian Information Criterion scores (BIC). For each model the corrected Akaike Information Criterion value (AICc), Maximum Likelihood value $(\operatorname{lnL})$, and the number of parameters are also presented. Models with the lowest BIC, AICc and $\operatorname{lnL}$ scores describe the substitution pattern the best. Variable model parameters included non-uniformity of evolutionary rates among sites (a discrete Gamma distribution $(+\mathrm{G})$ with 5 rate categories) and the assumption that a certain fraction of sites are evolutionarily invariable $(+\mathrm{I})$. Where applicable the estimates of $+\mathrm{G}$ and $+\mathrm{I}$ are shown. The number of parameters in the model (\#), and the assumed or estimated values of transition/transversion bias (R) are also shown.

\begin{tabular}{|lllllllll|}
\hline Dataset & Model & $\#$ & BIC & AICc & InL & $+\mathbf{I}$ & $+\mathbf{G}$ & R \\
\hline Capsid & K2+G & 41 & 2646.841 & 2367.515 & -1142.503 & - & 0.27 & 1.93 \\
protein & K2+I & 41 & 2647.701 & 2368.374 & -1142.932 & 0.63 & - & 1.89 \\
gene & T92+G & 42 & 2652.166 & 2366.039 & -1140.752 & - & 0.27 & 1.96 \\
& T92+I & 42 & 2652.602 & 2366.475 & -1140.970 & 0.64 & - & 1.92 \\
& K2+G+I & 42 & 2655.666 & 2369.539 & -1142.503 & 0.00 & 0.27 & 1.93 \\
\hline
\end{tabular}

Table Appendix 4. The maximum likelihood fits for the five best-fitting models of the 24 different nucleotide substitution models calculated in MEGA7 for the DWV polyprotein gene sequenced (381 bases). Model abbreviations:, T92=Tamura 3-parameter; HKY=Hasegawa-Kishino-Yano; TN93=Tamura-Nei. The best-fitting substitution model was selected based on Bayesian Information Criterion scores (BIC). For each model the corrected Akaike Information Criterion value (AICc), Maximum Likelihood value $(\operatorname{lnL})$, and the number of parameters are also presented. Models with the lowest BIC, AICc and $\operatorname{lnL}$ scores describe the substitution pattern the best. Variable model parameters included non-uniformity of evolutionary rates among sites (a discrete Gamma distribution $(+\mathrm{G})$ with 5 rate categories) and the assumption that a certain fraction of sites are evolutionarily invariable $(+\mathrm{I})$. Where applicable the estimates of $+\mathrm{G}$ and $+\mathrm{I}$ are shown. The number of parameters in the model (\#), and the assumed or estimated values of transition/transversion bias (R) are also shown. 


\begin{tabular}{|lllllllll|}
\hline Dataset & Model & $\#$ & BIC & AICc & InL & $+\mathbf{I}$ & $+\mathbf{~ G}$ & R \\
\hline Capsid & T92 & 37 & 1774.054 & 1519.616 & -722.613 & - & - & 4.74 \\
protein & T92+G & 38 & 1780.212 & 1518.908 & -721.248 & - & 0.30 & 4.98 \\
gene & T92+I & 38 & 1780.771 & 1519.468 & -721.528 & 0.46 & - & 4.84 \\
& HKY & 39 & 1788.664 & 1520.495 & -721.031 & - & - & 4.75 \\
& T92+G+I & 39 & 1789.099 & 1520.930 & -721.248 & 0.00 & 0.30 & 4.98 \\
& & & & & & & & \\
\hline
\end{tabular}

Table Appendix 5. Estimates of evolutionary divergence over sequence pairs between groups. The number of base substitutions per site from averaging over all sequence pairs between groups are shown. Standard error estimate(s) are shown in italics. Analyses were conducted using the Maximum Composite Likelihood model (Tamura et al., 2004). The analysis involved 112 nucleotide sequences. Codon positions included were $1 \mathrm{st}+2 \mathrm{nd}+3 \mathrm{rd}+$ Noncoding. All positions containing gaps and missing data were eliminated. There were a total of 1913 positions in the final dataset. Evolutionary analyses were conducted in MEGA7.

\begin{tabular}{|c|c|c|c|c|c|c|}
\hline & Argentina & Australia & Europe & New Zealand & South Africa & $\begin{array}{l}\text { United } \\
\text { Kingdom }\end{array}$ \\
\hline Argentina & & 0.0010795104 & 0.0008720574 & 0.0011858365 & 0.0012081260 & 0.0011945131 \\
\hline Australia & 0.0025285601 & & 0.0005855053 & 0.0002711033 & 0.0008723367 & 0.0003135941 \\
\hline Europe & 0.0022574568 & 0.0016758126 & & 0.0007052708 & 0.0007110273 & 0.0007074617 \\
\hline $\begin{array}{l}\text { New } \\
\text { Zealand }\end{array}$ & 0.0026560583 & 0.0005828080 & 0.0018674334 & & 0.0009673632 & 0.0002606915 \\
\hline $\begin{array}{l}\text { South } \\
\text { Africa }\end{array}$ & 0.0032137586 & 0.0024489137 & 0.0020669629 & 0.0027175017 & & 0.0009951210 \\
\hline $\begin{array}{l}\text { United } \\
\text { Kingdom }\end{array}$ & 0.0031191714 & 0.0009675221 & 0.0023435144 & 0.0006503157 & 0.0032357996 & \\
\hline
\end{tabular}


